THE SLON COMBUSIION OP CXCLOPHOPANS

by

ARCRIBALD COOK HCDWAN, R.H.- W.C., A.R.I.C.

THSIS submitted for the degree of

DOCTOR OF FHILOSOPHY

Mey 1953,

University of Edinburgh.

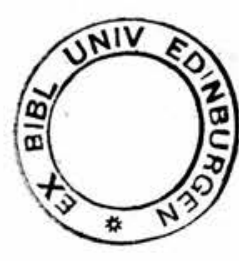


INTROOUCTION

EXPERIMENTAL RESULTS

KINETICS

ANALYSIS

THE EFFECT OF ADOING WATER VAPOUR TO THE REACTION MIXTURE

THE EFFECT OF ADOING FORMALOEHYDE TO THE REACTION MIXTURE

THE EXTENT OF THERMALLY-INDUCEJ ISOMERISATION OF CYCLOPROPANE 
$-1-$

INIRODECIIOI 
The discovery of fire and combustion must rank with the wheel as one of the earliest and most far-reaching of all the discoveries mace by man. Fire has alvays occupied a prominent place amongst the mysteries of the world and aroused the interest of the earliest philosophers. It was one of the four elements of the alchemists, and the study of its cause, nature and application became a matter of the greatest importance with the advent of the internal combustion engine. The slow combustion of hydrocarbons has been studied largely because of the facility of working at temperatures below the ignition point. New techniques have been developed and a unique field of research in chemistry has been revealed. The importance of slow combustion studies does not now rest so heavily on the application of the results to the technical combustion of fuels; rather do such studies reveal the application of the methods of kinetics to the elucidation of the mechanism of very complicated systems and in particular the results obtained may be used to provice some knowledge of bond dissociation energies in hydrocarbons.

The first exact knowledge of the chemistry of burning was mainly derived by the work of Davy and his comtemporaries which was designed to elucidate the causes of mine explosions. Though this work gave rise to no great theoretical developments it disclosed certain broac facts relating to the ignition of explosive mixtures, the influence of cold surfaces and narrow passages in the extinction of flames, the effect of rarefaction and dilution of explosive mixtures and permitted 
some conclusion to be dravn as to the relative combustibilities of gases and their explosive limits.

After Davy's death, there arose the mistaken dogma of selective combustion of hydrogen in hydrocarbon flames but this became untenable after the discovery, by Smithells and Ingle, of hydrogen in the interconal gases of aerated hycrocarbon flames. These workers indicated that the probable series of changes for methane might be represented by the equations

$$
\begin{array}{lll}
\mathrm{CH}_{4}+\mathrm{O}_{2} & \longrightarrow & \mathrm{CO}+\mathrm{H}_{2} \mathrm{O}+\mathrm{H}_{2} \\
\mathrm{CO}+\mathrm{H}_{2} \mathrm{O} & \longrightarrow \mathrm{CO}_{2}+\mathrm{H}_{2}
\end{array}
$$

In $1874 \mathrm{H}$. F. Armstrong (1) suggested that the oxidation by hydrocarbons proceeded by a mechanism involving the successive formation of hydroxy-compounds such as $\mathrm{CH}_{3} \mathrm{OH}, \mathrm{CH}_{2}(\mathrm{OH})_{2}, \mathrm{CH}(\mathrm{OH})_{3}$ which would be thermally unstable, leading to the production of simpler substances, mainly by thermal dehydration. Though Armstrong's theory lay untested for almost thirty years, it was to become a very great force in the study of hydrocarbon combustions.

About 1900, W.A. Bone began a series of classical researches, the results of which appeared to establish the hydroxylation theory as a working hypothesis. With various collaborators, Bone $(2,3,4,5)$ studied slow and ex losive combustion of methane, ethane, ethylene and acetylene. Two experimental techniques were employed. In the first the reaction mixture was heated in a sealed glass tube and the geses were analysed at various times. Secondly, flow experiments were conducted in which the gases were passed through a heated tube packed with porous porcelain and then into traps where soluble and 
condensible products were removec. Several iaportont points were recognisec. For exara le oxides of carbon, water, alchydes and ocica were found in the products but neither carbon or hyurogen was cetected. Jurther it was obaerved that cerbon dioxice was formed under conditions where the oxidation of cerbon monoxice was inconceivable and that eldehyces anpered In the products before stess or cnrbon-oxides. Pegerding these facts as explicable by the hy roxlyation theory, Bones's collaborators Newitt and Heffner, seeking wore direct proof, studied the oxidation of thane at high pressures and noted the formation of large mounts of methyl alcohol. (6).

In the Bakerian Lecture, 1932, Professor Bone (7) summarised the state of knowledge at that time and discussed in some detail the nature of the instialiy formed oxygenated molecule. It is not the leest reasricable ferture of hy rocerbon oxidations that most of the products contein one atom of oxygen so that the rode of scission of the diatomic oxygen rolecule is perhaps the key to the problea of combustion mechanis". Bone's hyciroxylation theory involved the breekdown of oxygen molecules into stoms. A vasty different fee had been advenced by Caliender in 1927 (B). He proposed thet the 1irst intereadate produot was forned by the ineorporetion of on oxygen molecule as a whole in the hydrocerbon molecule. Thus $\mathrm{R}-\mathrm{H}+\mathrm{O}=\mathrm{O} \rightarrow \mathrm{R}-\mathrm{O}-\mathrm{O}-\mathrm{R}$ or $\mathrm{R}-2-0-\mathrm{R}$. This prinoiple of primary peroxide-formation received strong support from a work by Bennett and Mardies (9) who considered that the separation of oxygen molecules into atoms would leed to a profusion of electrons but who could detect little or no ionisation during 
the slow combustion of some hydrocarbons.

At that time Bone concluded that all the evidence was in favour of the hydroxylation theory and that the first intermediate was a monohydric alcohol. Thus e.g. $\mathrm{CH}_{4}+\mathrm{O}_{2} \rightarrow \mathrm{CH}_{3} \mathrm{OH}$ This conclusion was probably justified as Bone and his collaborators had accumulated so much evidence for that process, whereas the peroxidation theory was too young to have any firm backing at that time.

About 1927 - 1930, Senenov, working in Leningrad, developed the theory of chain reactions. On the basis of the kinetic theory of gases he was able to explain the phenomenum of chain reactions and calculated certain relationships which were found to operate in very many cases. Semenov (10) recognised the existence of two types of reaction chains stationary or unbranched, and branching chains. An excellent example of a stationary chain is that operating in the photochemical synthesis of hyorogen chloride. The propagation steps are

$$
\begin{aligned}
& \mathrm{Cl}+\mathrm{H}_{2} \rightarrow \mathrm{HCl}+\mathrm{H} \\
& \mathrm{H}+\mathrm{Cl}_{2} \rightarrow \mathrm{HCl}+\mathrm{Cl}
\end{aligned}
$$

Chains with branching are different in that one complete cycle of operations results in a nett increase in the mumber of active centres. It will be seen that in the case of a stationary chain, while each step results in the formation of a chain 'carrier' it also consumes one (e.g. $\mathrm{H}+\mathrm{Cl}_{2} \rightarrow \mathrm{HCl}+\mathrm{Cl}$ ) and that although the chain length may be very great there is never any increase in the average number of chain carriers. In a branching-chain reaction, on the other hand, the number of chain carriers may increase freely. In the following general 
example $A, A B_{2}, C B$ and $A B$ are all active centres for reaction while the other species are normal stable nolecules.

$$
\begin{aligned}
& A^{x}+B_{2} \rightarrow A B \\
& \mathrm{AB}_{2}^{\mathrm{*}}+\mathrm{CA} \rightarrow \mathrm{AB}_{2} \mathrm{C}+\mathrm{A}^{\mathrm{H}} \text { (2) } \\
& \mathrm{AB}_{2} \mathrm{C} \quad \rightarrow \quad \mathrm{AB}^{\mathrm{X}}+\mathrm{CB}^{\mathrm{*}} \quad \text { (3) }
\end{aligned}
$$

The two reactions (1) and (2) constitute a nornal stationary chain while reaction (3) represente branching of the chain. It need hardiy be pointed out that even if AB were a stable rolecule reaction (3) would still result in branching since there is an overall gein of one ective boig as a result of the cycle of operations $A^{x}+B_{2}+A C \rightarrow A^{*}+A B+C B^{*}$. Calling the length of the primaxy (stationary) chain $v$, the probability of branching at any link $\delta$, and $\beta$ the probability of chain-breaking at any given link, Semenov has shown that the velocity of reaction at any time $t$ is given by $\omega=\frac{n_{0}}{\delta-\beta}\left\{\frac{(\delta-\beta) t}{e^{\Delta \gamma}}-1\right\}$ where $n_{0}$ is the number of initial active centres and $\Delta T$ is the time necessary for the formation of one link in the chain 1.e. the time for which an active centre created in the chain exists before entering the reaction. For lerge values of the expression reauces to $\omega=A e^{\phi t}$ where $A=\frac{\eta_{0}}{\delta-\beta}$

$$
\text { and } \phi=\frac{\delta-\beta}{\Delta \tau}=\frac{n_{0}}{A \Delta \tau}
$$

Assuming reasonable values for $\delta, \beta$ and $\Delta T$ Semenov indicated that a reaction of this type would increase its velocity by $e$ in titnes of the order of one second. However, meny reactions are known where the titne recuired for such an snorease in velocity is of the order of severel hours. To explein this phenomenum It is necessery to adint that $\Delta T$ mey be messured in mutes rather than in tenths of a secon as wes cone in the first case. This 
is the basis of the rather special theory of the existence of chains with degenerate branching. This postulates the operation of a primary chain, not accompenied by branching, which leacis to the formation of a relatively stable intermediate which, after a comparatively long time breaks down by non-radical reactions to form the final products of reaction. The intermediate may also be capable of a second reaction which incidentally creates further active centres, which, in turn, are able to start the chain of the primary reaction. Depending upon the stebility or the internediate, the degenerate branching mey teke place long after the perishing of the primary chain. The process may be renresented thus:-

$$
\begin{aligned}
& A \longrightarrow M \text { (formation of intermediate by the primary } \\
& \text { 1. } M \longrightarrow B \text { (direct product formation) } \\
& \text { 2. } M \stackrel{B}{\longrightarrow} B \text { (formation of products with incidental } \\
& \text { creation of initial centres of } A \rightarrow M \text { chains) }
\end{aligned}
$$

If the rate of generation of secondary chains (given by $v \delta$, where $v=$ primary chain-length and $\delta=$ probability that one nolecule of the intermediate M will create a secondary chain) exceeds the rate at which the primary chains perish, then the corsequent increase of the reaction velocity is given by $\omega(t)=\frac{\eta_{0} v}{\delta_{1} v-1}\left\{e^{\frac{\left(\delta_{0} v-1\right) t}{\theta}}-1\right\}$

where $\theta$ is the time between the commencement of the primary chain and the beginning of the secondary chain. Since the time of development of each primary chain is very small, $\theta$ may be regarded as the life-time of the intermediate 1. for high enough values of $t$ the above rate relationship reduces to $\omega(t)=A e^{\phi c}$ where $A=\frac{n_{0} v}{\delta_{,} v-1}$ and $\phi=\frac{\delta_{,} v-1}{\theta}=\frac{n_{0} v}{A \theta}$ By a consideration of the significance of $\delta$, and $\theta$ the 
expression for the rate can be further simplified. If the velocity of processes 1. and 2. are given by $k_{1}(K)$ and $k_{2}(M)$ then $\delta_{1}=$ the probability that $M \longrightarrow B$ by process 2 .

$$
=\frac{k_{2}(M)}{k_{1}(x)+k_{2}}=\frac{k_{2}}{k_{1}+k_{2}}
$$

Also $\theta=$ the sverage life of the molecule $M$

$$
=\frac{1}{\frac{1}{\theta_{1}}+\frac{1}{\theta_{2}}}
$$

But $\frac{1}{\theta_{1}}=k_{1}$ anã $\frac{1}{\theta_{2}}=k_{2}$

$$
\therefore \theta=\frac{1}{k_{1}+k_{2}}
$$

Thus

$$
\begin{aligned}
\frac{\delta . v-1}{\theta} & =\left(\frac{v k_{2}}{k_{1}+k_{2}}-1\right) \quad\left(k_{1}+k_{2}\right) \\
& =(v-1) k_{2}-k_{1}
\end{aligned}
$$

$$
\text { Hence } \begin{aligned}
\omega(t) & =\frac{n_{0} v\left(k_{1}+k_{2}\right)}{(v-1) k_{2}-k_{1}} \cdot e^{\left[(u-1) k_{2}-k_{1}\right] t} \\
& =\frac{n_{0} v\left(k_{1}+k_{0}\right)}{\phi} \cdot e^{\phi t} \text { where } \phi=(v-1) k_{2}-k_{1}
\end{aligned}
$$

The exponent $\phi$ has been described as the net-branching factor and is very important characteristic of a chain reaction with degenerate brenching. It mey be evaluated by measurement of the slope of the line obtained if the logarithm of the anount of change is plotted egeinst time. Semonov analysed the results of several workers and demonstrated the lineerity of this type of graph in the early stages of many reactions. Not the least remaricable feature of this type of reaction is the extreordinary sensitivity of the reaction rate to the Dtate of the walls of the vessel. Since there are two possibilities (homongeneous and heterogeneous) for esch of the two resctions (1. and 2.) of $M$, there are, oltogether, four 
cases to be considered

1. 1. homogeneous and 2.homogeneous

2. 1. homogeneous and 2.heterogeneous.

3. 1. heterogeneous and 2.homogeneous.

4. 1. heterogeneous and 2.heterogeneous.

Each of these four cases must be sub-divided according to whether the chains $A \rightarrow M$ are broken in the volume or on the walls. In each case where the primary chains are ruptured on the walls, $v=a^{2}$ where $d$ is the vessel diameter, and the rate is increased by increasing the vessel diameter; in the other case of primary chain mupture in the volume of the vessel, increase of the diameter leads to a decrease of the rate when reaction 2. is heterogeneous (cases 2. and 4. above), to an increase of the rate in case 3 . and in case 1. increasing the vessel diameter does not affect the reaction velocity. Apart from this extreme sensitivity of reaction velocity to the dimensions of the reaction vessel, the chain theory predicts several other characteristic properties, the existence of some of which in any particular case being considered as adequate demonstration of the operation of a chain mechanism. Among these are the existence of sharply defined explosion limits, the catalytic effect of traces of foreign substances, high quantum yielos, the existence of an incuction period and the operation of abnormal kinetic relationships and temperature dependences. Stimulated by the discovery (by Bockstrom (11)) of the chain characteristi 8 of the photo - and thernal - oxidation of benzaldehyde, Egerton (12) was led to subscribe to the 
peroxidation ideas proposed by Callendar (8); at the same time he advanced the idea that an energy chain operated. While studying the problem of knocking in internal combustion engines, Egerton found that one molecule of lead tetra-ethyl in 200,000 molecules of the fuel-air mixture was effective in the prevention of knock, which is, essentially, premature slow combustion of fuel This remarkably efficient inhibition was only expilcable in terms of a chain reaction and the following schere was suggested.

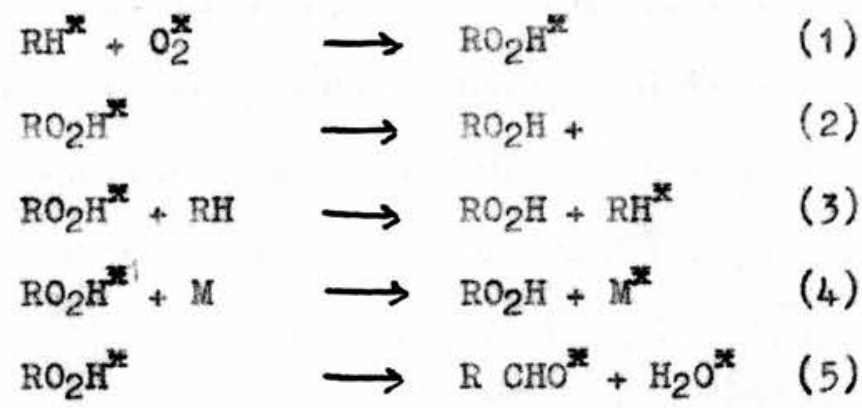

This energy chain explained the detectability of peroxides and aldehydes at an early stage in the reaction, the high efficiency of lead tetra-ethyl as an inhibitor and the luminescence often observed far below the ignition temperature.

The year 1935 saw the publication of two very important papers of a theoretical nature. The first, by Norrish (13), criticised the Bone hydroxylation theory on the grounds that it did not account for the kinetic evidence, the high efficiency of positive and negative catalysts, the inhibition due to increase of surface area, the effect of variation of the vessel diameter upon the ignition temperature, the existence of sharp kinetic limits of explosion and the difficulty of detection of alcohols in the early steges of the reaction. Norxish also criticised the Egerton energy-chain theory because of the difficulty of detection of peroxides during the induction period, the lack 
of effect on the induction period of adaition of peroxides and because the acaition of an inert ges dic not result in desctivation. This latter effect would certainly be anticipated in the case of an energy-chain reaction. Reviewing the work of Hinshelwood (14), Egerton (12), Haber (15) and Semenov (10), Norrish concluded that a chain reaction was in operation and advanced his atom chain theory to account for the oxidation of methane.

Thus

$$
\begin{aligned}
& \mathrm{O}+\mathrm{CH}_{4} \longrightarrow \mathrm{CH}_{4} \mathrm{O} \stackrel{x}{\longrightarrow} \longrightarrow \mathrm{CH}_{3} \mathrm{OH}+\mathrm{x} \\
& \mathrm{CH}_{4} \mathrm{O} \longrightarrow \mathrm{CH}_{2}+\mathrm{H}_{2} \mathrm{O} \\
& \mathrm{CH}_{2}+\mathrm{O}_{2} \longrightarrow \mathrm{CH}_{2} \mathrm{O}+\mathrm{O}
\end{aligned}
$$

This was the first theory of aydrocarbon combustion which involved the participation of hydrocarbon free radicals of short life, and the following year Norrish and Foord (16) reported the dernonstration of a degenerate chain-branching mechanism in the oxidation of methane. Describing fomaldehyde as the essential intermediate and using the atom chain to account for its formation, these authors postulated a mechanism, which, on the application of the stationary state method, led to the exnressinn.

$$
\frac{-\mathrm{d}\left(\mathrm{CH}_{4}\right)}{\mathrm{dt}}=\frac{\mathrm{K}\left(\mathrm{CH}_{4}\right)\left(\mathrm{O}_{2}\right) \mathrm{P} \cdot \mathrm{d}}{\mathrm{s}}
$$

where $\mathrm{P}=$ total pressure, $\mathrm{d}=$ diameter of vessel, $\mathrm{S}=$ surface area. The experimental regults had shown that the maximum rate of the reaction was, in fact, given by

$$
=\mathrm{K}\left(\mathrm{CH}_{4}\right)\left(\mathrm{O}_{2}\right) \mathrm{P}
$$

and that increase of the surface: volume ratio, by packing the vessel, reduced the rate and that increasing the vessel diameter increased the rate. 
The second important paper of 1935 was by vbbelohde (17) who dismissed the hydroxylation theory in favour of a chain mechanism for much the same reasons as Norrish. Arguing on the similarity between hyorocarbon oxidation and alchelade oxidation and the fact that oxygen atoms are very unlikely to feature in the latter reactions, Ubbelohde critised Norrish's atom chain theory. Ubbelohde favoured the peroxide type of mechanism which leads to the production of hydroxyl radicals which, it was known, are plentiful in llames and to the early production of excited formaldehyde molecules. This is an important point because spectral studies showed that the chemiluminescence in cool flames was always due to excited formaldehyde, irrespective of the hydrocarbon which was oxidising. The principal reactions in Ubbelohde's scheme were

$$
\begin{array}{lll}
\mathrm{RCH}_{2}+\mathrm{O}_{2} & \longrightarrow & \mathrm{RCH}_{2} \mathrm{O}_{2} \\
\mathrm{RCH}_{2} \mathrm{O}_{2}+\mathrm{RCH}_{3} & \longrightarrow & \mathrm{RCH}_{2} \mathrm{O}_{2} \mathrm{H}+\mathrm{RCH}_{2} \\
\mathrm{RCH}_{2} \mathrm{O}_{2} \mathrm{H} & \longrightarrow & \mathrm{RCH}_{2} \mathrm{O}^{\circ}+\mathrm{OH} \\
\mathrm{RCH}_{2} \mathrm{O}_{2} \mathrm{H} & \longrightarrow \mathrm{RCHO}^{\circ}+\mathrm{H}_{2} \mathrm{O} \\
\mathrm{RCH}_{2} \mathrm{O}+\mathrm{O}_{2} & \longrightarrow \mathrm{RO}_{2}+\mathrm{CH}_{2} \mathrm{O}
\end{array}
$$

Thus the two major kinetic theories of the slow combustion of hydrocarbons were formulated. They are very difierent but it would be very untrue to sey that there are two schools of thought since it is generally thought now that the peroxide-intermediate theory probably does amly to propane and higher parafins at lower temperatures but not to methane and ethane, while, the excellent work of Bolland and his colleagues (18) has demonstrated its operation in the case of 
the higher (liqguid) oletines. On the other hend there seers to be $l t t t l e$ doubt that formaldehycie is the efrective Intermediate in the slow combustion of methene end ethylene. This latter theory is clearly a descencent of the earlier hydroxylation theory.

Perheps the most important contributor to the peroxide theory has been Sir Cyril Hinshelwood. He and his collaborators, notably Culilis, Partington and Nulcahy have nade veluable studies of the slow conbustion of many parafin hydrocarbons and their simple delivatives (19). They have shown in these cases that an induction period is followed by the acceleration of the rate to meximum, that the rate is largely independent of the initial pressure of oxygen and dependent upon the hydrocarbon pressure to about the second power, and that acded inert gases heve 11 title or no effect upon the maximuta reaction rate. They have carried out enalyses of the proâcts of reaction st verioue steges in its course fincing that the peroxide content roae to a maximu in 8 manner parsilel to the veristion of rete and that formaldehyde was an early product of the reaction. The mechanisn which they heve suggested is given below.

$$
\begin{aligned}
& \mathrm{RCH}_{3}+\mathrm{O}_{2} \rightarrow \mathrm{RCH}_{2}+\mathrm{HO}_{2}^{-} \quad \text { Initiation } \\
& \mathrm{RCH}_{2}{ }^{+} \mathrm{O}_{2} \longrightarrow \mathrm{RCH}_{2} \mathrm{O}_{2} \\
& \left.\mathrm{RCH}^{\circ}+\mathrm{RCH}_{3} \rightarrow \mathrm{RCF}^{\circ} \mathrm{O}^{\circ}+\mathrm{RCH}^{\circ}\right\} \text { propagation } \\
& \left.\mathrm{BCH}_{2} \mathrm{O}_{2} \mathrm{H} \rightarrow \mathrm{RCH}_{2} \mathrm{O}^{\circ}+\mathrm{OH}^{\circ}\right\} \text { degenerate chain- } \\
& \left.\mathrm{RCH}_{2} \mathrm{O}_{2} \mathrm{H} \longrightarrow \mathrm{RCHO}+\mathrm{H}_{2} \mathrm{O}\right\} \text { branching reactions } \\
& \mathrm{RCH}_{2} \mathrm{O}_{2} \mathrm{H}+\mathrm{O}_{2} \rightarrow \text { inactive proaucts } \\
& \mathrm{RCH}_{2} \mathrm{O}^{\circ} \rightarrow \mathrm{R}^{\circ}+\mathrm{CH}_{2} \mathrm{O} \text { degredation }
\end{aligned}
$$


This scheme explains the observed kinetics $\rho_{\max } \bumpeq p_{\mathrm{RCH}_{3}}^{2}$ with no dependence upon the oxygen pressure unless this latter is small. The experimentel dependence of rate upon initial pressures of resctants and additives is seen to be quite different from the rate expression for the methene oxidation. The above scheme of reactions is very attractive in that the reaction steps are all very simple and feasible: for instance the degradation of the alkoxyl radical to the next lower alkyl and formaldehyde requires only the shift of one electron. The observed energies of activation are all of the order of $35 \mathrm{kcals} / \mathrm{mole}$ which is a reasonable figure for the branching reaction $\mathrm{R}-0-\mathrm{O}-\mathrm{H} \quad \mathrm{R}-\mathrm{O}^{\circ}+{ }^{\circ} \mathrm{O}-\mathrm{H}$ The initiation reaction has been criticised on account of the unlikelihoo of the existence of the $\mathrm{HO}_{2}^{2}$ radical. However, the existence of the $\mathrm{HO}_{2}$ radical has been amply denonstrated.(20.21.22). Norrish has opposed the theory expressing the view that the alkyl hydroperoxide does not fulfil all the requirements of the intermediate in a reaction with degenerate branching of the chains (23). He has shown that the essential intermediate must attain a pressure of several millimetres at the maximum rate to account for delayed branching and inclines to the view that aldehydes are responsible for the degenerate branching observed. The formeldehyde-intermeciate theory of Norrish was modified as a result of an investigation into the mechanism of oxidation of formaldehyde itself, by Axford and Norrish (24). Their mechanism for this reaction will be discussed later but it may be noted, at this stage, that the principal reactions 
suggested were

$$
\begin{aligned}
& \mathrm{CH}_{2} \mathrm{O}+\mathrm{OH} \longrightarrow \mathrm{H}_{2} \mathrm{O}+\mathrm{CO}+\mathrm{H} \\
& \mathrm{H}+\mathrm{O}_{2}+\mathrm{CH}_{2} \mathrm{O} \rightarrow \mathrm{CO}+\mathrm{H}_{2} \mathrm{O}+\mathrm{OH}
\end{aligned}
$$

the second reaction being regarded as a reaction of a highly energised $\mathrm{HO}_{2}$ complex rather then as a ternary reaction. This suggested mechenism for the formaldehyde oxidation shifted the emphasis from $\mathrm{CH}_{2}$ and $\mathrm{O}$ redicals to $\mathrm{CH}_{3}$ and $\mathrm{OH}$ radicals in the methane reaction (25). Thus the propagation steps were written

$$
\begin{aligned}
& \mathrm{CH}_{4}+\mathrm{OH} \longrightarrow \mathrm{CH}_{3}+\mathrm{H}_{2} \mathrm{O} \\
& \mathrm{CH}_{3}+\mathrm{O}_{2} \longrightarrow \mathrm{CH}_{2} \mathrm{O}+\mathrm{OH}
\end{aligned}
$$

and the formaldehyde thus formed reacted as shown above. Norrish has also suggested (23) that higher hydrocarbons are oxidised by a mechanism involving the production and reaction of aldehydes but it is now thought that the temperature of reaction influences the mechanism. Pease (26) observed (in the case of propane) a slackening of the reaction rate with increasing tenperature and that the Arrhenius curve actually passed through a minimum at about $360^{\circ} \mathrm{C}$. Mulcahy (27), discussing this important observation, has suggested that this indicates the extistence of two distinct regions of reaction high - and Iow - temperature and has pointed out that the pronounced structural effect on the rate of oxidation in the low-temperature region is not observed in the higher temperature range. Now this structurel effect has been interpreted by Hinshelwood $(28,29)$ in terms of the effect of the nature of the alkyl group in the decomosition of alkyl group in the decomposition alkyl hydroperoxides to alkoxyl and hydroxyl 
radicals. Consequently lulcahy concluded that the hightemperature reaction was not peroxidic in character and that the slackening in reaction rate with increasing temperature above $300^{\circ} \mathrm{C}$ was due to the gradual disappearance of peroxides from the reaction mechanism. It would then appear that methane and ethylene being simplest members of homologeous series exhibit rether singular behaviour in that they show no "low temperature" oxidation at all. Walsh (30) attempted to synthesise the two theories to some extent and sought to explain the absence of a low temperature methene oxidation on the ground that in this case the hydroperoxyl radical is too unstable to survive with the heat involved in its formation from methyl and oxygen. This conclusion was based, to some extent, on the results of Bates and co-workers $(31,32)$ who studiea the photo-oxidation of methyl (from methyl ioaide) and ethyl (from ethyl iodide). These workers concluded that in the latter case ethyl peroxyl was formed but that in the case of methyl, formaldehyde and hydroxyl were the products of the reaction $\mathrm{CH}_{3}+\mathrm{O}_{2}$.

Wolsh's theory of the high temperature mechanism of combustion is illustrated in his work on the combustion of di-isopropyl ether ( 30 ) at temperatures ranging from $360^{\circ} \mathrm{C}$ to $460^{\circ} \mathrm{C}$ (i.e. in the "high temperature" region). The radicals involved in his proposed aechanism included methyl, hydroxyl and hycrogen peroxyl, the chain propagation steps being

$$
\begin{aligned}
& \mathrm{CH}_{3}+\mathrm{O}_{2} \rightarrow \mathrm{CH}_{2} \mathrm{O}+\mathrm{OHI} \\
& \mathrm{OH}+\left(\mathrm{CH}_{3}\right)_{2} \mathrm{CHOCH}\left(\mathrm{CH}_{3}\right)_{2} \rightarrow \mathrm{H}_{2} \mathrm{O}+\left(\mathrm{CH}_{3}\right)_{2} \underset{\downarrow}{\mathrm{CHOCH}}<_{\mathrm{CH}_{2}}^{\mathrm{CH}_{3}} \\
& \left(\mathrm{CH}_{3}\right)_{2} \mathrm{CHO}+\mathrm{CH}_{3} \mathrm{CH}=\mathrm{CH}_{2} \\
& \mathrm{CH}_{3} \downarrow+\mathrm{CH}_{3} \mathrm{CHO}
\end{aligned}
$$


There has been very little work reported on the slow combustion of saturated cyclic hydrocarbons, although Chavanne and his co-workers have studied the products of oxidation of many substituted cyclohexanes and cyclopentanes (33). Levin ( 34 ) oxidised several alyl cyclonentenes and cyclohexanes in a static system at $200^{\circ} \mathrm{C}$ and observed that an induction period was followed by a decrease of the pressure of some $10 \mathrm{~m}$ ms. and eventually the pressure increased to a limiting value. Such a pressure decrease is very suggestive of primary peroxide formation and the products found by Chavanne also indicate the initial formation of an alkyl hydroperoxide. It would be quite unjustified to draw any more concrete conclusions from published work on the slow combustion of cycloparaffins. Cyclopropene or trimethylene, is the simlest homocyclic compound and its structure has been the subject of some controversy in recent jear's. It is well known that while cyclobutane and higher homologues are not attacked by hydrogen bromide and yield substitution products with bromine, eyclopropene forms propyl bromide with $\mathrm{HBr}$ and is slowly attacked by bromine to form $1: 3$ dibromopropane. Walsh (35) has suggested that such addition reactions of cyclopropane are due to the unsaturated character of the $\mathrm{C}-\mathrm{C}$ bonis. Arguing from the fact that the spectroscopic properties of cormounds containing the $\mathrm{CH}_{2}-\mathrm{CH}-\mathrm{CH}=\mathrm{CH}-$ grouping are properties characteristic of $\mathrm{CH}_{2}^{\prime}$

a conjugated system and from the fact that the dipole moment of cyclopropyl chloricie is $0.3 \mathrm{D}$ less than the values for 
isopropyl chloride and cyclopentyl chloride, walsh proposed thet the formule for cyclopropene should be written $\mathrm{CH}_{2} \underset{\downarrow}{\mathrm{d}}$

indicating the donation of elsotrons by the double bond to assist in the formation of a bond to the third wethylene. The existence of $\pi$ electron aative bonds had been auggested earlier by lewer (36) to account for some rearrangements of the hydrazobonzene $\rightarrow$ benzidine type and to explain some anomelies in aromatio substitution by cationoî resgents. Robinson (37) objected to this proposel, pointing out that the formule drawn by talsh of not possess the required syanetry an: that to achieve symetry by writing three icentical cenonicel roress was to assign to cyolopropane its classical structure. In replying to this criticism lalsh (38) remariced that the hybrid visuelised did differ from the clessical structure in that the orbital hybridisation in the carbon atoms was trigonel rather than tetrahedral. A very important piece of evicience for sp ${ }^{2}$ hybridisation is the low dipole moment of cyclopropyl ohloride since a trigonal carbon atom has a higher electronegativity in its $\mathrm{sp}^{2}$ valencies than has a tetrahecral carbon ators in its $8 p^{3}$ valencies. Further evidence for the similerity between the $\mathrm{C}-\mathrm{C}$ boncs in cyclopropane and ethylene is afforded by the determination of the angle HCH Bastiansen and Hassel as $118 \cdot 2 \pm 2$ (1.e. greater than tetrahedral and elmost trigonal)(39), by Linnett's caloulation of the $\mathrm{C}-\mathrm{H}$ stretching-force constent to be $5.0 \times 10^{5}$ dynes/cra. (compared wi.th $5 \cdot 1 \times 10^{5}$ dynes/cm. in ethylene and $4 \cdot 6 \times 10^{5}$ dynes $/ \mathrm{cm}$. 
in a paraffinic methylene group $(40)$, and by the high value of the quenching cross-section of cyclopropene for cadritum resonance radiation ( 41 ).

Having discussed the likelihood of trigonal hybridisation, Walsh then considered the synthesis of the cyclopropane ring from three $\mathrm{CH}_{2}$ groups whose $\mathrm{C}-\mathrm{H}$ valencies were of the $\mathrm{sp}^{2}$ type and whose planes were perpendiculor to the carbon ring plane (42). Molecular orbitals are then formed by the overlap o: (a) the $2 p$ atomic orbitals lying in the plane of the ring and (b) the third $s p^{2}$ orbitals whose axes also lie in the plane of the ring. The overlap is shown in figure 1. and the probability pattern of the electrons in the resultant molecular orbitals is show below it. Sugden (43) has reported a qualitative application of the non-localized molecular orbital theory to justify Walsh's conclusions as to the structure of cyclopropane. In contrast to the usual comparitive reactivity of cyclopropene its thermal oxidation shows it to be in some respects a stable substence. Doy and. Pease (44) studying the slow combustion of several hydrocerbons of different types found that like methane and ethylene, but unlike paraffins in general, cyclopropane gave no cool flames (which are a fair indication of combustion by a peroxide intermediate mechanism at low temperatures). Furthermore, cyclopropane was found to oxidise more slowly than propane or propylene whose ignition temperatures were considerably lower then that of the cyclic hydrocarbon. These authors gave three rates of reaction measured at $370^{\circ} \mathrm{C}$ which showed that the rate was independent 


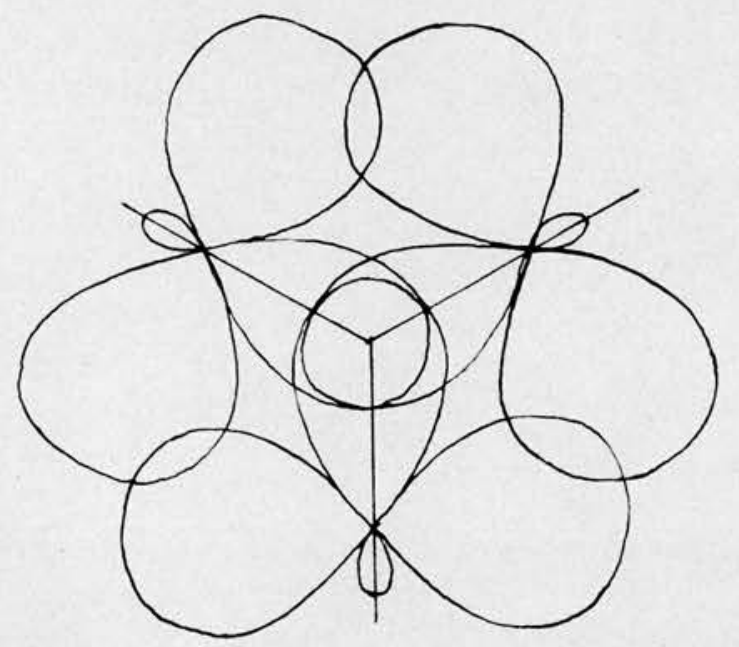

ORBITAL OVERLAP IN CYCLOPROPANE

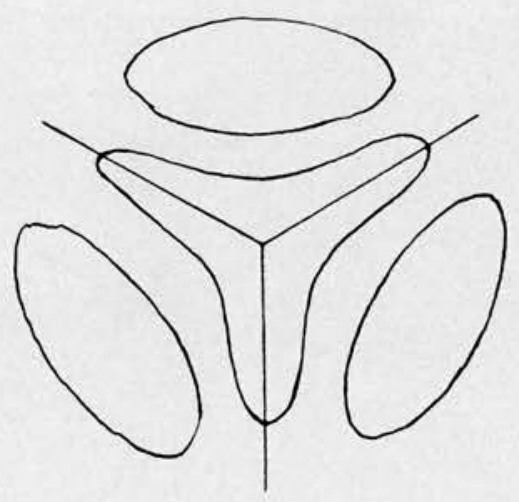

PROBABILITY PATTERN 
of the initial oxygen pressure and strongly depencent upon the initial pressure of cyclopropane. They also noted that the addition of a little acetaldehyde to the reaction mixture produced a shortening of the induction period..

The slow combustion has been studied, therefore, by the static method, kinetically and analytically, in the temperature range $380^{\circ} \mathrm{C}$ to $430^{\circ} \mathrm{C}$, with partial pressures of the reactants between $40 \mathrm{mon}$ and $400 \mathrm{mom}$. 
$-21-$

BXPERIUEMEAL TBCHMIOUE 


\section{PHS APPARAYUS}

The apparatus employed in this investigation was of a conventional type and is illustrated diagranatically in figure 2. It was constructed in Pyrex glass throughout and all taps and interchangeable joints were lubricated with Apiezon Grease t.

The reaction vessel was thoroughly washed with hot concentrated nitric acid to remove contaminating materials on the glass. It was then rinsed with tap water for several hours and finally distilled water before being sealed on to the apparatus. The reection vessel was housed in a well-lagged furnace whose brass core was wound with nickel-chrome resistance wire. The resistance of the winding was 55 ohins and it was operated at a current of 2 amps. The irmut voltage (110 volts) was supplied by a varisc transformer.

Since pressure measurements were to be made with some accuracy, a considerable degree of temperature control was necessary. A Sunvic energy regulator was used to regulate the imput energy. It was found that when the mains voltage was steacy the temperature of the reaction vessel could be kept constant $\pm I^{\circ} \mathrm{C}$ with little difficulty.

Temperature measurements were made thermo-electrically. A Ferry-Bright-ray thermocouple was contructed and was calibrated by mantaining its cold junction at $0^{\circ} \mathrm{C}$ and measuring the thermal e.m. $f_{0} s_{0}$ procuced when its hot junction was placed in melting ice, condensing steam, condensing glycerol vapour, condensing sulphur vapour and cadmium, potassium dichromate and 

zinc at their respective melting points.

These e.m.f.s. were measured by means of a Cambridge potentiometer and a ballistic galvanometer. During reactions, experimental temperatures were measured by the same technique, the hot junction being kept inside the reaction vessel as shown (fig. 2).

The measurement of pressure in the kinetical study of gas reactions has aroused much interest and discussion. The direct use of a mercury manometer is impossible in free radical and other reactions due to the catalytio effect of metals. To overcome this difficulty many types of gauge have been devised. The Foord gauge has many advantages and one was used in conjunction with a mercury manometer in preliminary experiments. Its sensitivity, however, was unnecessarily high and its robustness, unfortunately, was not high enough.

A more robust and adequately-sensitive instrument is the spiral gauge (fig. 2). The construction of such a gauge has been described (45). A piece of glass-tubing ( $4 \mathrm{~m}, \mathrm{~m}$. diameter) was drawn down so that its wall thickness was very small but without greatly affecting the internal diameter. This was suspended from the end of a slightly tapered brass rod which was rotated at a very slow speed so that the rod moved, slowly, horizontally while the glass tube remained vertical. The glass tube was heated indirectly by an iron plate which was, itself, heated by an cxy-coal gas flame. In this way a delieate spiral of about eight turns was wound. This was sealed off at one end to which was affixed a thin glass pointer. The other end was sealed into an outer 
jacket and joined on to the apparatus as shown.

An optical system was arranged to give a ten-times magnification of pointer movement on a screen. The spiral gauge was used as a null-point instrument, the external pressure being adjusted by manipulation of taps $C$ and $I$, and, at the mull-point, pressures being read off on the mercury manometer. The spiral gauge was found to be very robust and the arrangement was found to be sensitive enough for all purposes.

The pumping system was not complex, consisting of a twostage vertical, annular-jet type of mercury-vapour pump backed by a Hyvac rotary oil-pump. A Mcleod gauge, which was joined to the evacuation line just before the liquid oxygen cooled trap, was employed for the measurement of pressure in the system during evacuation. It was found that the pressure could be reduced to $10^{-5}$ to $10^{-6} \mathrm{~m}, \mathrm{~m}$. of mercury after much less than one hour's evacuation.

The removal of the products for analysis was affected by use of a Toepler (Antropoff) pump of conventional construction. The gases used were taken from cylinders. The oxygen was drawn through a liquid-oxygen-cooled trap to remove condensible materials and was then allowed to leak into a twolitre bulb.

The cyclopropane was condensed in a trap cooled to $-180^{\circ} \mathrm{C}$ by liquid oxygen. It was then distilled, the midale fraction being trapped in a second cold trap. The midale fraction of a second distillation was then allowed to leak into an evacuated. five-litre reservoir. 
Nitrogen was taken from a cylinder, was passed over heated copper to remove oxygen and finally through two traps cooled in liquid oxygen before being allowed to leak into the system.

Hydrogen was also taken from a cylinder and received exactly the same pretreatment as nitrogen.

Pure liquid monomeric formaldehyde was prepared by the method of Spence and Wild (46). Paraformaldehyde, obtained by careful evaporation of a $40 \%$ aqueous solution of formaldehyde, was broken up and dried for two days over concentrated sulphuric acid in a vacuum desiccator. The product was then finely powdered and heated to $110^{\circ} \mathrm{C}$ in the distillation vessel of the apparatus (figure 3) which had been evacuated to $10^{-6} \mathrm{~m} . \mathrm{m}$ of mercury pressure while the condensing vessels were heated. While the first fraction was distilling these vessels were heated in a blow-pipe flane to prevent the condensation of water there.

The trap was then cooled to $-180^{\circ} \mathrm{C}$ and the tap to the pump was closed. As the distillation proceeded the oil-bath temperature was gradually raised to $120^{\circ} \mathrm{C}$ and when sufficient monomer had been collected, the oil-bath was removed and the trap was carefully sealed off. Alternate removal and replacement of the liquid axygen container brought all the formaldehyde to the foot of the trap which was then sealed on to the line in position.

The function of the separator, a compact block of three $\mathrm{U}$-tubes, was to alternately heat and cool the gases, whereby 

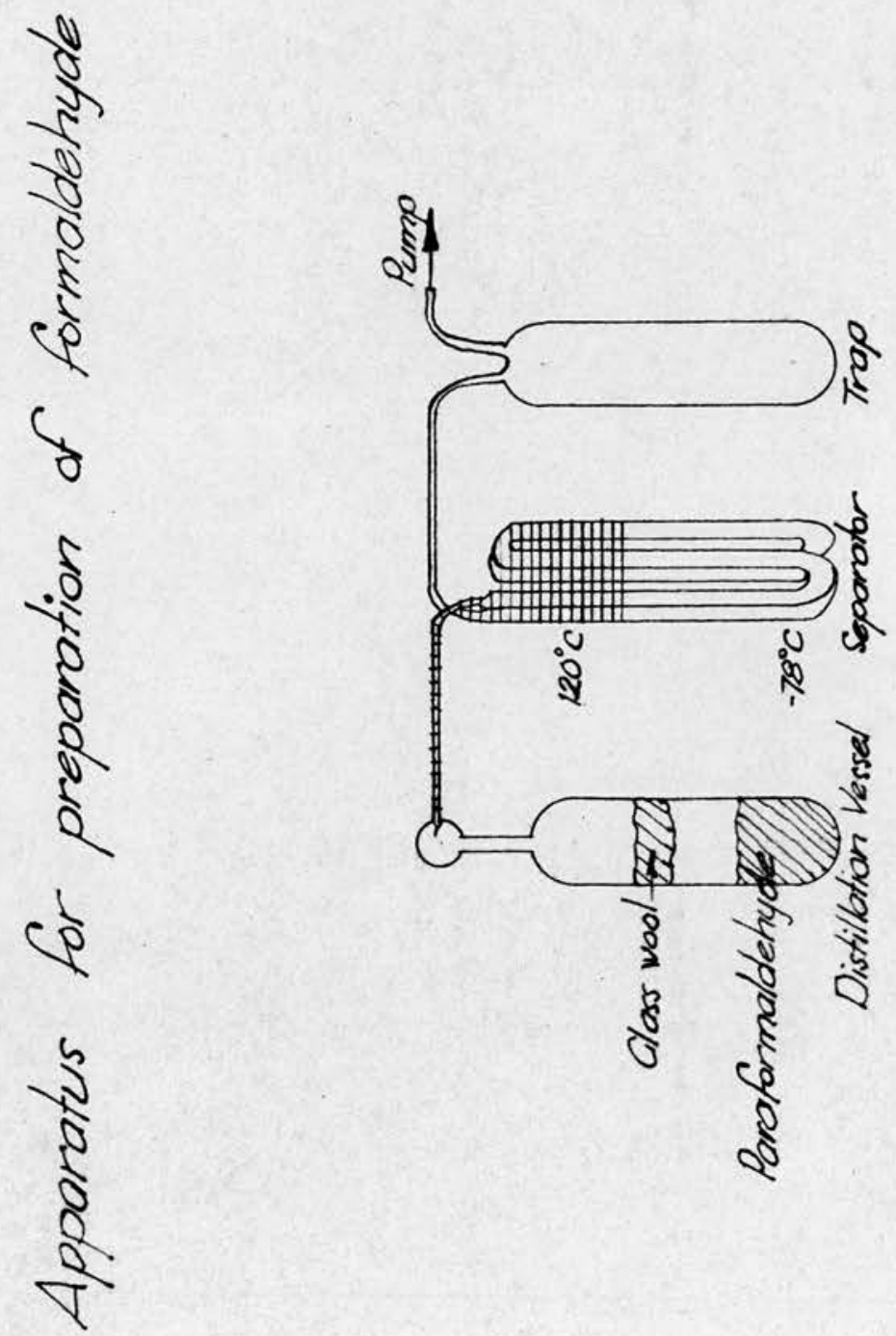
water was removed completely. (Slightly wet formaldehyde polymerises readily).

For the experiments involving the adition of water, a trap was attached to the line containing freshly boiled distilled water. This was freed from dissolved air by alternate heating in a warm water bath and cooling to $-180^{\circ} \mathrm{C}$; the gases liberated on warming were pumped away.

It is obvious that a knowledge of the reaction volume (which includes the dead space of the capillary tube and the spiral of the gauge) is essential if an attempt is to be made to study the stoichiometry of the reaction.

The pressure of a certain amount of oxygen was measured in the reaction vessel at a noted temperature. The oxygen was then removed by Toepler pump and its volume was determined at room-temperature and pressure. 


\section{GAS ANALYSIS}

The apparatus employed is represented diagramatically in figure 4.

By way of tube $B$, the gases were drawn from the collecting tube A into the absorption tube C. The volume of the sample was measured by transferring it to the $10 \mathrm{~m}, 1$, burette $D$, closing tap $J$ and adjusting the height of the reservoir $\mathrm{E}$ until the mercury levels in $D$ and $F$ were the same (with tap $G$ open to the air) i,e, when the gas in D was at atmospheric pressure (less the saturated vapour pressure of water). A slow flow of water through the jacket ensured sone constancy of temperature which was read off on a thernometer.

The sample was then transferred to $C$ and some of the reagent required was drawn in from $\mathrm{H}$. A few drops of mercury were added to form a seal between $\mathrm{H}$ and $\mathrm{C}$. After absorption was complete the gas was pushed back to the burette $D$ and the spent reagent was removed at $\mathrm{H}$. Last traces of reagents were washed out first with dilute sulphuric acid, and finally with water.

I is a silica combustion tube containing copper oxide heated by a small furnace around it to $550^{\circ} \mathrm{C}$. Before the beginning of an analysis it was evacuated by manipulation of the reservoir E. By a Toepler-like procedure gas was drawn from I into D. Tap J was then closed to I and the gas was pushed over to $\mathrm{C}$ and was eventually removed at $\mathrm{H}$.

The reagents used for the various gases were as follows:- 
FlG. 4

GAS ANALYSIS APPARATLS

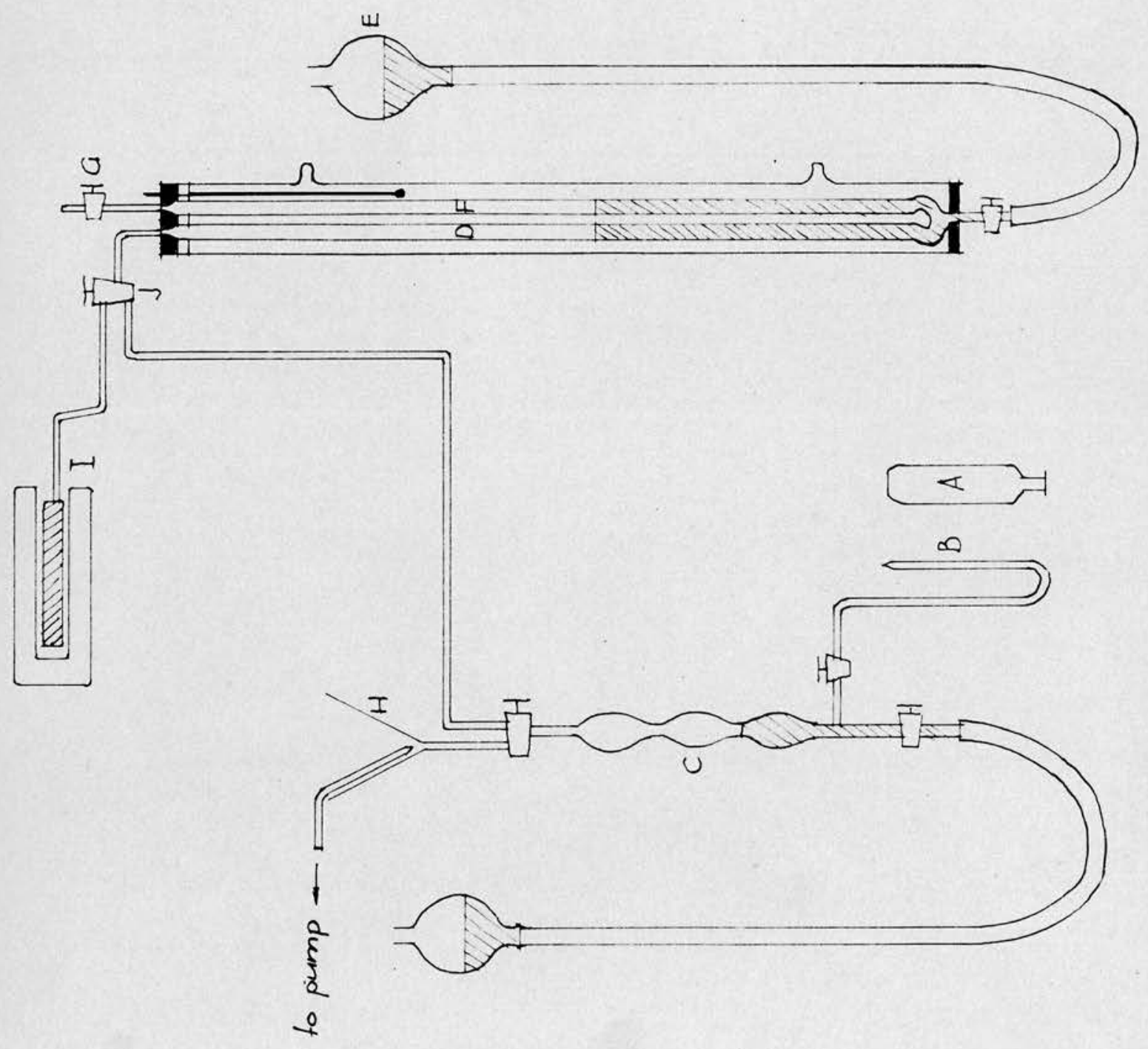


$\underline{\text { Gas }}$

Carbon dioxide

Oxygen

Ethylene

Propylene

Cyclopropane

Acetylene

Carbon monoxide
Reagent

$30 \%$ aqueous caustic potash

A.lkaline pyrogallol.

Saturated bromine water.

A solution of $57 \mathrm{~g}$. mercuric sulphate in 200 gins.

$22 \%$ sulphuric acid.

$87 \%$ sulphuric acid.

Alkaline potassium mercuri-iodide solution.

10\% cuprous chloride in conc. HC1.

Hydrogen and paraffin hydrocarbons were determined by combustion and nitrogen was obtained by difference. In actual practice some separation of the products was effected before analysis. The product gases were pumped through a trap cooled in Iiquid oxygen by the Toepler pump. The fraction, gaseous at this temperature was collected and analysed for carbon dioxide, oxygen, unsaturated hydrocarbons, cyclopropane, carbon monoxide, hydrogen, methane, and nitrogen. The trap was then allowed to warm up to $-78^{\circ} \mathrm{C}$, by replacing the liquid oxygen by acetone cooled with solid carbon dioxide. Incidentally, it was found that the addition of a few drops of paraffin oil to the acetone prevented excessive frothing when the carbon dioxide was added.

A second gas fraction was then pumped off and analysed for carbon dioxide and cyclopropane. The contents of the trap were then allowed to warm up to room temperature and air, dried by passage through a calcium chloride tube, was then admitted to the trap.

Qualitative Examination of the Condensible Products.

The accumulated products from several experiments were examined qualitatively. It was dissolved in $20 \mathrm{mls}$. of water. 
It had a cherecteristic odour and was slightly add to 11 tmis.

1. It was found that $1 \mathrm{ml}$. of the solution restored the colour to Sahife's Keagent, slowly and on standing.

2. The presence of formaldehycte was establiahed by the production of a violet colour when $1 \mathrm{ml}$, of the solution was heated with a sulphuric acid solution of chrorotropic aoid (1:8-aihyàroxymaphthelene - 3:6 disulphonio acid).(47).

3. The absence of acetone was inâjaated by the fatiure of the sodium nitroprussice test. $(48)$.

4. The acidsty of the solution was only slight, $10 \mathrm{mls}$, of it required only $1 \mathrm{ml}$. of 100 alkali for neu ralisation. The neutral solution thus obtained was evayorated gently to about half bulk. A few dropa of acqueaus silver nitrate were adod but no preaipitate appeared. On further evaporation some silver was deposited by oridation of aldehyde but no silver salts appeared.

5. One $\mathrm{ml}$. of solution was tested for peroxides with a methanolis solution of Perrous thiooyanate.(49) There was no development of the ferrio thiocyanate colcur, thus indicating the absence of percoxides.

6. The presence of acrolein in the condensible products was suspeoted for some time. The fallure of the o-dianisidine reaction an not be said to je due to the naskins effect of formaldehyde since the reagent is four mundred. tines more sensitive to acxyile aldehyde than formaldehyde and since the former aldehyle gives darker colours with the reagent than formaldehyde. (50). 
7. The failure to obtain a trinitrobenzoyl derivative indicated the absence of a reasonable quantity of alcohols and various colorinetric tests were applied with negative results for other aldehydes. (51).

\section{Determination of water formed in the reaction}

There are many physical methods available for the determination of reasonably large quantities of water. Of the many attempts to determine small amounts chemically, by far the most successful is the Karl Fischer method which involves the following reations between sulphur dioxide, iodine, pyridine, nethanol and water. Smith, Bryant and Mitchell (52) represented the reaction as follows:-

$$
\begin{aligned}
& \mathrm{SO}_{2}+\mathrm{I}_{2}+\mathrm{H}_{2} \mathrm{O}+3 \mathrm{C}_{5} \mathrm{H}_{5} \mathrm{~N} \rightarrow 2 \mathrm{C}_{5} \mathrm{H}_{5} \mathrm{~N} \cdot \mathrm{HI}+\mathrm{C}_{5} \mathrm{H}_{5} \mathrm{~N}<\mathrm{S}_{0}^{\mathrm{SO}_{2}} \\
& \mathrm{C}_{5} \mathrm{H}_{5} \mathrm{~N}<\mathrm{O}_{\mathrm{O}}^{\mathrm{SO}_{2}}+\mathrm{CH}_{3} \mathrm{OH} \rightarrow \mathrm{C}_{5} \mathrm{H}_{5} \mathrm{~N}<\mathrm{SO}_{4} \cdot \mathrm{CH}_{3}
\end{aligned}
$$

The solution of sulphur dioxide, iodine and pyridine dissolved in dry methenol (the Karl Fischer reagent) is unstable, partly due to its extremely hygroscopic nature and partly due to the other reactions taking place even in the absence of water. For this reason it must be standardised against a standard solution of water before use.

The visual determination of the end-point (change from chromate-yellow to a yellow permanently tinged with the reddishbrown of free iodine) is uncertain. For this reason and also to prevent absorption of moisture during titration a comercial titration unit was use which was claimed to exclude moisture 
and which incorporated a sensitive micro-amneter to measure conductance between two platinum electrodes immersed in the titration mixture which is stirred by a stream of dry nitrogen. At the beginning of the titration the meter registers about five scale divisions while the end-point was taken when the meter registered about eighty scale divisions for at least half a minute.

The Karl Fischer reagent was prepared according to the formula of Sinith, Bryant and Mitchell.(52). A solution of $84.7 \mathrm{~g}$. iodine and $269 \mathrm{mls}$. pyraine in $667 \mathrm{mls}$. dry methanol was cooled in a slurry of ice. $64 \mathrm{~g}$. of liquid sulphur dioxide was added slowly and with stirring. The solution was rapidly transferred to the storage bottle on the apparatus.

\section{Determination of Formaldehyde Formed in the Reaction}

The amount of formaldehyde present in the condensible products was determined by a method similar to that of Bricker and. Jolinson (53).

100 mgms, \pm 10 mgms, of chromotropic acid were weighed into a $30 \mathrm{mls}$. beaker and $1 \mathrm{ml}$. of solution of formaldehyde was added. $5 \mathrm{mls}$, of concentrated sulphuric acid were added slowly and with cooling and the solution was then heated for 30 minutes on a boiling water bath. The solution was then cooled and diluted to $50 \mathrm{mls}$. in a graduated Plask. When the temperature fell to that of the room the volume vas made up to exactly $50 \mathrm{mls}$, and the optical intensity of the solution was then compared with that of a reagent blank at $570 \mathrm{m.m}$. 
In exactly the same way the optical intensity was measured of solutionsobtained by treatment of $1 \mathrm{ml}$. of various standard solutions of formalcehyce. These were prepered by suitable dilution of 32 formelin solution which was stendardised by titration with ioaine.

\section{$\underline{\text { Results }}$}

$2.5 \mathrm{ccs}$, of the formalin solution were diluted to $500 \mathrm{cos}$ with distilled water. Two $25 \mathrm{mls}$. samples were pipetted into conical flasks where they were treated with $50 \mathrm{ccs}$. of $0.0955 \mathrm{~N}$ iodine introcuced by pipette. The solutions were then treated with 10,0 caustic soda until a pale yellow colour developed and were aliowed to stand for 15 minutes with occasional shaking. On acidifying with dilute hydrochloric acid, unchanged hypoidite was reliberated as iodine and this was then back titrated in the usual way with $0.0947 \mathrm{~N}$ thiosulphate.

Titrations $=21.53 \mathrm{mls}$. and $21.57 \mathrm{mls}$.

i. e. mean titration: $21.55 \mathrm{mls}$. $0.0947 \mathrm{~N}$ thio-sulphate.

Thus $25 \mathrm{mls}$. of the diluted forralin solution required

$(50-21.55 \times 0.0947) \mathrm{mls}$. of $0.0955 \mathrm{~N}$ iodine for oxidation

But $30 \mathrm{gms} . \mathrm{CH}_{2} \mathrm{O}=2$ li. $\mathrm{N} \mathrm{I}$

- Formalchyde present in $25 \mathrm{mls}$. solution

$=(50-21.55 \times 0.0947) \times 0.0955 \times 0.00150 \mathrm{gms}$.

Hence $1 \mathrm{cc}$ of this solution contains $0.00164 \mathrm{gms}$. of formaldehyde.

By suitable dilution of $10 \mathrm{mls}$. samples of this solution, solutions containing $8.9,16.4,32.8,65.6,82.0,104.0$ and 164.0 
micrograms of formaldehyde/ml, were obtained. These provided satisfactory colorimetric standards and the data in table no. 1 illustrate the variation of extinction coefficient wh changing formaldehyde concentration.

TABLE NO. 1.

Conc. of Formaldehyde

$(\mathrm{x} / \mathrm{ml}$.)

Log. $\frac{I_{0}}{I}$

$8 \cdot 2$

$16: 4$

$32 \cdot 8$

$65 \cdot 8$

$82 \cdot 0$

$104 \cdot 0$

$164 \cdot 0$

$0 ; 074$

0.157

0.287

0.544

0.670

0.754

0.948 
$-34=$

BXPERINEITALRBSUITS 


\section{A TYPTCAT EXPBRTIMNT}

The apparatus was evacuated for one hour, so that the pressure in the system was $10^{-5} \mathrm{~m}, \mathrm{~m}$, or below, as measured by the Molseod gauge. It was ensurea that the temperature was constant at $678^{\circ} \mathrm{A}$. The taps $A, B, C, D, E$ and $F$ were then closed and dry air was admitted through tap I to the gauge jacket until the manometer showed a pressure head of $177 \cdot 4 \mathrm{~m}$. $\mathrm{m}$.

By opening $\operatorname{tap} G$ the connecting tubing was filled with cyclopropane. Tap $G$ was then reclosed and by manipulation of taps $D$ and $E$ the hydrocarbon was cautiously admitted to the reaction vessel until the gauge-pointer's shadow returned to the mull point on the screen. Tap A was then opened to remove all cyclopropane left in the connecting tubing.

Dry air was again admitted to the gauge jacket until the manometer registered a pressure of $328 \cdot 8 \mathrm{~m}, \mathrm{~m}_{\text {. }}$ and $151 \cdot 4 \mathrm{~m}_{*} \mathrm{~m}_{\text {. }}$ of oxygen were allowed into the reaction vessel in a manner similar to that adopted in the case of hydrocarbon. The stop-watch was started just as the first of the oxygen entered the reaction vessel.

After all the residual oxygen in the tubing had been purnped away, the pressure in the gauge jacket was increased by adnission of a little more air and the manometer readings were taken. When the pointer's shadow returned to the zero mark, the time was noted and the extermal gauge pressure was again altered. By this procedure, the rather cumbersone technique of altering the external pressure to balance the pointer movement was avoided. 
The alterations of pressure were designed to give time intervals of between one minute and ninety seconds. When there vas no further change of pressure and the final reading had been taken, taps $\mathrm{D}, \mathrm{B}$ and $\mathrm{F}$ were opened and the products were pumped through the trap $J$ as previously described. After the gas fractions had been collected and the trap $J$ had warmed up to room temperature, dry air was admitted to it. $20 \mathrm{mls}$. of ary methenol were then pipetted into the trap which was then carefuliy removed and stoppered. Meanwhile the tap F was closed and the remainder of the apparatus was evacuated in readiness for the next experiment. The pressure-time record is given in table No, 2. The table also gives the values of the rates operative over the times between consecutive pressure readings. The times t'midway between these readings are also given. Another colurm in the table lists the logaritims of the pressure changes noted at each time. 


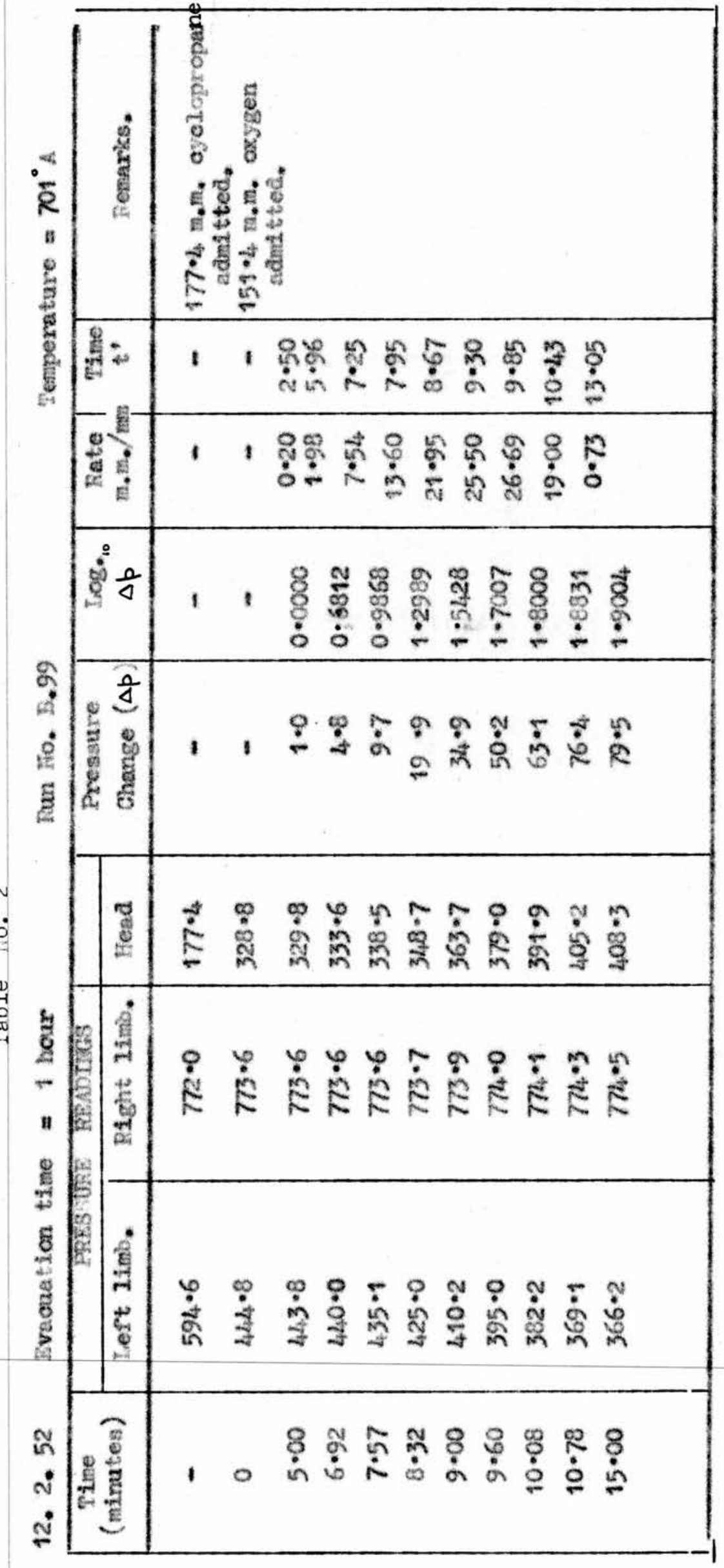


From the data in the table many important factors may be determined. The graph No. 1 illustrated the veriation of with time. The curve is a smooth S-shaped one of the type normally found in free radical hydrocarbon oxidations, which are also characterised by a long induction period. The second graph (No. 2) illustrates the method of determination of the maximum rate. The rates (table No. 2) are plotted against time $\left(t^{\prime}\right)$ and the curve shows the gradual increase of rate to a maximum after which it falls off again to zero.

The application of the Senenov theory of degenerate branching chains to the reaction is justified by the graph (No. 3) of $\log _{10} \Delta p$ against time. This graph is linear over a very considerable period but begins to curve away some time before the attainment of maximum rate, and raust be considered to be a better line than many which have appeared in the literature. The gradient of the line, 1f multiplied by 2.303 gives the net-branching factor $\phi$ but since this offers no particular advantage, future reference in this thesis to the net-branching factor $A^{\prime}$ actually meens the gradient of the line relsting $\log _{10} \Delta p$ and $t$ i.e. $\frac{\phi}{2 \cdot 303}$

It is to be concluded from the results obtained in this typical experiment that the rate of the reaction increased to a maximum value and that the early part of the reaction, at least, proceeded in accordance with the relationship $\Delta P=A e^{\phi t}$. Furthermore the reaction was characterised by a long induction period. These are characteristic features of a chain reaction with 
GRAPH N NI

Pressure - Time Curve (Run N: B99)

$p_{c \text { c. }}=177.4 \mathrm{mom}$.

$p_{o_{2}}=151.4 \mathrm{mom}$

$T^{2}=701^{\circ} \mathrm{A}$

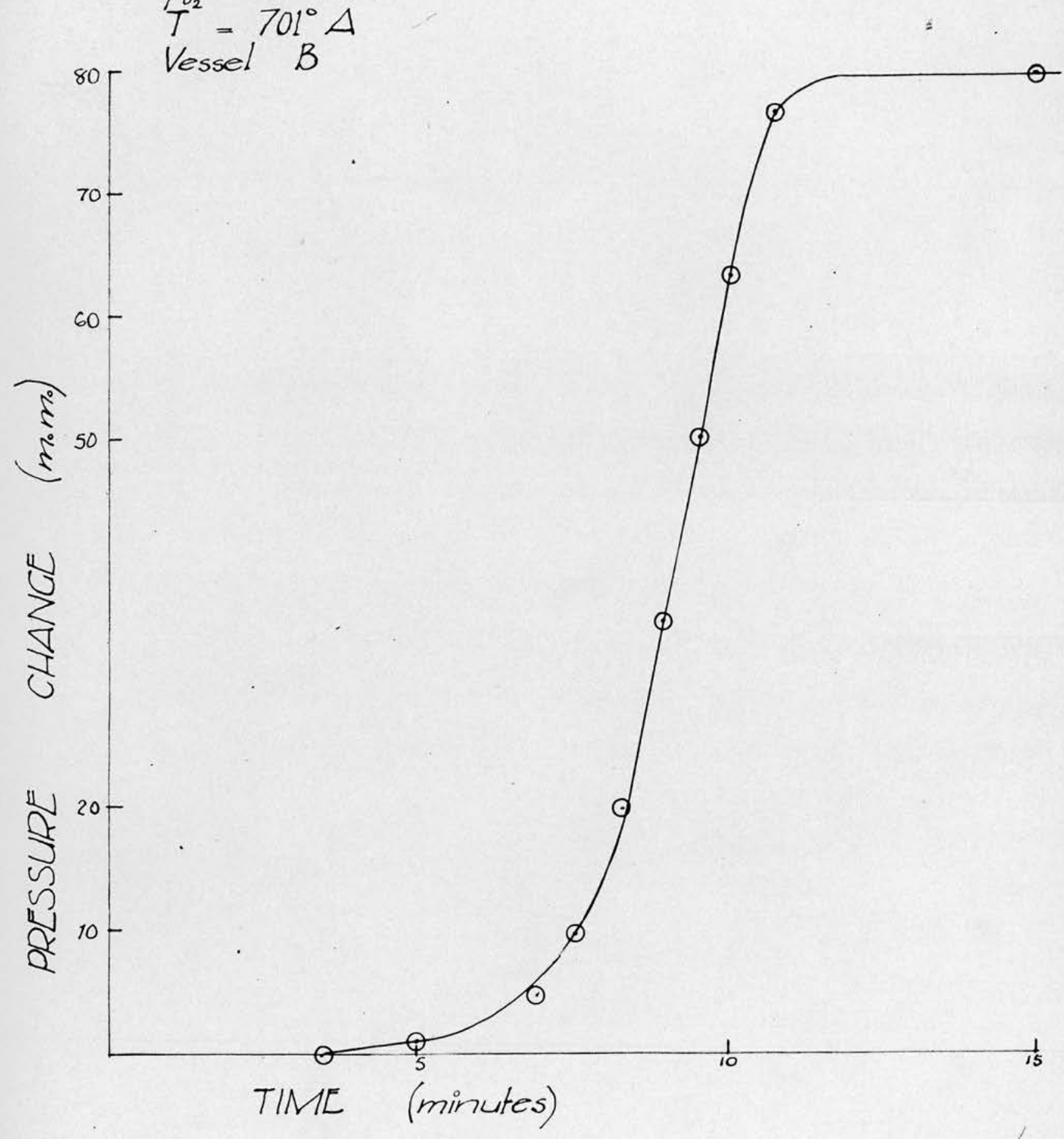


Rate - Time Curve (Run N. B99)

$$
\begin{aligned}
& p_{c \text { P. }}=177.4 \mathrm{~m} \cdot \mathrm{m}_{0} \\
& p_{o_{2}}=151.4 \mathrm{~m} \mathrm{~m}_{0} \\
& T=701^{\circ} \mathrm{A} \\
& \text { Vessel } \mathrm{B}
\end{aligned}
$$

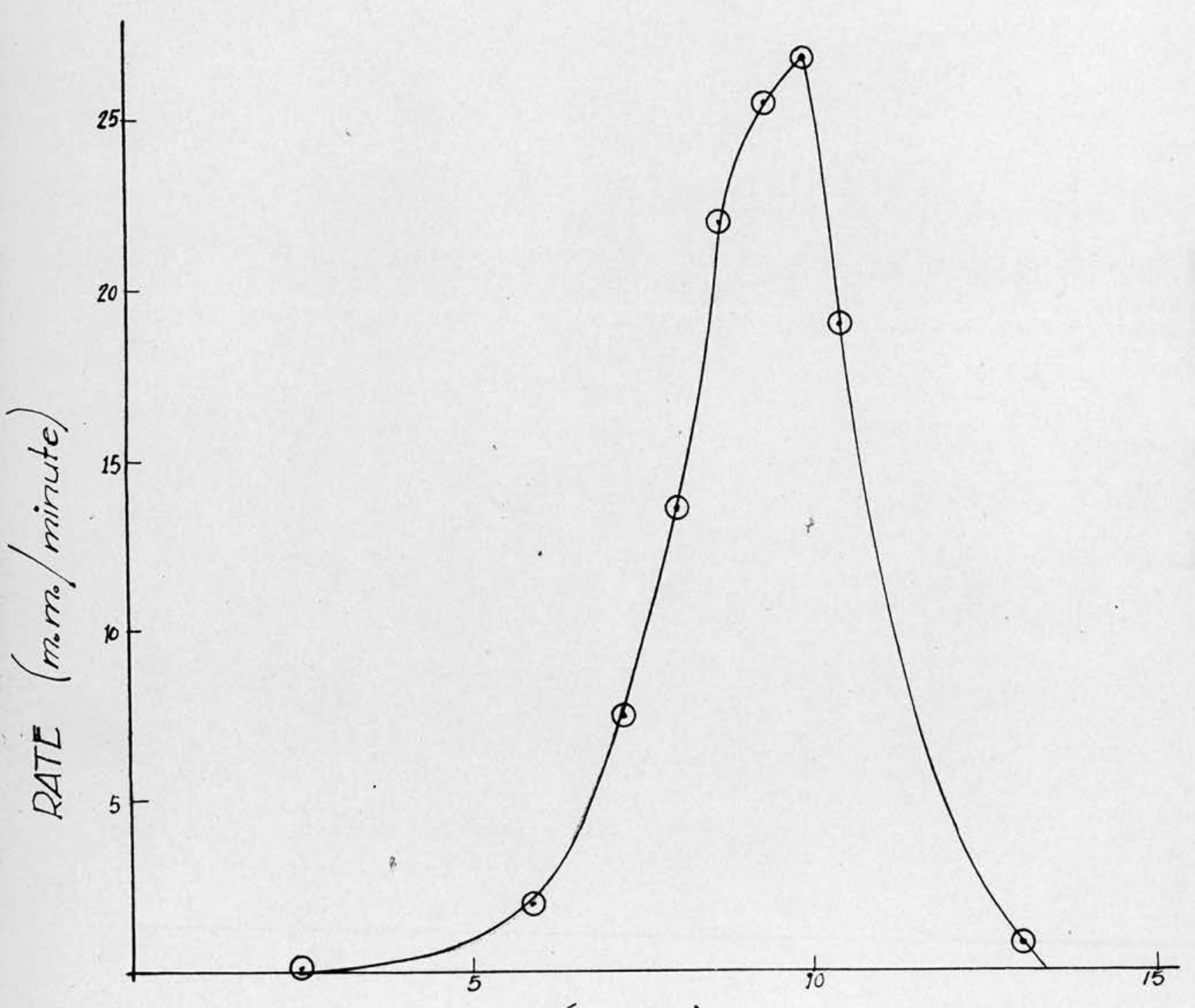

TIME (minutes) 


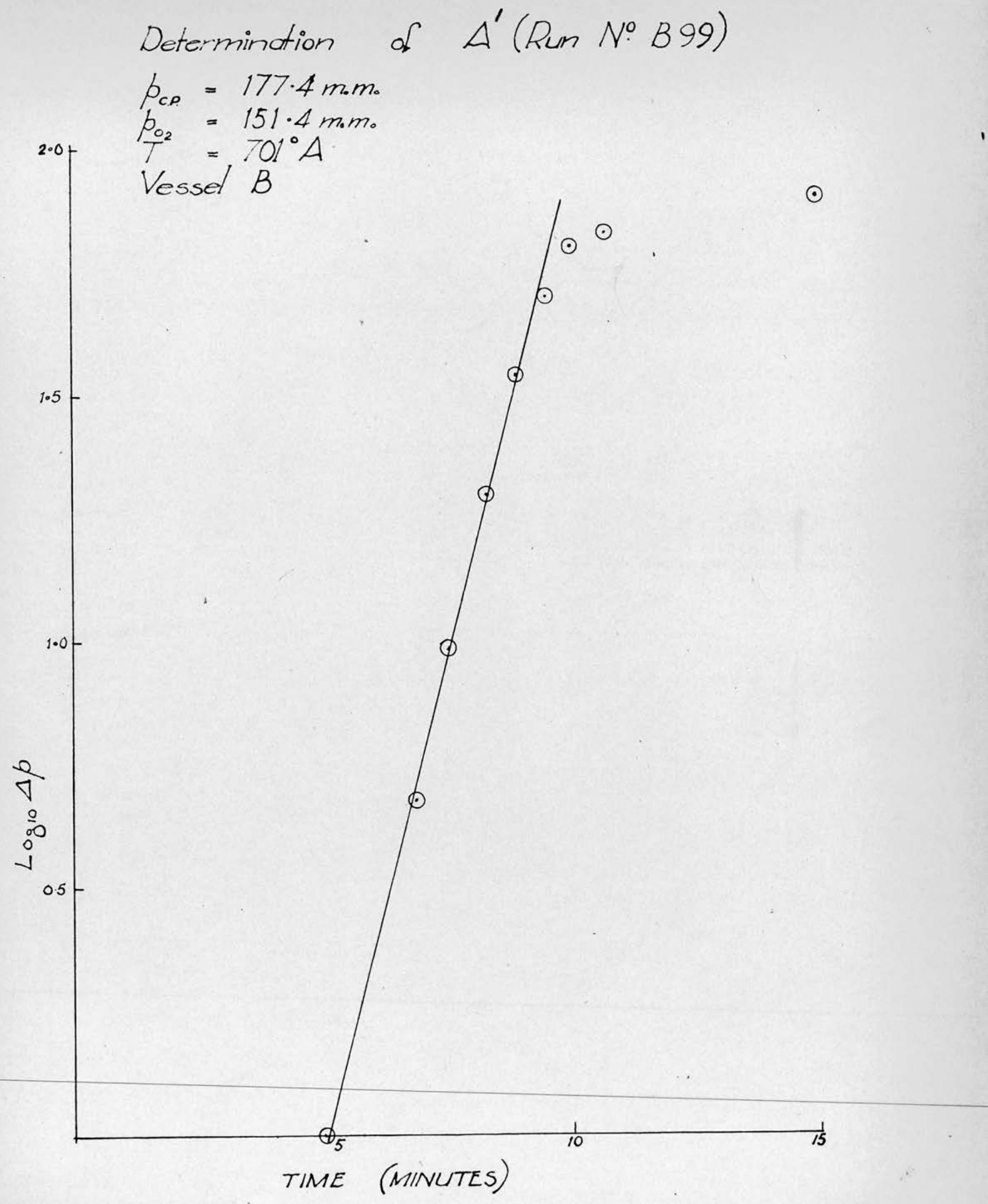


degenerate branching and in accordance with earlier work in the slow-combustion field the following parameters of the reaction were considered to be of imnortance - the maximum rate, $\rho_{\max }$; the net-branching factor $A^{\prime} ;$ the time elapsing before the occurrence of a pressure change of 1 millimetre, $\tau_{\text {; }}$ the time elapsing before the attainnent of maximum rate, $\theta$; the pressure change occurring during the time $\theta, \Delta p_{\max } ;$ and the total pressure change, $\Delta p_{\infty}$. The values of these parameters ore given in table No. 3 which refers to the typical experiment just described.

\section{TABLS NO. 3.}

\section{Results of a Typical Fxperiment}

Run No. $\quad 8.99$

Initial pressure of cyclopropane $\left(p_{c p}\right)=177.4 \mathrm{~m} . \mathrm{m}$. Initial pressure of oxygen $\quad\left(p_{\mathrm{o}_{2}}\right)=151.4 \mathrm{~m} \cdot \mathrm{m}_{0}$ Termerature $=701^{\circ} \mathrm{A}$

$$
\begin{aligned}
\rho_{\max } & =26.8 \mathrm{~m} \cdot \mathrm{m}_{\bullet} / \text { minute } \\
A^{\prime} & =0.394 \\
\tau & =5.0 \mathrm{mins} \\
\theta & =9.8 \mathrm{mins} . \\
\Delta p_{\max } & =56 \mathrm{~m} \cdot \mathrm{m}_{\bullet} \\
\Delta p_{\infty} & =79.5 \mathrm{~m} \mathrm{~m}_{0}
\end{aligned}
$$

Determination of the Reaction-vessel Volume

A volume of oxygen was adritted to the reaction vessel

(by which is understood the vessel itself and the dead space up to the tan and up to the gauge) and when it came to therral equilibriur, the gauge pointer was brought back to the zero 
mark and the external (balancing) pressure was read off on the manometer. The temperature of the vessel was noted. The oxygen was then removed by the Toepler pump and was collected over mercury. Its volume was measured in the usual way in the gas analysis apparatus; the mercury in the burette was moistened with water and the volume was corrected for the pressure of saturated water vapour.

Results

$\begin{aligned} \text { In the vessel, pressure of oxygen } & =90.3 \mathrm{~m} \cdot \mathrm{m}_{*} \\ \text { Temperature of vessel } & =682.5^{\circ} \mathrm{A} . \\ \text { In the gas analysis burette, volume } & =8.48 \mathrm{c.cs} . \\ \text { atmospheric pressure } & =746.7 \mathrm{~m} . \mathrm{m} . \\ \text { saturated vapour pressure } & =17.0 \mathrm{~m} . \mathrm{m} . \\ \text { temperature } & =292.5^{\circ} \mathrm{A} .\end{aligned}$

Since the gas employed was axygen the applicability of the gas laws is unquestionable. Hence the reaction volume is given by:-

$$
v=\frac{729 \cdot 7 \times 8.48 \times 682.5}{90.3 \times 292.5} \text { c.cs. }
$$

i.e. reaction volume $=159.9 \mathrm{c.cs}$ :

A second determination showed the volume to be $159 \cdot 1$ c.cs. and so the true volume was taken to be $159 \cdot 5$ c.cs. (i.e. the mean of two results).

Typioal Gas Analysis:- (Fun no. E54).

First fraction (permanent gases)

Total volume $=16.45 \mathrm{ccs}$. Barometric pressure $=741.5 \mathrm{~m} \cdot \mathrm{m}$. Temperature $=10.5^{\circ} \mathrm{C}$. S.V.P. at $10.5^{\circ} \mathrm{C}=9.5 \mathrm{~m} \cdot \mathrm{m}_{0}$ 
Vol. of sample -9.51 ces.

Vol. Less $\mathrm{O}_{2}-4 \cdot 21$ ccs. Vol of $\mathrm{O}_{2}$ in sample $=5 \cdot 30$ ces. Pressure of $\mathrm{O}_{2}$ in vessel $=100 \cdot 6 \mathrm{~m} . \mathrm{m}$. Vol. Less $\mathrm{C}_{3} \mathrm{H}_{6}=4.19 \mathrm{ccs}$. Vol. of $\mathrm{C}_{3} \mathrm{H}_{6}$ in sample $=0.02$ ccs. Pressure of $\mathrm{C}_{3} \mathrm{H}_{6}$ in vessel $=0.2 \mathrm{~m}, \mathrm{mo}$. Vol. less 0.0 .23 ccs. Vol. of $\mathrm{CO}$ in sample $-3 . \%$ ccs. Pressure of $\mathrm{CO}$ in vessel $=75 \cdot 1$ m. Vol. after cosbustion Vol. of $\mathrm{H}_{2}$ in sample $=0.08$ ccs. Pressure of $\mathrm{H}_{2}$ in vessel $=1.5 \mathrm{~m}, \mathrm{~m}$. - 0.15 ccs. Vol. of $\mathrm{CH}_{4}$ in sample $=0.03$ ccs. Pressure of $\mathrm{CH}_{4}$ in vessel $=0.7 \mathrm{man}$. Vol. less $\mathrm{CO}_{2}=0.12 \mathrm{ccs}$. Vol. of $\mathrm{W}$ in saple $=0.12$ ecs. Pressure of $\mathrm{N}_{2}$ in vessel $=2.4 \mathrm{a.m}$. Second fraction (non-peraanent gases)

Total volune -16.32 ccs. Barometric pressure $=741.5$ a.m. Tenperature $=10.5^{\circ} \mathrm{C}$.

$$
\text { S.V.P. at } 10.5^{\circ} \mathrm{C}=9.5 \mathrm{mom} .
$$

Vol. of semple 9.31 ccs.

Vol. Less $\mathrm{C}_{3} \mathrm{H}_{6}=0.38$ ces. Vol. of $\mathrm{C}_{3} \mathrm{H}_{6}$ in sample $=8.93 \mathrm{ccs}$. Pressure of $\mathrm{C}_{3} \mathrm{H}_{6}$ in vessel $=171.9 \mathrm{~m}=\mathrm{a}$, Vol. less $\mathrm{CO}_{2}=0.00$ ccs. Vol. of $\mathrm{CO}_{2}$ in sample $=0.38$ ccs. Pressure of $\mathrm{CO}_{2}$ in vessel $=7.3 \mathrm{a} . \mathrm{a}$. Analysis of gaseous products (as pressures in vessel $\mathrm{E}$ at $678^{\circ} \mathrm{A}$ )

$\begin{array}{lll}\mathrm{C}_{3} \mathrm{H}_{6} & = & 172.1 \mathrm{~m} \cdot \mathrm{m}_{\bullet} \\ \mathrm{O}_{2} & = & 100.6 \mathrm{~m} \cdot \mathrm{m}_{\bullet} \\ \mathrm{CO} & = & 75.1 \mathrm{~m} \cdot \mathrm{m}_{\bullet} \\ \mathrm{CO}_{2} & = & 7.3 \mathrm{~m} \cdot \mathrm{m} . \\ \mathrm{H}_{2} & = & 1.5 \mathrm{~m} \cdot \mathrm{m}_{\bullet} \\ \mathrm{CH}_{4} & = & 0.7 \mathrm{~m} \cdot \mathrm{m}_{\bullet} \\ \mathrm{N}_{2} & = & 2.4 \mathrm{~m} \cdot \mathrm{m}_{\bullet}\end{array}$

Typical analysis for water :- (Run no. E8)

The contents of the trap were treated with $25 \cdot 0 \mathrm{mls}$. of methanol and two $10 \mathrm{mls}$. samples were titrated with the Karl Fischer reagent. Two $10 \mathrm{mls}$. samples of the methanol used were also titrated with the reagent, as were two $10 \mathrm{mls}$. samples of the standard water solution containing $1 \mathrm{~g}$. of water per litre of the same methanol. 
Results

Titration of $10 \mathrm{mls}$, of wethanol. Titres - 3060 als, and 3.62 als. - $3.61 \mathrm{mls}$. Titration of $10 \mathrm{mls}$. of standard solution. Titres -8.61 als, and 8.61 als. Titration of 10 mls, of unknown solution. ritrss $=5080$ als, and 5.83 ats. 99.9 als. of methanol - 36.06 als. of Karl Fischer reagent So 0.1 g. HzO - 86.1 als. - 36.1 als. - $50.0 \mathrm{mls}$. reagent f.e. $1 \mathrm{ml}$. reagent $=0.0020 \mathrm{ge} \cdot \mathrm{H}_{2} \mathrm{O}$ How 25 als. of methanol - $2.5 \times 3.61$ als. Karl fischer reagent $\mathrm{H}_{2} \mathrm{O}$ in the trap $-2.5 \times(5.82-3.61)$ uls, reagent

$=2.5 \times 2.21 \times 0.0020 \mathrm{ge} \cdot \mathrm{H}_{2} \mathrm{O}$

- $2.5 \times 2.21 \times 0.0020 \times \frac{22400}{18}$ ces. steam at M.T.P.

- 13.75 ccs. stean at N.T.P. 
$-43-$

KINBIICS 


\section{THE BAFECT OF THE SURFACE}

A characteristic of reactions involving chains with degenerate branching, which may be explained in the light of the Semenov analysis is the extraordinary sensitivity of the reaction rate and more markedly the induction period to the state of the walls of the vessel. Several different reaction vessels were employed in this investigation and, although the differences in their surface and volume dimensions were small they gave different results for the same experiment. Table No. 4 gives the measured parameters for five vessels for the reaction of $200 \mathrm{~m}_{*} \mathrm{~m}_{\text {, }}$ of cyclopropane with $200 \mathrm{~m}_{*} \mathrm{~m}_{\text {, }}$ of oxygen at $405^{\circ} \mathrm{C}\left(678^{\circ} \mathrm{A}\right)$. The table also includes details of surface and volume measurements.

\section{Table No. 4.}

$$
\text { Initial } p_{c p}=p_{\bullet_{2}}=200 \mathrm{~m}_{0} m_{0} \quad T=678^{\circ} \mathrm{A} \text {. }
$$

\begin{tabular}{|c|c|c|c|c|c|c|c|c|}
\hline Vessel & $\begin{array}{l}\text { Surface } \\
\text { Area }\end{array}$ & $\begin{array}{l}\text { Volume } \\
\text { s.cs. }\end{array}$ & $f_{\max }$ & $A^{\prime}$ & $\tau$ & $\theta$ & $\Delta p_{\max }$ & $\Delta p_{\infty}$ \\
\hline A & 190 & 197 & $5 \cdot 9$ & 0.122 & 31 & 45 & $53 \cdot 1$ & $100 \cdot 8$ \\
\hline B & 172 & 159 & $10 \cdot 4$ & 0.163 & 15 & 20 & $55 \cdot 7$ & $100 \cdot 0$ \\
\hline C & 188 & 180 & $9 \cdot 1$ & 0.165 & 28 & 38 & $52 \cdot 4$ & $99 \cdot 6$ \\
\hline$D$ & 166 & 151 & $11 \cdot 2$ & 0.240 & 18 & 27 & $51 \cdot 0$ & $99 \cdot 2$ \\
\hline B & 160 & 145 & $6 \cdot 3$ & 0.115 & 23 & 37 & $58 \cdot 1$ & $100 \cdot 0$ \\
\hline
\end{tabular}

It will be seen that the rates in vessels $A$ and $I$ are of the same order while those in the other three vessels are also comparable with each other. Apart from the smaller volumes of vessels $A$ and $E$, there seems to be little distinction between them and the other three. It is possible, of course, that some slight difference in the nature of the glass accounts for 


$$
-45-
$$

the results in table No. 4.Kinetionl experiments vere ourried out in vessels $A, B$ and $D$ (mainly in $B$ ) ana the form of the kinetical characteristias of the reaction was found to be unaltered by change of vessel, although the absolute velues of the poraneters varled between the three vessels.

The behaviour of the vessels during the ageing prosess is also worthy of coment. Vessels $C, D$ and $\mathrm{B}$ requirea the perPormance of oniy a few (about 6) experiments before steady state conditions attained. In vessels $A$ and $B$, on the other hand, the rate gradually increased beocming steady after some twenty experimonts. It was also noted that the incuotion periods in the first three experiments were roughly the seme as the final (ateady state) value of $\theta$ but during the intervening experiments $\theta$ rose to a maximum. In the oase of the naximan rate, however, the trend was slow and contimuous from $3 \cdot 7$ in the first to 9.7 in the nineteenth experiment. The results of these nineteen experimenta are given in table No. 5.

Table No. 5. Ageing on a new vessel.

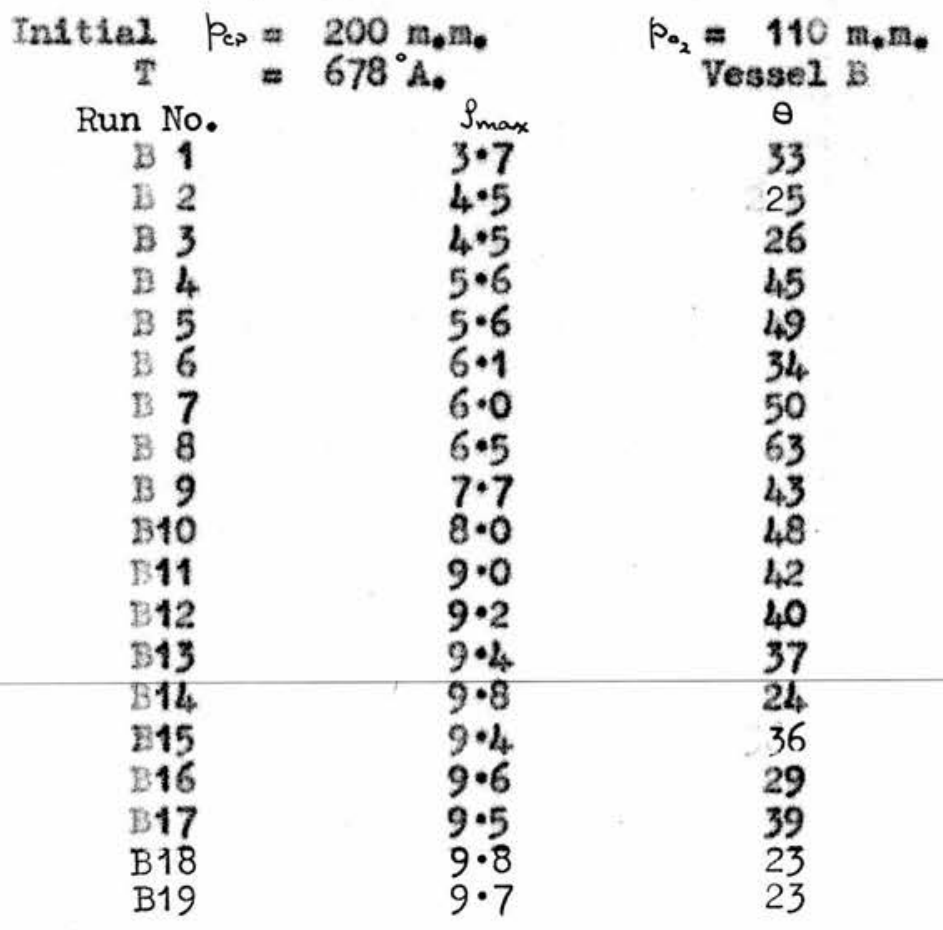


Even after the attainment of a steady state the reproducibility of results could be drastically changed. For example if the vessel was allowed to cool down without admitting air to it and was then reheated, the ensuing experiments yielded low results for the naximum rate and high values for the induction period. Gradually these parameters returned to their normal value as is shown in table No. 6.

Table No. 6.

Ixperiments performed after cooling of the vessel

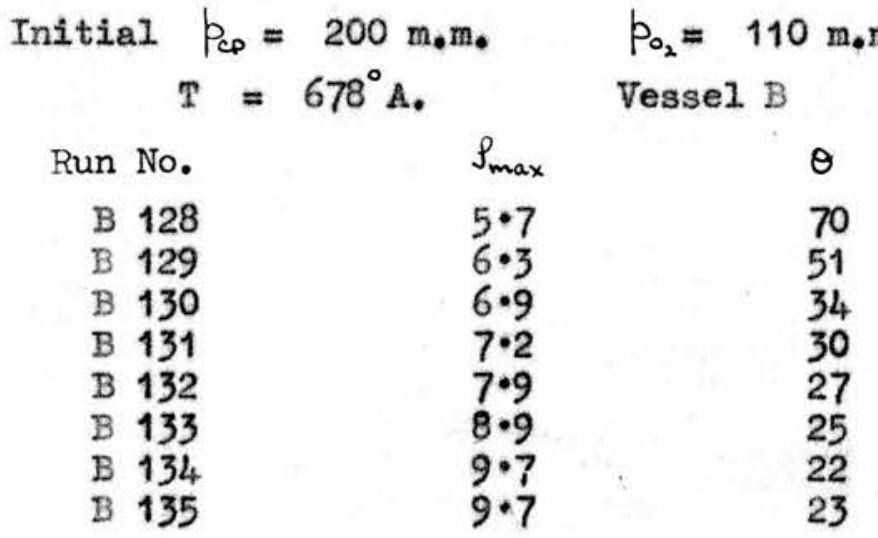

It will be observed that the cooling of the vessel only reduced the rate by some $35 \%$ and that only eight experiments were needed for the reattainment of equilibrium conditions. $\left(\rho_{\max }=9.7, \theta=23\right.$. ). In this connection it will also be noted that the trend in $\theta$ is continuous in table no. 6 from 70 minutes in experiment No. 128 to 23 in No. 135. Another effect of great importance was that obtained by the admission of air to the hot vessel. This manifested itself in the production of lower rates and shorter induction periods which, however, soon returned to normal.

Apart from these considerations the state of surface of 
the vessels seemed sometimes to change in some way very suddenly and in contrast with those effects above, the change, on occasion, was irreversible. Two examples, each of a different nature, will suffice to illustrate the point. In vessel $\mathrm{D}$ during a series of experiments to determine the effect of variation of initial axygen pressure upon the reaction, results consistent with expectation were obtained. These included an experiment with $300 \mathrm{~m}, \mathrm{~m}$. of axygen and $100 \mathrm{~m}, \mathrm{~m}$, of cyclopropane at $701^{\circ} \mathrm{A}$ ( $x$ no. D 14). When some time later, the same run was repeated curing the study of the effect of variation of initial hydrocarbon pressure (run No. D 21), different results were obtained for the reaction parameters. These latter results, however, were consistent with the other values obtained in the study of the variation of initial cyclopropane pressure. The results are given in table No. 7 .

Table No. 7.

$$
\begin{aligned}
\text { Initial } p_{c p} & =100 \mathrm{~m}_{0} \mathrm{~m}_{0} & p_{\bullet_{2}}=300 \mathrm{~m} \cdot \mathrm{m}_{\bullet} \\
\mathrm{T} & =701^{\circ} \mathrm{A} & \text { Vessel } \mathrm{D}
\end{aligned}
$$

Run No. $\quad \rho_{\max } \quad A^{\prime} \quad \theta$

$\begin{array}{llll}D & 74 & 0.27 & 12\end{array}$

$\begin{array}{llll}\text { D } 21 & 8 \cdot 6 & 0.183 & 18\end{array}$

The second example of this sudden change occurred in vessel $B$. During the runing - in of this vessel the steady state induction period for a mixture of $200 \mathrm{~m} \cdot \mathrm{m}_{\text {. }}$ cyclopropane and $110 \mathrm{~m} \cdot \mathrm{m}$. oxygen at $678^{\circ} \mathrm{A}$ was 23 minutes (table No. 5). During the study of variation of oxygen pressure with initial hydrocarion pressure $200 \mathrm{~m} \cdot \mathrm{m}_{*}$, results were obtained with which to be 
consistent an induction period of 59 minutes would be required for that experiment. No change had taken place in the maximum rate, however, which was $9.7 \mathrm{~m}, \mathrm{~m}$. per minute in each case. The change in $\theta$ with no accompanying change in rate became even more remarkable when, a very considerable time later, during the experiments on the effect of cooling of the vessel (table No. 6) there was a return (in the steady state) to the value of 23 minutes for the induction period.

Mr. W. N. Broatch obtained some very interesting results in experiments designed to determine the effect of changes of surface upon the reaction parameters. He compared these oharacteristics for the reaction of $200 \mathrm{~m} . \mathrm{m}_{\text {. }}$ of each gas in a cylindrical pyrex vessel with those obtained in a second vessel of identical geometry packed with pyrex capillary tubing so that its surface to volume ratio was 11,7 times that of the unpacked vessel. The changes which occurxed are tabulated below.

\section{Table No. 8.}

Comparison of results in packed and unpacked vessels.

$$
\text { Initial } p_{c p}=200 \mathrm{~m}_{0} \mathrm{~m}_{*}=\text { Initial } p_{\mathrm{O}_{2}}
$$

Vessel

Packed vessel

Unpacked vessel

$$
\begin{array}{cccccc}
\rho_{\max } & A^{\prime} & \tau & \theta & \Delta p_{\max } & \Delta p_{\infty} \\
0.86 & 0.008 & 283 & 349 & 56.3 & 80 \\
8.1 & 0.078 & 35 & 51.0 & 55.5 & 103
\end{array}
$$


THE DEPENDWYEE OF THE MAXTMUM RATE UPON CONDITIONS.

1. Dependence Upon Initial Oxygen Pressure

A series of experiments was performed at $678^{\circ} \mathrm{A}\left(405^{\circ} \mathrm{C}\right)$

with a fixed cyclopropane pressure of $178 \mathrm{~m}, \mathrm{~m}$, and with varying anounts of oxygen over the range $50-200 \mathrm{~m}, \mathrm{~m}$. Other similar series of experiments were then performed at the same temperature with the fixed initial cyclopropane pressures $200 \mathrm{~m}_{\bullet} \mathrm{m}_{\bullet}, 250 \mathrm{~m}_{\bullet} \mathrm{m}_{\text {. }}$ and $300 \mathrm{~m} . \mathrm{m}$. respectively. The results are shown in tables Nos. 9, 10, 11, 12 and on the graph (No. 4)

Table No. 9

Initial $k_{p}=178 \mathrm{~m}, \mathrm{~m} . T=678^{\circ} \mathrm{A}$ Vessel $B$ Run No.
Table No. 10

Initial $p_{c p}=200 \mathrm{~m} \cdot \mathrm{m} . \quad T=678^{\circ} \mathrm{A}$ Vessel $B$ Fun No. $\mathrm{po}_{2}$ $\rho_{\max }$

$\begin{array}{rrrr}\text { B } 24 & 50 \cdot 0 & 4 \cdot 4 \\ \text { B } 26 & 70 \cdot 0 & 6 \cdot 3 \\ \text { B } 25 & 100 \cdot 5 & 8 \cdot 9 \\ \text { B } 27 & 130 \cdot 0 & 10 \cdot 3 \\ \text { B } 30 & 199 \cdot 8 & 10 \cdot 4 \\ \text { B } 28 & 248 \cdot 7 & 10 \cdot 2\end{array}$

Table No. 12
Initial $p_{c p}=250 \mathrm{~m}, \mathrm{~m}_{0} \mathrm{~T}=678^{\circ} \mathrm{A}$ Vessel $B$

Fun No.

$$
\mathrm{PO}_{2}
$$

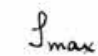

B 35

B 34

B 33

B 38

B 32

B 31

B 36

B 37

$\begin{array}{rr}48 \cdot 3 & 5 \cdot 4 \\ 94 \cdot 5 & 11 \cdot 4 \\ 109 \cdot 8 & 12 \cdot 7 \\ 124 \cdot 7 & 13 \cdot 9 \\ 134 \cdot 8 & 16 \cdot 0 \\ 180 \cdot 0 & 16 \cdot 7 \\ 198 \cdot 8 & 16 \cdot 2 \\ 250 \cdot 0 & 16 \cdot 4\end{array}$
Run No. Initial $p_{c p}=300 \mathrm{~m}, \mathrm{~m}, \quad \mathrm{~T}=678^{\circ} \mathrm{A}$ Vessel $\mathrm{B}$

\section{It will be clearly seen that there are two distinct} regions on each curve. There is, at lower oxygen pressures, 


\section{Variation of Initial Oxygen Pressure at $678^{\circ} \mathrm{A}$ (Vessel B)}

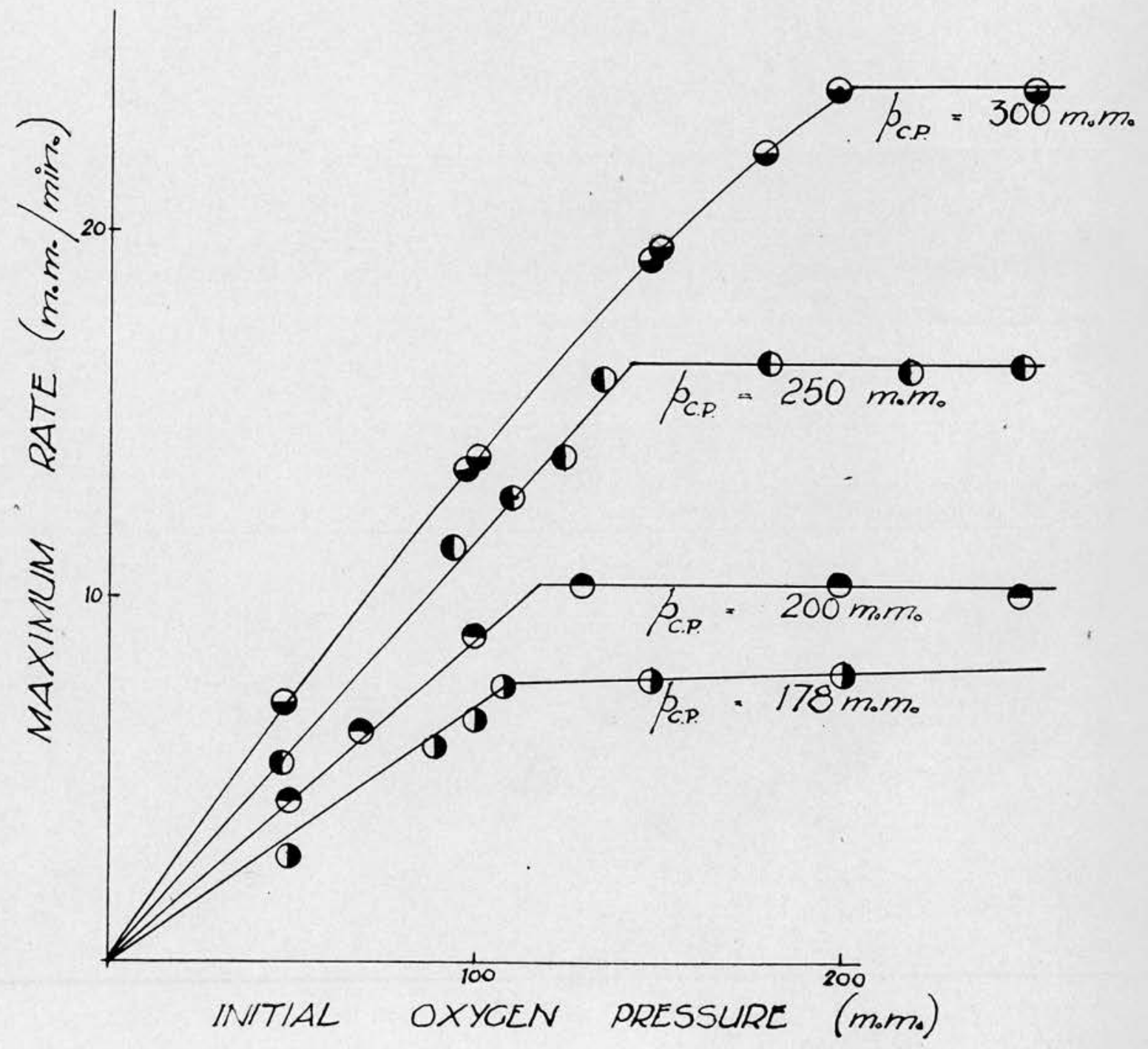


an apparently linear dependence of the maximum rate which changes to an independence at higher pressures of cxygen. The transition from dependence to independence is seen to be fairly critical at lower oyclopropane pressures, whereas with $300 \mathrm{~m} . \mathrm{m}$. of hydrocarbon, the linear relationship obtains only at lower oxygen pressures the change to independence being much more gradual.

It is also evident that the "critical oxygen pressure" increased with the increase of initial hydrocarbon pressure. Table No, 13 shows the quantitative influence of the latter upon the oritical oxygen pressure which has been found by extrapolation of the early linear part of each graph to out the line of oxygen independence. Graph (No. 5) demonstrates the relation existing between critical oxygen pressure and initial cyclopropane pressure. Furthernore table No. 14 1llustrates the dependence of the gradient of the early (linear) part of each graph upon the initial hydrocarbon pressure. These results are plotted upon the same graph (No. 5).

TABLE ก. 13

$p_{C P}$ Extrapolated $p_{O_{2}} \frac{p_{C P}}{\text { Extrapolated } p_{O_{2}}} p_{C P}$

178

200

250

300
108 118 143 168
1.65

$1 \cdot 70$

1.75

$1 \cdot 78$
TABLE ND. 14

Gradient of
extrapolated line

178

0.0741

2402

0.0873

2291

250

0.1140

2191

0.1429

2100

Now, in the region wherein $\rho_{\max }$ depends upon the initial cxygen pressure, the gradient of the line and hence the rate at 


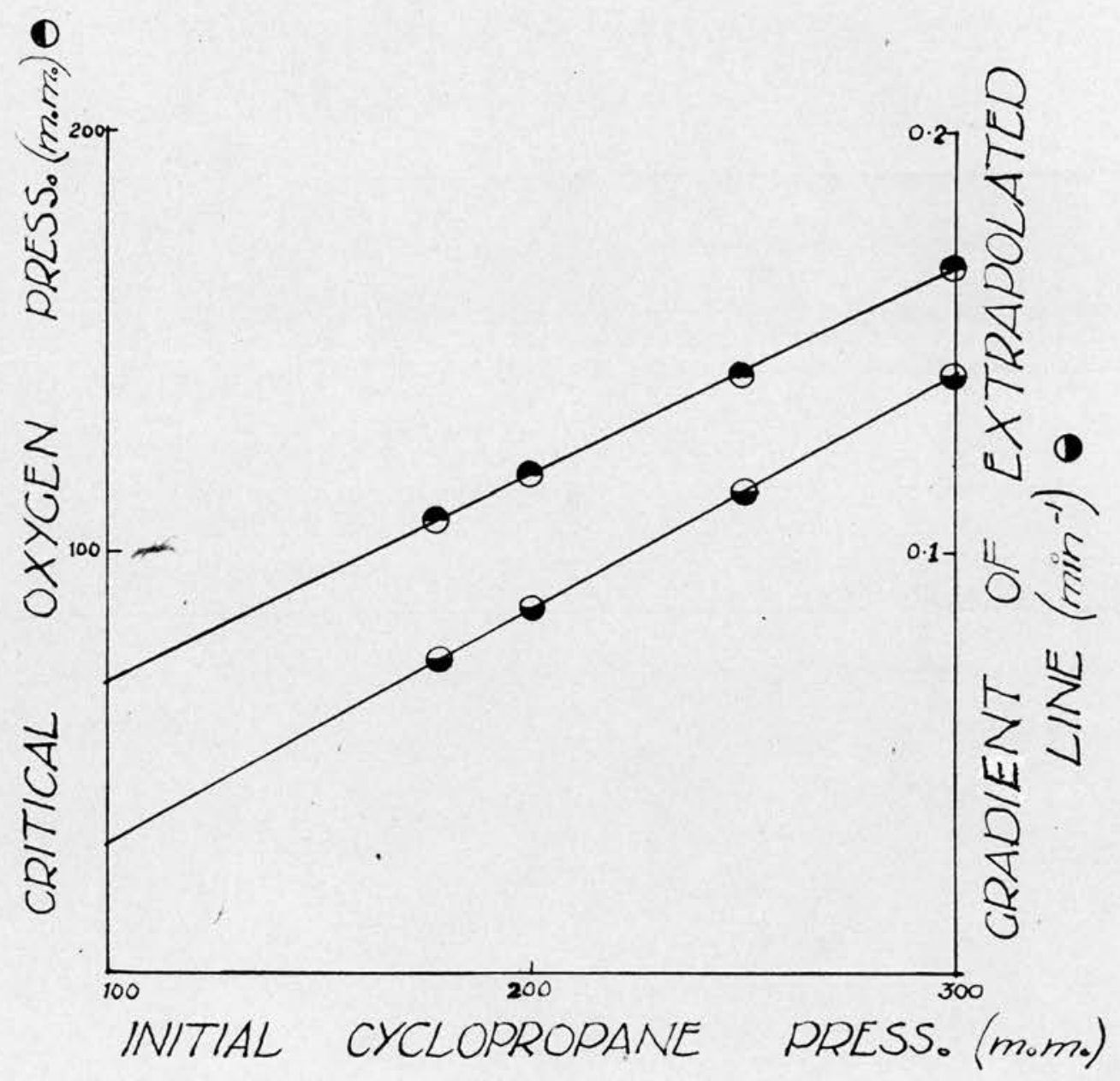


any oxygen pressure, below the critical pressure, depends also upon initial ayclopropane pressure, i.e. Rate $\alpha p_{c p} \cdot p_{\mathrm{O}_{2}}$. Above the critical axygen pressure, however, the maximun rate is independent of oxygen pressure but, being given by the product of the gradient of the line and the critical oxygen pressure, is proportional to the scuare of the initial hydrocarbon pressure i.e. Rate $\alpha p_{c p}^{2} p_{O_{2}}^{\cdot}$. Thus the two distinct regions of oxygen pressure dependence appear to indicate two totally different regions of order $v i z$. Rate $=k_{1} p_{c p} \cdot p_{o_{2}}$ below the critical oxygen pressure and Rate $=k_{2} p_{c p}^{2} p_{o_{2}}^{0}$ above the oritical axygen pressure.

The dependence of rate upon initial oxygen pressures was determined for an initial cyclopropane pressure of $250 \mathrm{~m}, \mathrm{~m}$. at a temperature of $651^{\circ} \mathrm{A}\left(378^{\circ} \mathrm{C}\right)$. The results are given in table No. 15 and graph (No. 6) shows the dependence of the maximum rate upon initial oxygen pressure for $250 \mathrm{~m}, \mathrm{~m}$. of hydrocarbon both at $651^{\circ} \mathrm{A}$ and at $678^{\circ} \mathrm{A}$.

Table No. 15

$\begin{array}{crl}\text { Initial } p_{c p}=250 \mathrm{~m} \cdot \mathrm{m}, & T=651^{\circ} \mathrm{A} \text { Vessel B } \\ \text { Run No. } & p_{\mathrm{O}_{2}} & \rho_{\max } \\ \text { B } 95 & 40 \cdot 0 & 1 \cdot 8 \\ \text { B } 94 & 69 \cdot 9 & 3 \cdot 1 \\ \text { B } 93 & 99 \cdot 0 & 3 \cdot 8 \\ \text { B } 92 & 134 \cdot 2 & 4 \cdot 2 \\ \text { B } 91 & 180 \cdot 4 & 4 \cdot 4 \\ \text { B } 90 & 233 \cdot 7 & 4 \cdot 7\end{array}$

In principle, the graphs are the same but both the gradients of the lines representing low oxygen pressure dependence, and the critical oxygen pressures are vastly different in the two

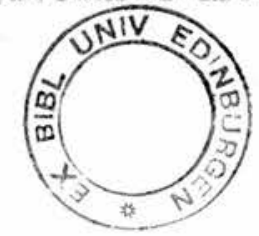


Variation of Initial Oxygen Pressure $\left(p_{c \cdot .}=250 \mathrm{~m} . \mathrm{m}_{0}\right)$
Vessel $B$

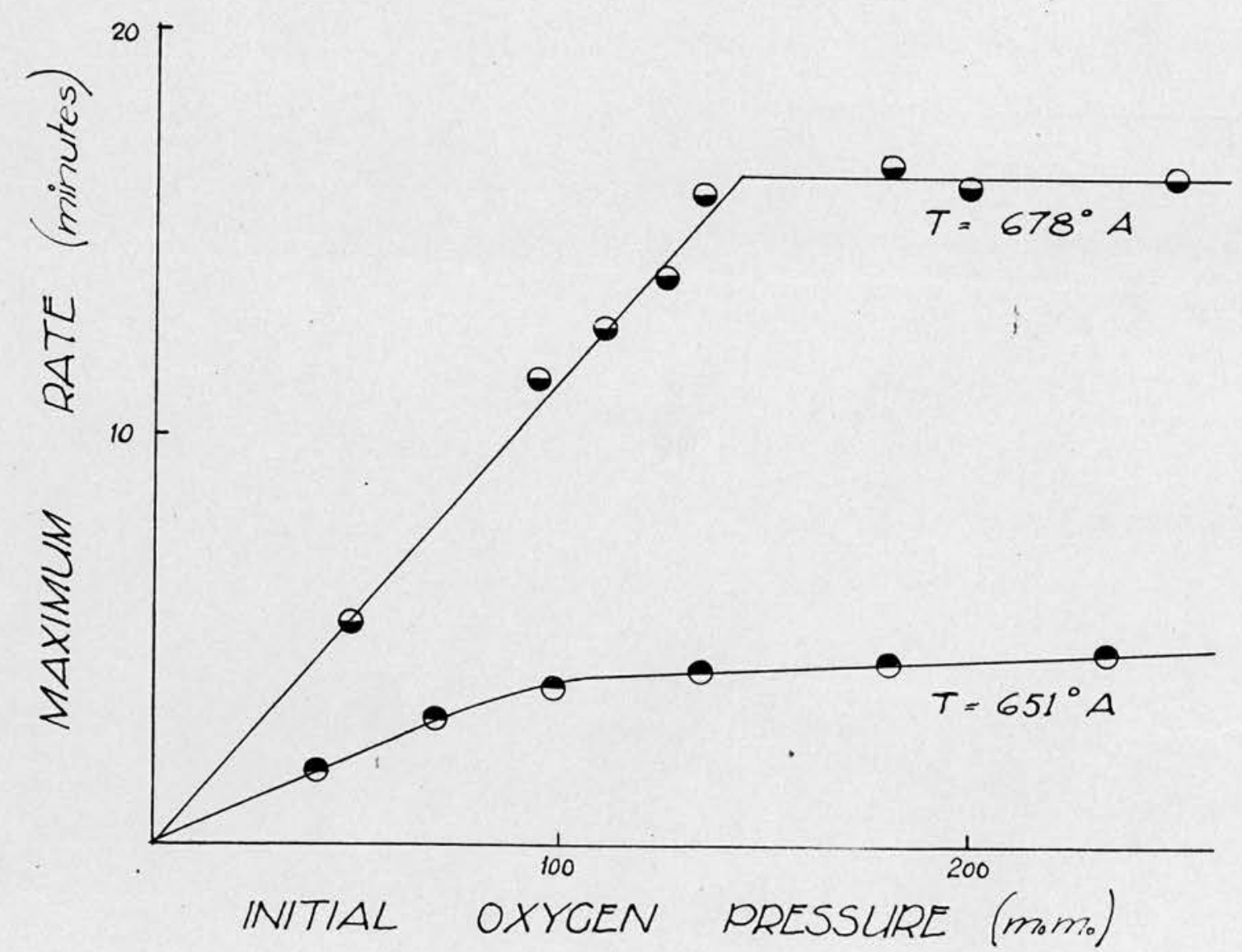


cases. The transition from dependence to independence is probably much more gradual at the lower temperature and it will be clearly seen that the kinetics Rate $\alpha p_{c p} \cdot p_{0_{2}}$ are operative over a considerably shorter oxygen pressure range at $651^{\circ} \mathrm{A}$. The oxygen-pressure dependence was redetermined for an Initial eyclopropane pressure of $178 \mathrm{~m}, \mathrm{~m}$, at $701^{\circ} \mathrm{A}$. As might have been anticipated from the temperature effect observed above, the kineties Rate $\alpha p_{c p} p_{o_{2}}$ operate over a very large range of axygen pressures in this case. Results are given in table No. 16 and graph No. 7 illustrates the change of the curve (rate against initial oxygen pressure) for a fixed cyclopropane pressure of $178 \mathrm{~m} \cdot \mathrm{m}$. at $701^{\circ} \mathrm{A}$ and $678^{\circ} \mathrm{A}$.

\begin{tabular}{crc}
\multicolumn{4}{c}{ Table No. 16} \\
Initial $p_{c p}=178 \mathrm{~m} . \mathrm{m}$. & $T=701^{\circ} \mathrm{A}$ Vessel $\mathrm{B}$ \\
Run No. & $p_{0_{2}}$ & $\rho_{\max }$ \\
B 97 & $50 \cdot 7$ & $6 \cdot 9$ \\
B106 & $78 \cdot 8$ & $14 \cdot 0$ \\
B 98 & $98 \cdot 6$ & $16 \cdot 6$ \\
B 99 & $151 \cdot 4$ & $26 \cdot 7$ \\
B100 & $200 \cdot 3$ & 36
\end{tabular}

The experiments described so far were all performed in the second reaction vessel $B$ and it is interesting to study the effect of change of vessel upon the oxygen dependence of the maximum rate of reaction. Table No. 17 lists the results obtained at $678^{\circ} \mathrm{A}$ with $200 \mathrm{~m}, \mathrm{~m}$. of cyclopropane and varying amounts of oxygen. The graph No. 8 shows two lines, one relating to each vessel, for $200 \mathrm{~m} . \mathrm{m}$. of hydrocarion at $678^{\circ} \mathrm{A}$. It will be seen that, apart from differences in the absolute 
Variation of Initial Oxygen Pressure
$\left(p_{c . \text {. }} \cdot 178 \text { m.mo }\right)^{-17}$

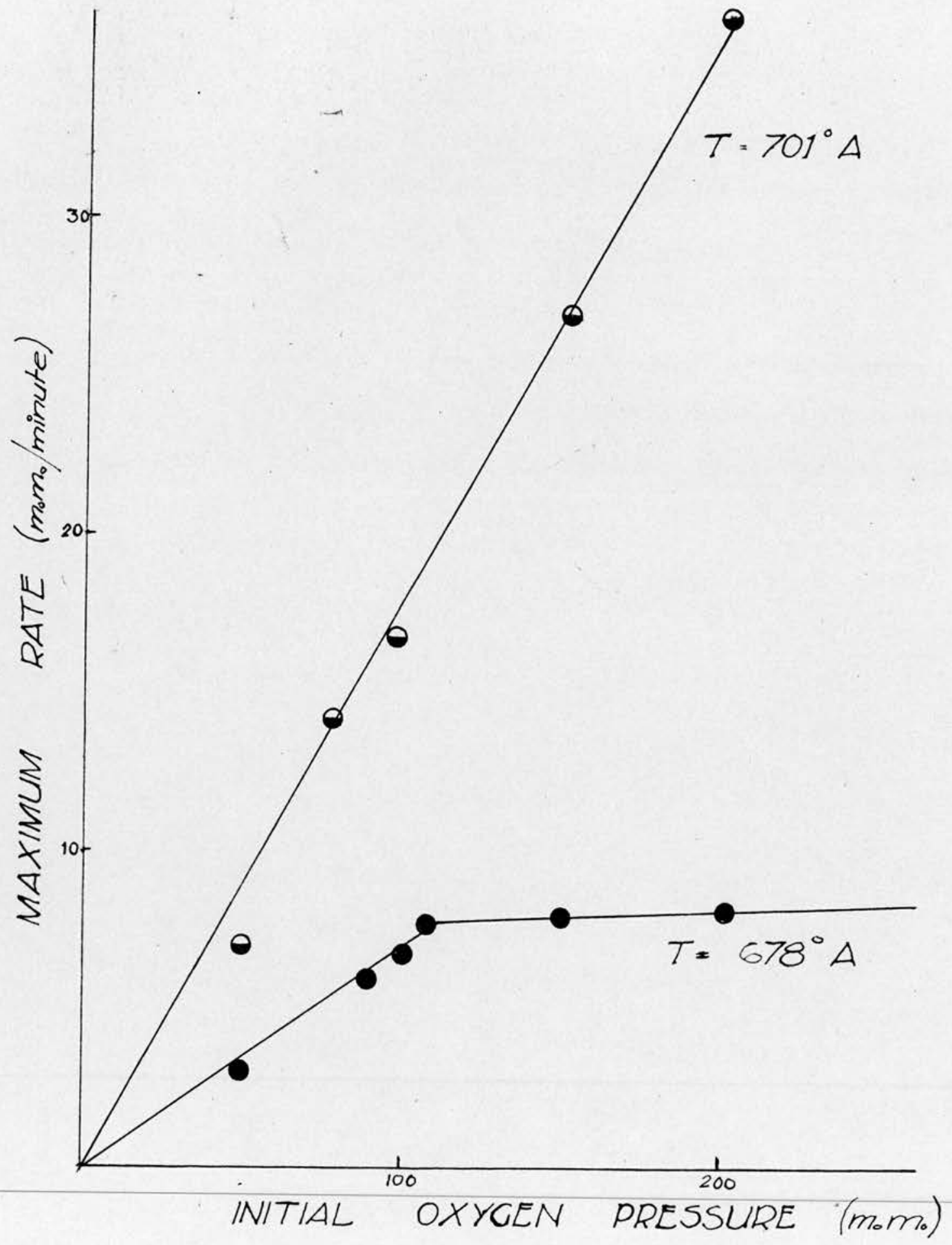


values of the rates, the kinetical characteristics are the same in the two cases, although the critical cxygen pressure is somewhat higher in the second vessel (B)

Table No. 17

$$
\text { Initial } p_{c p}=200 \mathrm{~m}, \mathrm{~m}, \quad \mathrm{~T}=678^{\circ} \mathrm{A} \text { Vessel } \mathrm{A}
$$

Run No.
A 41
A 42
A 37
A 40
A 38
A. 39

$\mathrm{P}_{\mathrm{O}_{2}}$

$52 \cdot 1$

$84 \cdot 7$

$106 \cdot 5$

150.9

$189 \cdot 8$

$234 \cdot 8$

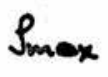

$2 \cdot 6$

$4 \cdot 3$

$5 \cdot 5$

$5 \cdot 7$

$5 \cdot 9$

$6 \cdot 1$

Table No, 18 and graph No. 9 illustrate the maximum rateinitial axygen pressure relationship in vessel $D$ at $701^{\circ} \mathrm{A}$ with on initial hydrocarbon pressure of $100 \mathrm{~m}, \mathrm{~m}_{*}$ Once again, the kinetical behaviour is seen to be the same as in other cases, there existing a region of linear dependence which is followed by an independence.

Table No. 18

$\begin{array}{ccc}\text { Initial } p_{C P}=100 \mathrm{~m} \cdot \mathrm{m} . & T=701^{\circ} \mathrm{A} & \text { Vessel D } \\ \text { Fun No, } & p_{0_{2}} & \rho_{\text {max }} \\ \text { D } 18 & 49 \cdot 0 & 3 \cdot 2 \\ \text { D } 13 & 100 \cdot 5 & 5 \cdot 9 \\ \text { D 17 } & 144 \cdot 5 & 6 \cdot 5 \\ \text { D 15 } & 186 \cdot 3 & 6 \cdot 9 \\ \text { D 16 } & 240 \cdot 0 & 7 \cdot 3 \\ \text { D 14 } & 298 \cdot 8 & 7 \cdot 6\end{array}$

2. Dependence Upon Initial Cyclopropane Pressure

The proved existence of two regions of oxygen dependence and the prediction (from critical oxygen pressures) of two 


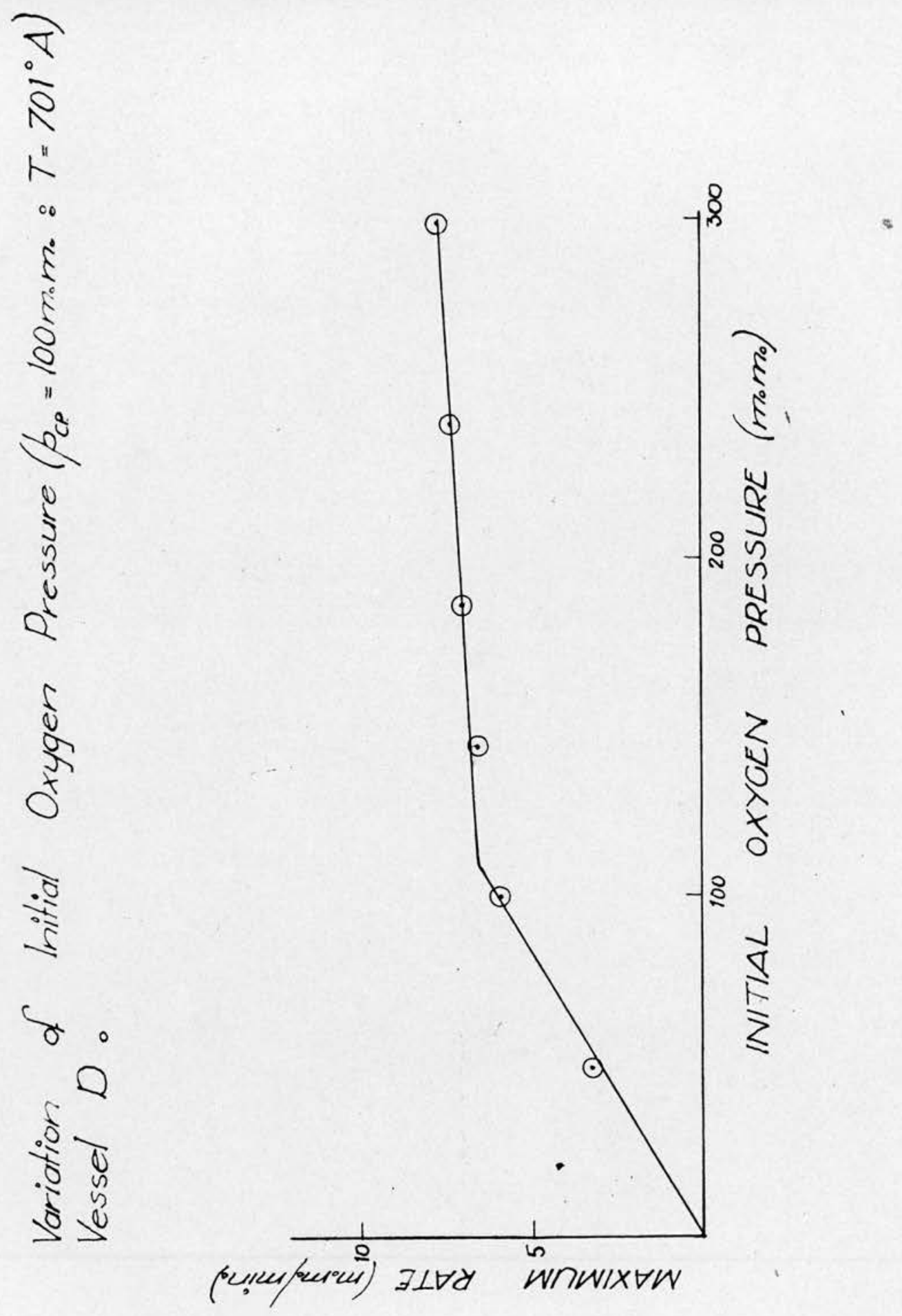


regions of cyclopropane dependence necessitated care in selection of conditions for study of the effect of variation of initial hydrocarbon pressure upon the maximum rate. The knowledge gained of the critical axygen pressures and their dependence upon initial oyclopropane pressure and temperature facilitated the study of dependence of the rate upon the hydrocarbon pressure in the different regions.

A series of experiments was carried out at $678^{\circ} \mathrm{A}$ with initial oxygen pressure of $200 \mathrm{~m}, \mathrm{~m}$, and cyclopropane pressures in the range $150 \mathrm{~m} \cdot \mathrm{m}_{\text {. }}$ to $300 \mathrm{~m} \cdot \mathrm{m}$. In other words it was as certained that for each cyclopropane pressure employed, $200 \mathrm{~m} . \mathrm{m}$. of oxygen was above the critical axygen pressure. The results are given in table No, 19 and are plotted on graph No. 10.

\begin{tabular}{|c|c|c|c|c|c|}
\hline Initial & $o_{o_{2}}=200$ & $\mathrm{~m}_{0} \mathrm{~m}_{0}$ & & $T=678^{\circ} \mathrm{A}$ & Vessel B \\
\hline Fun No, & $p_{c p}$ & & $\rho_{\max }$ & $p_{c p}^{2}$ & \\
\hline $\begin{array}{l}\text { B } 21 \\
\text { B } 23 \\
\text { B } 49 \\
\text { B } 20 \\
\text { B } 36 \\
\text { B } 64\end{array}$ & $\begin{array}{l}152 \cdot 0 \\
159 \cdot 0 \\
177 \cdot 9 \\
200 \cdot 0 \\
249 \cdot 7 \\
300 \cdot 0\end{array}$ & & $\begin{array}{r}5 \cdot 9 \\
6 \cdot 4 \\
8 \cdot 0 \\
10 \cdot 4 \\
16 \cdot 3 \\
24 \cdot 0\end{array}$ & $\begin{array}{l}23100 \\
25280 \\
31650 \\
40000 \\
62350 \\
90000\end{array}$ & \\
\hline
\end{tabular}

Another series of experiments was carried out at the same temperature $\left(678^{\circ} \mathrm{A}\right)$ with initial oxygen pressure of $70 \mathrm{~m} \cdot \mathrm{m}$. the hydrocarbon pressures varying over the range $150 \mathrm{~m} . \mathrm{m}$. to $400 \mathrm{~m} . \mathrm{m}$. i.e. every cyclopropane pressure was so high that $70 \mathrm{~m} . \mathrm{m}$. of oxygen fell below the critical oxygen pressure. The results are given in table No. 20 and are plotted on the same graph No. 10. 


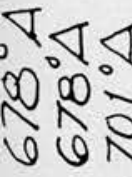

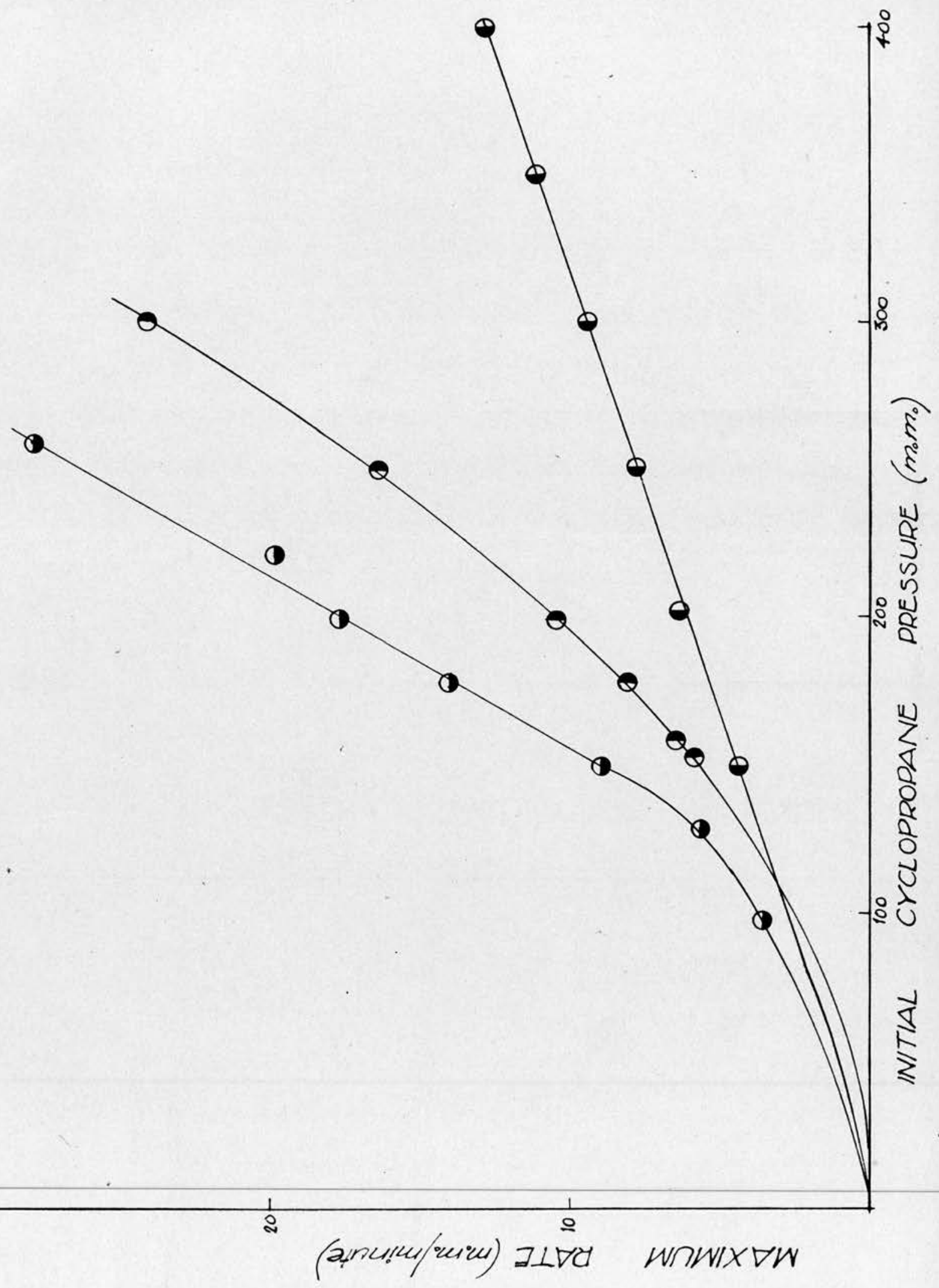

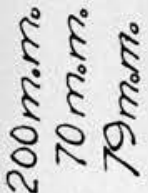

"

inim

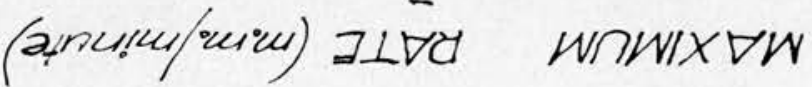


Table No. 20

$\begin{array}{ccc}\text { Initias } p_{\mathrm{O}_{2}}=70 \mathrm{~m} . \mathrm{m}, & \mathrm{T}=678^{\circ} \mathrm{A} & \text { Vess } \\ \text { Run No. } & p_{\text {cp }} & \rho_{\text {max }} \\ & 150 \cdot 0 & 4 \cdot 3 \\ \text { B } 74 & 202 \cdot 5 & 6 \cdot 3 \\ \text { B } 78 & 252 \cdot 0 & 7 \cdot 7 \\ \text { B } 77 & 300 \cdot 0 & 9 \cdot 3 \\ \text { B } 73 & 350 \cdot 0 & 11 \cdot 0 \\ \text { B } 76 & 400 \cdot 0 & 12 \cdot 7 \\ \text { B } 75 & & \end{array}$

The third ourve on the graph was obtained by plotting maximum rate against initial cyclopropane pressure for several experiments at $701^{\circ} \mathrm{A}$ with an initial pressure of $79 \mathrm{~m}$. case. The results are given in detail in table No. 21.

Table No. 21

$$
\text { Initial } p_{\mathrm{O}_{2}}=79 \mathrm{~m} \cdot \mathrm{m} . \quad T=701^{\circ} \mathrm{A} \quad \text { Vessel } \mathrm{B}
$$

\begin{tabular}{lrrr} 
Run No. & \multicolumn{1}{c}{$p_{c p}$} & $\rho_{\text {max }}$ & $p_{c p}{ }^{2}$ \\
B 108 & $99 \cdot 2$ & $3 \cdot 6$ & 9840 \\
B 107 & 128.5 & $5 \cdot 6$ & 16510 \\
B 117 & 150.0 & $9 \cdot 0$ & \\
B 106 & $177 \cdot 8$ & 14.0 & \\
B 116 & $198 \cdot 7$ & 17.6 & \\
B 115 & $221 \cdot 2$ & $19 \cdot 8$ & \\
B 114 & 258.8 & 27.8 &
\end{tabular}

The graphs clearly dernonstrate the verification of the prediction of the existence of the two regions of dependence of rate upon cyclopropane pressure. Thus it is evident that, at $678^{\circ} \mathrm{A}$, with oxygen pressures below the oritical, the rate is proportional to the cyclopropane pressure. With oxygen pressures above the oritical, at $678^{\circ} \mathrm{A}$, the dependence is obviously greater than linear and the linearity of the plot of rate against the square of the initial oyclopropane pressure shows the index of dependence to be two (graph No. 13). Hence 
there is complete justification, now, for expressing the rate in terms of initial pressures in the following form:-

Rate $\alpha p_{\mathrm{Cp}} \cdot p_{\mathrm{O}_{2}}$ if $p_{\mathrm{O}_{2}}<$ critical oxygen pressure Rate $\alpha p_{\mathrm{CP}^{2}}^{2} \cdot p_{\mathrm{O}_{2}}^{\cdot}$ if $p_{\mathrm{O}_{2}}>$ critical oxygen pressure

It is instruotive to observe that in this second case, the graph indicates that the linear relationship mast be replaced by the dependence when the hydrocarbon pressure falls to about $120 \mathrm{~m} \cdot \mathrm{m}$. by which time, of course, the condition $p_{\mathrm{o}_{2}}$ less than the critical axygen pressure no longer holas since the critical axygen pressure for a eyclopropane pressure of $120 \mathrm{~m}$. would be expected to be about $70 \mathrm{~m}, \mathrm{ma}$.

The third graph on the paper, referring to the experiments at $701^{\circ} \mathrm{A}$ with $79 \mathrm{~m}, \mathrm{~m}$. of oxygen, elearly shows the change of mechanism at about $130 \mathrm{~m} \cdot \mathrm{m}$. of cyclopropane. Above that pressure the relationship is obviously a linear one. Below $130 \mathrm{~m}$, $\mathrm{m}_{\text {, of }}$ cyclopropane; however, the relationship is more complex and the graph of maximum rate against the square of the hydrocarbon pressure for lower pressures shown on graph No.13 reveals that the dependence is again a square one.

The experiments so far described were all performed in the second reaction vessel (B) but apart from the lower absolute values of the rates observed in vessel (A) the kinetical characteristics were found to be identical. Table No, 22 lists rates measured in the latter vessel at $678^{\circ} \mathrm{A}$ with an initial oxygen pressure of $150 \mathrm{~m}, \mathrm{~m}$. (higher than the critical axygen pressures for the cyclopropane pressures employed). The results are plotted on graph No. 11 and the square dependence is 

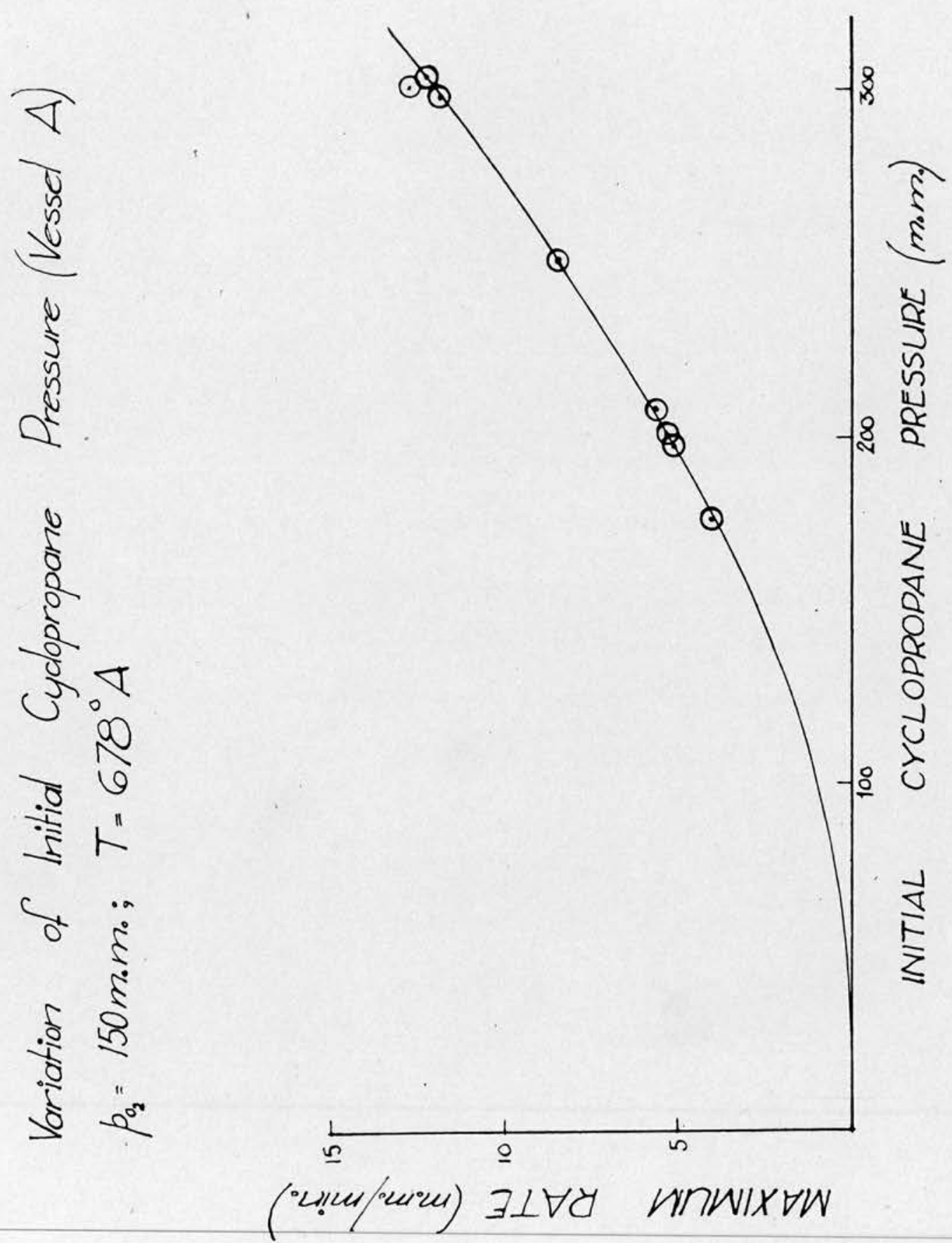
proved on graph No. 13.

Table No. 22.

Initial $p_{\mathrm{O}_{2}}=150 \mathrm{~m} \cdot \mathrm{m} \cdot \quad T=678^{\circ} \mathrm{A} \quad$ Vessel $\mathrm{A}$

$\begin{array}{lccc}\text { Run No. } & p_{c e} & \rho_{\max } & p_{c p}{ }^{2} \\ \text { A } 35 & 176 \cdot 3 & 4 \cdot 1 & 31070 \\ \text { A } 25 & 199 \cdot 1 & 5 \cdot 1 & 39650 \\ \text { A } 23 & 201 \cdot 8 & 5 \cdot 3 & 40720 \\ \text { A } 14 & 208 \cdot 0 & 5 \cdot 6 & 43270 \\ \text { A } 33 & 250 \cdot 5 & 8 \cdot 4 & 62750 \\ \text { A } 28 & 299 \cdot 0 & 11 \cdot 9 & 89430 \\ \text { A } 32 & 302 \cdot 2 & 12 \cdot 6 & 91330 \\ \text { A } 30 & 304 \cdot 0 & 12 \cdot 2 & 92380\end{array}$

Since a.1 these experiments were carried out with a stoichiometric excess of cyclopropane, a series of experiments with $300 \mathrm{~m} \cdot \mathrm{m}$. of oxygen and varying quantities of hydrocarion

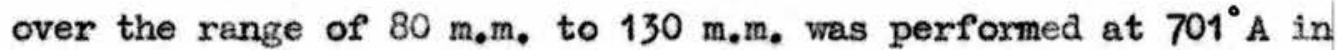
vessel. D. The results are detailed in table No. 23 and the figures are plotted on graph No, 12. This is a graph of the form Rate $\alpha p_{c p}^{2}$.

Table No. 23

Initial $p_{\mathrm{O}_{2}}=300 \mathrm{~m} \cdot \mathrm{m}, \quad \mathrm{T}=701^{\circ} \mathrm{A} \quad$ Vessel $\mathrm{D}$

Run No.

D 26

D 21

D 20

D 22

D 24 $p_{c p}$

90

$100 \cdot 0$

$110 \cdot 2$

$120 \cdot 0$

$130 \cdot 0$ $\rho_{\text {max }}$

$7 \cdot 0$

$10 \cdot 0$

$12 \cdot 2$

$14 \cdot 4$ $p_{c p}^{2}$.

8100

10000

12150

14400

16900

Graph No. 13 shows the linear relation between maximum rate and the square of the initial hyarocarbon pressures. It refers to the experiments listed in tables Nos, 19, 22 and 23

and to the experiments in table No. 21 at lower hydrocarbon pressure. 
CRADH № 12

Variation of Initial Cyclopropane Pressure (Vessel D) $p_{o_{2}}=300 \mathrm{~m}_{0} \mathrm{~m}_{0} ; \quad T=701^{\circ} \mathrm{A}$

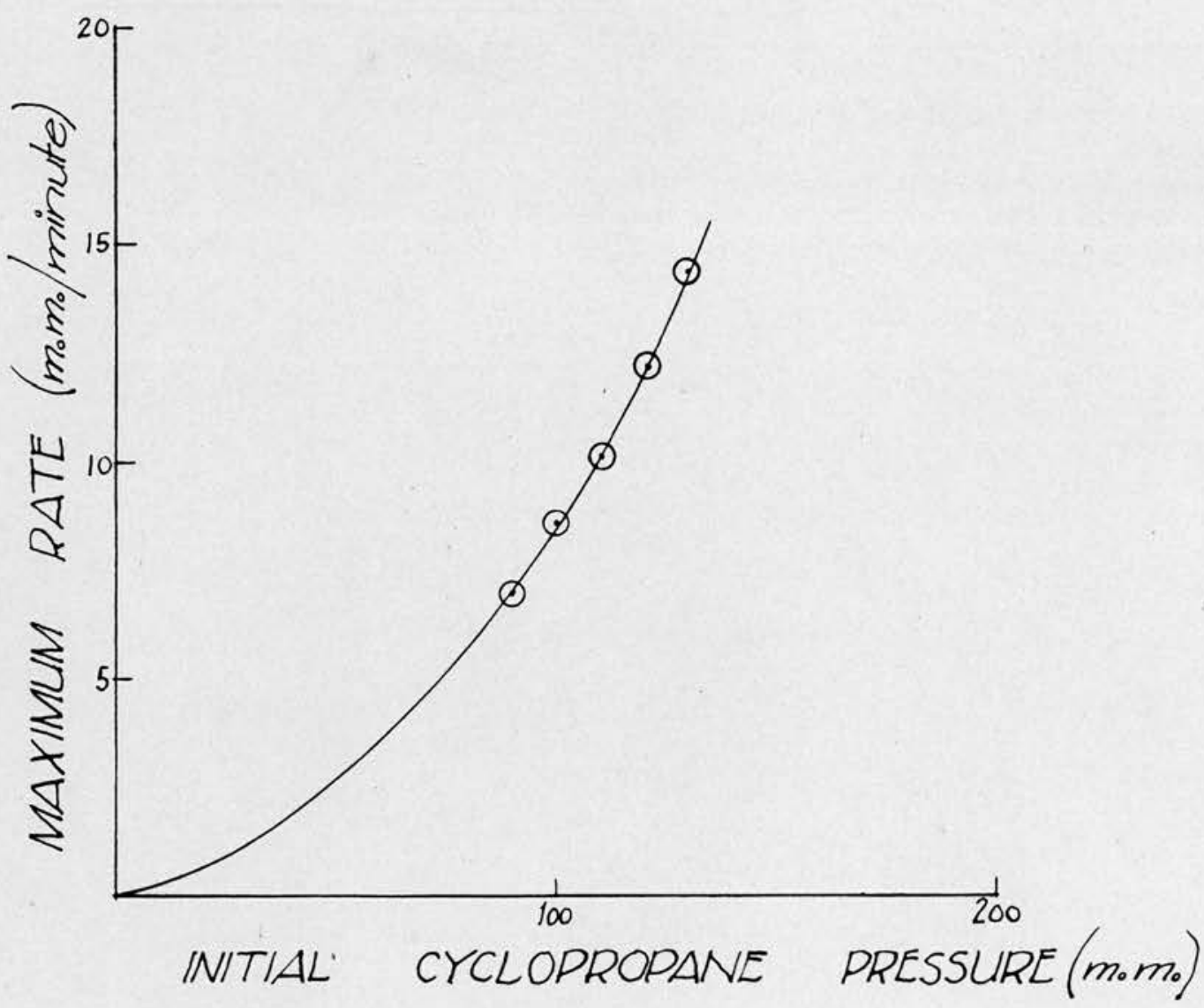




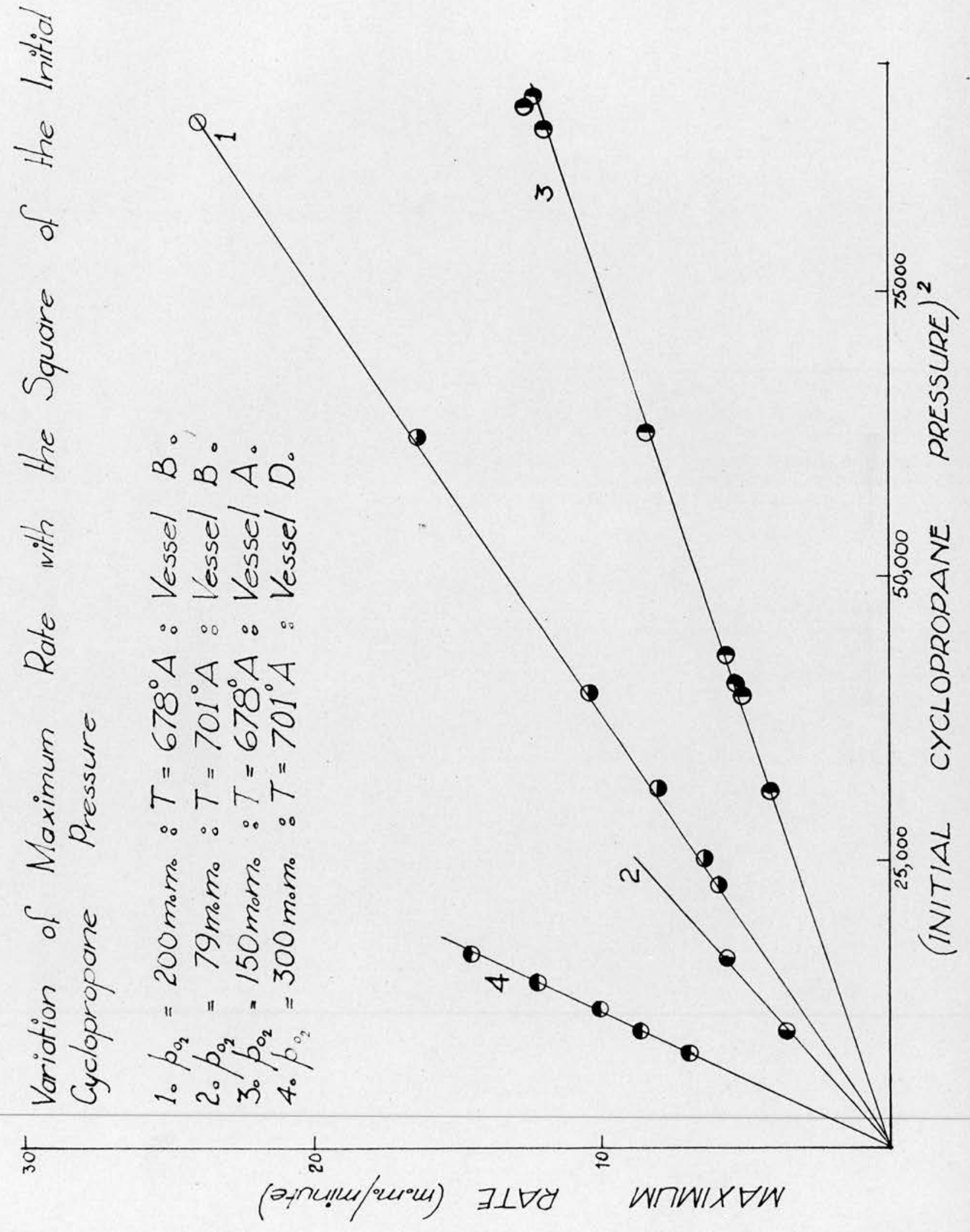




\section{Dependence Upon the Temperature}

The effect of temperature changes upon the maximum rate of an autocatalytic chain reaction is in principle the same as the influence of temperature change upon the rate of more simple reactions. In the latter case, however, the dependence of rate upon temperature has a very important significance, The well-ionown expression due to Arrhenius is found to apply.

$$
k=A e^{\frac{-E}{R T}}
$$

where $\mathrm{k}=$ the specific rate constant

$R=$ the gas constant

$\mathrm{T}=$ the absolute temperature

$\mathrm{A}$ and $\mathrm{E}$ are constants over small temperature ranges, $\mathrm{A}$ being practically independent of temperature and $\mathrm{E}$ an energy term, the activation energy of the reaction.

In the case of a chain reaction, the Arrhenius relation is usually obeyed but the "activation energy" is then of complex significance being a function of the activation energies of all the elementary reactions in the chain.

By taking logarithms of the Arrhenius expressions we obtain:-

$$
\log \mathrm{k}=\log \mathrm{A}-\frac{\mathrm{E}}{\mathrm{RT}}
$$

Thus by plotting $\log k$, or what is equivalent, $\log$ maximum rate against the reciprocal of the absolute temperature, a straight line of gradient $\frac{-\mathrm{T}}{\mathrm{R}}$ should be obtained.

In the case in point two different series of experiments were performed to investigate the influence of temperature upon the maximum rate. In the first series, the rate of reaction 
of a mixture of $250 \mathrm{~m}, \mathrm{~m}$. cyclopropane and $70 \mathrm{~m} . \mathrm{m}$. of oxygen was measured at various temperatures over the range $651^{\circ} \mathrm{A}-705^{\circ} \mathrm{A}$. The results are given in table No. 24. In the second series of experiments the mixture employed consisted of $178 \mathrm{~m}, \mathrm{~m}$, of cyclopropane and $200 \mathrm{~m}, \mathrm{~m}$. of oxygen while the temperatures ranged from $660^{\circ} \mathrm{A}-701^{\circ} \mathrm{A}$. These results are given in table No. 25. Two Arrhenius plots are drawn on the graph No. 14.

TA3LE ND. 24

Initial $p_{c p}=250 \mathrm{mon}, p_{02} 70$ m.m. Vessel 8

Run No. $T \frac{10^{3}}{T} \quad \rho_{\max } \log _{10} \rho_{\max }$ Run $N . T \frac{10^{3}}{T} \rho_{\max } \log _{10} \rho_{\max }$ $\begin{array}{llllllllll}889 & 651 & 1.536 & 3.3 & 0.5185 & 356 & 660 & 1.515 & 4.5 & 0.6532\end{array}$

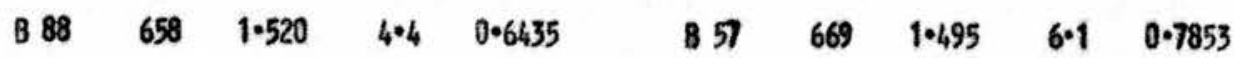
$\begin{array}{llllllllll}887 & 665 & 1.504 & 4.9 & 0.6902 & 358 & 673 & 1.486 & 7.7 & 0.8865\end{array}$ $\begin{array}{llllllllll}B 86 & 671 & 1.490 & 6.2 & 0.7924 & 849 & 678 & 1.475 & 8.0 & 0.9031\end{array}$ $\begin{array}{llllllllll}\text { B } 77 & 678 & 1.475 & 7.7 & 0.8865 & \text { B } 48 & 683 & 1.464 & 10.7 & 1.0294\end{array}$

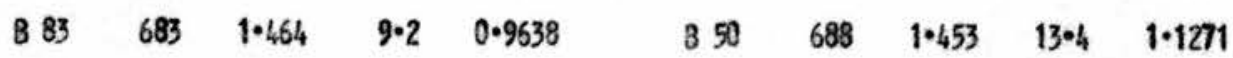
$\begin{array}{llllllllll}\text { B } 80 & 689 & 1.451 & 11.6 & 1.0645 & \text { B } 52 & 692 & 1.445 & 15.2 & 1.1818\end{array}$

$\begin{array}{llllllllll}B 81 & 697 & 1.435 & 15 \cdot 2 & 1.1818 & 351 & 694 & 1.441 & 17 \cdot 8 & 1.2504\end{array}$

\begin{tabular}{llllllllll}
\hline \& 4 & 702 & 1.425 & 19.7 & 1.2945 & B 47 & 697 & 1.435 & 23.7 & 1.3747
\end{tabular} $\begin{array}{llll}3100 & 701 \quad 1.427 \quad 36 & 1.5563\end{array}$

It has already been demonstrated that there are two very distinct types of kinetic behaviour characteristic of the slow combustion of cyclopropane and that the proportion of oxygen in the reacting mixture and the temperature are two important factors which decide which of the two rate expressions Rate $\alpha p_{c p} \cdot p_{\mathrm{O}_{2}}$ or Rate $\alpha p_{c p}^{2}$ is operative. Thus the curvature over part of the activation energy plots is hardly unexpected. The significance of the curvature will be discussed in some detail 


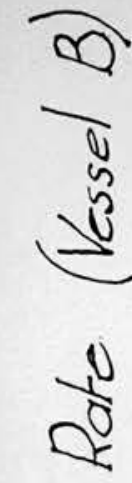

$\frac{5}{5} \frac{5}{x}$

5
$\frac{2}{0}$

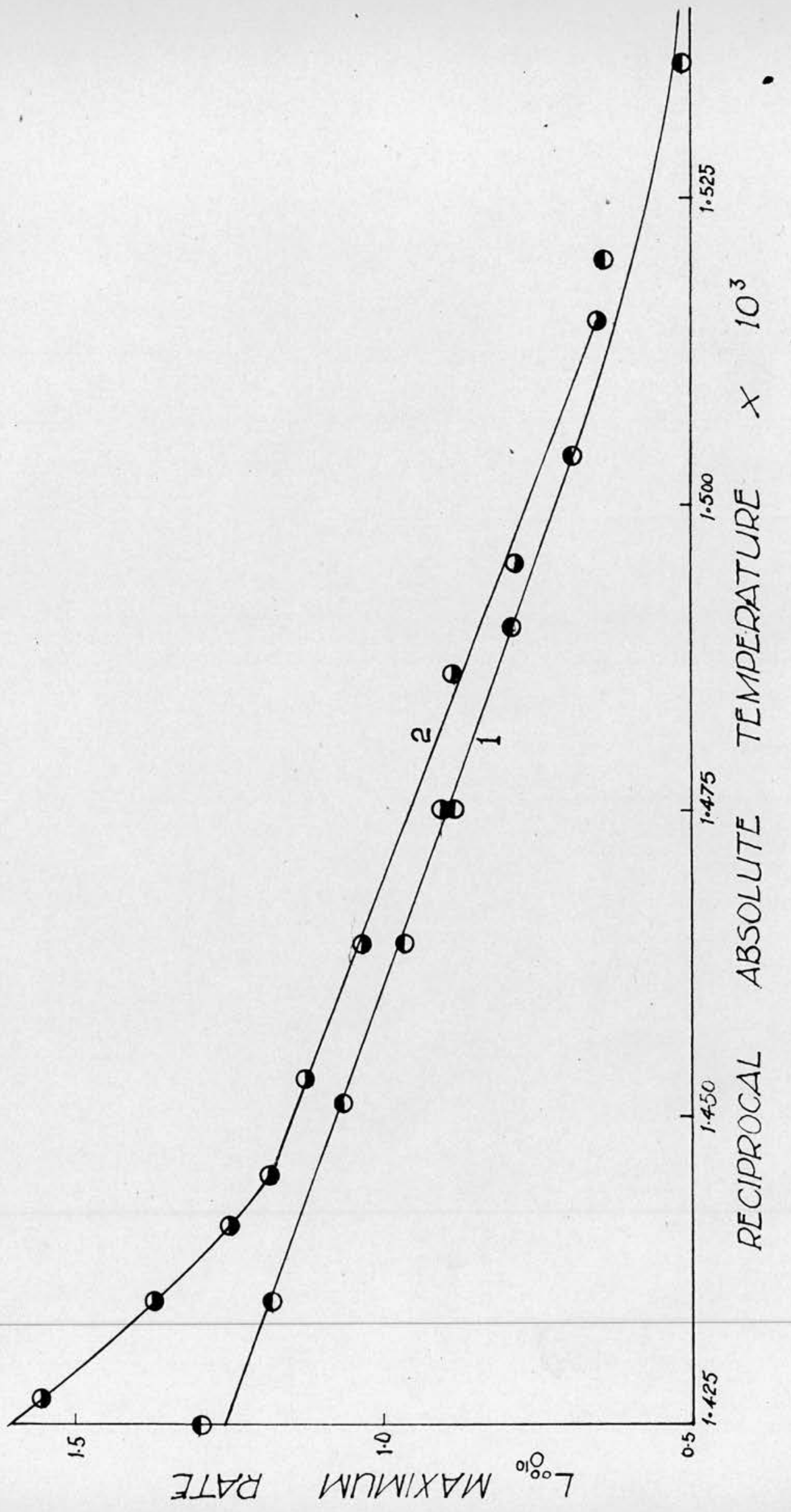


later.

Meanwhile, it may be noted that the curvature occurs at the high temperature end of the line referring to the oxygenrich mixture and at the low temperature end of the other graph. The overall activation energies caloulated from the slopes of the straight portions are approximately the same, $34 \cdot 1$ and $35 \cdot 0$ respectively. It is interesting to note that $\mathrm{Mr}$. Broatch determined the activation energy of the reaction as $35.2 \mathrm{kcal} / \mathrm{mole}$ in the packed vessel already desoribed. 
4. The effect of Added Nitrogen

In the slow combustion of cyclopropane, the existence of two distinct types of kinetic behaviour necessitated the study of a possible inert gas effect on each case. A series of experiments was performed with $200 \mathrm{~m}, \mathrm{~m}$, each of cyclopropane and oxygen at $673^{\circ} \mathrm{A}$ i.e. in a region where the kinetical relation Rate $\alpha p_{c p}^{2}$. $p_{O_{2}}$ was known to operate. The results given in table No, 26 show that the reaction rate was independent of total pressure, at least at moderate pressures, a result which was hardily unexpected in view of the fact that under these conditions increese of the oxygen pressure had no effect upon the rate.

A second series of experinents was carried out; this time at $701^{\circ} \mathrm{A}$ with $178 \mathrm{~m} \cdot \mathrm{m}$, of hydrocarbon and $79 \mathrm{~m} . \mathrm{m}_{\text {. }}$ of axygen i.e. where the kinetical expression Rate $\alpha p_{c p} . p_{o_{2}}$ was known to hold, The results given in table No. 27 again show the absence of an inert gas effect.

Table No. 26 Table No. 27

Initial $p_{c p}=200 \mathrm{~m}_{0} \mathrm{~m}_{0} p_{\mathrm{o}_{2}}=200 \mathrm{~m}, \mathrm{~m}_{\text {. Initial }} p_{c p}=178 \mathrm{~m} \cdot \mathrm{m}_{0} p_{\mathrm{o}_{2}}=79 \mathrm{~m}_{0} \mathrm{~m}_{0}$ $\mathrm{T}=678^{\circ} \mathrm{A} \quad \mathrm{Vessel} \mathrm{B}=701^{\circ} \mathrm{A} \quad$ Vessel $\mathrm{B}$

$\begin{array}{cccccc}\text { Run No. } & p_{N_{2}} & \rho_{\max } & \text { Fun No. } & p_{N_{2}} & \rho_{\max } \\ \text { B } 122 & - & 10 \cdot 4 & B 106 & - & 14 \cdot 0 \\ \text { B } 121 & 50 \cdot 0 & 10 \cdot 4 & B 103 & 50 \cdot 3 & 14 \cdot 0 \\ \text { B } 120 & 98 \cdot 4 & 10 \cdot 4 & B 104 & 99 \cdot 6 & 14 \cdot 0\end{array}$

Using the packed vessel already described, Mr. W. N. Broatch studied the effect of the addition of $100 \mathrm{~m} \cdot \mathrm{m}$. of nitrogen to a mixture of $200 \mathrm{~m} \cdot \mathrm{m}$, each of cyclopropane and oxygen, at $696^{\circ} \mathrm{A}$. The maximum rate was $1.4 \mathrm{~m} . \mathrm{m}_{0} /$ minute with or without the addition of nitrogen. 


\section{The Effect of Added Hydrogen}

It has been previously observed that molecular hydrogen inhibits hydrocarbon oxidation markedly (54). It may be pointed out that the molecular velocity of hydrogen is $\sqrt{14} x$ the molecular velocity of nitrogen and that consequently hydrogen molecules suffer collisions (perhaps deactivating a chain carrier) some four times as frequently as nitrogen. The specific effect of hydrogen upon pseudo-unimolecular reactions has been discussed by Hinshelwood (55). It appears that the effect is not due entirely to the greater velocity of hydrogen since helium has no similar effect though, of course, the five degrees of freedom of the hydrogen molecule, as compared with the three of the helium molecule, must facilitate the transfer of energy.

Ubbelohde (56) believes the process of inhibition by hydrogen in hydrocarbon oxidation to be due to the deactivation of the $\mathrm{RO}_{2}$ " radicals (i.e. Those endowed with excess energy). Thus $\mathrm{RO}_{2}{ }^{*}+\mathrm{H}_{2} \longrightarrow \mathrm{RO}_{2}+\mathrm{H}_{2}{ }^{*}$

Such a transfer of internal to translational energy would lead to inhibition of the reaction. Prettre, on the other hand, considers the retardation to be a surface effect (57).

In the present work, the effect of added hydrogen was studied in reaction vessel $\mathrm{D}$ at $678^{\circ} \mathrm{A}$ with $200 \mathrm{~m}, \mathrm{~m}$. each of cyclopropane and oxygen. The results are given in table No. 28 


\section{TABגE ผ. 28}

\begin{tabular}{|c|c|c|c|}
\hline Run No. & Pretreatment & $p_{\mathrm{H}_{2}}$ & $P_{\text {max }}$ \\
\hline 03 & One hour's evacuation & - & $11 \cdot 2$ \\
\hline D 4 & One hour's evacuation & 50 & $9 \cdot 8$ \\
\hline 05 & $\begin{array}{l}50 \text { m.m. of products of run No. } 04 \text { (incl. } 5 \text { m.a. H } \text { H }_{2} \text { ) } \\
\text { left in the heated vessel for } 37 \text { hours } \\
\text { One hour's evacuation }\end{array}$ & - & $8 \cdot 5$ \\
\hline 06 & one hour's ovacuation & - & $8 * 6$ \\
\hline 07 & One hour's evacuation & - & 8.9 \\
\hline 08 & $\begin{array}{l}50 \mathrm{mon} \text {. of products of run } \mathrm{No} .07 \text { ( } \mathrm{no} . \mathrm{H}_{2} \text { ) left } \\
\text { in the hot vessel for } 67 \text { hours } \\
\text { One hour's evacuation }\end{array}$ & - & $11 \cdot 2$ \\
\hline 09 & $\begin{array}{l}50 \text { moth. of hydrogen placed in the hot vessel for } \\
40 \text { minutes folloned by one hour's evacuation }\end{array}$ & - & $8 \cdot 6$ \\
\hline 010 & Seven hour's evacuation & - & $9 \cdot 4$ \\
\hline
\end{tabular}

From these results it can be seen that the hydrogen effect is not merely a gas effect and is due in large part to a change in the surface of the vessel. The results indicate that normally the reaction wall.s are coated with some substance formed in the reaction, that is removed by hydrogen but is not replaced (since long evacuation has little effect) by any hydrogenous substance. 


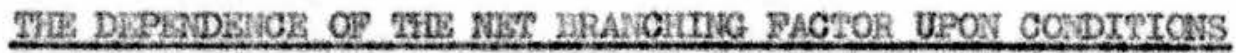

\section{Dependenoe upor Initial Oxysen Pressure}

The experiments which yielded this information have been desoribed already and it only remains to indicate the results. In general, the net-branching fector varied with initial oxygen pressure in a manner analagous to the maximun rate. Tables Nos. 29, 30, 31 and 32 give detatis of experinents performed at $678^{\circ} \mathrm{A}$ in reaction vessel $\mathrm{B}$ with $178,200,250$ and $300 \mathrm{~m}, \mathrm{~m}$. of eyclopropane reapeotively. The results of these four series of experiments are plotted on graph No. 15.

THBE N. 29

laitial $\beta_{\text {ce }}=178$ n.a. $\quad T=678^{\circ} \mathrm{A}$

Vessel B
TAQLE W. 30

$$
\text { Initiat } p_{C P}=200 \text { as. I. } \quad T=678^{\circ} \mathrm{A}
$$

Vessel $B$

\begin{tabular}{|c|c|}
\hline 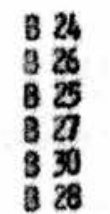 & $\begin{array}{c}50 \cdot 9 \\
7000 \\
10205 \\
130 \cdot 0 \\
199 \cdot 8 \\
248 \cdot 7\end{array}$ \\
\hline
\end{tabular}

3 30
TABLE NO. 31

Initial $p_{C p} * 250=1=675^{\circ} \mathrm{A}$ Vessel B

aun lits.

$\begin{array}{ll}8 & 35 \\ 8 & 34 \\ 8 & 33 \\ 3 & 38 \\ 8 & 32 \\ 6 & 31 \\ 6 & 36 \\ 3 & 37\end{array}$ $\mathrm{po}_{2}$

$48 \cdot 3$

94.5

109.8

124.7

134.8

100.0

$19 \% 8$

25000

\section{$A^{\prime}$}

0.095

O०+128

0.145

0.1100

0.170

$0 \cdot 160$

TABLE BD. 32

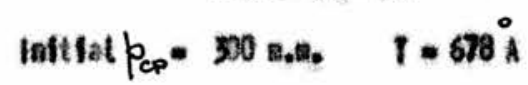

Vessel 8

$\operatorname{Ran} \tan$.

$\mathrm{PO}_{2}$

$A^{\prime}$

867

362

B 68

0.145

0.251

0.225

0.240

0.250

0.250

0.250

$3 \pi$

B 7

3 72

364

366

$\begin{array}{cc}49 \cdot 5 & 0 \cdot 191 \\ 97 \cdot 4 & 0.274 \\ 101 \cdot 7 & 0.310 \\ 147 \cdot 2 & 0.320 \\ 149 \cdot 7 & 0.367 \\ 178.3 & 0.370 \\ 199.0 & 0.370 \\ 252 \cdot 7 & \end{array}$



Variation of Initial Oxygen Pressure of $678^{\circ} \mathrm{A}$
Vessel B)

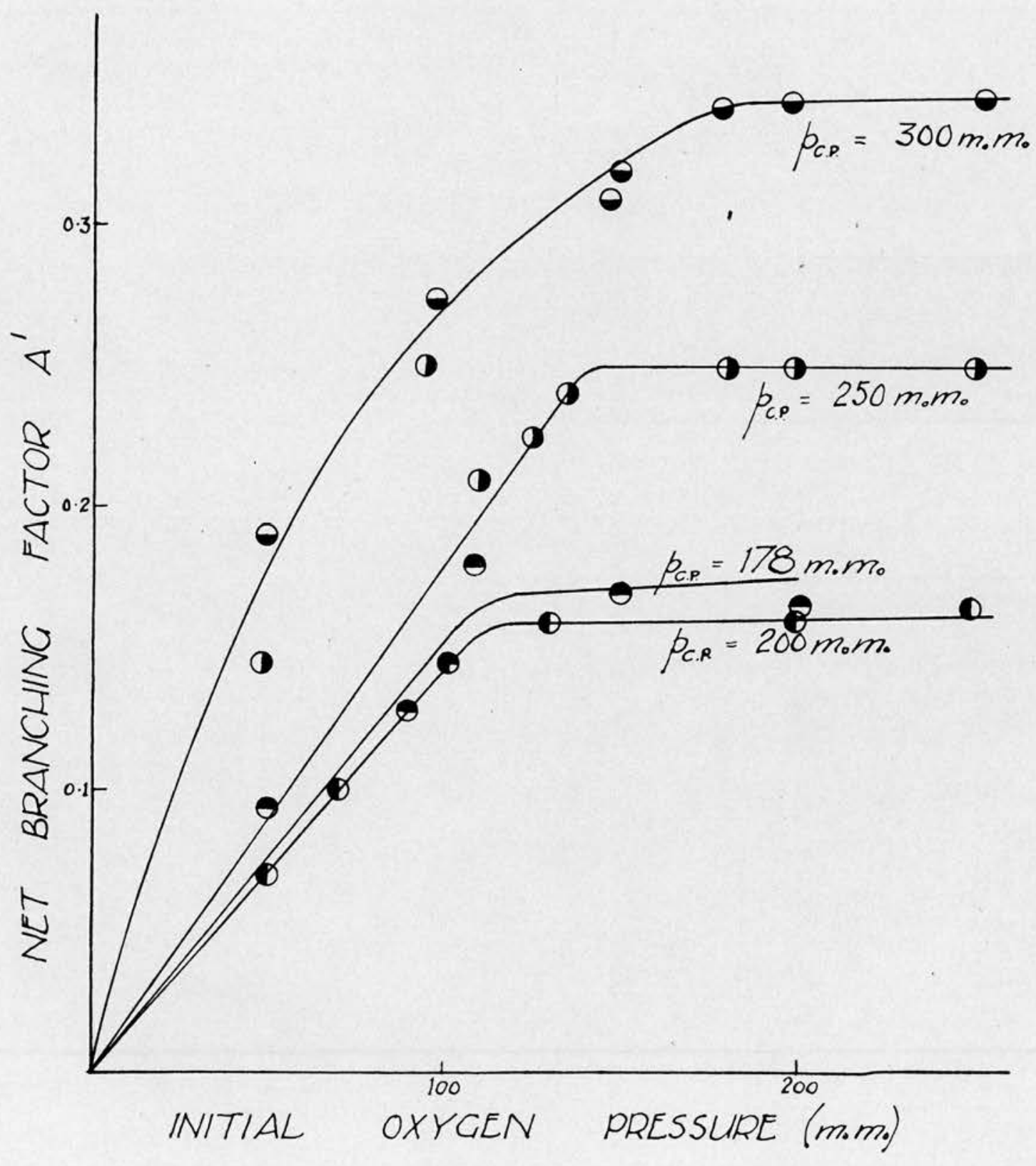


Table No. 33 and graph No, 16 illustrate the variation of the net-branching factor with change of oxygen pressure at $651^{\circ} \mathrm{A}$ the initial cyclopropane pressure being again $250 \mathrm{~m}, \mathrm{~m}$, The graph also shows for comparison, the corresponding curve for $250 \mathrm{men}$. of hydrocarion at $678^{\circ} \mathrm{A}$.

$$
\begin{aligned}
& \text { Table No. } 33 \\
& \text { Initial } p_{c p}=250 \mathrm{~m}_{\bullet} \mathrm{m}_{0} \quad \mathrm{~T}=651^{\circ} \mathrm{A} \text { Vessel } \mathrm{B} \\
& \text { Run No. } \quad p_{\mathrm{O}_{2}} \quad A^{\prime} \\
& \begin{array}{lll}
\text { B } 95 & 40.0 & 0.080
\end{array} \\
& \text { B } 94 \quad 69.9 \quad 0.085 \\
& \text { B } 93 \quad 99.0 \quad 0.086 \\
& \begin{array}{lll}
B & 132 \cdot 2 & 0.101
\end{array} \\
& \begin{array}{lll}
\text { B } 91 & 180.4 & 0.108
\end{array} \\
& \begin{array}{lll}
\text { B } 90 & 233 \cdot 7 & 0.104
\end{array}
\end{aligned}
$$

Table No. 34 gives the details of experiments with $178 \mathrm{~m}, \mathrm{~m}$. cyclopropane at $701^{\circ} \mathrm{A}$ and graph No. 17 illustrates the influence of temperature upon the net-branching factor-initial oxygen pressure curve for $178 \mathrm{~m}_{0} \mathrm{~m}_{\text {, }}$ of hydrocarbon. The next table of results (No. 35) gives the data for experiments carried out in the first reaction vessel (A) at $678^{\circ} \mathrm{A}$ with $200 \mathrm{~m}, \mathrm{~m}$, of cyclopropane and with varying amounts of oxygen. The graph (No. 18) compares the corresponding curves for the two vessels.

TABLE $\mathrm{MD} .34$

Initial $p_{C P}=178 \mathrm{gon} . \quad T=701^{\circ} \mathrm{A}$

Vessel B
TABLE NO. 35

$$
\text { Initial } P_{c p^{\circ}} \underset{\text { Yessel A }}{200 \mathrm{asa},} \quad T=678^{\circ} \mathrm{A}
$$

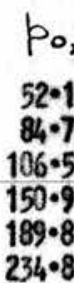

$A^{\prime}$

$\begin{array}{ccc}\text { Run tho. } & p_{\mathrm{O}_{2}} & \mathrm{~A}^{\prime} \\ 897 & 50.7 & 0.286 \\ 8106 & 78.8 & 0.343 \\ 898 & 98.6 & 0.403 \\ 899 & 151.4 & 0.386 \\ 899 & 200.3 & 0.38\end{array}$


Voriation of Initial Oxygen Pressurc (Vessel B) $p_{C D}=250 \mathrm{~mm}$.

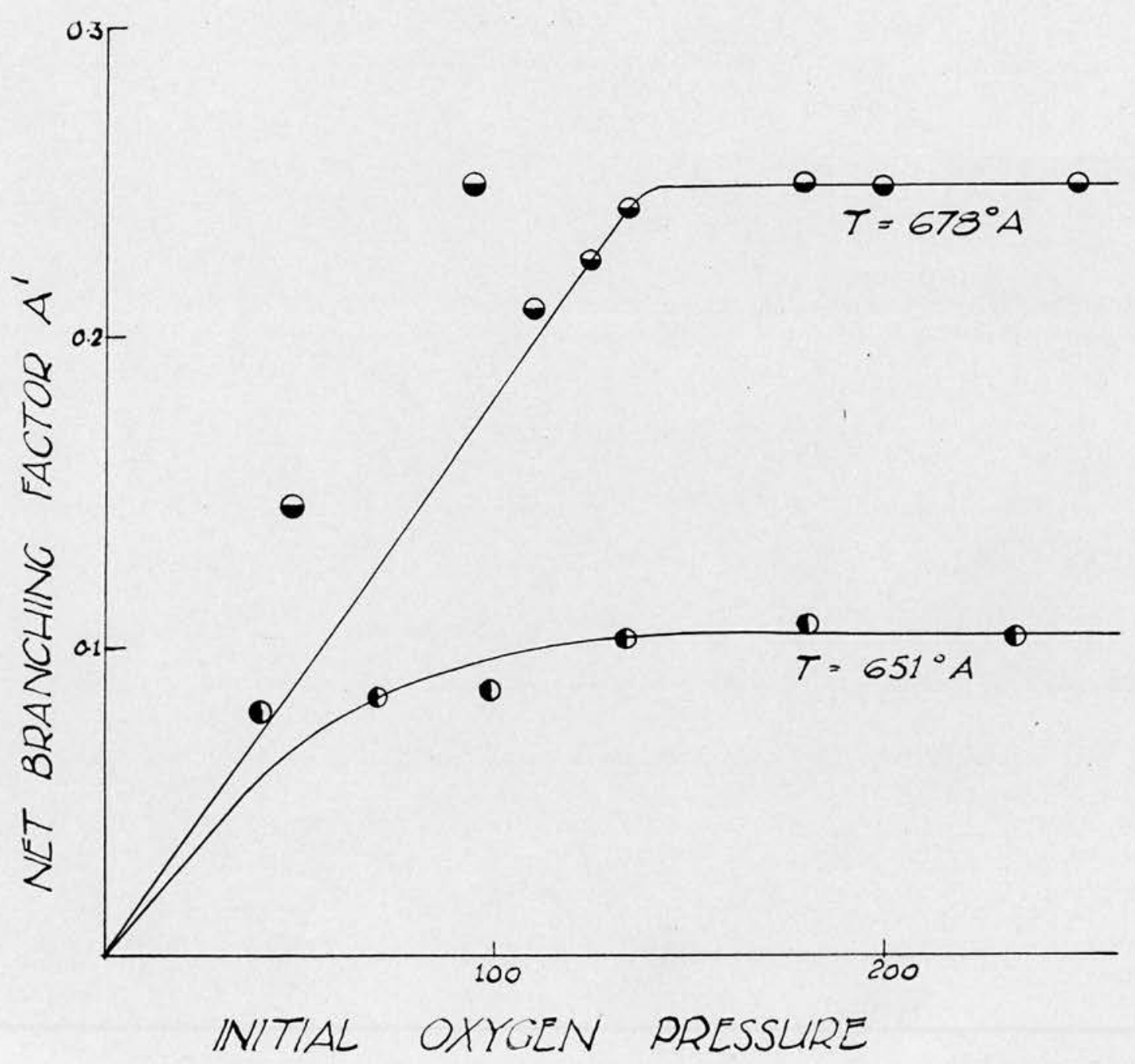


Variation of Initial Oxygen. Pressure (Vessel B) $p_{C . P}=178$ mom.

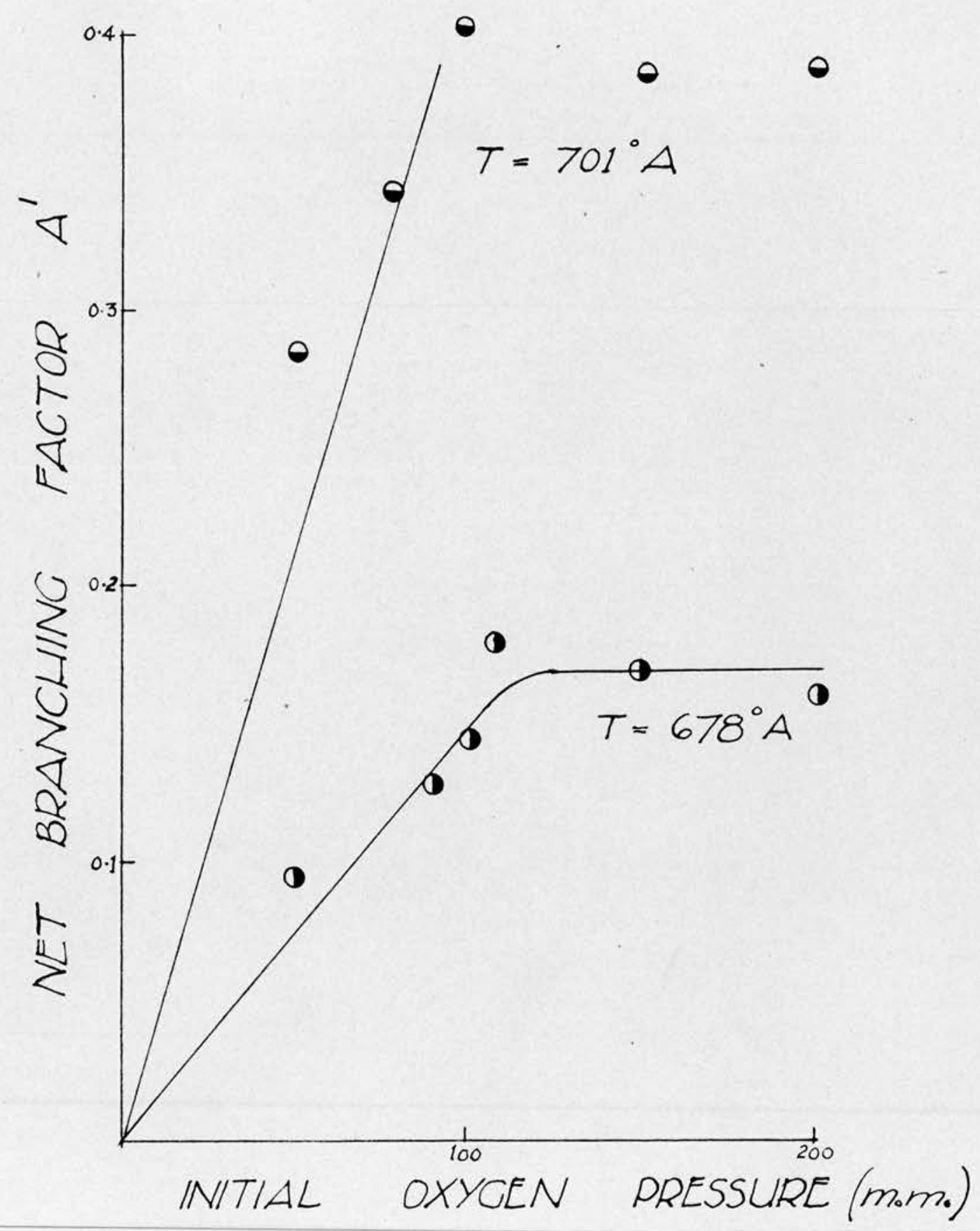


Variation of Initial Oxygen Pressure $\left(p_{c . P}=200 \mathrm{~mm} ; \mathrm{m}=678^{\circ} \mathrm{A}\right)$

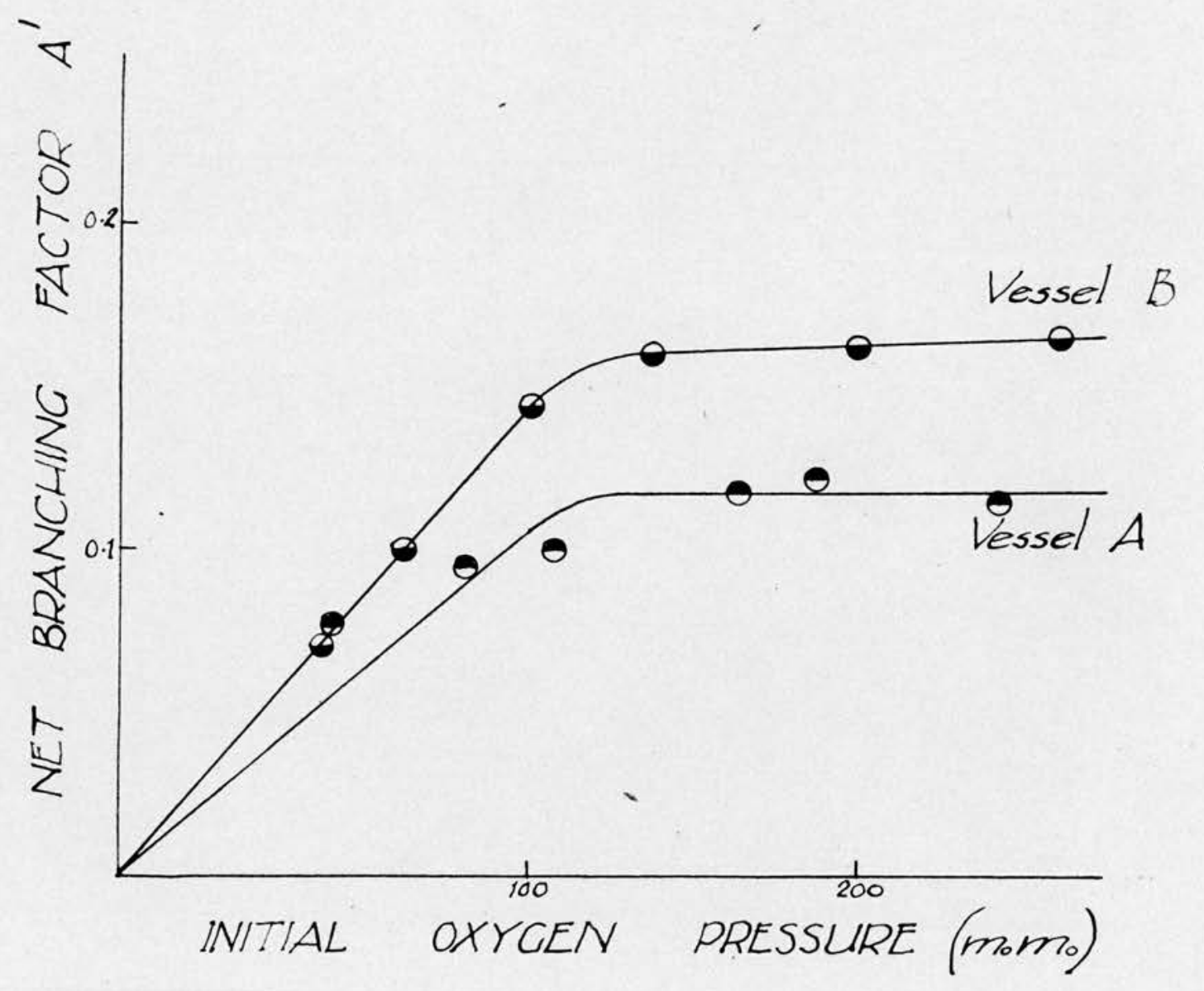


Table No. 36 contains the results of the experiments carried out in vessel $\mathrm{D}$ at $701^{\circ} \mathrm{A}$. The initial hydrocarbon pressure in each experiment was $100 \mathrm{~m} . \mathrm{m}$, and the oxygen pressures ranged between 49 and $300 \mathrm{~m}, \mathrm{~m}$. The graph (No. 19) again demonstrates that the kinetic behaviour is largely independent of the vessel, although the actual values of the parameters may vary considerably from vessel to vessel.

Table No. 36

$\begin{array}{ccc}\text { Initial } P_{C P}=100 \mathrm{~m}, \mathrm{~m}_{*} & T=701^{\circ} \mathrm{A} & \text { Vessel D } \\ \text { Run No. } & P_{\mathrm{O}_{2}} & A^{\prime} \\ \text { D } 18 & 49 \cdot 0 & 0.16 \\ \text { D } 13 & 100.5 & 0.19 \\ \text { D } 17 & 144.5 & 0.24 \\ \text { D } 15 & 186.3 & 0.25 \\ \text { D } 16 & 24.0 \cdot 0 & 0.24 \\ \text { D } 14 & 298.8 & 0.27\end{array}$

2. Dependence Upon Initial Cyclooropane Pressure

Tables No. 37, 38 and 39 give the details of experiments carried out at $678^{\circ} \mathrm{A}, 678^{\circ} \mathrm{A}$ and $701^{\circ} \mathrm{A}$ with $200 \mathrm{~m}, \mathrm{~m}_{\bullet}, 70 \mathrm{~m}, \mathrm{~m}$. and $79 \mathrm{~m}, \mathrm{~m}$. of oxygen respectively. The three series are represented on the graph (No. 20).

TABLE พD. 37

$$
\text { Initial } p_{\mathrm{O}_{2}}=200 \text { a.a. } \quad T=678^{\circ} \mathrm{A}
$$

Vessel :

\begin{tabular}{|c|c|c|}
\hline $\begin{array}{l}821 \\
823 \\
823 \\
849 \\
820 \\
836 \\
864\end{array}$ & $\begin{array}{l}152 \cdot 0 \\
159 \cdot 0 \\
17 \cdot 9 \\
200 \cdot 0 \\
249 \cdot 7 \\
300 \cdot 0\end{array}$ & $\begin{array}{l}0.080 \\
0.0990 \\
0.160 \\
0.163 \\
0.250 \\
0.370\end{array}$ \\
\hline
\end{tabular}

TABLE W. 38

$$
\text { Initial } p_{\mathrm{O}_{2}}=\underset{\text { Vessol }}{70} \text { B no.a. } T=678^{\circ} \mathrm{A}
$$




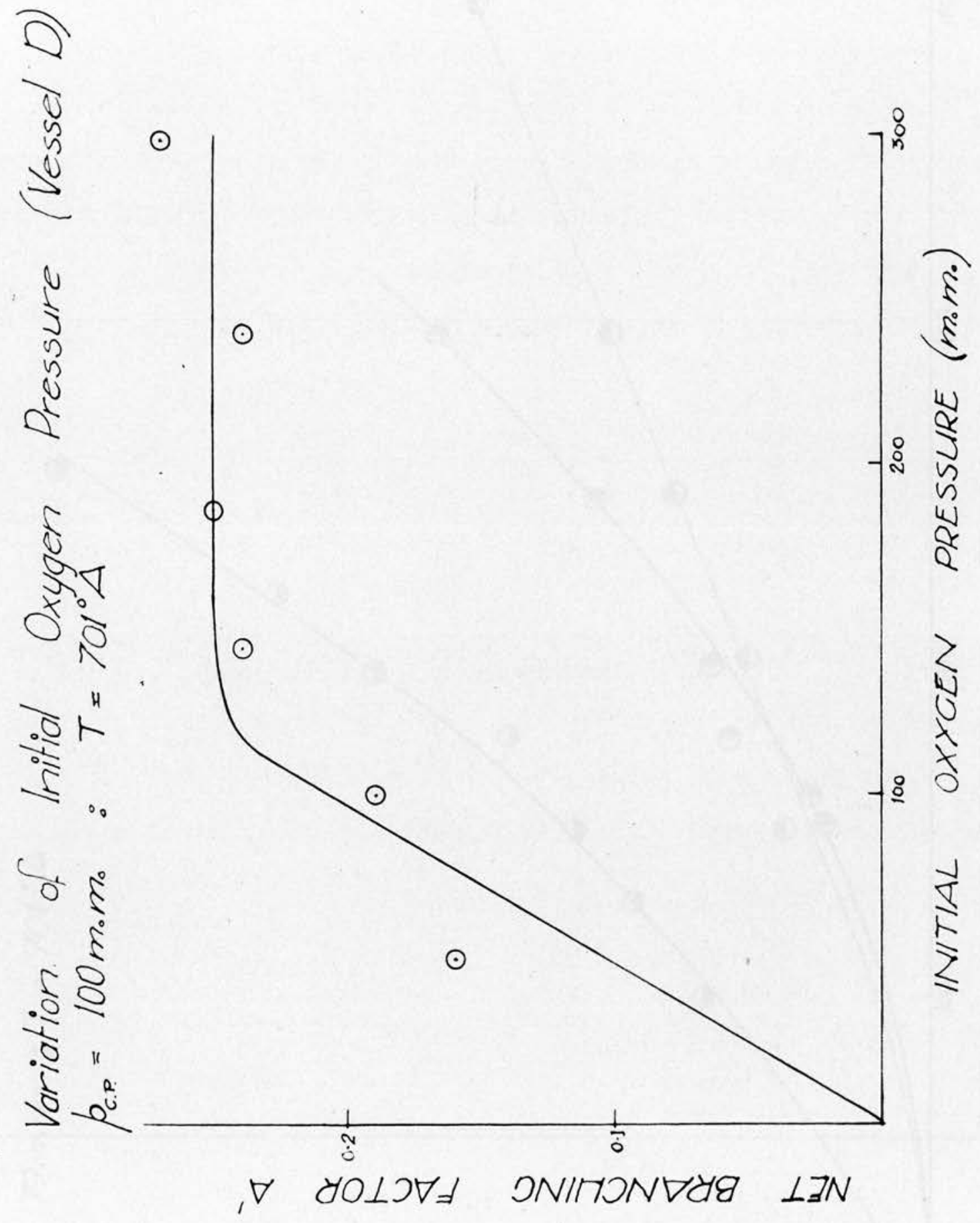


Table No. 39

Initial $p_{\mathrm{o}_{2}}=79 \mathrm{~m}, \mathrm{~m} . \quad \mathrm{T}=701^{\circ} \mathrm{A}$
Vessel $\mathrm{B}$

Run No,

B 108

B 107

B 117

B 106

B 116

B 115

B 114 $p_{c p}$

$99 \cdot 2$
$128 \cdot 5$
$150 \cdot 0$
$177 \cdot 8$
$198 \cdot 7$
$221 \cdot 2$
$258 \cdot 8$

$A^{\prime}$

0.170

0.221

0.264

0.316

0.415

0.490

Table No, 40 gives results obtained in the vessel A with $150 \mathrm{~m} . \mathrm{m}$. $\mathrm{O}_{2}$ at $678^{\circ} \mathrm{A}$ and the graph (No, 21) illustrates the dependence of $A^{\prime}$ upon $P_{c P}$. The other figure on the graph relates to the results in table No, 41 obtained in vessel $\mathrm{D}$ by varying the cyclopropane pressure at $701^{\circ} \mathrm{A}$ with a stoichionetric excess $\left(300 \mathrm{~m}, \mathrm{~m}_{\bullet}\right)$ of oxygen.

\section{TABLE ND. 40}

Initial $p_{o_{2}}=150$ a.m. $T=678^{\circ} \mathrm{A}$

Vessel A
TABLE NO. 41

Initial $p_{\mathrm{O}_{2}}=300$ molle. T- $701^{\circ} \mathrm{A}$

Yessel 0

\begin{tabular}{|c|c|c|c|c|c|c|}
\hline Run No. & $p_{c p}$ & $A^{\prime}$ & $p_{c P}^{2}$ & Bun tho. & $p_{c p}$ & $A^{\prime}$ \\
\hline $\begin{array}{ll}A & 35 \\
A & 25 \\
A & 23 \\
A & 14 \\
A & 33 \\
A & 28 \\
A & 32 \\
A & 30\end{array}$ & $\begin{array}{l}176 \cdot 3 \\
199 \cdot 1 \\
201 \cdot 8 \\
208 \cdot 0 \\
250 \cdot 5 \\
299 \cdot 0 \\
302 \cdot 2 \\
304 \cdot 0\end{array}$ & $\begin{array}{l}0.077 \\
0.100 \\
0.105 \\
0.112 \\
0.166 \\
0.218 \\
0.226 \\
0.223\end{array}$ & $\begin{array}{l}31070 \\
39550 \\
40720 \\
43270 \\
62750 \\
89430 \\
91330 \\
92380\end{array}$ & $\begin{array}{ll}0 & 25 \\
0 & 26 \\
0 & 21 \\
0 & 20 \\
0 & 22 \\
0 & 22 \\
0 & 24\end{array}$ & $\begin{array}{r}80.0 \\
90.0 \\
100 \cdot 0 \\
110.2 \\
120 \cdot 0 \\
130.0\end{array}$ & $\begin{array}{l}0.085 \\
0.145 \\
0 \cdot 183 \\
0.220 \\
0 \cdot 320 \\
0.400\end{array}$ \\
\hline
\end{tabular}

Two types of dependence will be recognised, a linear dependence and a higher dependence. That this second dependence was a square one was shown by the straight-line graph of $A^{\prime}$ against the square of the initial cyclopropane pressures (graph No. 22) shown in tables No. 37,40 and 41. 


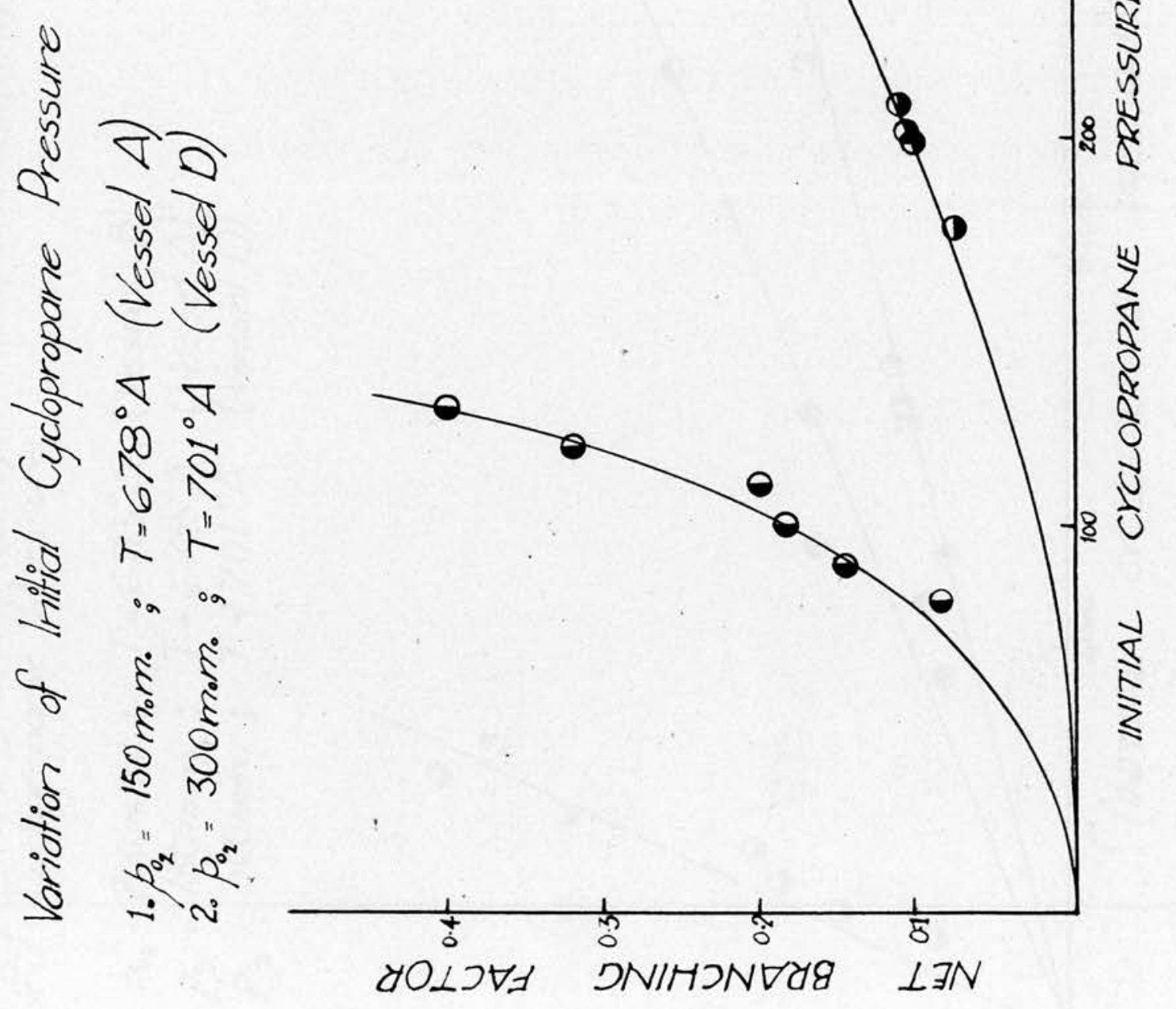


3. Dependence Upon the gemperature

Experiments designed to elucidate the temperature dependence of the reaction have been already described in the section dealing with maximum rates. Two distinct series of experiments were performed and the net-branching factors have been calculated and are tabulated in tables Nos. 42 and 43 , the former relating to experiments at different temperatures with a mixture of $250 \mathrm{~m} . \mathrm{m}$. cyclopropane and $70 \mathrm{~m} . \mathrm{m}$. of oxygen and the latter referring to the raaction of a mixture of $178 \mathrm{~m}, \mathrm{~m}$. of hydrocarbon and $200 \mathrm{~m}, \mathrm{~m}$. of oxygen at various temperatures over the range $651^{\circ} \mathrm{A}-705^{\circ} \mathrm{A}$. Graph No. 23 illustrates the variation of $\log A^{\prime}$ with reciprocal absolute temperature for the two series.

$$
\begin{gathered}
\text { Table No. } 42 \\
\text { Initial } p_{c p}=250 \mathrm{~m} \cdot \mathrm{m}_{\bullet} p_{\mathrm{o}_{2}}=70 \mathrm{~m} \cdot \mathrm{m}_{\bullet}
\end{gathered}
$$

Vesse1 B

$\begin{array}{ccccc}\text { Run No. } & T & \frac{10^{3}}{T} & A^{\prime} & \log _{10} A^{\prime} \\ \text { B } 89 & 651 & 1.536 & 0.105 & 0.0212 \\ \text { B } 88 & 658 & 1.520 & 0.120 & 0.0792 \\ \text { B } 87 & 665 & 1.504 & 0.123 & 0.0899 \\ \text { B } 86 & 671 & 1.490 & 0.181 & 0.2577 \\ \text { B } 77 & 678 & 1.475 & 0.216 & 0.3345 \\ \text { B } 83 & 683 & 1.464 & 0.263 & 0.4200 \\ \text { B } 80 & 689 & 1.451 & 0.320 & 0.5051 \\ \text { B } 81 & 697 & 1.435 & 0.477 & 0.6785 \\ \text { B } 84 & 702 & 1.425 & 0.576 & 0.7604\end{array}$


2 $\left\{\begin{array}{l}0 \\ 5 \\ 4 \\ \text { uै }\end{array}\right.$

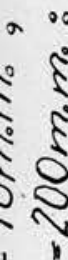
$0^{N}-0^{2}$

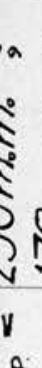

2

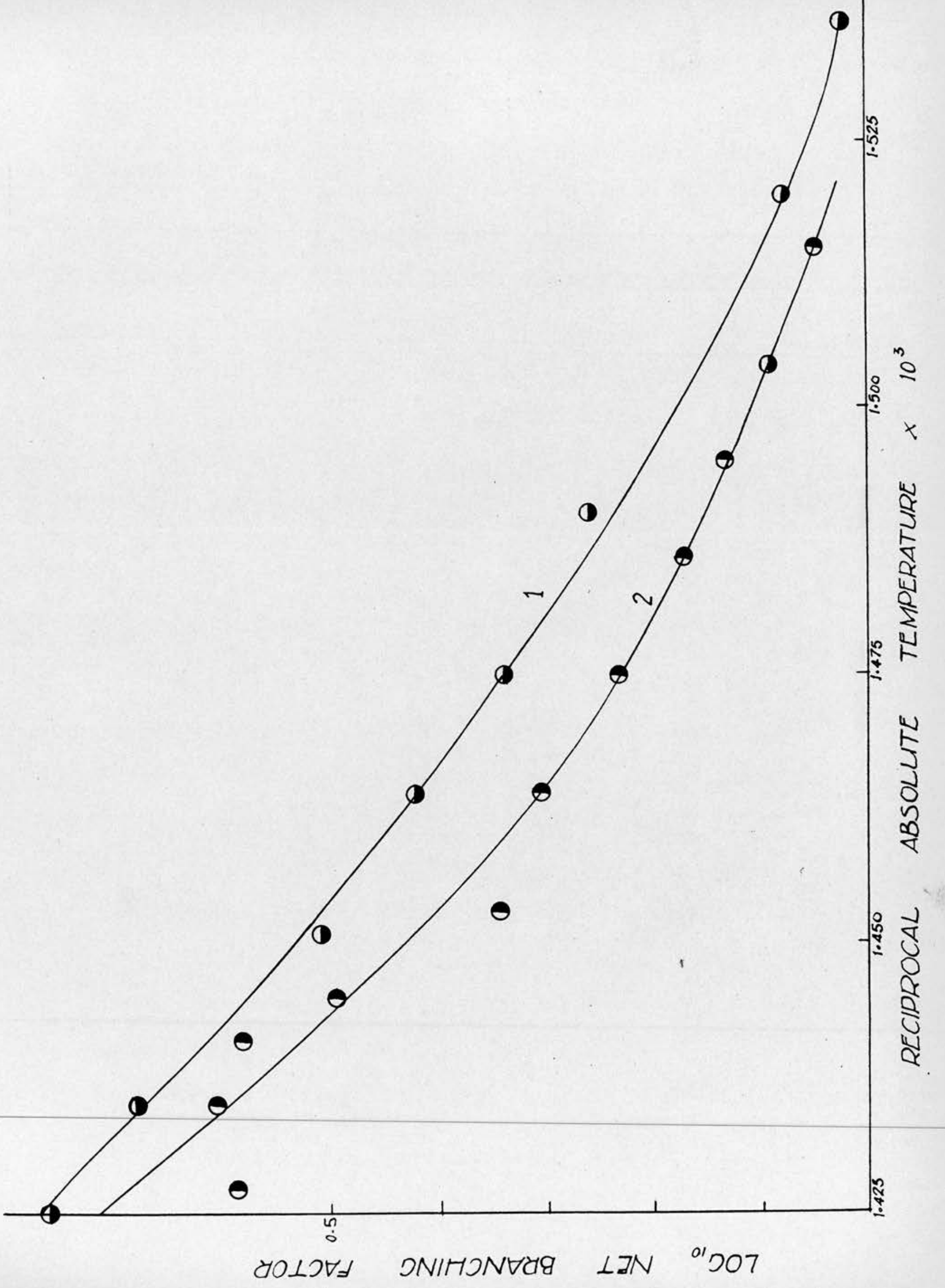




\section{Table No. 43}

$$
\text { Initial } p_{c p}=178 \mathrm{~m} \cdot \mathrm{m}_{0} \quad p_{\mathrm{o}_{2}}=200 \mathrm{~m} \cdot \mathrm{m}_{0}
$$

Vessel B

$\begin{array}{ccccc}\text { Ean No. } & T & \frac{10^{3}}{T} & A^{\prime} & \log _{10} A^{\prime} \\ \text { B 56 } & 660 & 1.515 & 0.112 & 0.0492 \\ \text { B } 57 & 669 & 1.495 & 0.135 & 0.1303 \\ \text { B } 58 & 673 & 1.486 & 0.147 & 0.1673 \\ \text { B } 49 & 678 & 1.475 & 0.170 & 0.2304 \\ \text { B 48 } & 683 & 1.464 & 0.200 & 0.3010 \\ \text { B 50 } & 688 & 1.453 & 0.220 & 0.3424 \\ \text { B 52 } & 692 & 1.445 & 0.310 & 0.4914 \\ \text { B 51 } & 694 & 1.441 & 0.380 & 0.5798 \\ \text { B } 47 & 697 & 1.435 & 0.404 & 0.6064 \\ \text { B100 } & 701 & 1.427 & 0.387 & 0.5877\end{array}$

The graphs closely resemble the log maximum rate against reciprocal absolute temperature plots and the activation energies calculated from the slopes of their straight portions are $35.0 \mathrm{kcals}$, and about $35 \mathrm{kcals}$, respectively, the consideraile curvature (or perhaps scatter) in the latter case making selection of a best line difficult.

4. Effect of added. Nitrogen

Fxperiments previously described yielded some information as to the effect of nitrogen upon the net-branching factor. The results are given in table No. 44 referring to experiments

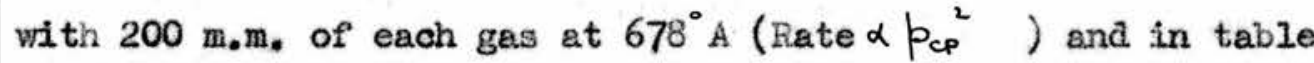
No, 45 roferring to experiments at $701^{\circ} \mathrm{A}$ with $178 \mathrm{~m} \cdot \mathrm{m}$, oyclo-

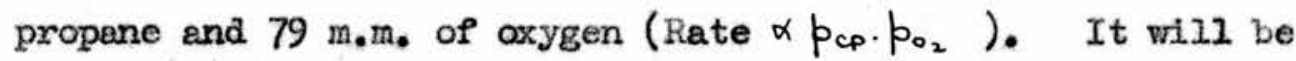
seen that the net-branching factor was unaffected by dilution of the reaction mixture with nitrogen. 
TABLE ND. 44 .

$$
\begin{array}{cl}
\text { Initial } p_{C P}=200 \text { mods, } & p_{\mathrm{O}_{2}}=200 \mathrm{mom}, \\
T \cdot 678^{\circ} \mathrm{A} & \text { Vessel B }
\end{array}
$$

TABLE NO. 45

Initial $p_{C p}=178 \mathrm{mom}, \quad p_{O_{2}}=79 \mathrm{mon}$

\begin{tabular}{|c|c|c|c|c|}
\hline Run No, & $p_{N_{2}}$ & $A^{\prime}$ & Run th. & $p_{N_{2}}$ \\
\hline $\begin{array}{ll}B & 122 \\
B & 121 \\
8 & 120\end{array}$ & $\begin{array}{l}50.0 \\
98.4\end{array}$ & $\begin{array}{l}0.163 \\
0.160 \\
0.165\end{array}$ & $\begin{array}{ll}8 & 106 \\
3 & 103 \\
\text { B } & 104\end{array}$ & $\begin{array}{c}50 \cdot 3 \\
99.6\end{array}$ \\
\hline
\end{tabular}
T. $701^{\circ} \mathrm{A}$

Vessel B

5. Effect of added Hydrogen

Table No, 46 illustrates the results of the study made on the effect of added hydrogen upon the net-branching factor. While it will be noted that the pretreatment of the vessel with hydrogen and the addition of hydrogen to the system led to the lowest values of $A^{\prime}$ very little can be concluded from the results as there is not such a distinct trend as was observed in the

\begin{tabular}{|c|c|c|c|}
\hline Run $\mathrm{No}$. & Pretreatment & & $A^{\prime}$ \\
\hline $\begin{array}{ll}0 & 3 \\
0 & 4 \\
0 & 5\end{array}$ & $\begin{array}{l}\text { One hour's evacuation } \\
\text { One hour's evacuation } \\
50 \text {. } \\
\text { left in of prociucts of run hot vessel for } 37 \text { hours }\end{array}$ & 50 & $\begin{array}{l}0.24 \\
0.20\end{array}$ \\
\hline $\begin{array}{ll}0 & 6 \\
0 & 7 \\
0 & 8\end{array}$ & $\begin{array}{l}\text { One hour's evacuation } \\
\text { One hour's evccuation } \\
\text { One hour's evacuation } \\
50 \text { mos. of products of run } \mathrm{No} .07\left(\mathrm{No} . \mathrm{H}_{2}\right) \text { left in } \\
\text { the hot vesset for } 67 \text { hours }\end{array}$ & & $\begin{array}{l}0.18 \\
0.22 \\
0.22\end{array}$ \\
\hline 09 & $\begin{array}{l}\text { One hour's evacuation } \\
50 \mathrm{a}, \mathrm{m} \text {. of } \mathrm{H}_{2} \text { heated in the vessel for } 40 \text { minutes }\end{array}$ & & 24 \\
\hline D 10 & Seven hour's evacuation & & 10 \\
\hline
\end{tabular}
case of the maximum rates.

\section{TABLE ND. 46}

In these experiments it was noted that the graphs of log against time showed more curvature than usual when hydrogen was presnnt. This gradual decrease of $A^{*}$ as the experiment proceeded made it necessary to consider the initial part of the graph only in the determination of $A^{\prime}$. 
THE DEPENDEWWCE OF THE IINUCTION PERTOD UPON CONDITIOINS

The definition and method of measurement of that remarkable feature of hydrocarbon cxidation -the inaustion period - requires a little discussion. The term induction period has been used to describe several distinct factors. These are (a) the time taken until the first measureable pressure change occurs, (b) the time taken until the rate reaches a certain small speed (say $0.5 \mathrm{~m} \cdot \mathrm{m}$. per minute), (c) the time taken for the attainment of the maximum rate and (d) the time measured by the extrapolation of the tangent to the $\Delta p-t$ curve at the maximum rate back to the time axis. These are illustrated on the graph (No. 24).

In the present work the initial time $\left(t_{0}\right)$ has been taken as the time of adition of the oxygen to the cyelopropane in the reaction. It will be seen later that so long as the time between admission of hydrocarbon and $t_{0}$ is small there is no danger of pyrolysis except at very high temperatures so that the description of to as time of admission of oxygen is justified.

It can easily be shown that the two extremes of induction period definition (a) and (c) above are sufficiently equivalent to make their separate study unnecessary. This is clearly shown on the graph (No. 31) where the reciprocals of $\theta$ and $\tau$ have been plotted against reciprocal temperature on the same paper.

In general, therefore, induotion period has been taken as the time elapsing between the admission of oxygen to the vessel and the attainment of maximum rate.

It has been found that no high degree of reproducibility 


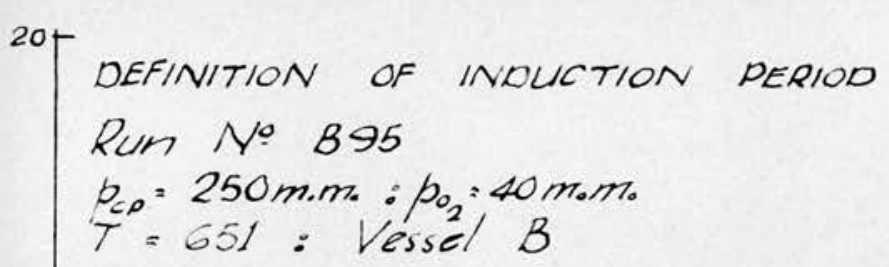


has been obtained in the study of induction periods. As earlier suggested, the state of the surface has a very pronounced effect upon the period of induction. With this limitation in mind, however, certain conclusions have been arawn with regard to the variation of induction period with change of conditions.

\section{Dependence Upon Initial Oxygen Pressure}

The induction periods and their rediprocals are detailed in tables Nos. 47, 48, 49 and 50 for the variation of initial oxygen with $178,200,250$ and $300 \mathrm{~m}, \mathrm{~m}_{\text {。 }}$ of cyclopropane respectively at $678^{\circ} \mathrm{A}$ in vessel $\mathrm{B}$. The results are shown on graph No. 25. Table No. 51 shows the variation of reciprocal induction period with change of initial oxygen pressure at $651^{\circ} \mathrm{A}$ (initial hydrocarbon pressure $=250 \mathrm{~m}, \mathrm{~m}_{\text {, }}$ ). The graph (No. 26) shows the relationship between $\frac{1}{\theta}$ and $p_{0_{2}}$ at $651^{\circ} \mathrm{A}$ and $678^{\circ} \mathrm{A}$ for $p_{c p}=250 \mathrm{~m} \cdot \mathrm{m}$.

TABLE MO. 47

$$
\begin{gathered}
\text { Initial } p_{c p}=178 \mathrm{mom} . \quad T-678^{\circ} \mathrm{A} \\
\text { yessel B }
\end{gathered}
$$

$\begin{array}{llll}\text { Run Ho. } & p_{0_{2}} & \theta & \frac{100}{\theta} \\ \text { B 43 } & 50.0 & 150 & 0.667 \\ \text { B 42 } & 89.7 & 93 & 1.085 \\ \text { B 44 } & 101 \cdot 0 & 82 & 1.220 \\ \text { B 39 } & 108 \cdot 4 & 76 & 1.316 \\ \text { B 41 } & 149.4 & 48 & 2.083 \\ \text { B 49 } & 200.9 & 35.5 & 3.817\end{array}$

TABLE MD. 48

$$
\begin{gathered}
\text { Initial } p_{c p}=200 \mathrm{~m}, 0 . \quad T=678^{\circ} \mathrm{A} \\
\text { Vessel } B
\end{gathered}
$$

Run Ho. $p_{\mathrm{O}_{2}} \quad \theta \quad \frac{100}{\theta}$

$\begin{array}{lllll}\text { B } & 24 & 50.0 & 142 & 0.704 \\ \text { B } 26 & 70.0 & 105 & 0.952 \\ \text { B } 25 & 100.5 & 71 & 1.41 \\ \text { B } 27 & 130.0 & 47 & 2 \cdot 13 \\ \text { B } 30 & 199.8 & 32 & 3.125 \\ \text { B } 28 & 248.7 & 25.2 & 3.922\end{array}$


Variation of Initiol Oxygen Pressure (Vessel B)

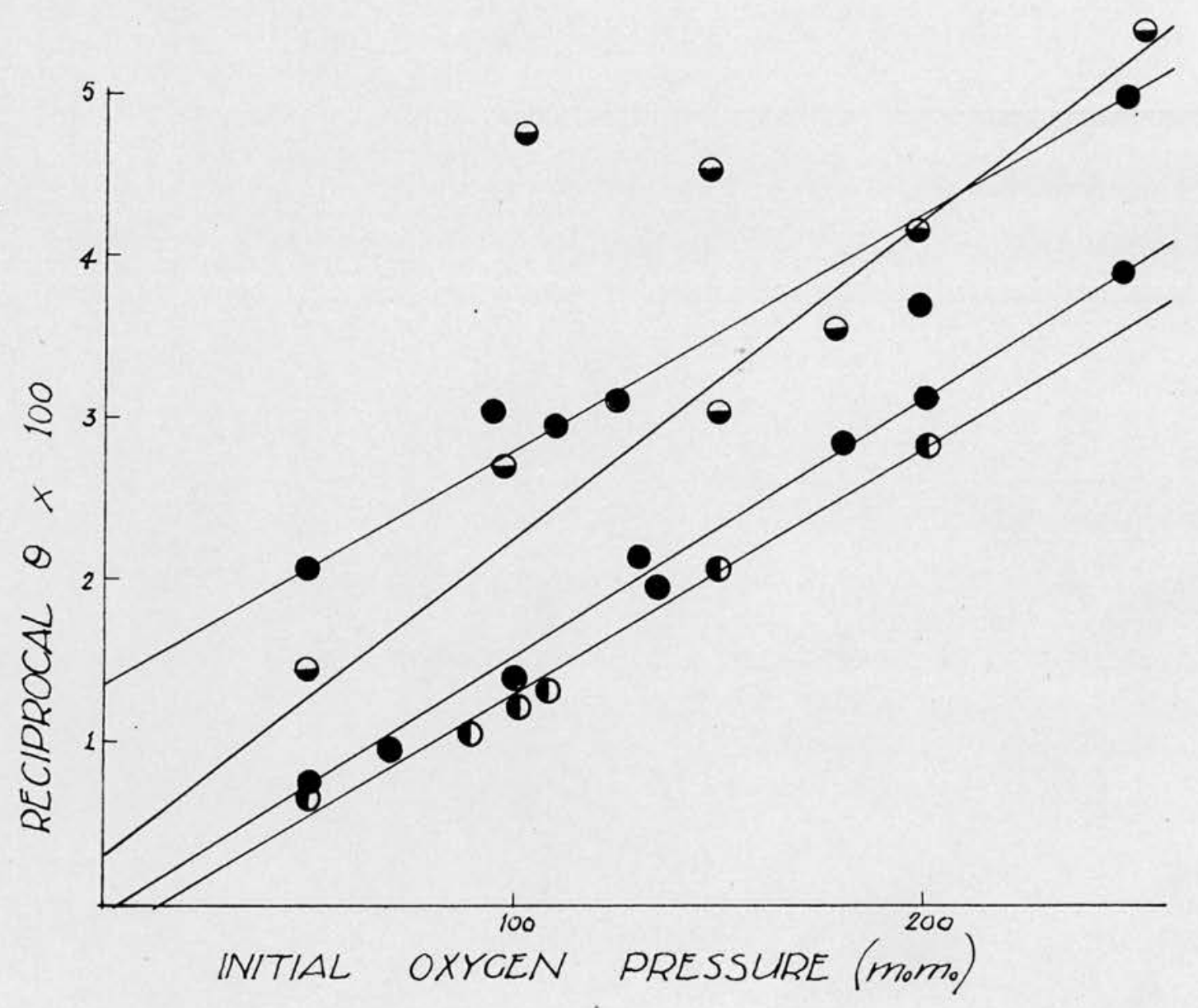


Variation of Initial Oxygen Pressure $\left(p_{c, p}=250 \mathrm{mom}_{0}\right.$; Vessel B)

1. $T=678^{\circ} \mathrm{A}$

2. $T=651^{\circ} \mathrm{A}$

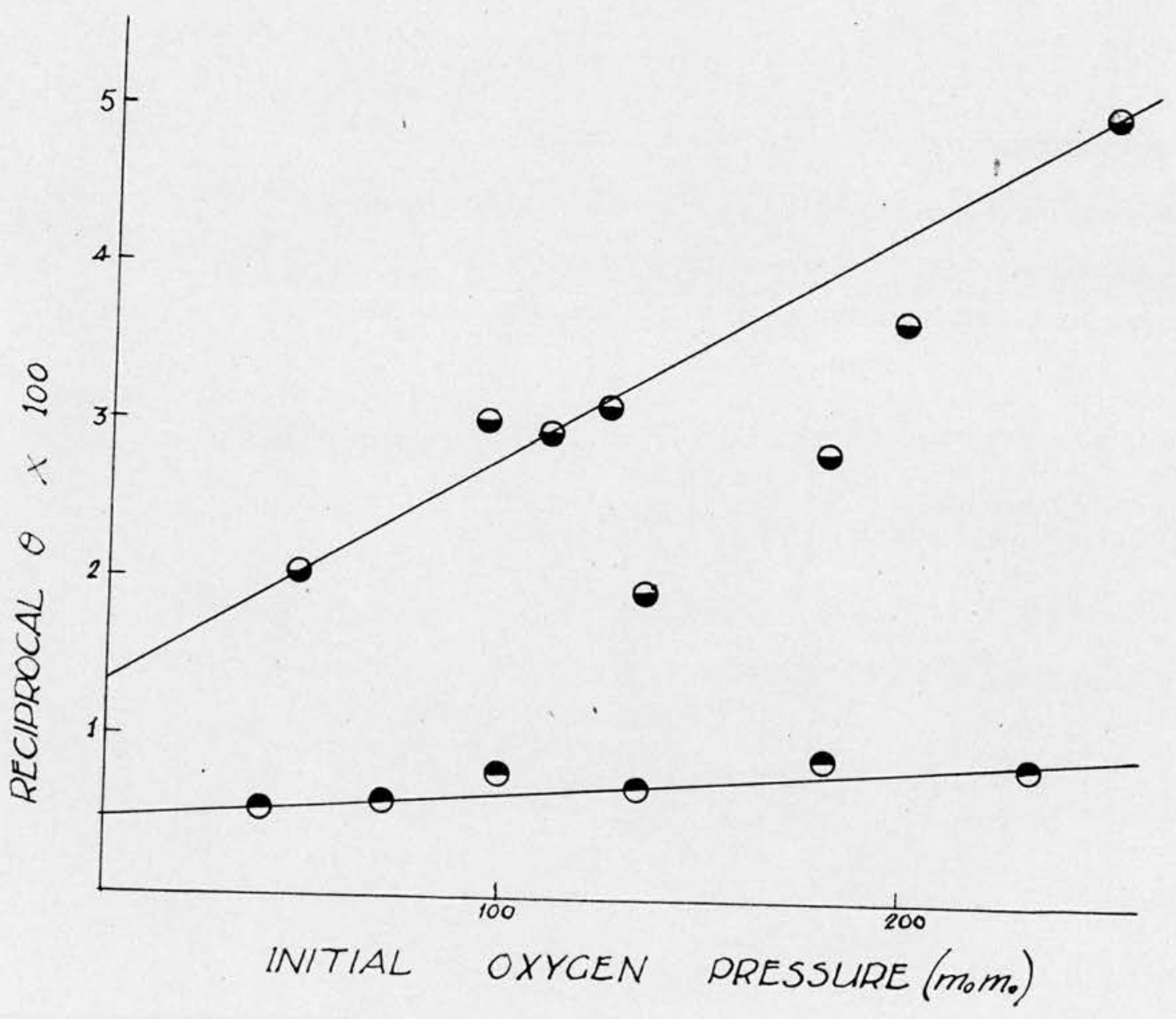


TABLE NO. 49

Initial $p_{c p}=250$ a.m. T $-678^{\circ} \mathrm{A}$

Vessel B

\begin{tabular}{|c|c|c|}
\hline Run Ho. & $p_{\mathrm{O}_{2}}$ & $\theta$ \\
\hline $\begin{array}{ll}8 & 35 \\
8 & 34 \\
8 & 33 \\
B & 38 \\
8 & 32 \\
8 & 31 \\
8 & 36 \\
8 & 37\end{array}$ & $\begin{array}{r}48 \cdot 3 \\
94 \cdot 5 \\
109 \cdot 8 \\
124 \cdot 7 \\
134 \cdot 8 \\
180 \cdot 0 \\
198 \cdot 8 \\
250 \cdot 0\end{array}$ & $\begin{array}{l}48 \cdot 5 \\
33 \\
34 \\
32 \\
51 \\
35 \\
27 \\
20\end{array}$ \\
\hline
\end{tabular}

TABLE MO. 50

Infitial $p_{\text {cp }}=300$ m.t. T. $=678^{\circ} \mathrm{A}$ Vessel $B$

Run in. $p_{\mathrm{O}_{2}} \quad 8 \quad \frac{100}{\theta}$

$\begin{array}{rrll}\text { B } 67 & 49.5 & 68 & 1 \cdot 471 \\ \text { B } 62 & 97 \cdot 4 & 37 & 2 \cdot 703 \\ \text { B } 68 & 101 \cdot 7 & 21 & 4 \cdot 762 \\ \text { B } 70 & 147 \cdot 2 & 22 & 4 \cdot 545 \\ \text { B } 71 & 149 \cdot 7 & 33 & 3 \cdot 030 \\ \text { B } 72 & 178 \cdot 3 & 28 & 3 \cdot 571 \\ \text { B } 64 & 198 \cdot 0 & 24 & 4 \cdot 167 \\ \text { B } 66 & 252 \cdot 7 & 18.5 & 5 \cdot 405\end{array}$

TABLE NO. 51

$$
\text { Initial } p_{c p}=250 \text { a.m. }
$$

$\begin{array}{cccc}\text { Run Ho. } & p_{\mathrm{O}_{2}} & \theta & \frac{100}{\theta} \\ \text { B } 95 & 40 \cdot 0 & 184 \cdot 5 & 0.545 \\ 894 & 69 \cdot 9 & 160 \cdot 0 & 0.625 \\ 893 & 99 \cdot 0 & 127 \cdot 5 & 0.791 \\ 892 & 134 \cdot 2 & 140.5 & 0.712 \\ 891 & 180.4 & 109 \cdot 0 & 0.917 \\ 890 & 233 \cdot 7 & 114 \cdot 0 & 0.877\end{array}$

Table No. 52 lists the induction times observed at $701^{\circ} \mathrm{A}$ with $178 \mathrm{~m}_{0} \mathrm{~m}$. cyclopropane and varying amounts of oxygen and the graph (No. 27) shows the relationship for $p_{c p}=178 \mathrm{~m} . \mathrm{m}$. at $678^{\circ} \mathrm{A}$ and $701^{\circ} \mathrm{A}$

TABLE MD. 52

$$
\text { Initial } p_{c e}=178 \text { mow. } \quad T \cdot 701_{\mathrm{A}}^{\circ}
$$

Vessel B

$\begin{array}{llll}\text { Run No. } & p_{02} & \theta & \frac{100}{\theta} \\ B 97 & 50 \cdot 7 & 17 & 5 \cdot 882 \\ 8106 & 78 \cdot 8 & 9.5 & 10 \cdot 53 \\ 898 & 98 \cdot 6 & 10 & 10.0 \\ 899 & 151 \cdot 4 & 10 & 10 \cdot 0 \\ 8100 & 200 \cdot 3 & 10 & 10 \cdot 0\end{array}$


Variation of Initial Oxygen Pressure.

( $p_{c . p}=178 \mathrm{mom}$; Vessel B)

1. $T=701^{\circ} \mathrm{A}$

2. $T=678^{\circ} \mathrm{A}$

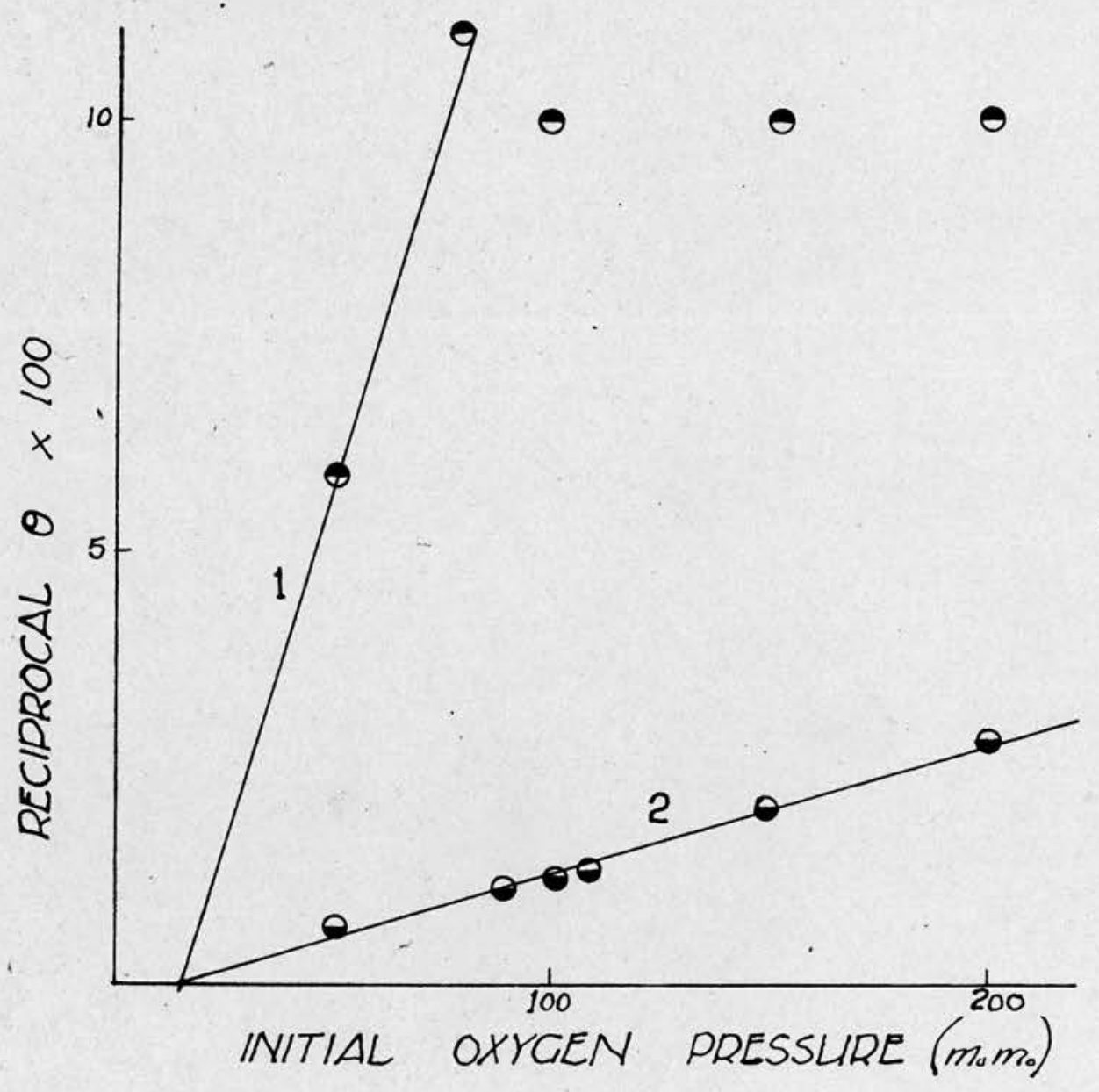


The data in table No. 53 and on the graph No. 28 refer to experiments in vessel A using $200 \mathrm{~m} . \mathrm{m}$. of cyclopropane and varying amounts of oxygen at $678^{\circ} \mathrm{A}$, while table No. 54 lists details of experiments in vessel D with $100 \mathrm{~m} . \mathrm{m}$, of cyclopropane at $701^{\circ} \mathrm{A}$. The figures in table No.54 are also plotted on the graph (No. 28)

TASLE พ. 53

Initial $p_{C P}=200$ mos. $\quad T=678^{\circ} \mathrm{A}$ Vessel A

\begin{tabular}{|c|c|c|c|c|c|c|c|}
\hline un No. & $p_{\mathrm{O}_{2}}$ & $\theta$ & $\frac{100}{\theta}$ & Run Ho. & $p_{\mathrm{O}_{2}}$ & $\theta$ & $\frac{100}{\theta}$ \\
\hline $\begin{array}{ll}A & 41 \\
A & 42 \\
A & 37 \\
A & 40 \\
A & 38 \\
A & 39 \\
A & 39\end{array}$ & $\begin{array}{r}52 \cdot 1 \\
84 \cdot 7 \\
106 \cdot 5 \\
150 \cdot 9 \\
189 \cdot 8 \\
234 \cdot 8\end{array}$ & $\begin{array}{l}92 \\
52 \\
55 \\
54 \\
48 \\
42\end{array}$ & $\begin{array}{l}1 \bullet 087 \\
1 \bullet 923 \\
1 \bullet 818 \\
1 \bullet 852 \\
2 \cdot 083 \\
2 \bullet 381\end{array}$ & $\begin{array}{ll}0 & 18 \\
0 & 13 \\
0 & 17 \\
0 & 15 \\
0 & 16 \\
0 & 14\end{array}$ & $\begin{array}{r}49 \cdot 0 \\
100 \cdot 5 \\
144 \cdot 5 \\
186 \cdot 3 \\
240 \cdot 0 \\
293 \cdot 8\end{array}$ & $\begin{array}{l}33 \\
40 \\
18 \\
18 \\
18 \\
12\end{array}$ & $\begin{array}{l}3 \cdot 030 \\
2 \cdot 500 \\
5 \cdot 556 \\
5 \cdot 556 \\
5 \cdot 556 \\
8 \cdot 333\end{array}$ \\
\hline
\end{tabular}

TABLE M. 54

Initial pepe 100 mos. $\quad T \cdot 701^{\circ} \mathrm{A}$ Vessel 0

It is very difficult to make definite conclusions from these results. Recognising that some of the induction periods observed were obviously not consistent with the others in the same series the graphs are still not very satisfactory. The data in tables Nos. 47 and 48 provides strong evidence for the existence of some linear relationship between initial oxygen pressure and reciprocal induction period. Apart from the figures in table No. 52, most of the other results could be said to show some semblance of such a dependence, and it is probably justified to conclude that, in general, the induction period decreased more or less regularly when the initial pressure of oxygen was increased.

2. Dependence Upon Initial Gyclopropane Pressure

Tables Nos. 55,56 and 57 give the details of experiments 


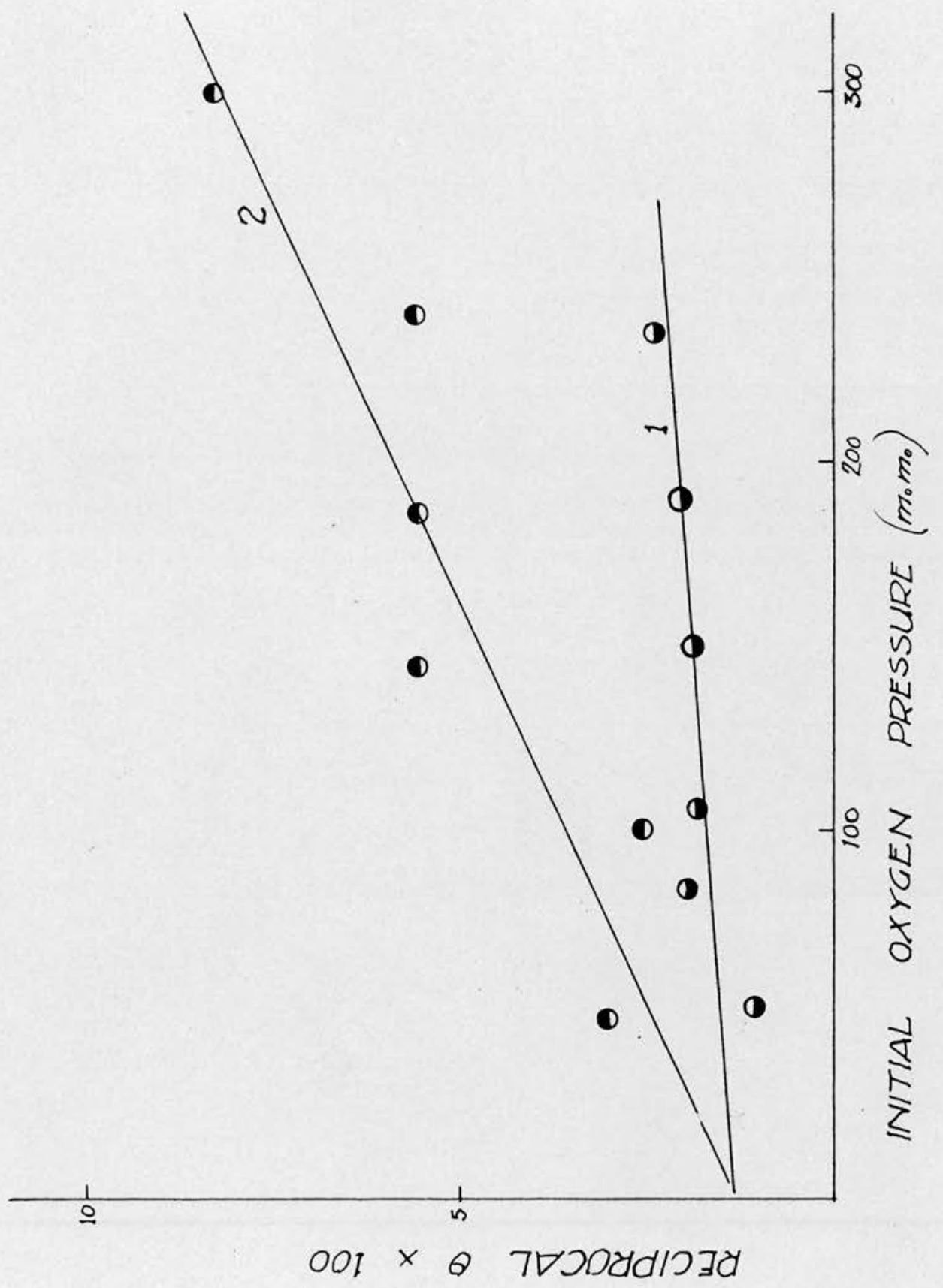


5

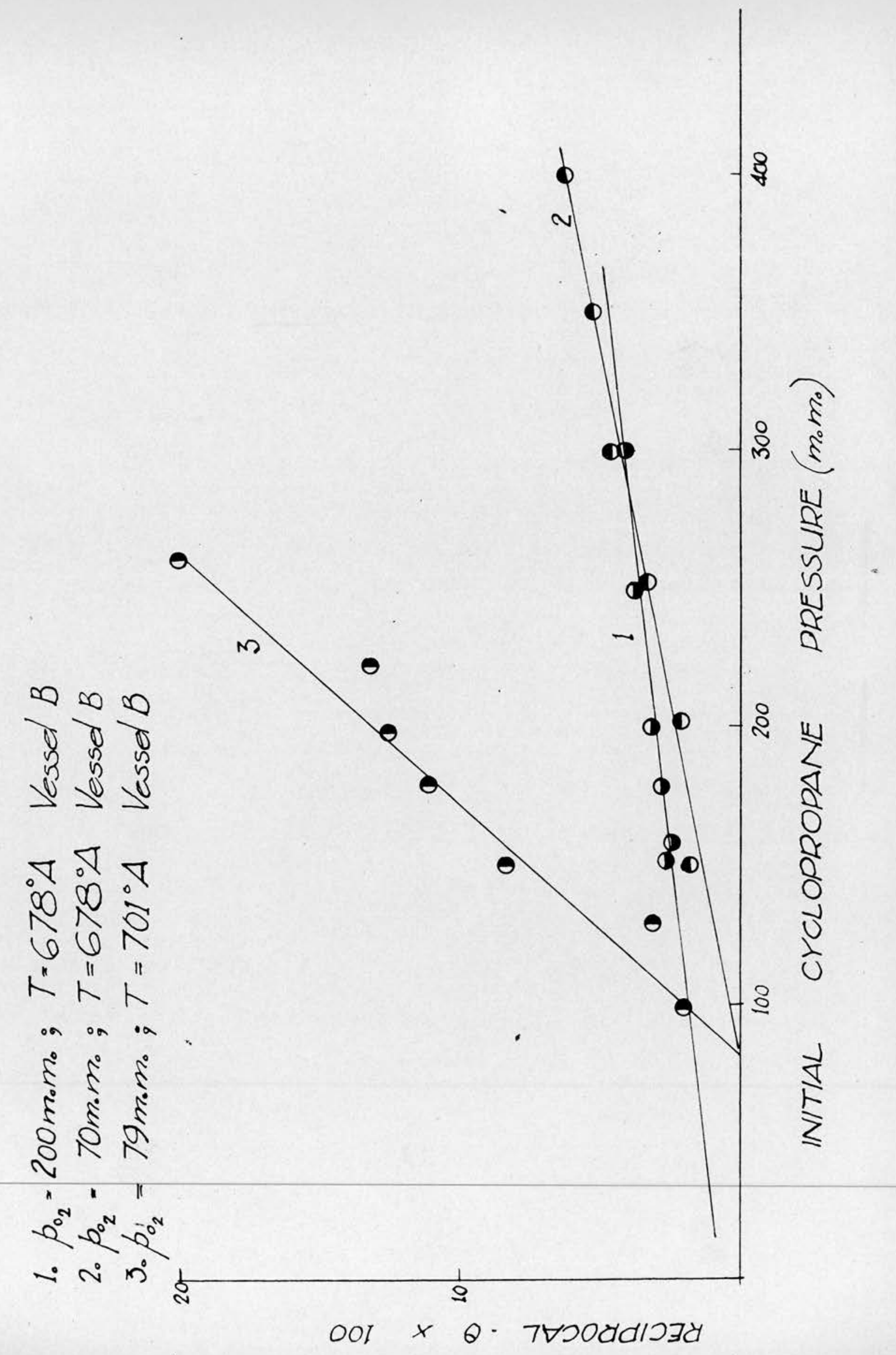


Table No. 58

$$
\text { Initial } p_{\mathrm{O}_{2}}=\underset{\substack{\text { Vessel } \\ \text { A }}}{150 \mathrm{~m}_{0}} \quad \mathrm{~T}=678^{\circ} \mathrm{A}
$$

$\begin{array}{lccc}\text { Run No. } & p_{c p} & \theta & \frac{100}{\theta} \\ \text { A } 35 & 176 \cdot 3 & 68 & 1 \cdot 471 \\ \text { A } 25 & 199 \cdot 1 & 54 & 1 \cdot 852 \\ \text { A } 23 & 201 \cdot 8 & 52 & 1 \cdot 923 \\ \text { A } 14 & 208 \cdot 0 & 48 & 2 \cdot 083 \\ \text { A } 33 & 250 \cdot 5 & 33 & 3 \cdot 030 \\ \text { A } 28 & 299 \cdot 0 & 29 & 3 \cdot 448 \\ \text { A } 32 & 302 \cdot 2 & 26 & 3 \cdot 846 \\ \text { A } 30 & 304 \cdot 0 & 25 & 4 \cdot 000\end{array}$

The series of experiments already described using vessel $D$ and a stoichiometric excess of oxygen at $701^{\circ} \mathrm{A}$ yielded the data in table No. 59. These data are also plotted on graph (No. 30). Table No. 59

$$
\text { Initial } p_{\mathrm{O}_{2}}=300 \mathrm{~m} \cdot \mathrm{m} . \quad T=701^{\circ} \mathrm{A}
$$

Vessel D

$\begin{array}{lrlc}\text { Run No. } & p_{C P} & \theta & \frac{100}{\theta} \\ \text { D 25 } & 80 \cdot 0 & 28 \cdot 5 & 3 \cdot 509 \\ \text { D 26 } & 90 \cdot 0 & 22 & 4 \cdot 545 \\ \text { D 21 } & 100 \cdot 0 & 18 & 5 \cdot 556 \\ \text { D 20 } & 110 \cdot 2 & 20 & 5 \cdot 000 \\ \text { D 22 } & 120 \cdot 0 & 14 \cdot 5 & 6.897 \\ \text { D 24 } & 130 \cdot 0 & 13 & 7.692\end{array}$

We may conclude from a study of these results that the reciprocal induction period was directly proportional to the initial pressure of cyclopropane.

3. Dependence Upon the Temperature

Two series of experiments have been described in the previous sections which were designed to illustrate the temperature coefficient of the reaction. During these experiments data were collected referring to the variation of induction period with temperature. Table No. 60 contains the detalls of 


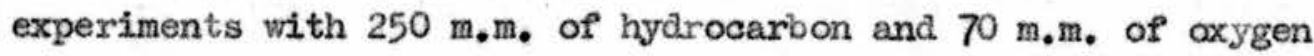
while table No. 61 lists the figures obtained using a mixture of $178 \mathrm{~m}, \mathrm{~m}_{\text {. }}$ of cyclopropane and $200 \mathrm{~m}, \mathrm{~m}$, of axygen at various temperatures. The former table also gives the values of $\boldsymbol{\tau}$ obtained. The graph (No. 31) shows three curves (one relating to table No. 61 and two to table No. 60).

It may be emphasised here that this graph proves the parallelism between the relationships of $\frac{1}{\theta}$ and $\frac{1}{\tau}$.

TABLE MO. 60

\begin{tabular}{|c|c|c|c|c|c|c|}
\hline \multicolumn{3}{|c|}{ Initial $P_{C P}=250$ mos. } & \multicolumn{2}{|c|}{$\mathrm{PO}_{2}=70$ =.m. } & \multicolumn{2}{|c|}{ Vessel B } \\
\hline No. & $T$ & $10^{3}$ & $\theta$ & $\log \frac{100}{\theta}$ & $\tau$ & $\log \frac{100}{\tau}$ \\
\hline 389 & $\begin{array}{l}651 \\
658 \\
665 \\
671 \\
678 \\
683 \\
689 \\
697 \\
702\end{array}$ & $\begin{array}{l}1.536 \\
1.520 \\
1.504 \\
1.490 \\
1.475 \\
10466 \\
1.451 \\
1.453 \\
1.425\end{array}$ & $\begin{array}{l}109 \\
75 \\
55 \\
38 \\
25 \\
17 \cdot 5 \\
13 \cdot 5 \\
8.5 \\
6 \cdot 75\end{array}$ & $\begin{array}{l}0.9626 \\
1 \cdot 1249 \\
1 \cdot 2596 \\
1.4203 \\
1 \cdot 6021 \\
1 \cdot 7569 \\
1.8696 \\
2 \cdot 3705 \\
2 \cdot 1706\end{array}$ & $\begin{array}{l}90 \\
55 \\
40 \\
30 \\
18 \\
12 \cdot 5 \\
9 \\
6 \\
4\end{array}$ & $\begin{array}{l}1 \cdot 0457 \\
1 \cdot 2596 \\
1 \cdot 3979 \\
1 \cdot 5228 \\
1 \cdot 7448 \\
1 \cdot 9031 \\
20045 \\
202219 \\
2 \cdot 3979\end{array}$ \\
\hline
\end{tabular}

TABLE NO. 61 Initial $p_{C P}=178$ m.m. $\quad p_{\mathrm{O}_{2}}=200$ m.n. Vessel B

\begin{tabular}{|c|c|c|c|c|}
\hline Run tio. & $T$ & $10^{3}$ & $\theta$ & $\log \frac{100}{\theta}$ \\
\hline $\begin{array}{l}B 56 \\
857 \\
B 58 \\
849 \\
848 \\
850 \\
852 \\
851 \\
847 \\
8100\end{array}$ & $\begin{array}{l}660 \\
669 \\
673 \\
678 \\
663 \\
6689 \\
692 \\
694 \\
697 \\
701\end{array}$ & $\begin{array}{l}1 \cdot 515 \\
1 \cdot 495 \\
1.406 \\
1.475 \\
1.464 \\
1.453 \\
1 \cdot 445 \\
1 \cdot 441 \\
1.435 \\
1.427\end{array}$ & $\begin{array}{l}87 \\
54 \\
39 \\
33 \\
25 \\
24 \\
15 \\
12 \cdot 5 \\
11 \\
10\end{array}$ & $\begin{array}{l}1 \cdot 0603 \\
1 \cdot 2677 \\
1.4089 \\
1.4814 \\
1.6021 \\
1.6198 \\
1 \cdot 8240 \\
1 \cdot 9031 \\
1 \cdot 9586 \\
2.0000\end{array}$ \\
\hline
\end{tabular}

The activation energies were calculated from the gradients of the three lines, They were found to be $50 \cdot 9,51 \cdot 7$ and $54 \cdot 2$ kcals/mole respectively. It will be noted that these energies are considerably higher than those determined for the maximurn 


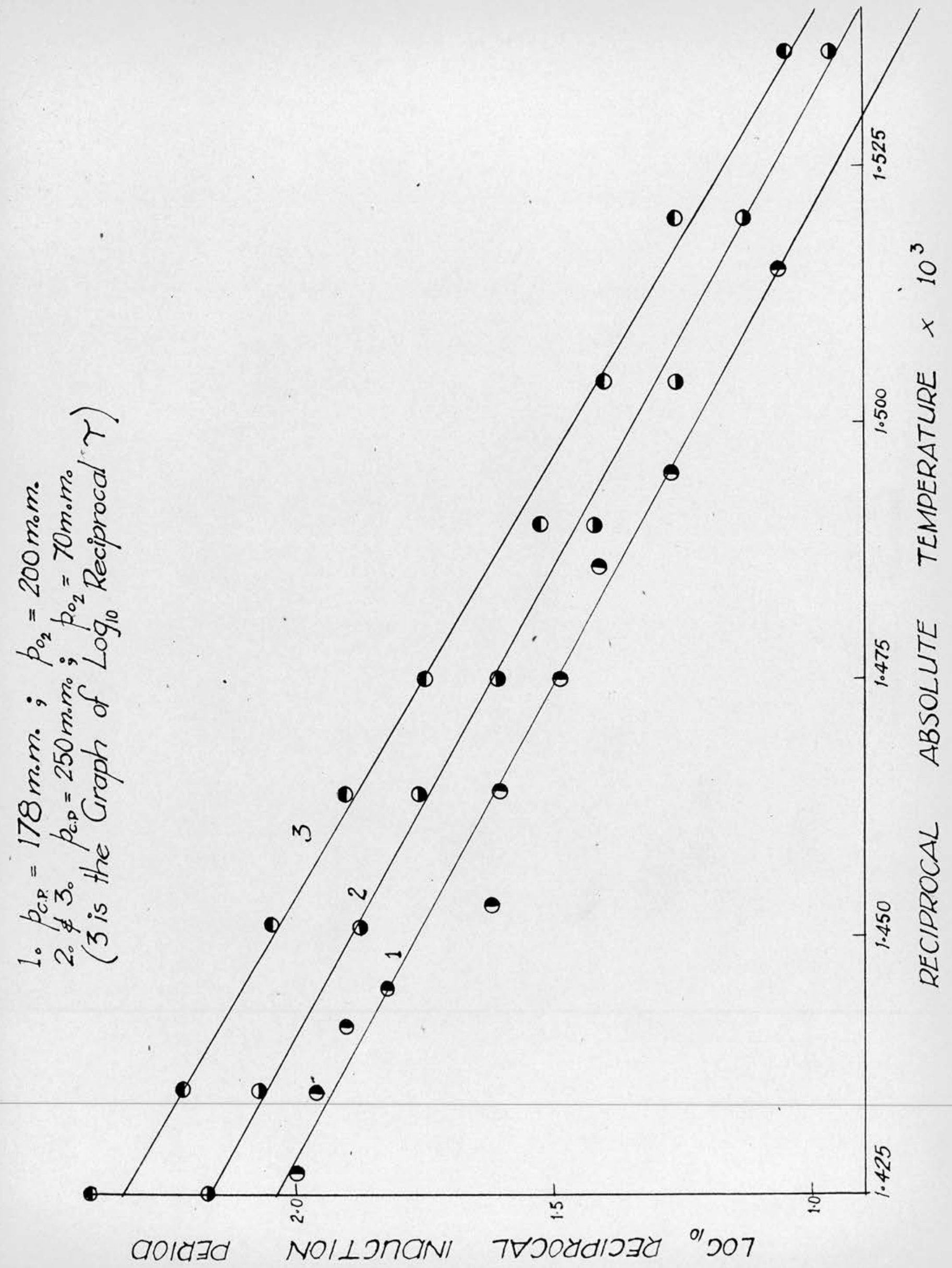


rate and the netmoranoing frotor. Further, there is good agreement betwoen the values found for the energy referring to $\frac{1}{\theta}$ in the two cases of partial pressure. The energies of activation of $\frac{1}{\theta}$ and $\frac{1}{\tau}$ do appeur to aiffer, although not by very mahn,

\section{The Effegt of Adied Natrogen}

In the experiments with added nitrogen it was found that the incuotion period, as well as the rate and net-brenching factor, was not affeated by the edastion of nitragen to the systen, irrespective of whether the operative kinetias were Rate $\alpha p_{\mathrm{CP}^{2}}{ }^{2} \cdot p_{\mathrm{O}_{2}}^{0} \quad$ or Rate $\alpha p_{c p} \cdot p_{\mathrm{O}_{2}}$ - Table No. 62 contains the results obtalned with experinents in vessel $\mathrm{B}$ at $678^{\circ} \mathrm{A}$ uaing $200 \mathrm{~m}$, each of cyolopropane and oxygen while table 10.63 refers to experiments at $701^{\circ} \mathrm{A}$ in the same vessel but if th $178 \mathrm{~m}, \mathrm{~m}$. of hydroceribon and $79 \mathrm{~m}, \mathrm{~m}_{\text {, of }}$ cxygen,

1ABLE 12. 62

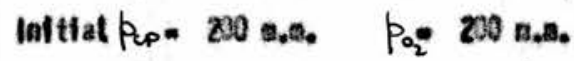
I. $678^{\circ} \mathrm{A}$ Vessel 8
TABL NOS

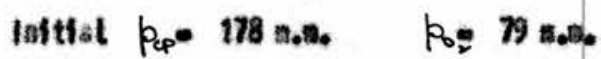
$t=71^{\circ} \mathrm{A}$ Vessel

\begin{tabular}{|c|c|c|c|}
\hline an & $\theta$ & an to. & $p_{\mathrm{N}_{2}}$ \\
\hline $\begin{array}{l}122 \\
3.121 \\
9120\end{array}$ & $\begin{array}{l}32 \\
35 \\
34\end{array}$ & $\begin{array}{l}3105 \\
8103 \\
83104 \\
83\end{array}$ & क्र००3 \\
\hline
\end{tabular}

5. The Bffeat of Adied Hudrogen

The experiments illustrating the influence of added hylrogen upon the reaction have already received scme attention. Unfortunately, the incuation periods measured shoved no trend at all and varied guite haphasardly between 26 and 66 minutes. 
While this is disappointing, it can hardly be described as unexpected since it has always been observed that $\theta$ is very mach more sensitive to changes, particularly of wall conditions, than is $\rho_{\max }$. Thus the completely illogical variation of with the hydrogen treatment and pretreatment can be regarded as further evidence that the hydrogen effect is a wall phenomenon. The results are given in table No, 64 along with the details of the pretreatment in each case.

\section{TABLE NO. 64}

Run No. Pretreatiment

O 3 One hour's vacuation

D 4 Ge hour's evacu tion

D $550 \mathrm{mos}$. of products from run $\mathrm{No} .124$ (incl. $5 \mathrm{~m}$. m. Hz) left in the hot vessel for 37 hours followed by one hour's evacuation

06 One hour's evacuation

D 7 One hur's evacuation

$0850 \mathrm{ag}, \mathrm{m}$, of products from run $\mathrm{No} .07\left(\mathrm{no}_{12}\right.$ ) left in the hot vessel for 67 hours; followed by

0 9 $50 \mathrm{~mm}$. n. of hydrogen heated in the vessel for 40

10 minutes; followed by one hour's evacuation

a 10 Seven hour's evacuation

$\begin{array}{cc}p_{H_{2}} & \theta \\ 50 & 27 \\ & 54 \\ - & 65 \\ - & 26 \\ - & 27 \\ & \\ - & 66 \\ - & 54 \\ - & 47\end{array}$




\section{THE DEPSUDMNCE OF $\Delta p_{\max }$ UPON CONDITIONS}

It should be pointed out that, experimentally, the

pressure change occurring before the attainment of maximum rate is the characteristic of a chain reaction in the gas phase which is least accurately determined. This is so because the maximum rate is never actually determined as such but is calculated from pressure changes over comparitively long time intervals (of the order of 60 seconds). Thus, in the case of a fairly speedy reaction whose maximum rate was $14.5 \mathrm{~m} . \mathrm{m}$. per minute but which maintained a rate of over $13 \mathrm{~m}, \mathrm{~m}$, per minute for a period of say, three minutes, it was very difficult to decide, with any great accuracy, the $\Delta p_{\max }$ although $l_{\max }$ and even $\theta$ might be stated with an accuracy of better than 98\%. Bearing this in mind, the results which are presented here must be regarded as accurate only to a certain extent, becoming less accurate in the case of experiments in which higher maximum rates were observed.

\section{Dependence Upon Initial Oxygen Pressure}

The experiments which furnished the figures in tables Nos. $65,66,67,68,69,70,71$ and 72 have been described elsewhere. Along with each table are given the conditions of cyclopropane pressure and temperature. Graph No. 32 illustrates the linear relationship existing between $\Delta p_{\max }$ and $p_{\mathrm{O}_{2}}$, demonstrates the independence of $\Delta p_{\max }$ upon initial hydrocarbon pressure and. indicates a temperature effect, and, to some extent the existence of a specific factor due to the reaction vessel. 
TABLE NO. 65

$$
\begin{gathered}
\text { Initial } p_{c e}=\underbrace{178=. \times .} \quad T=678^{\circ} \mathrm{A} \\
\text { Vessel } 8
\end{gathered}
$$

Run No.

$\begin{array}{ll}p_{02} & \Delta p_{\max } \\ 50 \cdot 0 & 12 \cdot 8 \\ 89 \cdot 7 & 29 \cdot 4 \\ 101 \cdot 0 & 32 \cdot 3 \\ 108 \cdot 4 & 32 \cdot 2 \\ 149 \cdot 4 & 41 \cdot 8 \\ 200 \cdot 9 & 56 \cdot 2\end{array}$

TABLE พ. 67

$$
\text { Initi } 1 p_{C P}=\begin{aligned}
& 250 \text { a.s. } \\
& \text { Vesset B }
\end{aligned} \quad T=678^{\circ} \mathrm{A}
$$

Run No.

$\begin{array}{ll}B & 35 \\ B & 34 \\ B & 33 \\ B & 38 \\ B & 32 \\ B & 31 \\ B & 36 \\ B & 37\end{array}$

$\mathrm{PO}_{2}$

48.3

$94 \cdot 5$

$109 \cdot 8$

$124 \cdot 7$

$134 \cdot 8$

$180 \cdot 0$

198.8

$250 \cdot 0$
TABLE MO. 66

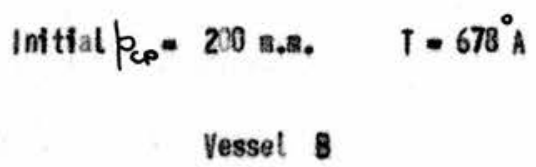

$\begin{array}{lcc}\text { Run 10. } & p_{02} & \Delta p_{\max } \\ \text { B 24 } & 50.0 & 13.3 \\ \text { B 26 } & 70.0 & 19.8 \\ 825 & 100.5 & 26.1 \\ 827 & 130.0 & 36.4 \\ \text { B 30 } & 199.8 & 55 \cdot 7 \\ \text { B 28 } & 248.7 & 70.0\end{array}$

TABLE MO. 68

$$
\begin{aligned}
& \text { Initial } p_{\text {ep }}=300 \text { m. . I. } \quad T=678^{\circ} \mathrm{A} \\
& \text { Vessel B }
\end{aligned}
$$

\section{Run tho.}

B 67

862

B 68

870

B 71

B 72

B 64

366

$p_{0,2}$

49.5

$97 \cdot 4$

$101 \cdot 7$

$147 \cdot 2$

$149 \cdot 7$

$178 \cdot 3$

$198 \cdot 0$

$252 \cdot 7$<smiles>[194In]</smiles>

$14 \cdot 3$

$29 \cdot 8$

30.9

$39 \cdot 8$

40.9

48.7

$56 \cdot 0$

$70 \cdot 7$

TABLE No. 69

\section{TABLE HO. 70}
Initial ke $=250$..3. $\quad$ T. $651^{\circ} \mathrm{A}$
Vessel B

$$
\text { Initial } p_{\text {CD }}=\underset{\text { Vessel B }}{ } 178 \text { m.a. } \quad T=701^{\circ} \mathrm{A}
$$

Run Ho.

$B 95$
$B 94$
$B 93$
892
891
$B 90$

895

B 93

392

B 90
$\mathrm{Po}_{\mathrm{O}_{2}}$

1000

69.9

99.0

$134 \cdot 2$

180.4

233.7
$\Delta p_{\max }$

13.0

$17 \cdot 6$

$24 \cdot 7$

33.1

$42 \cdot 0$

$55 \cdot 3$
Run Ho.

6 97

B106

B 98

B 99

8100 $\mathrm{po}_{2}$

50.7

$78 \cdot 8$

98.6

$151 \cdot 4$

200.3
$\Delta p_{\max }$

13.1

$26 \cdot 2$

32.3

$56 \bullet 4$

$69 \cdot 1$ 
TABLE MO. 7

laitial $p_{C P}=200$ a.m. $\quad T=678^{\circ} \mathrm{A}$

Vessel A

Run No.

A 41

A 42

A 37

A 40

A 38

A 39
$\mathrm{PO}_{2}$

$52 \cdot 1$

84.7

106.5

150.9

$189 \cdot 8$

$234 * 8$
$\mathrm{O}_{2}$

$\Delta p_{\max }$

$14 \cdot 0$

$22 \cdot 7$

26.0

$39 \cdot 0$

50.1

$63 \cdot 1$
TABLE N. 72

Initfal $p_{C P}=100 \mathrm{a}$ a.m. $T \cdot 701^{\circ} \mathrm{A}$

Vessel 0

Run No.
$P_{\mathrm{O}_{2}}$

49.0

$100 \cdot 5$

$144 \cdot 5$

$186 \cdot 3$

$240 \cdot 0$

$298 \cdot 8$

$\Delta p_{\max }$

$11 \cdot 1$

$17 \cdot 3$

$25 \cdot 2$

$32 \cdot 4$

4000

16

014

54.5

2. Dependence Upon Initial Cyclopropane Pressure

It will be evident from the fact that the same line (graph No. 32) is the best line for the points given in tables Nos, $65,66,67$ and 68 , that the change of pressure occurring before the attainment of the maximum rate is not at all dependent upon the initial oyclopropane pressure. 


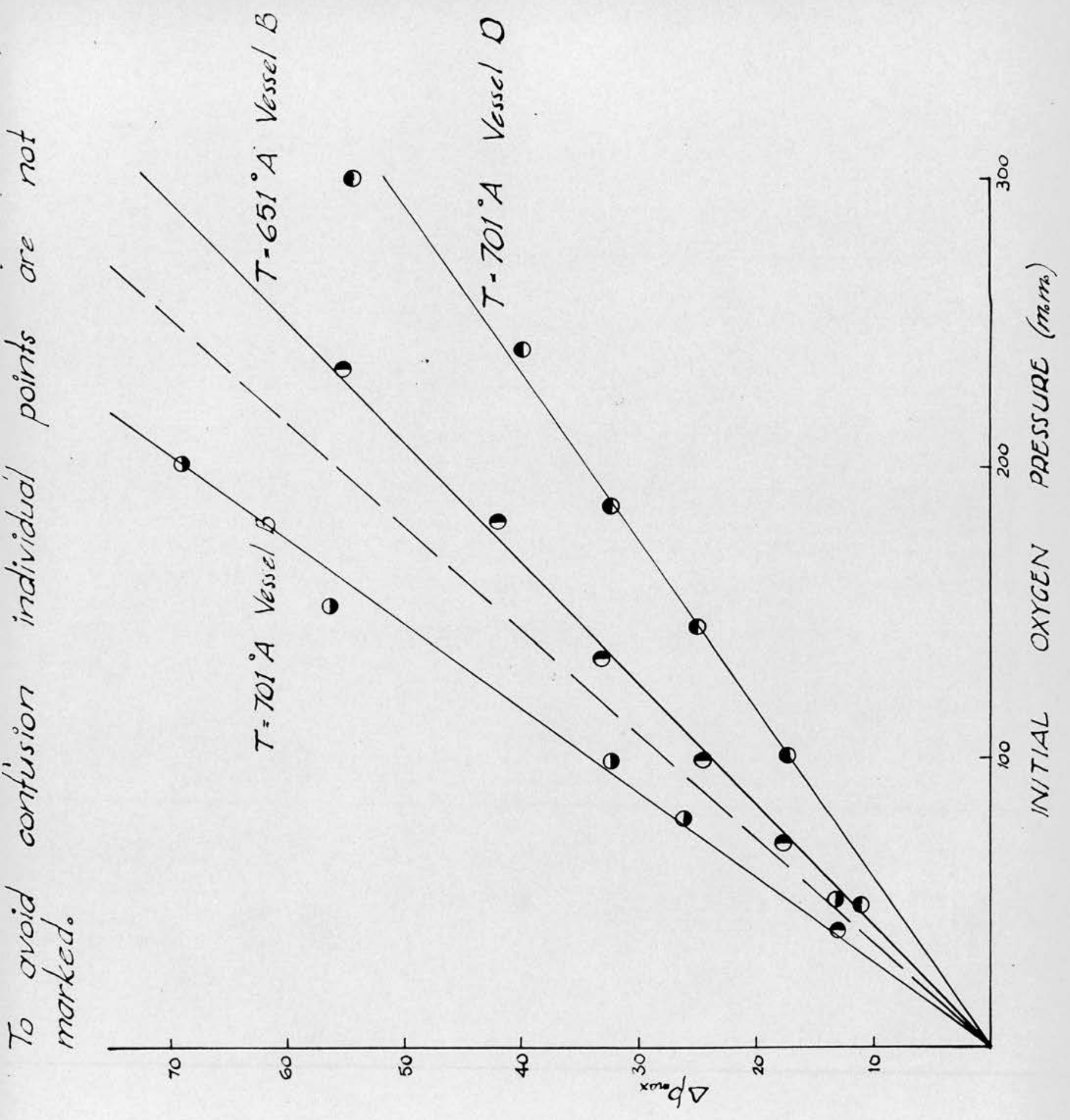




\section{THE DEPFANDENGE OF $\triangle p_{\infty}$ UPON CONDTITONS}

The total pressure change occurring during the oxidation is a very important characteristic of the reaction since it may indicate the relative predominance of various competing overall reactions, Since, in nearly every experiment performed, there was a stoichionetric excess of cyclopropane it was not surprising to find that $\Delta p_{\infty}$ was not at all dependent upon the initial hydrocarbon pressure.

Tables Nos, 73, 74, 75 and 76 and the graph No. 33, however, show that $\Delta p_{\infty}$ is direotly proportional to the inftial axygen pressure, the constant of proportionality being approximately 0.5. Tables Nos. 77 and 78 contain data obtained at $651^{\circ} \mathrm{A}$ and $701^{\circ}$ A respectively and these figures are also plotted on the graph (No. 33).

TABLE. N. 73

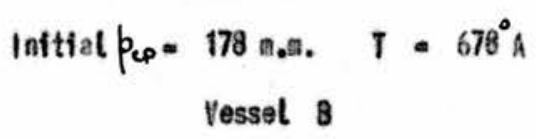
Run No.

B 43

B 42

B 44

B 39

B 41

B 49<smiles>[PbH]</smiles>
$50 \cdot 0$

$89 \cdot 7$

$101 \cdot 0$

$108 \cdot 4$

$149 \cdot 4$

209.9

TABLE HO. 75

Initial $p_{C p}=250$ a. ali. $T=678^{\circ} \mathrm{A}$

Vessel $B$

Run H.

B 35

B 34

B 33

B 38

B 32

B 31

B 36

B 37
$\mathrm{PO}_{2}$

$48 \cdot 3$

$94 \cdot 5$

109.8

$124 \cdot 7$

$134 \times 8$

180.0

198.8

$250 \cdot 0$
$\Delta p_{\infty}$

$22 \cdot 9$

46.0

$54 \cdot 2$

$62 \cdot 4$

$68 \cdot 5$

$91 \cdot 0$

$100 \cdot 2$

$125 \cdot 3$
$\Delta p_{\infty}$

$24 \cdot 9$

$44 \cdot 9$

50.5

$54 \cdot 2$

$74 \cdot 8$

$102 \cdot 1$

TABLE 19.74

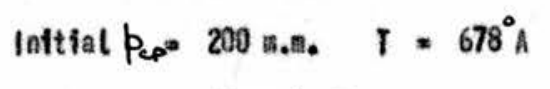

Vesset 8

Run No.

$\mathrm{po}_{2}$

$\Delta p_{\infty}$

$\begin{array}{ll}B & 24 \\ 3 & 26 \\ 8 & 25 \\ 8 & 27 \\ B & 30 \\ B & 28\end{array}$

$50 \cdot 0$

$70 \cdot 0$

$100 \cdot 5$

130. 3

$199 \cdot 8$

$248 \cdot 7$

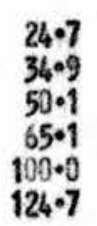

TABLE ND. 76

Initial $p_{c p}=300$ mos. T - $678^{\circ} \mathrm{A}$

Vessel B

Pun No.
B 67
B 62
B 68
B 70
B 71
B 72
B 64
B 66

po

$\Delta p_{\infty}$

B 66
49.5

$97 \% 4$

$101 \cdot 7$

$147 \cdot 2$
$149 \cdot 7$

178.3

198.0

$252 \cdot 7$
24,1

48.4

50.7

74.2

89.2

93.5

$125 \cdot 4$ 
TABLE HO. 71

$$
\begin{gathered}
\text { Initial Pes }=250 \mathrm{mom}, \quad T=651^{\circ} \mathrm{A} \\
\text { Vessel B }
\end{gathered}
$$

$\begin{array}{rrr}\text { Run Ho. } & p_{0_{2}} & \Delta p_{\infty} \\ \text { B } 95 & 40.0 & 19 \cdot 7 \\ 894 & 69.9 & 34.0 \\ 893 & 99 \cdot 0 & 49.5 \\ \text { B } 92 & 134.0 & 67.1 \\ \text { B } 91 & 180.4 & 86.4 \\ \text { B } 90 & 233.7 & 116.0\end{array}$

TABLE NO. 78

$$
\text { Initial } p_{c p}=178 \text { m.m. } \quad T=701^{\circ} \mathrm{A}
$$

Vesset 8

$$
\begin{aligned}
& \text { Run Ho. } \\
& 897 \\
& 8106 \\
& 898 \\
& 899 \\
& \text { B100 }
\end{aligned}
$$

The variation of $\Delta p_{\infty}$ with change of oxygen pressure in vessel $\mathrm{A}$ is recorded in the following table (No. 79) and the data have been plotted on graph No. 33 .

TABLE พ9. 79

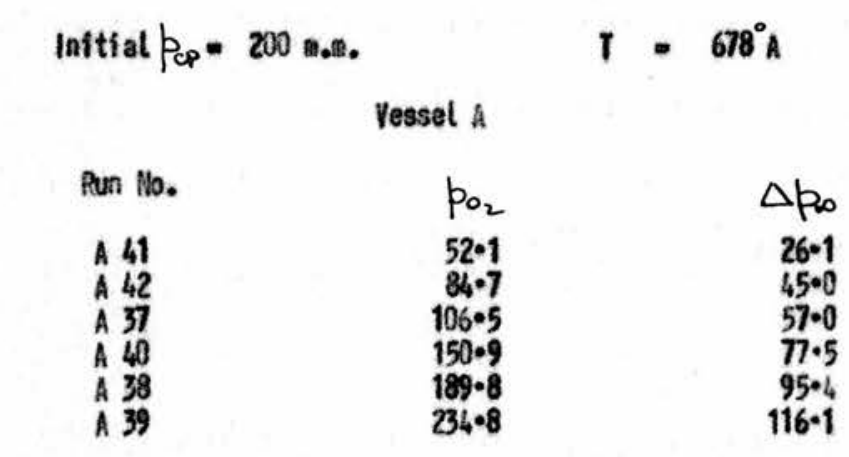

On graph No. 33 only one line has been dravn and no points are indicated. This is to avoid the confusion which would arise if it were attempted to mark each individual point. Suffice to say that $\Delta p_{\infty}$ was independent of the initial cyclopropane pressure, proportional to the initial oxygen pressure, was largely independent of the vessel but showed 


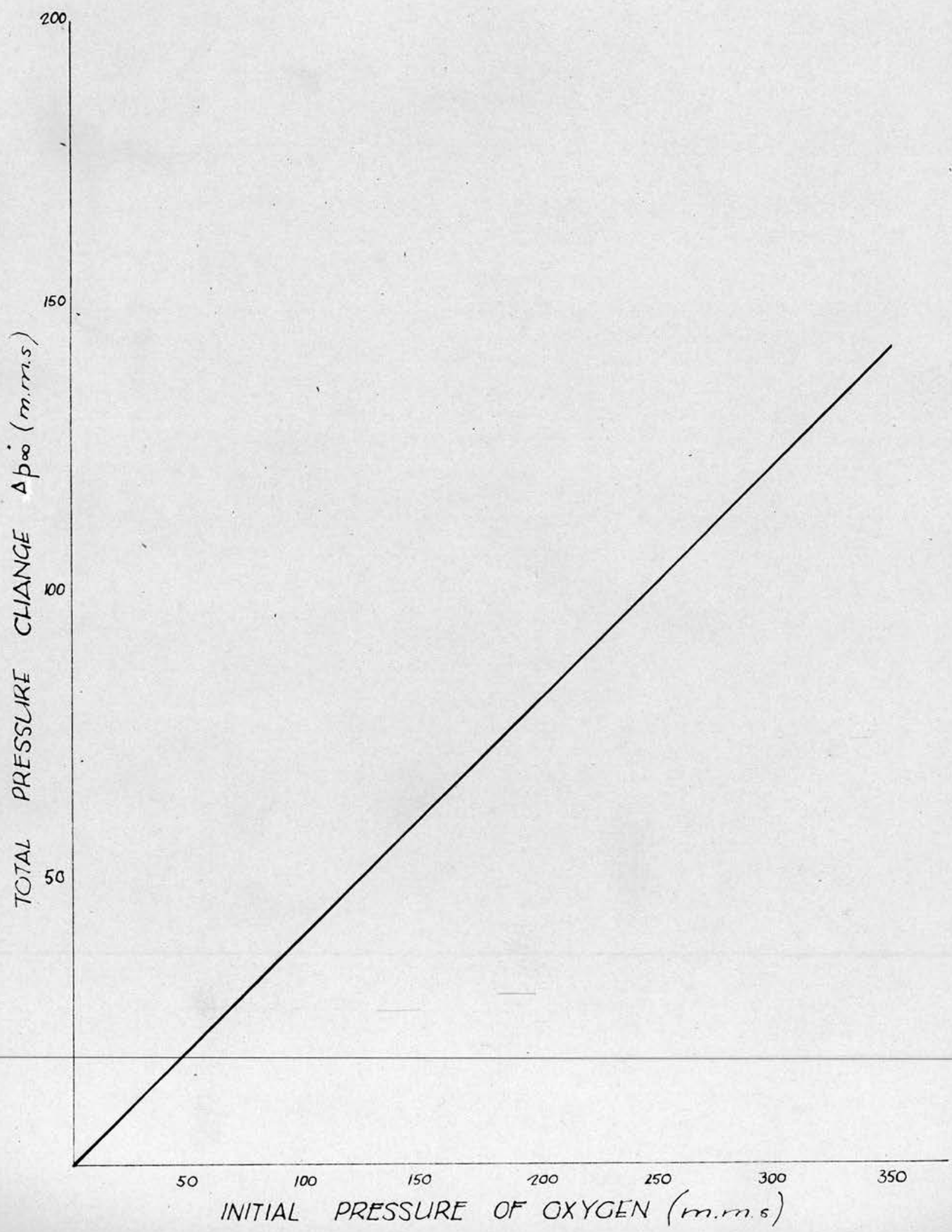


$-85-$

A N A I I IS 
VARTATION OF THE CHEMITCAL COMPOSITION OF THE REACTION MTXTURE

The variation of the chemical composition of the mixture during reaction was followed by stopping the reaction after various times and anslysing for unchanged cyclopropane and oxygen and for axides of carbon, water, formaldehyde, hydrogen and hydrocarbons. Due to the previously observed variance in induction times, the reaction was stopped when certain noted pressure changes had occurred. The stopping of the reaction was effected by opening the tap at the reaction vessel (when the pressure had increased by the desired amount) so that the gases expanded into the comparatively large space between the taps $\mathrm{A}$ and $\mathrm{F}$, the $\operatorname{trap} \mathrm{J}$ being maintained at $-180^{\circ} \mathrm{C}$ by liquid oxygen. After a few minutes, when equilibrium had been attained, the tap $K$ was opened and the permanent gases were collected over mercury by use of the Toepler pump. Fractionation of the gases was achieved as described previously and the condensible substances were analysed for water or formaldehyde as indicated earlier. Having repeated this operation at several points along the pressure-time curve the results were tabulated and plotted together on a graph against time (the time co-ordinates being obtained by reference to the pressure-time curve and from a knowledge of the pressure change which had occurred when the analysis was performed).

In view of the existence of two regions kinetically rather distinct this technique was applied to two typical experiments, one where the operative rate expression was Rate $\alpha p_{C p}{ }^{2}$ and the other where the relationship Rate $\alpha p_{\mathrm{cp}} \cdot p_{\mathrm{O}_{2}}$ held. The data in table No. 80 refer to the former experiment and are 
plotted on the graph (No. 34).

TABLE HO. 80 COAPSSITION OF GASES IN THE REACTION VESSEL.

Initíal cyclopropane pressure - initial axygen pressure - $200 \mathrm{mom}$. T $-678^{\circ} \mathrm{A}$

Run No. E10 E11 E12 E9 E54 E13 E 8

$\begin{array}{llllllll}\text { Time of extraction (mins) } & 16 & 25 \cdot 05 & 31 \cdot 8 & 34 \cdot 1 & 36 \cdot 14 & 40 \cdot 16 & 46\end{array}$

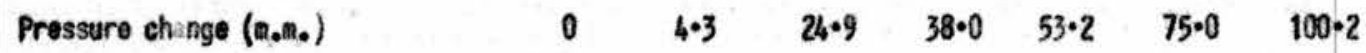

$\begin{array}{llllllll}\text { Cyclopropane (a.m.) } & 197.6 & 194.6 & 182 \cdot 3 & 178.5 & 172 \cdot 1 & 155 \cdot 9 & 140 \cdot 7\end{array}$

$\begin{array}{lllllll}\text { Oxygen (m.m.) (including nitrogen) } 197 \cdot 4,188.9 & 158.1 & 128.1 & 103.0 & 64.5 & 20.9\end{array}$

$\begin{array}{llllllll}\text { Carbon monoxide (*.4.) } & 0.9 & 6.4 & 32.5 & 55.5 & 75.1 & 106.5 & 142.8\end{array}$

$\begin{array}{llllllll}\text { Carbon dioxide (m.m.) } & 0.0 & 0.0 & 1.6 & 3.5 & 7.2 & 12.6 & 17.8\end{array}$

$\begin{array}{llllllll}\text { Vater (momol } & 0.9 & 604 & 34.1 & 59.0 & 82.3 & 119.1 & 160.6\end{array}$

$\begin{array}{llllllll}\text { Hydrogen }\left(\mathrm{w}_{0} . \mathrm{m}_{*}\right) & 0.0 & 0.6 & 1.1 & 2.5 & 1.5 & 2.0 & 2.3\end{array}$

$\begin{array}{llllllll}\text { Wethane (mom.) } & 0.0 & 0.0 & 1.6 & 1.9 & 0.7 & 1.4 & 2.9\end{array}$

$\begin{array}{llllllll}\text { Formaldehyde (n.m.) } & 0.1 & 0.3 & 4.6 & 5.1 & 5.6 & 4.3 & 1.5\end{array}$

The next table (No, 81) is a record of the variation of the composition of the reaction mixture at $701^{\circ} \mathrm{A}$ with an initial hydrocarbon pressure of $200 \mathrm{~m}, \mathrm{~m}_{\text {, and }} 100 \mathrm{~m}, \mathrm{~m}$. of coxygen. The results are plotted on graph No. 35.

TABLE No. 81. COAPSBITION Of gaSES IN THE RE CTION VESSEL Initial cyclopropane pressure - $200 \mathrm{mon}$. Initial oxygen pressure = 100 a.m. $T$ - $701^{\circ} \mathrm{A}$ $\begin{array}{lllllllll}\text { Run No. } & E 24 & E 23 & E 21 & E 19 & E 18 & E 17 & E 16 & E 15\end{array}$

$\begin{array}{lllllllll}\text { Tiae of extraction (min.) } & 7.0 & 10.42 & 14.05 & 14.95 & 15.48 & 15.77 & 16.58 & 17.72\end{array}$ $\begin{array}{lllllllll}\text { Pressure change (n.m.) } & 0 & 1.0 & 9.4 & 18.0 & 25.0 & 28.7 & 39.7 & 49.9\end{array}$ $\begin{array}{lllllllll}\text { Cyclopropane (mo.t.) } & 198 \cdot 2 & 193 \cdot 9 & 189 \cdot 4 & 184 \cdot 1 & 179 \cdot 9 & 180 \cdot 7 & 173 \cdot 0 & 164 \cdot 0\end{array}$ $\begin{array}{lllllllll}\text { axygen (n.m.) } & 99.5 & 96.9 & 82.6 & 67 \cdot 2 & 53.5 & 46.5 & 25.5 & 11 \cdot 2\end{array}$ $\begin{array}{lllllllll}\text { Carbon Monoxide (m.n.) } & 0.7 & 3.1 & 14.1 & 24 \cdot 1 & 35.8 & 39.5 & 55.5 & 67.9\end{array}$ $\begin{array}{lllllllll}\text { Carban oisxide (a.0.) } & 0.0 & 0.0 & 0.0 & 0.9 & 2.6 & 4.2 & 6.3 & 9.9\end{array}$

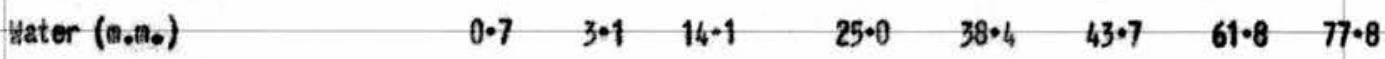

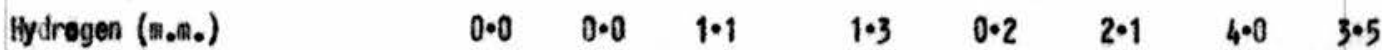
$\begin{array}{lllllllll}\text { Hethane (a.m.) } & 0.0 & 0.0 & 0.6 & 0.0 & 0.7 & 0.0 & 2.1 & 2.5\end{array}$ $\begin{array}{lllllllll}\text { Fornaldehydo (mom.) } & 0.0 & 1.0 & 4.75 & 6.0 & 7.5 & 5.8 & 3.9 & 1.8\end{array}$ 
ARIATION OF COMPOSITION OF GASES DLIRING REACTION (T-701:A)

C-cyclopropane $\square$ - carbon monoxide - total pressure

- - oxygen $\Delta$ - carbon diaxide $\nabla$-formaldehyde $\times 10$

-) - vater - hydrogen + methane
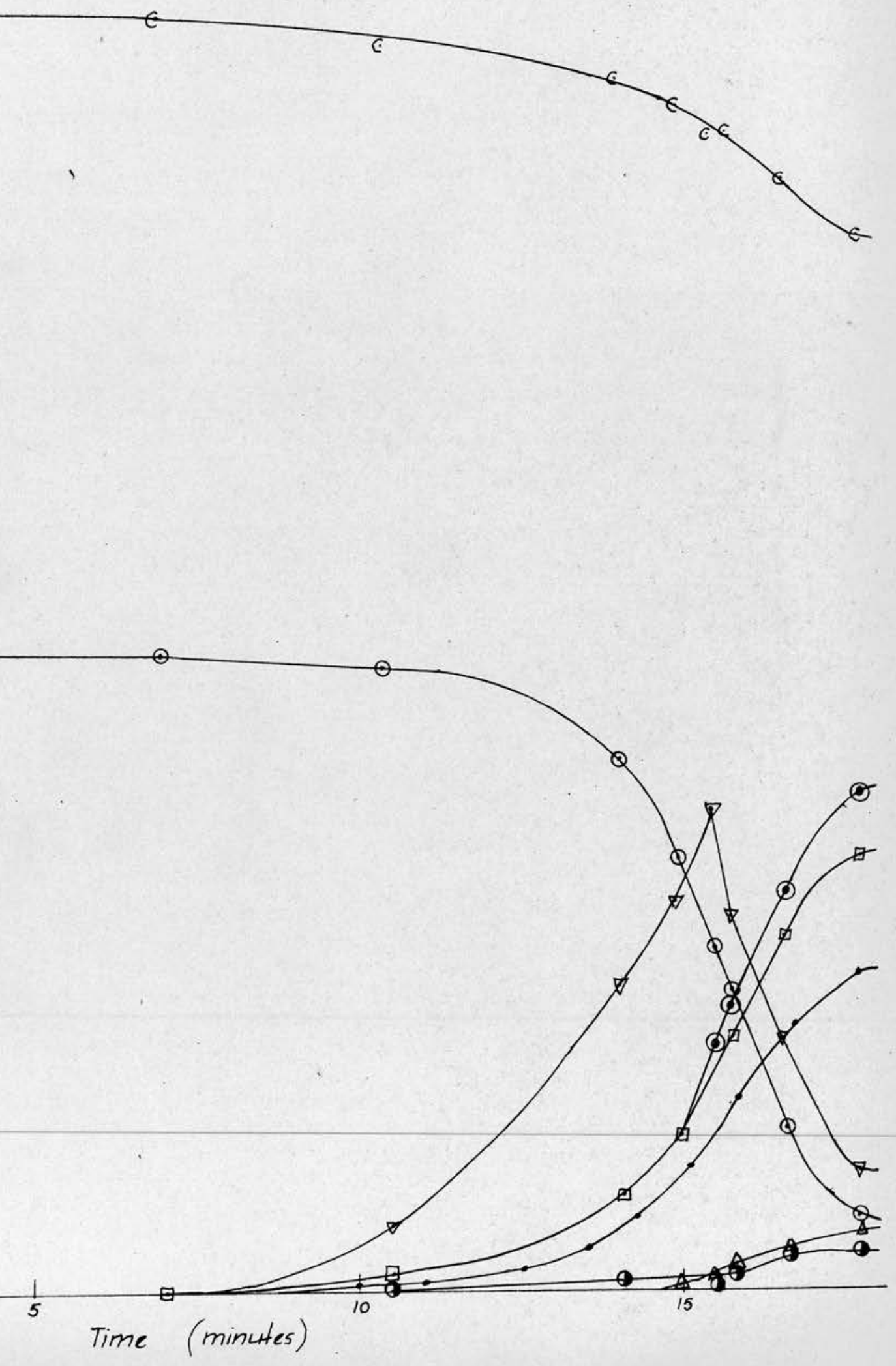
In work such as this it is necessary to attempt to show that the products of reaction are quantitatively equivalent to the reactants consumed. In each analysis quoted the criteria of equivalence have been (1) that the output volume agreed to within $5 \%$ with the volume anticipated from a knowledge of the pressure in the vessel at the moment of extraction, and (2) that the car on, hydrogen and oxygen found in the output gases each agreed to within $5 \%$ with the amounts of these elements in the original mixture. A typical input-output balance is given below for run No. B43 (table No, 80).

Pressure at time of extraction $=475 \cdot 0 \mathrm{~m} . \mathrm{m}$. Pressure by sum of constituent detemined pressures $=466 \cdot 3 \mathrm{~m} \cdot \mathrm{m}$. i.e. loss $=8.7 \mathrm{~m} . \mathrm{m}_{0} \quad=1.83 \%$

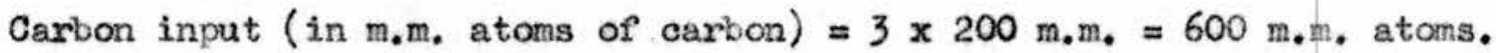
Carbon output $=3 \times 155 \cdot 9+106 \cdot 5+12 \cdot 6+1 \cdot 4+4 \cdot 3=592 \cdot 5 \mathrm{~m}, \mathrm{~m}$. atoms. Loss of carion $=7.5 \mathrm{~m} \cdot \mathrm{m}$. atorns $=1.25 \%$

Hydrogen input $=6 \times 200 \mathrm{~m}, \mathrm{~m}_{0}=1,200 \mathrm{~m}, \mathrm{~m}_{0}$ atons Hydrogen output $=6 \times 155 \cdot 9+2 \times 119 \cdot 1+2 \times 2 \cdot 0+4 \times 1 \cdot 4+2 \times 4 \cdot 3=$ $1,191 \cdot 8 \mathrm{~m} \cdot \mathrm{m}_{\text {. atoms. }}$

Loss of hydrogen $=8.2 \mathrm{~m} \cdot \mathrm{m}$, atoms $=0.68 \%$

Cxygen input $=2 \times 200 \mathrm{~m} \cdot \mathrm{m}_{0}=400 \mathrm{~m} \cdot \mathrm{m} \cdot$ atoms

Oxygen output $=2 \times 64 \cdot 5+106 \cdot 5+2 \times 12 \cdot 6+119 \cdot 1+4 \cdot 3=384 \cdot 1 \mathrm{~m}_{\bullet} \mathrm{m}_{\bullet}$ atoms.

Loss of oxygen $=15.9 \mathrm{~m} \cdot \mathrm{m}_{\cdot}$ atcms $=3.98 \%$

Balances were not always so accurate as this but analyses were disregarded if one of the losses exceeded $5 \%$. When one considers this fact in conjunction with the report of the negative results in the qualitative analysis of accumulated 
samples of the condensible products ( $\left.v_{\cdot} v_{\cdot}\right)$ it becomes evident that if any products, apart from those shown in tables Nos, 80 and 81 , are formed in the reation they must be formed in minute quantities indeed.

Several remarks may be made at this stage, with regard to these products, Firstly, there is the striking fact that there is no significant difference in the products or their rate of formation in the two cases; that is, although the two rates of reaction are governed by different kinetic relationships the products are essentially the same, Seconaly it vill be observed that the nature and relative amounts of the major products are very similar to those noted in the slow combustion of many other hydrocarbons. The data in the taibles can be used to justify the belief that the rate of pressure increase is a true measure of the rate of reaction. The latter may certainly be measured by the rate of removal of the reactants and by the rate of formation of the main products. The graphs Nos, 36 and 37 illustrate the linear dependence of changes of cyclopropane, oxygen and corbon monoxide concentration upon changes of total pressure. The first of these graphs was constructed from the data in table No. 82 while the second refers to the experiments reported in table No. 83 with initial oxygen pressure $=100 \mathrm{~m}, \mathrm{~m}_{\text {, }}$ at $701^{\circ} \mathrm{A}$.

\section{TABLE NO. 82}

Run Ho. E10 E11 E12 E9 E54 E13 E18

Time of extraction Increase in total pressure $\begin{array}{lllllll}16 & 25 \cdot 05 & 31 \cdot 8 & 34 \cdot 1 & 36 \cdot 14 & 40 \cdot 16 & 46\end{array}$ Decrease in cyclopropane pressure Decrease in oxygen pressure Increase in carbon asmoxide pressure

$\begin{array}{ccccccc}16 & 25 \cdot 05 & 31 \cdot 8 & 34 \cdot 1 & 36 \cdot 14 & 40 \cdot 16 & 46 \\ 0 & 4 \cdot 3 & 24 \cdot 9 & 38 \cdot 0 & 53 \cdot 2 & 75 \cdot 0 & 100 \cdot 2 \\ 2.4 & 5 \cdot 4 & 17 \cdot 7 & 21 \cdot 5 & 27 \cdot 9 & 44 \cdot 1 & 59 \cdot 3 \\ 6.2 & 11 \cdot 1 & 41 \cdot 9 & 71 \cdot 9 & 97 \cdot 0 & 135 \cdot 5 & 179 \cdot 1 \\ 0.9 & 6 \cdot 4 & 32 \cdot 5 & 55 \cdot 5 & 75 \cdot 1 & 106 \cdot 5 & 142 \cdot 8\end{array}$


CRAPH N:'S $36 \notin 37$
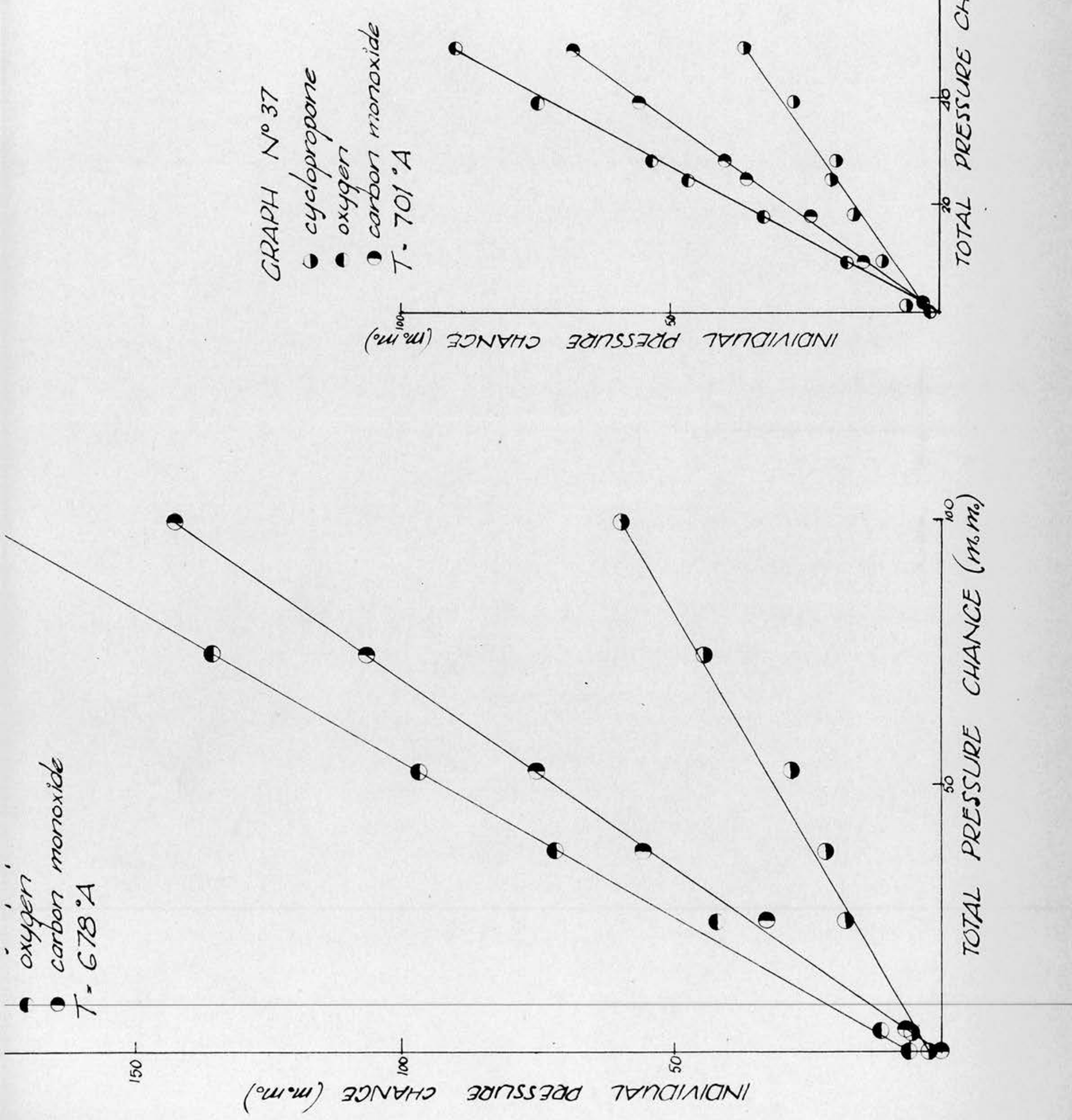
TABLE NO. 83

Run No. E24 E23 E21 E19 E18 E17 E16 E15

$\begin{array}{lllllllll}\text { Time of extraction } & 7 & 10 \cdot 42 & 14 \cdot 05 & 14 \cdot 95 & 15 \cdot 48 & 15 \cdot 77 & 16 \cdot 58 & 17 \cdot 72\end{array}$

$\begin{array}{lllllllll}\text { Increase in total pressure } & 0 & 1 & 9 \cdot 4 & 18.0 & 25.0 & 28.7 & 39.7 & 49.9\end{array}$

$\begin{array}{lllllllllll}\text { Decrese in cyclopropane pressure } & 1.8 & 6.1 & 10.6 & 15.9 & 20.1 & 19.3 & 27.0 & 36.0\end{array}$

$\begin{array}{lllllllll}\text { Decrease in oxygen pressure } & 0.5 & 3.1 & 17.4 & 32.8 & 46.5 & 53.5 & 74.5 & 89.8\end{array}$

$\begin{array}{llllllllllllll}\text { Increase in carbon monoxide pressure } & 0.7 & 3.1 & 14.1 & 24.1 & 35.8 & 39.5 & 55.5 & 67.9\end{array}$

In consequence of these straight line graphs we mey conclude that $\Delta p_{t} \alpha-\left(\Delta p_{c p}\right)_{t} \alpha-\left(\Delta p_{O_{2}}\right)_{t} \alpha\left(\Delta p_{c o}\right)_{t}$

$$
\therefore \frac{d(\Delta p)}{d t} \alpha \frac{-d\left(\Delta p_{c p}\right)}{d t} \alpha \frac{-d\left(\Delta p_{o_{2}}\right)}{d t} \alpha \frac{d\left(\Delta p_{c_{0}}\right)}{d t}
$$

Perhaps the most important feature of the analytical results is the way in which the formaldehyde concentration varies during an experiment. It is seen to increase to a maximum at about the time of the attainment of maximum rate and then decreases rapialy leaving, however, some fairly low pressure of formaldehyde at the end of the pressure increase. The graph (No. 38) compares the variation of formaldehyde pressure during the reaction of $200 \mathrm{~m} \cdot \mathrm{m}_{\text {. }}$ of cyclopropane and $200 \mathrm{~m} \cdot \mathrm{m}_{\text {. }}$ of oxygen at $678^{\circ} \mathrm{A}$ with the variation of the rate of reaction with time. The line shows the variation of rate with time and the points refer to the pressures of formaldehyde determined at the times indicated. These pressures of formaldehyde have been adjusted by multiplying them all by a factor of $1 \cdot 16$. The pressures of formaldehyde plotted are those given in table No. 80. This procedure was repeated with the results of the experiments which are in table No. 81 (i.e. with $200 \mathrm{~m} . \mathrm{m}$. of hydrocarbon and $100 \mathrm{~m} . \mathrm{m}$. of oxygen at $701^{\circ} \mathrm{A}$ ), the appropriate multiplication 
factor, in this case, being $1 \cdot 77$. The correspondence between formaldehyde pressure and rate under these conditions is shown on graph No. 39.

It will be noted that, particularly in the former case (graph No. 38), a definite relationship seems to exist between instantaneous rate and formaldehyde pressure. The parallelism is not so marked after the time of attainment of maximum rate (since there was always some residual formaldehyde after the reaction had ceased) or in the very early stages, but is very striking over a considerable portion of the reaction, up to and including the time of maximum rate and formaldehyde pressure. Since formaldehyde appeared to be a highly important intermediate in the reaction the variation of its pressure during the slow combustion was considered in more detail. It seemed of interest to investigate the manner in wich the maximum formaldehyde pressure observed in an experiment depended upon conditions of pressure and temperature.

\section{Variation of the initial oxygen pressure}

A series of experiments was conducted in which an initial cyclopropane pressure of $200 \mathrm{~m}, \mathrm{~m}$. was always taken and in which the temperature was kept at $701^{\circ} \mathrm{A}$. From a knowledge of the pressure change occurring before the attainment of the maximum rate, it was possible to extract the gases, in the usual way, at that point in each experiment. The permanent gases were pumped away by the Toepler pump and a definite volume of water was pipetted into the cold trap. The Dewar flask was then removed and the contents allowed to warm up. One $\mathrm{ml}$. of the 
Comparison rate with formaldehyde pressure $p_{c p}=200 \mathrm{~mm}$. por $T=678^{\circ} \mathrm{A}$

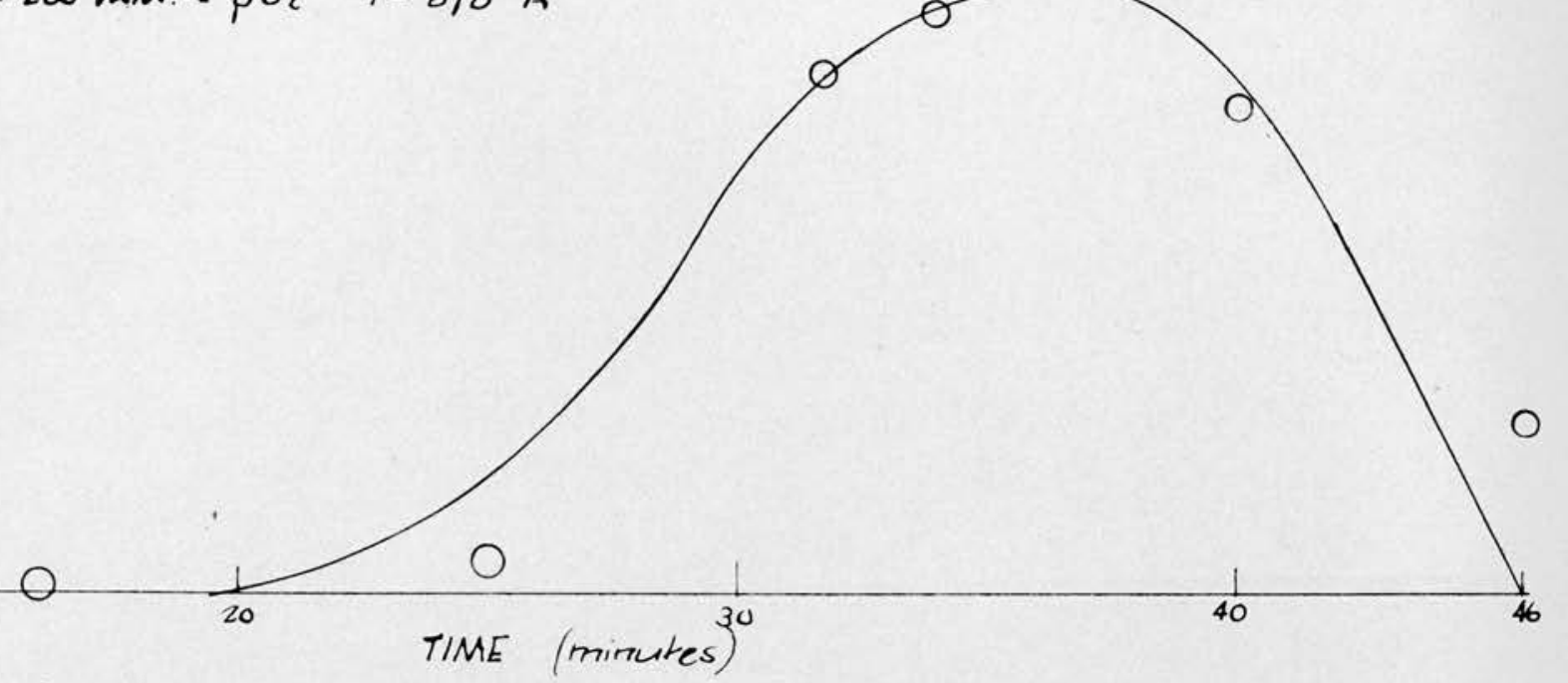

Comparison of rate with formaldehyde presserre $P_{C P}=200 \mathrm{~mm} \quad P_{02}=100 \mathrm{~mm}$. T. $701^{\circ} \mathrm{A}$ 
resultant solution was analysed for formaldehyde as described. earlier. The results are embodied in table No. 84 winile table No. 85 gives the variation of maximum rate with oxygen pressure under the same conditions of temperature and hydrocarion pressure. The data in the two tables are plotted together on the same paper (graph No. 40)

\section{TABLE W. \&}

Run tho.

E 28

ย 27

E 31

E 20

E 26

E 29

E 30

Run No.

E 35

E 33

E 32

E 31

E 34
Initial pressure of oxygen

28

50

70

102

150

200

250

TABLE MO. 85

Initial pressure of oxygen

50

100

152

200

254
Max. pressure of formaldehyde

$3 \cdot 29$

$4 \cdot 48$

$6 \cdot 28$

$7 \cdot 49$

$7 \cdot 12$

$7 \cdot 12$

6.94

The graph shows that both rate and formaldehyde pressure become independent of axygen pressure as the latter is increased but that the two curves could not be made to be coincident by the introduction of a suitable factor. The critical oxygen pressure at which the rate loses its dependence upon oxygen pressure is about $180 \mathrm{~m} \cdot \mathrm{m}$. whereas the critical cxygen pressure for formaldehyde dependence is much lower, namely about $80 \mathrm{~m} . \mathrm{m}$. 
GRAPH NOLO.

Variation of the maximum formaldehyde pressure with the initial oxygen pressure

Initial cyclopropane pressure - $200 \mathrm{~mm}$.

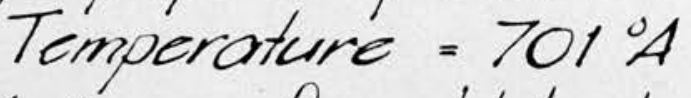

(a) Maximum formaldehyde pressure

(b) Maximum rate

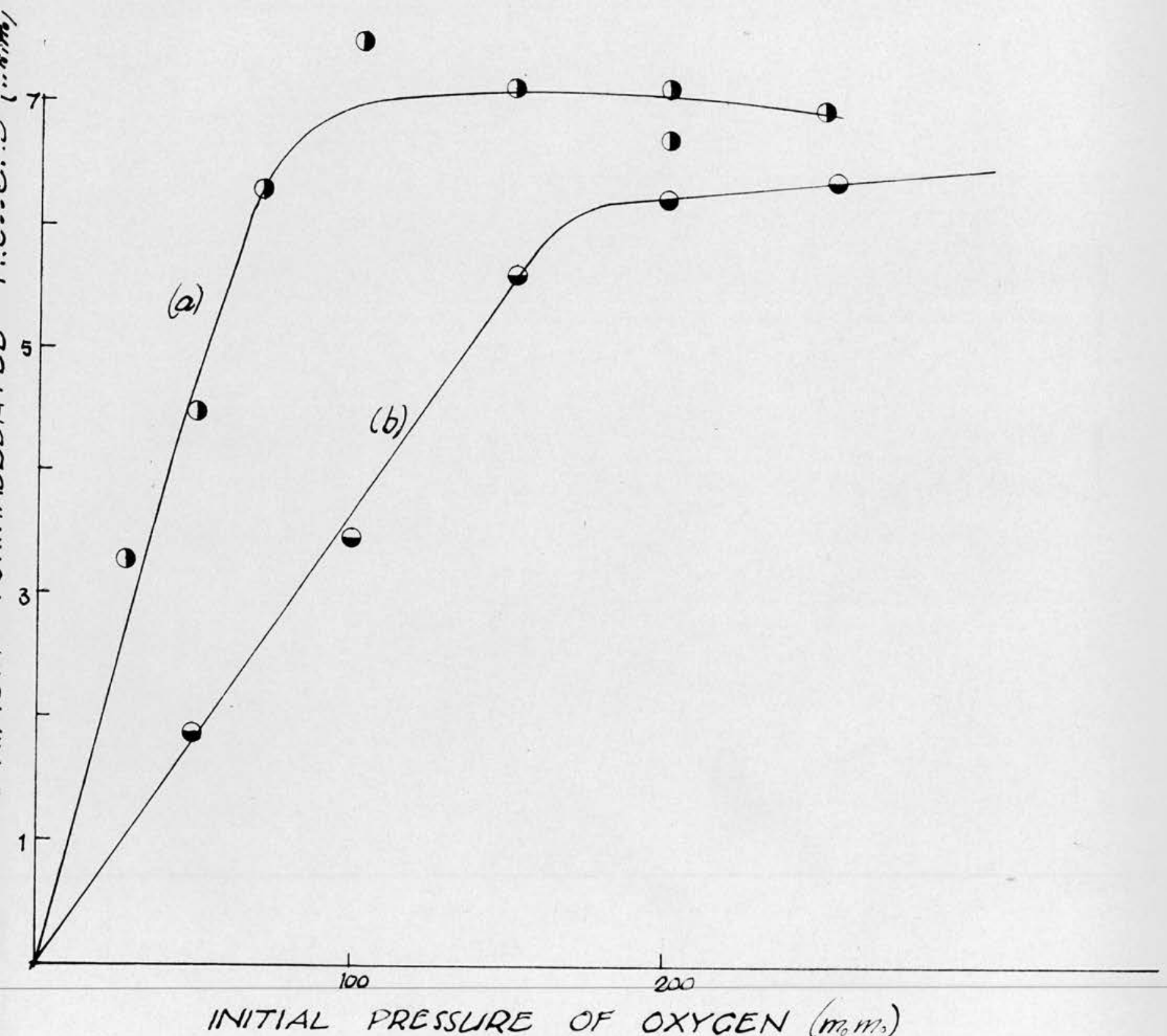

INITIAL PRESSLRE OF OXYGEN (mom) 
2. Variation of the initial cyclopropane pressure.

Two sets of experiments were performed under this heading:-

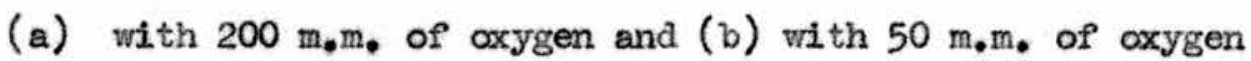

(temperature $=701^{\circ} \mathrm{A}$ in each case). The results are given in the following two tables and are plotted together on graph No. 41.

TABLE NO. 86

Initfal oxygen pressure - $200 \mathrm{mon}$. Temperature $-701^{\circ} \mathrm{A}$

Run No. Initial pressure of cyclopropane Max. pressure of foraldehyde

200

$7 \cdot 12$

E 37

150

$4 \cdot 93$

E 40

50

$1 \cdot 74$

E 41

100

$3 \cdot 47$

TABLE NO. 87

Dun No.

Initial pressure of eyclopropane Max. pressure of formaldehyde

E 49

100

$2 \cdot 24$

E 46

150

$4 \cdot 02$

E 27

200

$4 \cdot 48$

E. 44

300

$4 \cdot 66$

E 43

350

$5 \cdot 02$

E 48

500

$5 \circ 66$

The graph indicates quite clearly that the formaldehyde pressure depends linearly upon the initial hydrocarbon pressure but that the dependence falls away at higher cyclopropane pressures, 1.e. when the initial axygen pressure is 10w. In neither case is there any similarity to the corresponding rate relationships. 
VARIATION OF THE MAXIMLM FORMALDEHYDE PRESSURE WITH THE INITIAL CYCLOPROPANE DRESSLIRE (TEMP. = 701 ${ }^{\circ} \mathrm{A}$ )

a) INITIAL OXYGEN DRESSLIRE $=200 \mathrm{~m}_{0} \mathrm{~m}_{0}$

(b) INITIAL OXYGEN PRESSURE $=50 \mathrm{~m} \cdot \mathrm{m}$.

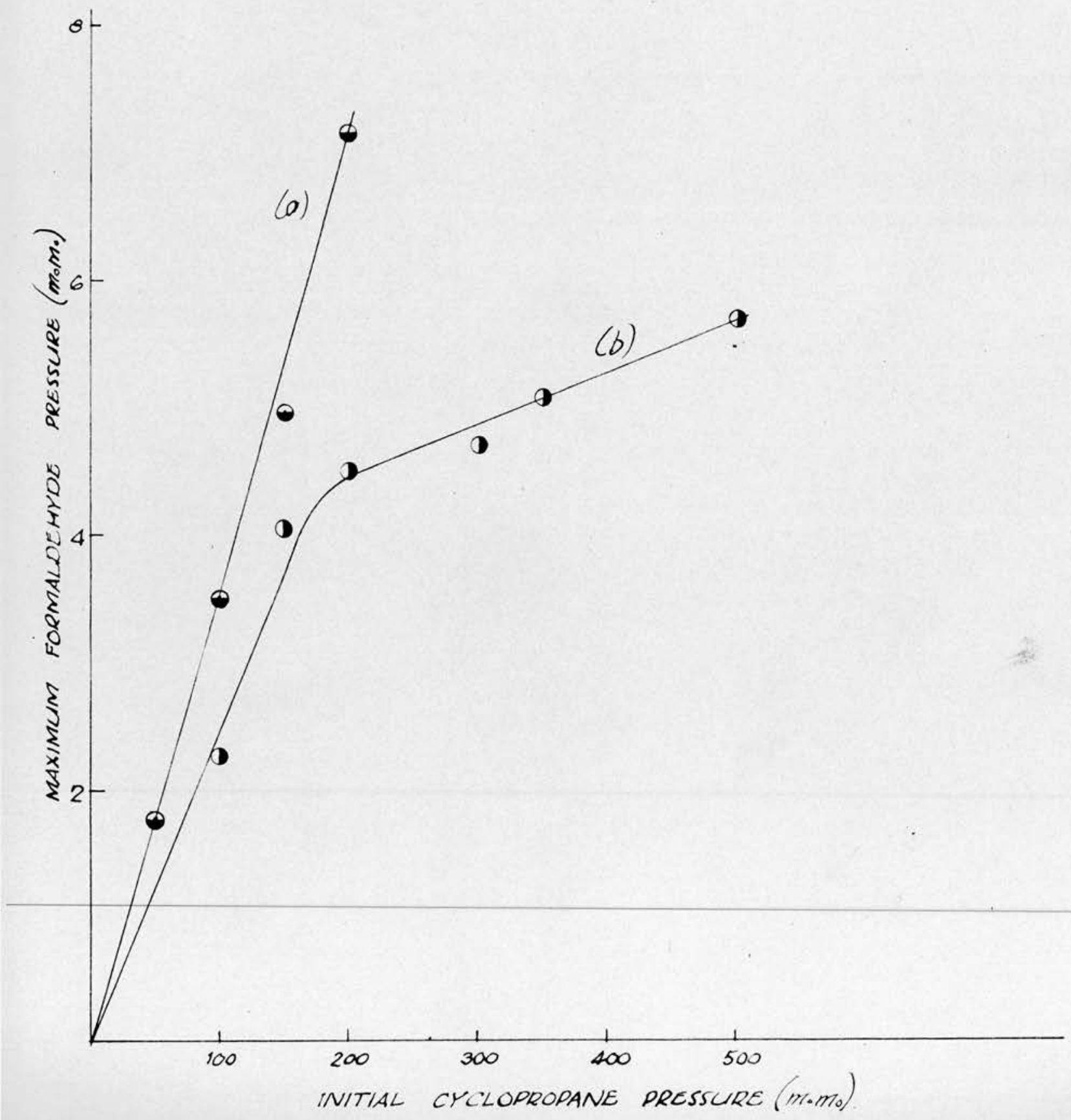


3. Variation of the temperature.

A series of experiments was carried out using a mixture of $200 \mathrm{~m}, \mathrm{~m}$, each of cyclopropane and oxygen at various temperatures over the range $650^{\circ} \mathrm{A}$ to $701^{\circ} \mathrm{A}$ i.e. the range over which the kinetics of the reaction had been studied. The results are embodied in the table No. 88 and the Arrhenius plot of log maximum formaldehyde pressure against reciprocal absolute temperature is given (graph No, 42 ).

THBLE MD. 88

$\begin{array}{ccccc}\text { Run No. } & \text { Temp. }{ }^{\circ} \text { A. } & \frac{10^{3}}{T} & p_{\mathrm{CH}_{2} \mathrm{O} \max } & \log _{1.0} p_{\mathrm{CH}_{2} \mathrm{O}} \\ \text { E 56 } & 650 & 1.538 & 3.89 & 0.5899 \\ \text { E 55 } & 658 & 1.520 & 4.54 & 0.6571 \\ \text { E 53 } & 670 & 1.493 & 5010 & 0.7076 \\ \text { E 54 } & 678 & 1.475 & 5.61 & 0.7490 \\ \text { E 29 } & 701 & 1.427 & 7.12 & 0.8525\end{array}$

The graph provides a straight line of little gradient and yields an "energy of activation" of sone $10.5 \mathrm{kcals} . / \mathrm{mole}$. The interpretation of this figure is not a simple matter and consideration of its significance will be deferred until the discussion of results. 
CRAPH N*42.

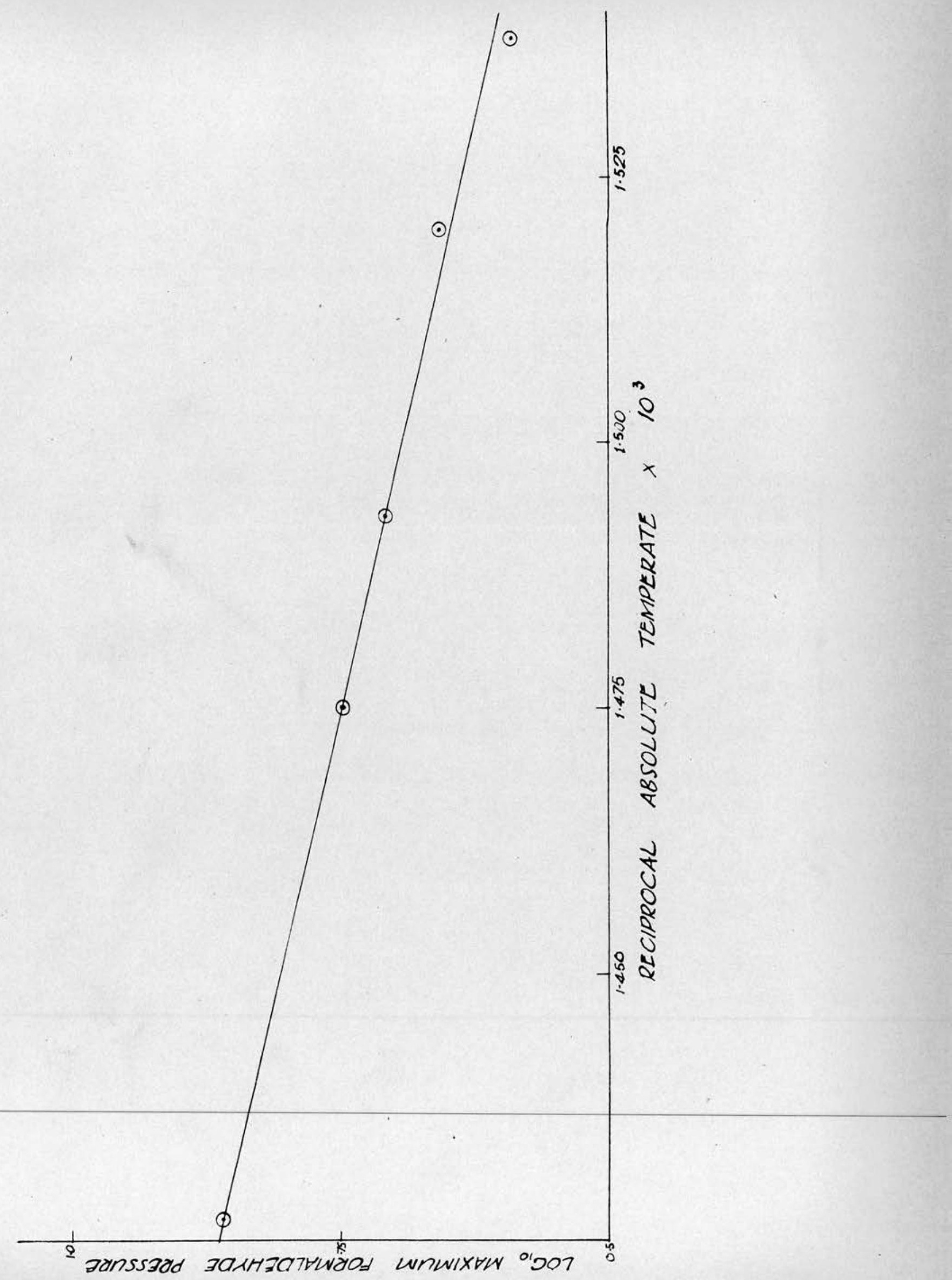


THE BFFECT OF ADDTIG WATTER VAPOUR TO THS REACTION MIXIURE

Several workers have reported that the addition of water vapour to hydrocarbon-oxygen mixtures exerted a consideraible influence upon the reaction rates and induction pexiods. A recent study of the methane oxidation indicated that the kinetics of the water-catalysed reaction might be expressed:Rate $\propto p_{\mathrm{CH}_{4}}^{2.3} \cdot p_{\mathrm{O}_{2}}^{0.4} \cdot p_{\mathrm{H}_{2} \mathrm{O}}$.

In view of the possibility that water might affect the reaction between cyclopropane and axygen, a series of experiments was carried out using $200 \mathrm{~m}$. $\mathrm{m}_{\text {. }}$ of hydrocarion and $100 \mathrm{~m}, \mathrm{~m}$. of oxygen and various amounts of water vapour at $701^{\circ} \mathrm{A}$. The results are embodied in table No. 89 and are illustrated on the graphs (No. 43 and No. 44 ).

\section{THBLE W. 89}

EFFECT OF AODEO WATER VAPOUR.

Run Ho. Pressure of water vapour (n.m.) Maxiaum rate Induction period $\frac{100}{\theta}$

E 109

E 111

E 110

E 112

E 108

E 113

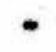

$3 \cdot 3$

$7 \cdot 4$

$12 \cdot 2$

$16 \cdot 9$

$17 \cdot 7$
11.9

$13 \cdot 0$

$13 \bullet 6$

$14 \cdot 0$

$14 \cdot 2$

$14 \cdot 3$
$12 \bullet 88$

$11 \cdot 47$

$10 \cdot 50$

$11 \cdot 80$

$11 \cdot 43$

$11 \cdot 93$ 
GRAPH N'S $43 \neq 44$.
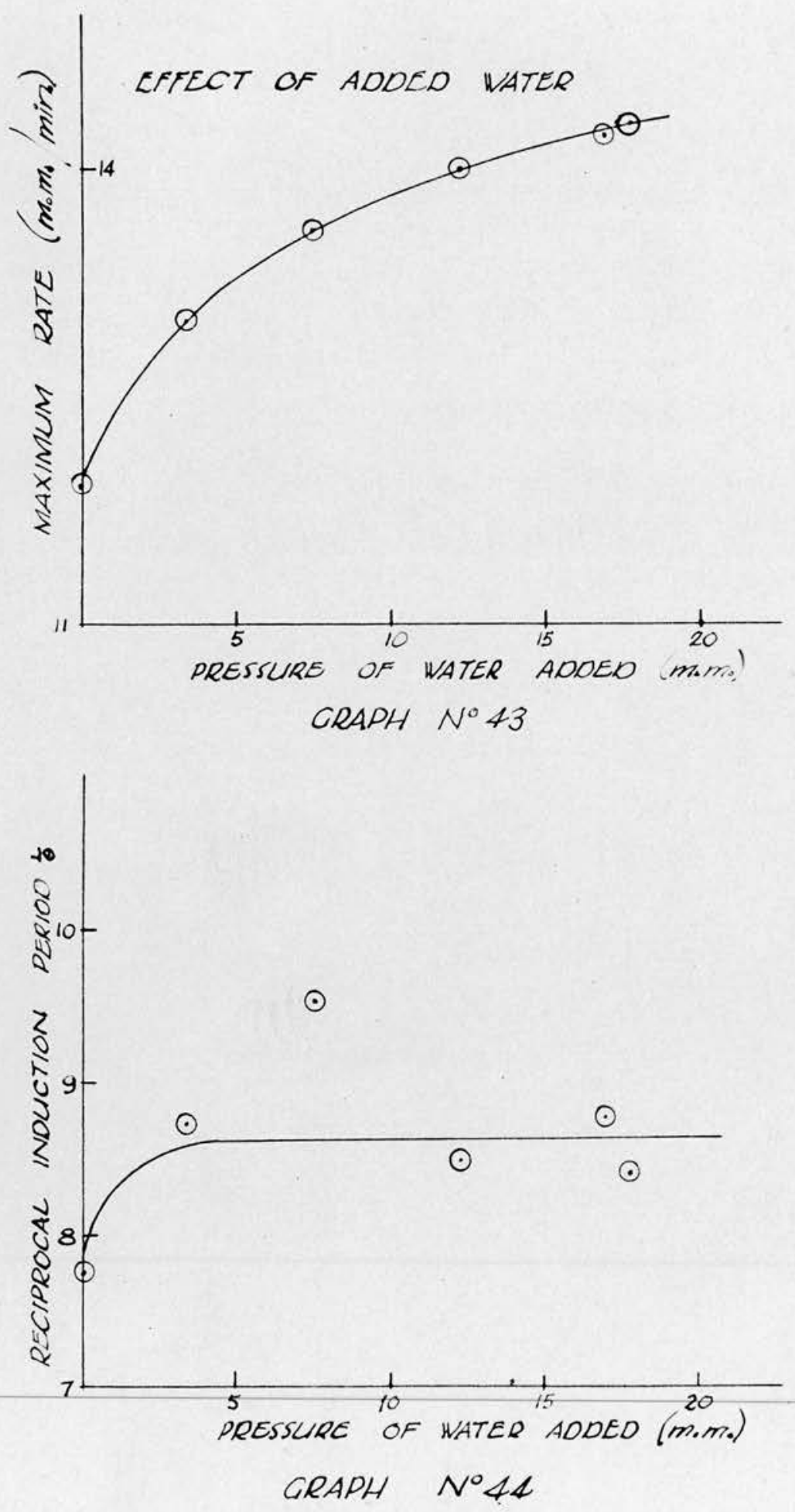
THE EFTECT OF ADDING FORMALDEHYDE TO THE REAGTION UTXTURE Since formaldehyde was the only intermediate product detected and since it was known to react with axygen at $400^{\circ} \mathrm{C}$, a series of experiments was carried out with varying quantities of formaldehyde, added to $200 \mathrm{~m}$. of axygen at $701^{\circ} \mathrm{A}$ in vessel $\mathrm{E}$ before the beginning of the reaction. It was found that progressive addition of formaldehyde to the mixture reduced the induction period without considerably affecting the meximum rate or the pressure change preceding the attainment of maximum rate. The total pressure change showed a gradual increase but not a consideraile one as the pressure of added formaldehyde was increased. These facts are obvious from the pressure-time records shown in the graph No. 45. It should be pointed out that the addition of quantities of formaldehyde less than about $10 \mathrm{~m} . \mathrm{m}$. produced no change in the maximum rate $\left(11.9 \mathrm{~m} \cdot \mathrm{m}_{0} / \mathrm{minute}\right)$. The addition of greater quantities of formaldehyde did lead to some increase of maximum rate $(\mathrm{e} . \mathrm{g}$. the experiment with $35.2 \mathrm{~m}, \mathrm{~m}$. of added formaldehyde showed a maximum rate of about $14 \mathrm{~m} \cdot \mathrm{m}_{0} /$ minute) but it should be emphasised that in such cases the rate increased to the maximum at about the usual $\Delta p_{\max }$ and fell avay again in the usual way. Even when the pressure change appeared to begin at a rate of $12.0 \mathrm{~m} . \mathrm{m}_{0} /$ minute, its rate of change accelerated slowly to $14 \mathrm{~m} \cdot \mathrm{m} / \mathrm{mimate}$.

It will be seen that the effect of added formaldehyde upon the induction period was very great at first but that the effect decreased in importance as the amount of additive was increased. 
Effect of addition of formaldehyde :0 $200 \mathrm{~mm}$. cyclopropane +100 oxygen at $701^{\circ} \mathrm{A}$

$35.2 \mathrm{~mm} . \mathrm{CH}_{2} \mathrm{O}$

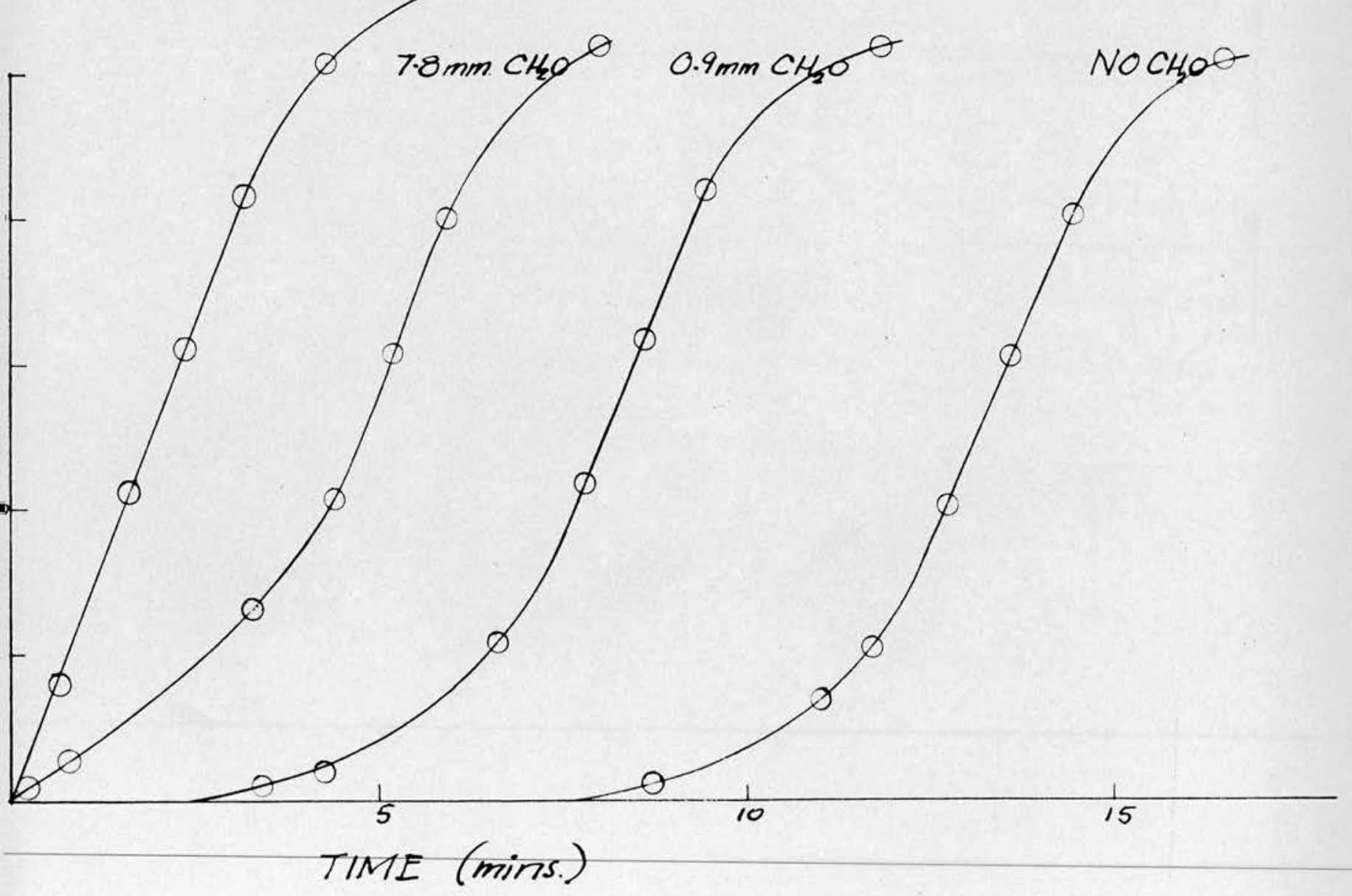


This fact is clearly demonstrated by the data in table No. 90 and by the graph (No, 46). The values of $\theta$ were computed in the usual way but some of the shorter values of $\tau$ could not be determined directly and were taken from the pressure-time records of the experiments concerned.

TABLE M. 90

THE EFFECT OF AODED FORHALEHTE.

Run Wo. Prossure of added formoldehyde

$\theta$

E 128

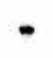

$13 \cdot 05$ mins.

$\tau$

E 136

$0.9 \mathrm{~m}, \mathrm{~m}$.

$8 \cdot 17$

8.7 mins.

E 125

1.5

$7 \cdot 03$

$3 \cdot 4$

E 117

$2 \cdot 4$

6.63

2.5

E 119

$4 \cdot 1$

$5 \cdot 58$

$1 \cdot 9$

E 118

$5 \cdot 9$

$5 \cdot 25$

1.0

E 121

$7 \cdot 8$

4.75

0.6

E 122

$12 \cdot 0$

E 127

$13 \cdot 2$

E 123

$17 \cdot 1$

E 126

$20 \cdot 2$

E 131

$25 \cdot 4$

E 132

$29 \cdot 9$

E 135

$35 \cdot 2$

$4 \cdot 28$

$4 \cdot 23$

$3 \cdot 07$

$3 \cdot 02$

$2 \cdot 78$

$2 \bullet 37$

$1 \cdot 98$

0.1
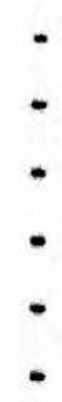


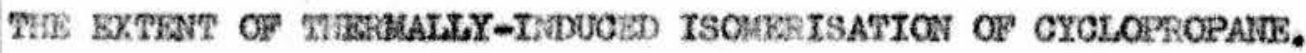

The thermal isckerisation of ayolopropane (to propylene) has cen studied by several vorkers $(59),(60)$ over the tenperature range $440^{\circ} \mathrm{C}$ to $520^{\circ} \mathrm{C}$ (Corner and Pease $(60)$ ) It seemed important to deterzine the degree of isomerdsation at the lower teruperatures at which the oxidation had been studied. In conseguence, semples of $200 \mathrm{~m}, \mathrm{~m}$, of oyolopropene were enolosed In the reaction vessel for various periods as indianted in the table (No, 91). Analysis then showed the extent of iscrerisation. TABSIS No, 91

Fun No. Texp. A. Pop Time Propylene A $78 \quad 678 \quad 200 \mathrm{~m} \mathrm{~m}_{*} \quad 24$ hours. $\quad 18 \%$

A $79701 \quad 200 \mathrm{~m}, \mathrm{~m}$. 24 hours $47 \%$
A 80
701
$200 \mathrm{~m}, \mathrm{n}$.
1 hour
2.5\%

It was oonoluded from these experinents that the iscmerisation of ayclopropane was unlikely to be of any great importance In the study of 1ts cxidation, since at $701^{\circ}$ (the highest temperature employed in the slow corbustion studies) the induotion pertoas were very muoh shorter thain an hour (or the order of 5- 10 minutes) and sinoe at $678^{\circ} \mathrm{A}$ induction times were only of sone $30-40$ minutes duration. It was possible that the isomerisation was facilitated by the presence of oxygen but this was not tested. In any event it was probable that an cxygen-oatalysed isomerisaticn would follow a reaction mechanism similar to that of coxidation.

It was of great interest to note, however, that in one experiment $255 \mathrm{~m}, \mathrm{~m}_{*}$ of ayclopropene ves heated at $693^{\circ} \mathrm{A}$ for 
about 24 hours, On the addition of $110 \mathrm{~m}, \mathrm{~m}$. of cxygen, a small explosion vecurred almost immediately. The pressure change which had occurred after the explosion was only $38.6 \mathrm{~m} . \mathrm{m}$. as compared with the usual change of $55 \mathrm{~m}, \mathrm{~m}$. This seemed to suggest that the propylene formed by isomerisation at $693^{\circ} \mathrm{A}$ oxidised very rapidly when the cxygen was admitted to the vessel but failed to stimulate the oxidation of the remaining cyciopropane. If this were so then the isomerisation of eyclopropane could be disregarded as a factor of importance in the slow combustion of that cornound. The matter was not studied further and the suggestion is a very tentative one. 
- $100-$

DISCUSSION OF YHE RESULIS 
In the first instance it $w i l l$ be instructive to collect and compare certmin of the results and to emphasise their significance. The experimental results constitute a considerable body of evidence for the legitimate application of the Sensenor theory $(10)$ of a reaction with degenerate branching chains to the thermel oxidation of cyclopropane. Firstly many similar reactions proceed by such a mechant $\mathrm{am}$. Furthertore the shape of the pressure change - time curves is typicel ond the linear relationship shown to exist between the logarithes of the pressure chenge and the time demonstrates that, in the early stnges at lesst, the law of pressure change is an exponential one. The long incuction periods observed (of the order of minutes and hours) are also characteristic of chsing with degenerate branching while the extreme sensitivity of the rete and net-branching factor and zoore particularly of the induction period to the state of the surface of the reaction vessel and 1 ts extent provides strong evidence for the vocurrence of such chains. In this connection there has been adequate demongtration of the importince of the immediate past-history of the vessel (cooling, admission of air, and variation of the duration and effleiency of the evroustion al1 producing chsracteristic effects).

One of the features predicted by the Semenov anslysis is a pronounced inert gos effect. This might manifest itaelf as a thira-body effect or might opernte by deactivation of "hot" radicels or simply by preventing diffusion to the walls and since the effect might be applied to an initintion, propegation, branching or ternination reaction the overnil effect might lesd 
to an increase or a cecrease in the reaction rate. In the present investigation the eidition of nitrogen to the system did not change any of the reaction characteristics at all. This was rather surprising since the observed atferences of rate etc. in vessels of similar aimensions and the drastic ohanges in kinetic aharacteristios of the reaction following a twelve-fold increase of the surfece: volume ratio seemed interpretable as indicative of the heterogeneous nature of the branching and/or non-brenching reactions end possibly of the initiation and terningtion reactions too. Consequently one rnight have onticipated that the addition of inert gas might influence the rate and incuction period. It was possible of course that the absence of an overell erfect was due to balan ing of several offecta some enhancing and some retarding the progreas of the reaction. This seemed lesu likely, however, when it was found thet, under en entirely different set of conditions of teperature and pressure, there was still no inert ges effect. A second possible ex lanstion of the results was that the omount of nitrogen added was too small to exert eny great influence. In the most Iavourable case the nitrogen constituted about $2 Q \%$ of the rixture and yet showed no effect. Ixperinental dificulties would attend sny very great increase in this percentage but it would be of interest to find whether 30, of nitrogen aid increase the rate of reaction in a vessel whose walls had been treatec 80 as to increase their chain-terminating activity (e.g. by coating with potsasiusa chloride). 
In striking contrast to the ineffectiveness of adding nitrogen to the reaction mixture, adaltion of hycurogen had a most pronounced result. Induction perious becane quite irreproducible (their inconstancy persisted for some time) but the investigation of the efiect of hydrogen upon the rate showed that the rate was reduced either by the iact that hydrogen wes present ouring reaction or by the pretreatment of the vessel with hyarogen (the norial evacuation technique being sapopted before the comencement of the next experiment). Furthermore the rete gradueliy returned to noral after a few combustions or more rapidy if the prodicts from an oxidation were left in the vessel for sore tirse. These frcts, corbined with the observation that even prolonged evacuation of the vessel in its "low rate" stete had very little effect upon the maximum rate of the next experiment, made it clear that hydrogen renoved from the vallis some substance which nomelly facilitated reaction and that this wall-catalyst was gracually replaced in the next experiments or by leaving a few centimetres pressure of the products of reaction in the hot vessel. There wes no evidence that the hydrogen did not exert a homogeneous gasmphase effect (such as hes been studied by ubbelohde (56)) as well es the wall effect. Two possible explanntions of the results seemed leasible. The first was that hydrogen changed the nature and hence the catalytic activity of the easorbed substance end that this altered forn was graitully rechanged by the ensuing reactions and resction products. This did not sees very probeble wince the hydrogen was licely to reduce the adsorbed material. which 
could be re-oxidised by the oxygen involved in the next experiment but which could probably not be remoxidised by the products of resction which contained little or not oxygen (thie being far less than the stolchionetric requirements of the cyclopropane in these particulor experiments). The second possible explanation was that hydrogen removed the substance froin the adsorbed phase altogether, leaving a clean glass surface. This seemed more resonable suggestion since, it hed been noced that rate results in a new clean vessel were, at first, low and gredunlly incressed as the number of experinents increased. The precise neture of the reaction produet which was normally resident on the walls can not be stated with certainty but of the products detected in reaction the one nost likely to exert a catalytic effect upon the rate was water. Just why hydrogen should be so effective in desorbing water from the walls is a very difficult question to answer and further speculation as to the noture of the catalyst and its mode of action can be of no great value.

Semenov has shown that $\Delta p=\frac{B}{\phi^{2}} \cdot e^{\phi t}$ where $\Delta p=$ pressure change, $\phi=$ the net-brsnching fector, $t=t$ twe and $B=\frac{\eta_{0} v}{\theta}$ where $n_{0}=$ the number of active centres forned per second by the priasry initiation process, $v=$ the chain longth and $\theta=$ the time elapsing between the comeneement of the priwery chaing and that of the secondary chains. Taking logerithas, $\log _{10} \Delta p=\log _{10} \frac{B}{A^{2}}{ }^{2}+A^{\prime} t$ and plotting $\log _{10} \Delta p$ against $t$,

a stroight line of gradient $A^{\prime}$ should result. Whe intercept of this line on the $\log _{10} \Delta p$ axis ahould be $\log _{10} \frac{B^{2}}{2}$ which 
we shall call $\log _{10}$ N. N was obviously determinable from the graphs normally employed for net-branching factor evaluation and from a knowledge of the net-branching factor it was possible to calculate $B$. Now $B($ and $N$ ) are dependent upon the rate of initiation of primary chains by other means than by radicals formed by the intermediate responsible for the degenerate brenching. It seemed of great interest to consider the variation of $B$ and $N$ with the experimental conditions but little success was had so far as reactent pressure variation was concerned. On the other hand $\mathrm{B}$ and $\mathrm{N}$ were found to vary in a remarkable way with the temperature. The results which are given in tables No. 92 and 93 were calculated from the data previously determined. In graphs No. 47 and $48 \log _{10} \mathrm{~N}$ and $\log _{10}$ B have been plotted against reciprocol absolute temperatmre. Calculation showed the activation energies for $N$ to be 160 and $280 \mathrm{kcals} / \mathrm{mole}$ and those for B to be 280 and $340 \mathrm{kcols} / \mathrm{mole}$. Now of the various factors of $B, \nu$ and $\theta$ are unlikely to have very high activation energies so that the very high activation energy of $B$ must be largely attributed to the rate initiation of primary chains. This primary initiation could hardy have been a homogeneuos one and probably took place on the walls of the vessel, since the apparent activation energies of heterogeneous reactions may include heats of adsorption which may be considerable.

It was therefore concluded that the slow combustion of cyclopropane proceeded by a chain reaction with degenerate branching of the chains and that the primary initiation reaction was heterogeneous in nature having a very high energy of activation. 
TABLS NO. 92

Initial $P_{c p}=250 m_{0} m$. Initial $p_{0_{2}}=70_{m} \cdot m_{0}$ Vessel $\mathrm{B}$ Rum No. Terap. $\frac{10^{3}}{T} \quad \log _{10^{N}} \quad \log _{1} 0^{B}\left(=\log _{10^{3}}+2 \log _{10^{A}}\right)$
B 89
$651^{\circ}$ A $1.536-9.45$
$-11 \cdot 41$
888
$658 \quad 1.520 \quad-6.60$
$-8 \cdot 44$
B 87
$665 \quad 1.504 \quad-4 \cdot 92$
$-6 \cdot 74$
B 86
$671 \quad 1 \cdot 490 \quad-5.43$
$-6.91$
$\begin{array}{llll}\text { в } 77 & 678 & 1.475 & -3.89\end{array}$
$-5.22$
B 83
$683 \quad 1.464 \quad-3.26$
$-4.42$
B 80
$\begin{array}{lll}689 & 1.451 & -2.88\end{array}$
$-3.87$
81
$\begin{array}{lll}697 \quad 1.435 & -2.86\end{array}$
$-3.50$
B 84
$\begin{array}{lll}702 & 1.425 & -2.30\end{array}$
$-2.78$

ThBLE No. 93

Initiel $p_{c p}=178 m_{0} m_{0}$ Initial $p_{0_{2}}=200 m_{0}$. ve vesel B Run No. Terap.T. $\frac{10^{3}}{T} \quad \log _{10^{N}} \quad \log _{10^{3}}\left(=\log _{1} N+2 \log _{10^{A}} A^{\prime}\right)$
B 56
$660^{\circ} \mathrm{A} \quad 1.515-7.84$
$-9.74$
B 57
$669 \quad 1.495 \quad-5.40$
$-7.14$
B 58
$\begin{array}{lll}673 & 1.486 & -5.15\end{array}$
$-6.82$
B 49
678
$1.475 \quad-3.57$
$-5.11$
B 48
$\begin{array}{lll}683 & 1.464 & -3.80\end{array}$
$-5.20$
B 50
$\begin{array}{lll}688 & 1.453 & -3.52\end{array}$
$-4.84$
B 52
$692 \quad 1.445 \quad-2.95$
$-3.97$
B 51
$694 \quad 1.441 \quad-2.85$
$-3.69$
B 47
697
$1.435-2.83$
$-3.62$
B 100
701
$1.427-1.55$
$-2.38$ 


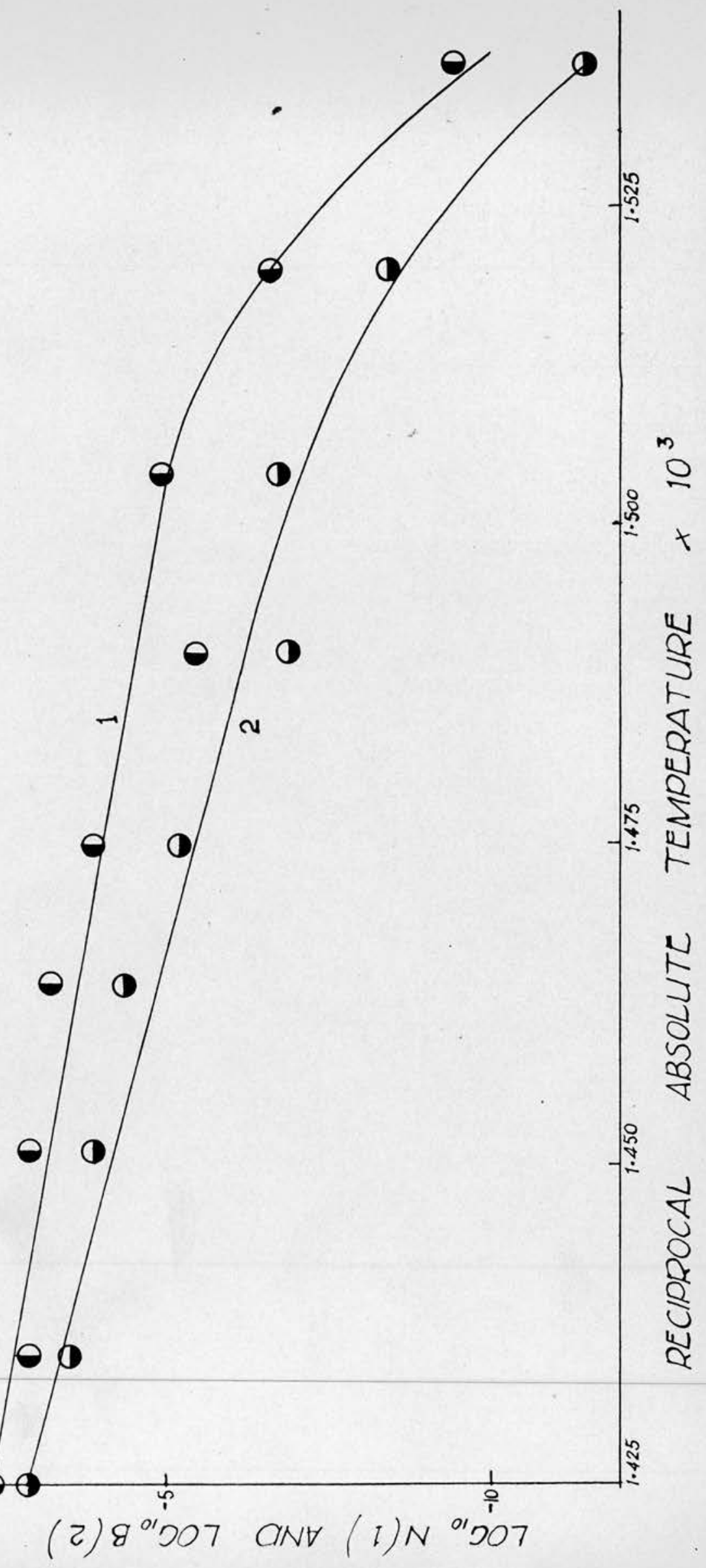


$\infty$

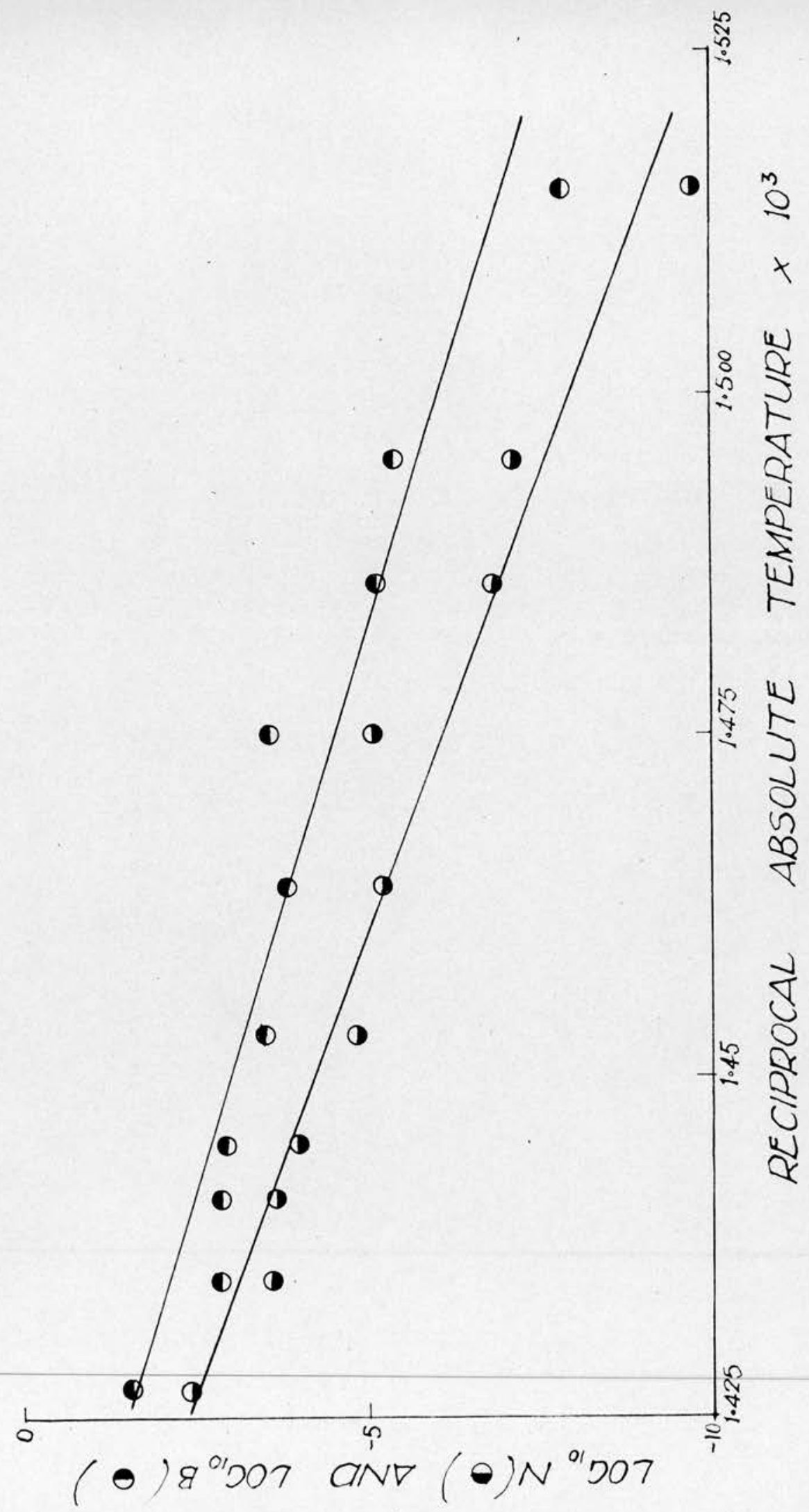


Several workers have attempted to derive theoretical expressions relating the various choracteristics. Bardwell (61), discussing the oxidation of butanone, integrated the general rate expression $\rho=\frac{B}{A^{\prime}}\left(e^{A^{\prime} t}-1\right)$ to obtain $\Delta p=\frac{B}{A^{2}}\left(e^{A^{\prime} t}-A^{\prime} t-1\right)$ Substitution of the rate $\rho$ for $\frac{B}{A},\left(e^{A^{\prime} t}-1\right)$ in the integrated expression and disregard for $A^{\prime} t$ in comparison with $e^{A^{\prime} t}-1$ yielded the simple relationship $\Delta p=\frac{\rho}{A^{\prime}}$ or $\rho=A^{\prime} \Delta p$. At the time of the maximum rate this became $\rho_{\max } \alpha A^{\prime} \Delta p_{\max }$. Vis lsh derived the same expression in a sinilar way in a paper on the slow combustion of di-isopropyl ether and methane (62). These outhers then showed that $\Delta p_{\max }$ was virtually constant and thus were able to explain their observations that the dependences of maximum rate upon the conditions ran parallel with the netbranching factor dependences upon pressure and temperatures.

In the present work it was shown that the pressure chonge occurring up to the attainment of maximum rate $\Delta p_{\max }$ was independent of the initial cyclopropene pressure but was directly proportional to the initial pressure of oxygen and showed a smell temperature effect. The combination of this knowledge with the derived relationship between maxirram rate, net-branching factor and $\Delta p_{\max }$ predicted that at constant oxygen pressure, veriation of the initial cyclopropane pressure would produce parellel effects upon maximum rate and the net-branching factor. That this is in fact true is shown on the graph No. 49 where the lines refer to the variation of the maximum rate and the points to netbranching factors. To obtain this graph each line was drawn to a special scale so as to coincide with the net-branching 
Pactor points. This was achleved by multiplying all the rates obtained under one set of conditions of oxygen pressures and temperatures by $\mathrm{s}$ factor. These factors and the conditions of the experiments to which they were epplied are liated in table No. 94 along with two other sets of dats.

TABLE NO. 94

$\begin{array}{cccc}p_{\mathrm{O}_{2}} & \text { Term }^{\circ} \mathrm{A} & \text { Vessel } & \text { Pactor } \\ 200 & 678 & \mathrm{~B} & 0.0154 \\ 70 & 678 & \mathrm{~B} & 0.0244 \\ 79 & 701 & \mathrm{~B} & 0.0248 \\ 150 & 678 & \mathrm{~A} & 0.0192 \\ 300 & 701 & \text { D } & 0.0232\end{array}$

The theories of Walsh and Bardwell prealet thet, in experiments with constent hyärocerbon pressure and at a constent tempersture, the net-branching factor would be independent of the pressure of oxygen when this was 10w, and inversely proportionsl to 1 t at higher pressures (since $f_{\max } \propto p_{o_{2}}^{\prime}$ or $\rho_{\max } \propto p_{\mathrm{O}_{2}}{ }^{\circ}$ and $\Delta p_{\max } \alpha p_{\mathrm{O}_{2}}^{\prime}$ ). This, of course, wes not the onse and the graph (No. 49) shows the parsileliam between rete end branching factor when the initiel oxygen pressure was varied. The graph was constructed in the same manner as the previous one from some of the dats in teble No. 95 which contains detalls of initial cyclopropane pressures, texperntures, vessels and the necessery rate-adjustiment factors. 
o $p_{\mathrm{O}_{2}}=200 \mathrm{~mm} \cdot \mathrm{m}=678^{\circ} \mathrm{A}:$ Foctor 0.0154

$\theta p_{o_{2}}=70 \mathrm{~mm}: \mathrm{T}=678^{\circ} \mathrm{A}$ : Factor 0.0244

$b_{v_{2}}=150 \mathrm{~mm}$ : $: T=678^{\circ} \mathrm{A}$ : Foctor 0.0192
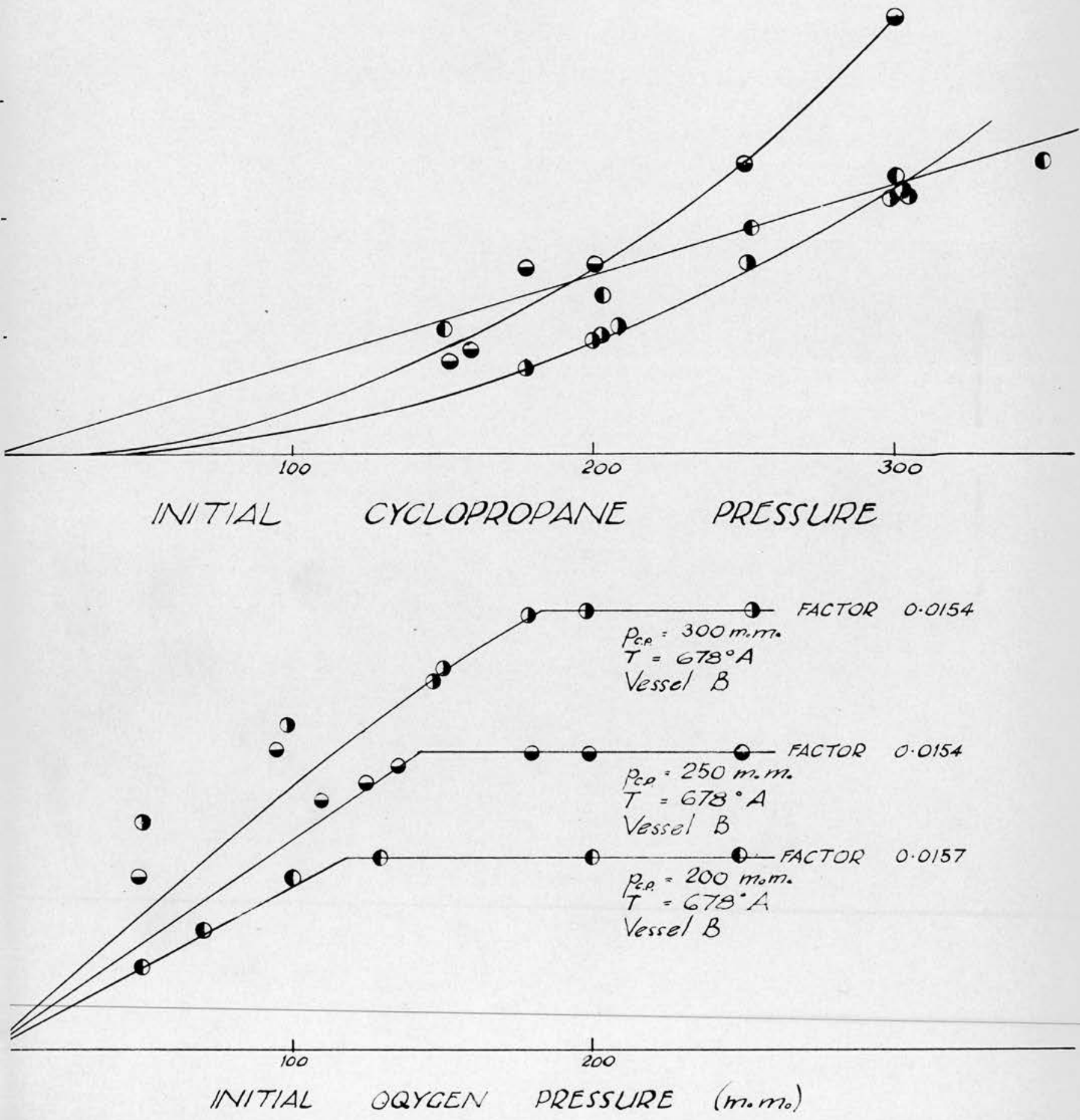


\begin{tabular}{|c|c|c|c|}
\hline$p_{C P}$ & Terap ${ }^{\circ} \mathrm{A}$ & Vessel & Paotor \\
\hline 178 & 678 & B & 0.0200 \\
\hline 200 & 678 & $B$ & 0.0157 \\
\hline 250 & 678 & $B$ & 0.0154 \\
\hline 300 & 678 & B & 0.0154 \\
\hline 250 & 651 & 3 & 0.0221 \\
\hline 178 & 701 & B & 0.0105 \\
\hline 200 & 678 & $\mathbf{A}$ & 0.0526 \\
\hline 100 & 701 & $D$ & 0.0333 \\
\hline
\end{tabular}

It was noted, then, that a distinct parallelism obtained between the variation of rate and net-branching fsctor with external conaitions but that the theoretical relation $\rho_{\max } \propto A^{\prime} \Delta p_{\max }$ was not verified uniess the "constant of proportionality" itself depended upon conditions. It seened probable that $\rho_{\max } \propto A^{\prime}$ but that the proportionnlity constant wo not $\Delta p_{\max }$.

Various attempts have been made to deduce a theoretical. expression relating the induotion period with maximum rate and net-branching Pactor. Thus Berdwell (61) showed that the reciprocel of the time $\theta$ elepsing before the ettrintent of a definite rate $\rho$ was given by $\frac{1}{\theta}=\frac{A^{0}}{\log \left(1+\frac{P A}{B}\right)}$ so that $\frac{1}{\theta}$ should be more sirongly dependent upon the net-brenching factor A' than upon the initiation factor B. Similerly Walsh (62) indiceted that $\frac{1}{\tau}$ was proportionel to the maximum rets. Thase authors found experimental verification of these expressions in certein coses. In the cyclopropane oxidation, there wa a 
striking contrast between the dependence of rate (or netbranching fretor) upon conditions and the behavlour of reciprocel induction period, the latter being apperently proportional to the product of the pressures of cyclopropane and oxygen. The only theoreticslly derived induction period-constituent pressures reletionship differing from the rate expression was that of loulcahy (63) which was deduced on the basis of the hydroperoxide theory of low-temperature slow combustion. This was of the form $\frac{1}{\theta}=k_{1}(\mathrm{RII})\left(\mathrm{O}_{2}\right) \pm \mathrm{F}_{\mathrm{s}}$ where $\mathrm{F}_{\mathrm{s}}$ was a function of the surface conditions while the corresponaing rate expression was, as usuel, $\rho_{\max }=k_{2}(R H)^{2}$

It does seem strange that Mulcahy verified his expression in the cases of n-butane and propylene while Barcwell verified his in the case of butanone oxidation; and yet both authors seek to explain their general results in terms of the hydroperoxide intermediate theory.

Before proceeding to compare the kinetic reletionships in the cyclopropene oxidation with those reported for the slow combustion of other hydrocarbons it will be wise to summarise the kinetic results. It was shown that the dependence of the maximum rate upon the initinl pressure was extremely complicated. The maximum rate could be either strictly proportional to the initial pressure of oxygen or quite independent of it, which of these two laws operated was found to depend upon (a.) the initial oxygen pressure itself, since at lower oxygen pressures the former dependence was observed while at higher oxygen pressures the independence was hoted, (b.) the initial hydrocarbon pressure, 
since as this was increased (all other things being equel) the region of oxygen incieyendence was diminisher, the critical oxygen pressure being increased, and (c.) the temperature, because as this was increased the critical oxygen pressure again rose so that at higher teraperatures the moximum rate was depencent upon the initial oxygen pressure over a vider range of oxygen pressures.

It wes elso shown thet the meximum rate veried sometimes with the scuare of the cyclopropene pressure and sonetimes was directly proportional to the hycrocerbon presaure. Which of these two depencences hel good in any perticular case was found to depend upon the initiel pressures of both cyclopropane and oxygen and the temperature of reaction. The total order of reaction was found to be always two so that the two regions of kinetic dependence were described by the equations $\rho_{\max } \alpha p_{c p}^{2} p_{O_{2}}^{0}$ and $f_{\max } \propto p_{c p} \cdot p_{o_{2}}$. It was possible to combine these in an empirical but single expression

$$
\rho_{\text {max }}=\frac{k_{1} p_{C p}^{2} \cdot p_{O_{2}}}{k_{2} p_{C p}+k_{3} p_{O_{2}}}
$$

Thus uncier the appropriste conditions when $k_{2} p_{c p} \gg k_{3} k_{\mathrm{O}_{2}}$ then the maximara rate was given by $\frac{k_{1}}{k_{2}} \cdot p_{c p} \cdot p_{o_{2}}$. Suitable conditions for such a simplification were considered to be increase of cyclopropne pressure, recuction of the oxygen pressure or increase of temperature if $\mathrm{k}_{2}$ were more temperature cependent than $k_{3}$ by a large anount. This single relationship was verified when such conditions prevailed. On the other hend, ot lower cyclopropane pressures, higher oxygen pressures or lover temperatures $k_{3} p_{\mathrm{O}_{2}}$ would become the more significant term 
in the denotainator whence $\rho_{\max }=\frac{k_{1}}{k_{3}} \cdot k_{c p}^{2}$

A term must be included in the rate expression to account for the powerful influenoe of surface extent and character upon the maximum rate. Inserting a term and the exponential fector to account for the overall temperature arfect the general equation for the maximum rate of the reaction became

$$
\rho_{\text {max }}=\frac{k_{1} p_{c p^{2}} \cdot p_{o_{2}}}{k_{2} p_{c p}+k_{3} p_{O_{2}}} \cdot \frac{1}{f_{S}} e^{-\frac{35,000}{R T}}
$$

With reference to the overall activation energy of the reaction, Arrhentus diagrams were constructed for experiments where the kinetics couza be represented $f_{\max } \alpha p_{c p}{ }^{2}$ and $\rho_{\text {max }} \alpha b_{c p} \cdot p_{O_{2}}$. Some curvature was noted at the ends of the lines but the graphis were straight and parallel over a consiceroble temperature renge. This incicated that the major factor contributing to the ectivation energy was $k_{1}$ in the above equation.

Bxpressions of a similar type have been reported for other hydrocarbons although the cyclopropane oxidation linetics were not guite the same as any othere. The variation of the maxilum rate with the conditions of the reaction hus been investigated in a systematic wey for the slow combustion of only a very lew substances. Apparent orciers of up to $s i x$ with respect to the pressure of the organic substances have been reported for the butanone combustion (61), though for the majority of corapounds studied the order is about two. For example methane (16), ethylene (64), propane (65), n - pentane (28), n - hexane (28), d-isopropyl ether (30), chloroparaffins (66) and certein aliphatic amines (67) oxidise at a rate determined by the 
pressure of fuel raised to about the second power. It is possible that very high or fractional orders with respect to the fuel, which have been reported, may find an explanation in the observation that the dependence of maximum rate of oxidation of cyclopropane upon the initial cyclopropane pressure could change from second to first order as the hydrocarbon was increased. For example two rate-hydrocarbon pressure curves reported for $\mathbf{n}$ - butane by Mulcahy (63) might be interpreted as showing the transition from second to first order. In this connection it is interesting to note that if the kinetics changed from $\rho_{\max } \alpha p_{R_{H}}^{2}$ to $\rho_{\max } \alpha k_{2} p_{R_{H}}$ and if the constant $k_{2}$ were high, then the apparent order of the overall rate - hydrocarbon pressure curve would be high. The meximum rate of the slow combustion of methylamine at $330^{\circ} \mathrm{C}$ was approximately proportional to both the methylamine and oxygen pressure but this reaction was perhaps somewhat anomalous in that it showed no period of inappreciable pressure change and started off at a finite rate (68). In all other oxidations in the "low-temperature" range the change from dependence to independence of the maximum rate on the oxygen pressure has been noted, Sometimes the curve exhibited a maximum (e.g. with the lower ethers (69) and butenone (70)) but in general the curves illustrating the effect of varying the oxygen pressure were of the same type as those reported for the cyclopropane oxidation. The observation that the critical oxygen pressure depended upon conditions had not been previously reported but, with the exception of Barâwell's experiments with butanone, no workers appear to have studied the oxygen dependence of the maximum rate in any detail. 
In the case of butanone there was no shift of the oritical oxygen pressure (in this case the position of the maximura of the curve) with changing conditions, The butanone combustion must, however, be regexded es exceptionel in many ways since there is a maximum in the oxygen-rate curve end also since the oxidative degradation is not cormlete, there being $B$ high concentration of acetone (which is cormaratively stable to oxidation) in the final products.

In the slov combustion of carbon compounds at higher temperatures (27) and in the oxidetion of methane (16) et all reasble temperatures, it has been genorally agreed that the maximum rate was stron $l y$ dependent upon the oxygen concentration. In viev of the discovery that the mextmus rate of oxication of cyclooropane could be mede cepencent upon or independent of the oxygen pressure by suitable choice of coniltions of pressure and temperature, it seened reasonable to consider the possibility that there was really no aharp distinction between "high" and "low" temperature kinetics of hydrocarbon oxidation. If this were so, one inight expect to find that the rate sight becone independent of the oxygen pressure in the high terperature zone of the combustion of a hydrocarbon, if the ratio of oxygen to hyarocarbon pressure becane high enough. The results of a recent investigation of the ethylene exidation at $400^{\circ} \mathrm{C}$ were interpreted by Harding and Iorrish (64) as indicating rateoxygen pressure proportionality but certainly appeaxed to show - tendency to oxygen independence at higher oxygen pressures. One of the other characteristic features of slow conbustions 
In the "high-terperature" region is the dependence of maximum rate upon the totel pressure of the aysten. In the "lowtemperature" range, the absence of en inert gas effect is equelly characteristio. This property of "low-temperature" combustions is herdly unexpected since, in such cases, the maximum rate is largely independent of the oxygen pressure and because there seens to be no very great reeson why nitrogen or other inert gas should be much more efficient in the prevention of diffusion of redicels to the malls than oxygen. In the cyclopropane oxidation, added nitrogen had no effect under any circumstances. It may be significant that the data published on the effect of total pressure on the rate of oxidation of methane (16) and ethylene (64) indicated that the dependence of rate upon totel pressure tenced to becose less st the highest presure used. It is interesting to speculate whether the rate of a slow combustion in the "low-tenperature" sone would become total-pressure-cependent st very low pressures. The kinetic denendences of the net-brenching foctor closely paralleled those of the meximum rate of oxidation of cyclopropene and a very similar rate-equation could be set up to describe its variation with changes of pressure and temperature. As has been incicated Talsh (62) studied the oxidation of methene and di-isopropyl ether and found that $A^{\prime}$ was proportional to $\rho_{\max }$. Bardwell's studies of the butanone oxidation have also been discubsed with reference to $\rho_{\max }$ A' relationship. Apart from these investigations very little mention is to be found of the kinetic dependences of $A^{\prime}$ in the 
iiterature of hydrocarbon slow combustion.

On the other hend, the reciprocal induction period depended upon the conditions in a manner quite different from the maximum rate and the net-brenching fector. It was shown that there was no significant difference between the behaviour of $\frac{1}{\theta}$ and $\frac{1}{\tau}$, although there was some evidence that in experiments where high maximum rates were subsequently attained the value of $\frac{1}{\theta}$ tended to become fairly constant at some high level when the time $\theta$ was so small that $(\theta-\tau)$ became larger in comparison with $\tau$. The general equation for the reciprocal induction period might be written:-

$$
\frac{1}{\theta}=k \cdot p_{c p} \cdot p_{o_{2}} \cdot f_{s}^{\prime} \cdot e^{-\frac{53000}{R T}}
$$

The linear dependence of the reciprocel inauction period upon the initial hydrocarbon pressure was compared with a similar finding in the cases of propylene (63), n-butane (63), n-hexane (28) and 2-methyl pentane (71) and its proportionality to the initial oxygen pressure has been previously reported in a.lmost every oxidation stuaied. Notable exceptions to this latter type of behaviour are butanone and propane (61). Some slow combustions are characterised by a grester then linear dependence of reciprocal induction period upon the pressure of combustible substance e.g. methane (16), ethane (72), isobutane (63), n-pentane (28), butanone and di-isopropyl ether( 30$)$. It is very difficult to generalise with reference to these observations but it should be pointed out that in sorne cases $\frac{1}{\theta}$ behaves similarly to $\rho_{\max }$ and in some cases $\frac{1}{\theta} \alpha p_{R_{H}} \cdot p_{O_{2}}$. 
The presence of inert gas had no effect upon the induction period in the cyclopropane oxidation but it has been reported that in the slow combustion of methene, n-pentane and diisopropyl ether the induction period was reduced by increasing the total pressure.

The effect of change of temperature on the oxidation of cyclopropane was, in general terms, to increase the maximum rate and the net-branching factor and to reduce the induction period. On graph No. 50 are plotted the Arrhenius graphs for maximum rate, net-branching factor and the reciprocal induction periods $\left(\frac{1}{\theta}\right.$ and $\left.\frac{1}{\tau}\right)$. The experiments were carried out with $250 \mathrm{~m}$. m. of cyclopropene and $70 \mathrm{~m} . \mathrm{m}$. of oxygen in vessel B and the temperature range was about $50^{\circ}$. It will be noted that the two lines referring to reciprocal induction period are parallel and show no tendency to curve at the ends, their gradients correspond to activation energies of $51 \cdot 7$ and $54 \cdot 2$ kcals./mole. The two other curves are parallel to each other, the activation energies referring to the meximum rate and the net-branching factor being $35 \mathrm{keals./mole.} \mathrm{These} \mathrm{observations}$ were seen to be very different from some nade by Chamberlain and $\mathrm{Walsh}(62)$ who found that the activation energy of the maximum rate, net-branching factor and the reciprocal induction period were all close to a value of $51 \mathrm{kcals} . / \mathrm{mole}$. for the oxidation of methane between $470^{\circ} \mathrm{C}$ and $510^{\circ} \mathrm{C}$. Mulcahy, however, has reported that the activation energy of the reciprocal induction period in the propylene oxidation was twice 


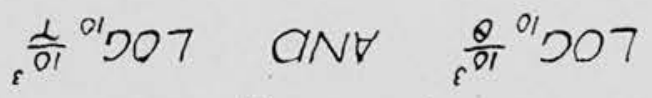
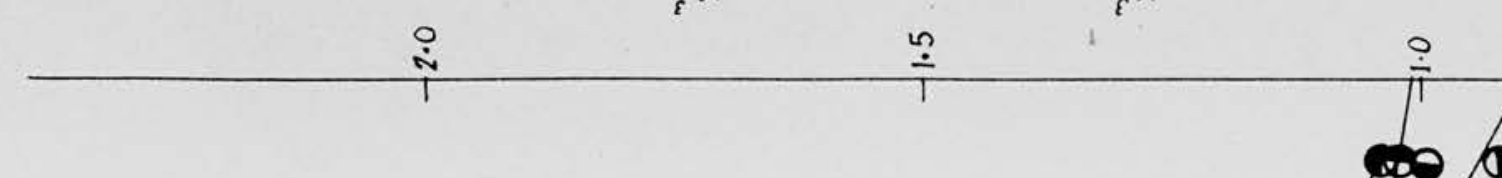

$\frac{1}{4}$

2

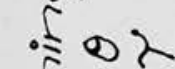

a

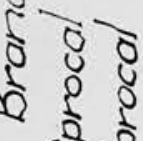

रa

$\sim \dot{0}$

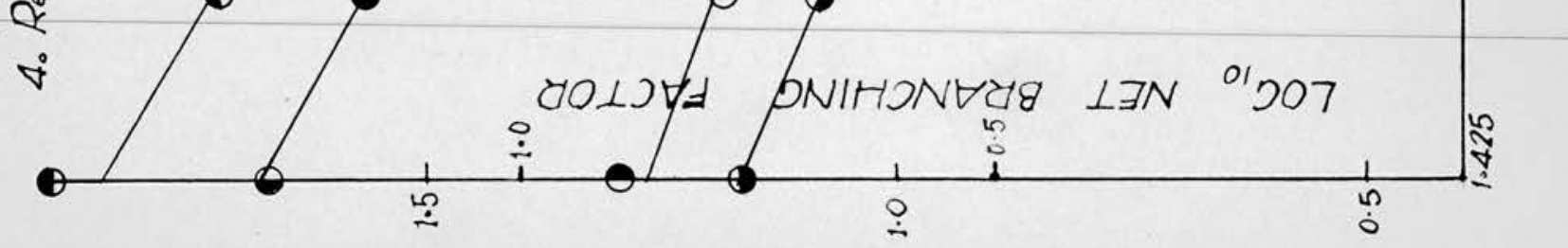

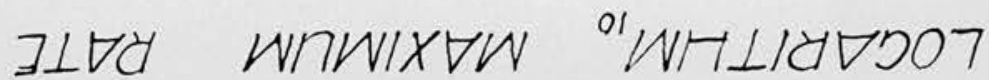


that of the raximum rate (63). In the same comanication Bulcahy reported that the efiect of chenge of teraperature wes very much grester upon $\frac{1}{\theta}$ than $\rho_{\max }$ in the slow combustion of propane.

As to the perticular velues deterined for the sotivetion energies, iittle can be said. In most ceses, Arrhenius plots have been found to be curved so that in the case of any perticular hydrocarbon the activation energy could be said to vary. For instance the overall sotivation energy of the reaction of etryione with oxygen (64) was found to very from $26 \mathrm{kcal}$. at $400^{\circ} \mathrm{C}$ to $53 \mathrm{kcal}$. st $500^{\circ} \mathrm{C}$. This represents a gradual chenge in cormarison with the activation energy of the propane oxidation which was found to becone actually negative over part of the range (26). A very important observation was mede by Mulcahy (27) who compared the effect of change of tempersture of propylene, propene and several substituted propenes. He found that the very greet differences in rate observed at low temperatures tended to disappear at higher temperatures. Nov since the effect of structure upon reation rate at low temperatures had been attributed to the effect of strueture unon the ease of breakdown of the internediate hydroperoxide Rook (by ission of the $-0-0-$ bond), Sulcshy concluded that the results showed that peroxide breakdown was of less consequence (or none at all) at the higher temperatures and that at these temperatures oxidation proceeded by a more general mechanisn involving the same or similar radicals irrespective of the tuel. These 
radicals would be expected to be less complex than alkylperoxyl radicals - hydroxyls, alkyls etc. being more likely.

The total pressure change occurring during an oxidation was considered to be a measure of the extent of reaction and it was hardy surprising to find that it was proportional to the oxygen pressure when this was in excess and independent of the cyclopropane pressure. Increase of temperature produced a small increase of the total pressure change. Since analysis showed the main products of oxidation to be oxides of carbon and water it was possible to write down two stoichiometric chemical equations to describe the complete oxidation. These were:-

$$
\begin{aligned}
& \text { 1. } \mathrm{C}_{3} \mathrm{H}_{6}+3 \mathrm{O}_{2} \rightarrow 3 \mathrm{CO}+3 \mathrm{H}_{2} \mathrm{O} \\
& \text { 2. } 2 \mathrm{C}_{3} \mathrm{H}_{6}+9 \mathrm{O}_{2} \rightarrow 6 \mathrm{CO}_{2}+6 \mathrm{H}_{2} \mathrm{O}
\end{aligned}
$$

Comparing the pressure changes involved in these reactions it was seen that, relative to nine volures of oxygen in each case, the pressure changes were six volumes in equation 1. and one volume in equation 2. This suggested that the small temperature effect on the pressure change was due to the gradual withdrawal from prominence of reaction 2. as the temperature was increased. This was a reasonable idea since it was likely that carbon dioxide wes procuced from cerboxylic ecids which would be less likely to be formed at higher temperatures and analysis showed that inereese of temperature did, in feot, bring about an increase of the ratio carbon monoxide: carbon dioxide. The relatively small amounts of carbon dioxide found 
seemed to be nearly a.1 forned after the attainnent of maximum rate.

Other important facts revealed by analysis were that the process of isomerisation of oyolopropane was probably negligible under the conditions of experinent, that the rate of presaure change was a measure of the rate of renotion of both cyclopropane and oxygen and was a measure of the rate of production of the end products. Only a few compounds were found in the products and only one interwediate was deteoted. The possibility of the presence of othex intermediate products in small quantity was a real one but the relative acouracy of the carbon, hydrogen and oxygen balances made it less 1ikely. In faimess it should be pointed out, however, that the outputs of these elements were almost without exception lower then their inputs. The andiftioal results were alscussed rather fully in the experimentel seotion.

Semenov's simple sohene for a chain reaction involving degenerate brenching is:-

Stage (a) Procuation of aotive centres, i.e. radioals, which initiate 8 tage (b).

Stage (b) Primary cheins Involving oxygen and the combustible substance and of average length 2 . These chains Iead to the production of a substance $r$ which has a reasonable life-time and stabllity.

Stage (c) Reacticn of the intermediate $\mathrm{N}$ in two ways (one proacing active radicals, the other not)

Thus inactive products, causing a pressure

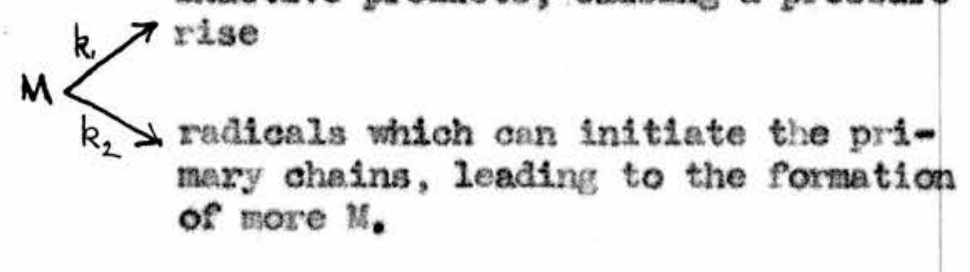


The conditions to be obeyed are that $k_{1} \gg k_{2}$ and that $M$ should have a lifetime of the order of seconds or minutes. Norrish (23) has demonstrated that if the nolecule $M$ can survive for one minute between its formation and its entering into a branching reaction then it would be expected to attain a pressure of several m.ms. during the reaction. For this scheme the net branching factor is given by $k_{2}(v-1)-k_{1}$. Presumably the acceleration of the rate falls off to zero because $v$ or $k_{2}$ decreasesafter the initial autocatalytic period due to depletion of reactants or accumulation of products. Harding (73) suggested the existence of a second type of degenerate branching in which the radicals from 16 , as well as initiating primary chains, can decompose molecules of if to give inactive products. According to this scheme a limiting rate could occur early in the reaction before there was any serious depletion of reactants. This latter type of chain branching seemed to be out of the question in the cxidation of cyclopropane since analysis had shown that at the time of attainment of maximum rate, the reaction was well on its way to completion and that about half of the reactant not present in excess had been consumed. This suggested that the reason for the failure of the rate to continue to increase exponentially was, in fact, the serious depletion of reactants.

The identity of the intermediate $M$ in the cyclopropane oxidation was decided to be formaldehyde. Only two types of slow combustion intermediate have been described previously peroxides and formaldehyde. In the present investigation all 
the evidence was against peroxides. Despite repeated and very careful attempts to detect peroxides in the products of the reaction (the condensible products romoved at the time of attainment of maximum rate of seversl experiments were collected and the aggregate was tested for peroxide by the ferrous thiocyanate and starch-iodide nethods) it was quite certain that even at the lowest temperature studied $(378 \mathrm{c})$ no percaide could be deteated in the products. On the other hand, formaldehydo was found to be present in reasonable amount under al1 conditions of temperature and pressure. It was considered to be very signifieant that its conoentration varied wi.th time in a mamer analagous to the rate end, in particular, that its presaure reached a maximu value at just dicut the same time as the rate reached its meximum. Thus in any single experiment the rate at any given tine appeared to depend upon the anount of Cormaldehyde present at that time. In contrast with this was the fact that the neximu rate depended rather upon the initial pressures of reactants.

The stuay of the effect of adaing formaldehycle to the oxidation system yielded sone extremely interesting results. The first was that the addition of a small quantity of formaldehyle (about $0 \cdot 3$, of the total) reduced the induction period $\theta$ by $37 \%$ and, still more striking, reanced $\tau$ by $61 \%$ without altering the maximum rate at all. Inorease of the amount of formaldehyde added progressively reduced $\gamma$ which was very close to zero $(0.1$ mimutes) when the quantity of adaltive was $7 \cdot 8 \mathrm{~m} \cdot \mathrm{m}$. This increased adation of the aldehyde had a less 
profound effect upon $\theta$ since the pressure change preceding the attainment of maximum rate was constant and independent of the added formaldehyde within the limits of experimental error and since a certain, finite time was always necessary for the occurrence of that pressure change. Thus the effect of formaldehyde addition upon $\theta$ was great at first but decreased in magnitude later. When the amount of additive exceeded about $10 \mathrm{~m}, \mathrm{~m}$, a slight effect upon the maximum rate was observed and this rate gradually increased from 11.9 to $14 \mathrm{~m}, \mathrm{~m}_{*} /$ minute when the pressure of added formaldehyde was increased from $7 \cdot 8 \mathrm{~m}, \mathrm{~m}$. to $35 \cdot 2 \mathrm{~m}, \mathrm{~m}$.

These results were rather different from those of Harding and Norrish (64) who added formaldehyde to ethylene-oxygen mixtures and found that the decrease in induction period (measured by the intercept on the time axis of the tangent to the pressure-time curve at $\left.\Delta p_{\max }\right)$ was proportional to the pressure of added formaldehyde and that addition of the intermediate in amounts greater than that required to eliminate the induction period led to increases in the initial rate of oxidation over the normal maximum rate. The rate subsequently fell to its normal value. In the ethylene-oxygen reaction, however, the rate reached a maximum after a comparatively small pressure change whereas the maximum rate of slow combustion of cyclopropane occurred after about $50 \%$ of the reactant not in excess had been consumed. Thus the failure of the rate to continue to increase with time was due to consumption of the reactants in the latter reaction. The two combustions, therefore, must be regarded as essentially different. 
In view of these facts it was conoluded that the essential intermediate responsible for the degenerate chain branohing in the slow combustion of eyclopropane was formaldehyde. Bxperiments showed that the maximum pressure of formeldehyge was independent of the initial cxygen pressure except when this was very low and was proportional to the initial cyclopropane pressure, although this proportionnlity mas less mariced at hisher cyolopropane pressures (possibly due to diffioulties of extraction or analysis). The maximun preasure of fomaldehyle varied with the temperature in a manner corresponding to an activation energy of $10.5 \mathrm{kos} . \mathrm{s}$. per mole. There vas, thus, desplte the proportionality between rate and pressure of Intermediate auring one experiment, a great aiffernece between the pressure and temperature relations of the moximun rate and those of the mexinum formaldehyde pressure. Before attenpting to deduce a mechanism for the reaction it would be well to surnarise the varlous types of elementary reaotion which are regarded as auffictently plausible to be postulated in a gas phase chaln reaction schene. Whalsh emphastsect the necessity of writing reaction steps energetically feasible and having a favourable steria factor (74). Such elementary reations he divided into four olasses:(a) reactions involving the breaking of one bond, e.g.

$$
\mathrm{OH}_{3}-\mathrm{CH}_{3} \longrightarrow \mathrm{CH}_{3}+\mathrm{CH}_{3}
$$

(b) reactions involving the formation of one bond, $0 . \mathrm{g}$.

$$
\mathrm{CH}_{3}+\mathrm{CH}_{3} \rightarrow \mathrm{CH}_{3}-\mathrm{CH}_{3} \mathrm{H}
$$


(c) abstractions of an atom (partioulerly of hyarogen) from a molecule by a redical (involving the breaking of one bond and the formation of another), e.g.

$$
\mathrm{CH}_{4}+\mathrm{OH} \longrightarrow \mathrm{OH}_{3}+\mathrm{H}_{2} \mathrm{O}
$$

(d) resctions involving the transfer of energy from a radical or molecule e.g.

$$
\mathrm{CH}_{3}-\mathrm{CH}_{3}{ }^{*}+\mathrm{H} \rightarrow \mathrm{CH}_{3}-\mathrm{CH}_{3}+\mathrm{M}^{3}
$$

Sone of the, reactions which have been subgested by Norrish do not fall into one of these four classes and might therefore appear suspeot. Ubbelohde too has oriticised some of Norrish's proposed reaction steps, minly on the grounals that their gecmetry indleates that their aotivation energies may be almost as high as the energies required for fissicn of the bonds coneerned and that there is no ouvious source of these activation energies (75).

Walsh did make one very importent exception to his rules, stating that it was not unpleusible to suppose the ooourrence of a reaction more ocmplicated than those given above for an energy-rich radical A particularly if this were a large enough body to allow distribution of the excess energy over various vibrational ägrees of freedcn. If whoh were the osse the radioal would be undergoing far greater geometrical distortions than usual thus facilitating the ocourrence of what would norrally be described as less likely reactions. Furthermore an energy-rioh radical, if not dosotivated by collisions, would be expeoted to take part in reactions normally requiring en activation energy high enough to make 
such reactions Improbable. So long as the radioal preserves its exergy of formation, however, the energy of activaticn of a subsequent reaction vill be consicerably less than the endotheraicity of that reaction. These considerations were borne in mina in the decuation of reaction mechantsm.

The eluaidaticn of the mechanism of the reaction was divided into two perts - a consideration of the possible modes of formation of formazdehyle and an examination of 1ts function as the degenerate branohing-chain internediate.

One might write down vorious possible reactions involving cyelopropane and leading to the formation of formaldehyde e.g.

$$
\mathrm{C}_{3} \mathrm{H}_{6}+\mathrm{O} \rightarrow \mathrm{C}_{2} \mathrm{H}_{4}+\mathrm{CH}_{2} \mathrm{O}
$$

This reaction was disregarded imediately since tests for the presence of ethylene in the reaction products were cuite negative. In any event wah oritisa could ve direoted at such a reaction from the point of view that the partioipation of coxygen atcons was unlikely at the temperatures involved. A second possible reaction was:-

$$
\mathrm{C}_{3} \mathrm{H}_{6}+\mathrm{O}_{2} \rightarrow \mathrm{C}_{2} \mathrm{H}_{4} \mathrm{O}+\mathrm{CH}_{2} \mathrm{O}
$$

It was imnediately noted that this involved the flssion of two C - bonds and one $0-0$ bond, and the fornation of two $\mathrm{C}-0$ and one $0=0$ bonds. Thus 1 t would be expected that the reaction woula have a very low steric Pactor since anch a large rearxangement would se necessary in the activated corplex and for that reason this reaction also was disregarded. 
A third auggestion involved the inftial breaking of a C $C$ bond in oyclopropene and the subsequent reaotion of the alradical formed. Thus:-

$$
\begin{aligned}
& \mathrm{O}_{3} \mathrm{H}_{6} \longrightarrow \mathrm{OH}_{2}-\mathrm{CH}_{2}-\mathrm{OH}_{2} \\
& \mathrm{O}_{2}+\mathrm{CH}_{2}-\mathrm{CH}_{2}-\left.\mathrm{CH}_{2} \mathrm{i} \rightarrow\right|_{0} ^{\mathrm{CH}_{2}-\mathrm{OH}_{2}-\mathrm{CH}_{2}} \longrightarrow \mathrm{CH}_{2} \mathrm{O}+\mathrm{CH}_{2}
\end{aligned}
$$

Now the production of methylene radioals in that way would lead to the foxmation of cxygen atcras which might degrade the $\mathrm{C}_{3} \mathrm{H}_{6}$ alradion by auocessive ciestruction of $\mathrm{CH}_{2}$ groups. Thass-

$$
\begin{aligned}
\mathrm{CH}_{2}+\mathrm{O}_{2} & \rightarrow \mathrm{CH}_{2} \mathrm{O}+\mathrm{O} \\
\mathrm{O}+\mathrm{CH}_{2}-\mathrm{CH}_{2}-\mathrm{CH}_{2} & \rightarrow \mathrm{CH}_{2} \mathrm{O}+\mathrm{CH}_{2}-\mathrm{CH}_{2} \text { eto. }
\end{aligned}
$$

This idea was disoarded largely because of the fact that the ${ }_{3}{ }^{1} 6$ afradical had been suggested as the intermediate in the Isomerisation of oyclopropene and beoause the adtivation energy of 1ts formation from oyclopropane had been found to be $65,200 \mathrm{eals} /$ mole (60). If the mechanism above were adopted the splitting of the ring would bo the rate controlling step and the cotivation energ of the conisustion vould have had to be 65,200 onls/raole (which it was not) since it was alffioult to imagine hov the diradical formation oould prooeed in any wry other than unimolecularly. This also raised the point that this meohanism did not suggest any explanation of the autooatalysis. A very frecuently postalated reaction is hydrogen abstraction from hydrooarbons by radioals (including cxyzen molecules). Thus:-

$$
\begin{aligned}
& \mathrm{RH}+\mathrm{X} \rightarrow \mathrm{R}+\mathrm{HX} \\
& \mathrm{Ox} \quad \mathrm{C}_{3} \mathrm{H}_{6}+\mathrm{X} \rightarrow \mathrm{C}_{3} \mathrm{H}_{6}+\mathrm{HX}
\end{aligned}
$$


Consideration of the value of suah a reaction step was made with view to determining whether it facilitated explanation of the formation of formaldehyde and whether this could proceed by a simple chain reaction involving the oyolopropyl radiaal. It is well known that aligy radicals react with oxygen to form alkylperoxyl radioals whloh, if itable, can react with another fuel molecule to form percorldes (this is the basis of the peroxide theory of the "lov-temperature" mechanism of hyarocarion axidation). In the event of instability of the percoxyl radical (which is endowed with a greet excess of energy just after its formation) due to its chemial constitution or to the temperature, it may decompose to yleld active products. Since no percxides had been detected at any time, even at lower temperatures, the cyolopropylperoxyl radical would have been unstable, if formed.

$$
\mathrm{C}_{3} \mathrm{Hi}_{5}+\mathrm{O}_{2} \longrightarrow \mathrm{C}_{3} \mathrm{HH}_{5} \mathrm{O}_{2}
$$

The possible decomposition of this radical acoording to the ecuation

$$
\mathrm{O}_{3} \mathrm{H}_{5} \mathrm{O}_{2} \longrightarrow \mathrm{CO}+\mathrm{OH}_{2} \mathrm{O}+\mathrm{CH}_{3}
$$

was stolohicmetrically possible but at first sight such a reaction would appear to violate all the rules regarding simpliaity of elementary chenges, since it requires the flsaion of one $C-H$, three $C-C$ bonds, one $0-0$ bond and the formation of one $6=0$ bond and one $C x$ bond. However, in viev of the fact that the formation of metiny radicals provided the basis for a primary chain resotion involving oyolopropane (and, of course, methane had beon deteoted, in sall amounts, in the 
proluots) the reaotion was oonsliered in nore detail. It wes re-viritten as a series of simpler steps.

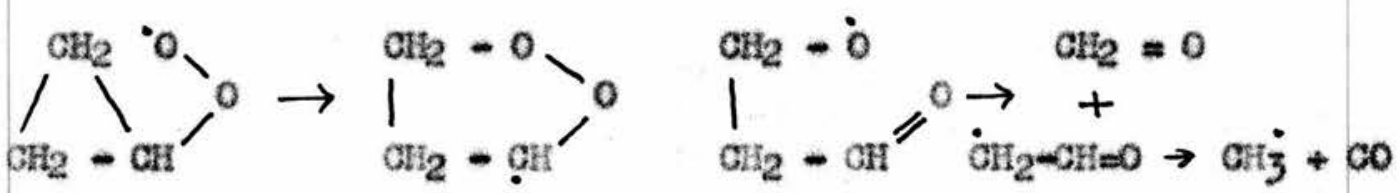

The first step involves the novement of one electron, presumably exolted by the acounulation of sufficient of the energy (earned by the raaical) in the $a-c$ bond conoerned. It leads to the probuation of a five-nembered ring systen whose weakest Iinic Is the 0-0 band, partiaulariy when the $\alpha$ carion atom bears a free eleotron which will tend to disarpear by the formation of a caxponyl graxp (again by the movement of only one eleatron). The molecule now has the struature of an aldomalkoxy2 redical and loses formaldehyde readily by the process postulated in the peroxide mechanisa of hydrocarbon oridation. It will be noted that this third step again involves the movenent of only one eleotron. Wow the remaining radical CH2 CH=0 may be regarded as a simple type of aldehyde, extrenely unstabie due to 1 ts being a ractioal and also on acocunt of the laxge ancunt of energy it carries away from its exothermic formation. It would, therefore, be expected. to pyrolyse to aarbon moncuxide and methyl very rapdaly.

Thus an apparently over-aonplex reaction when studied, step by step, was seen to involve three seperate oneweleotron shifts and a prototroplo change all of whtch oould be regarded es simple and guite Iikely, partioularly in view of the feat that the original realcal was energy-rich, It should, perhaps, 
be emphasised that, even under such favourable starting conditions, cnly a uninolecular decomposition coula be so conplex and yet so Hikely.

Accepting then the formation of formaldehyle from the cyclopropyl radical

$$
\mathrm{C}_{3} \mathrm{H}_{5}+\mathrm{O}_{2} \rightarrow \mathrm{C}_{3} \mathrm{H}_{5} \mathrm{O}_{2} \rightarrow \mathrm{CO}+\mathrm{CH}_{2} \mathrm{O}+\mathrm{CH}_{3}
$$

one next considered the use of the methyl redicals in propagation of a primary ohain reaction. The only likely mechanism was

$$
\begin{aligned}
& \mathrm{CH}_{3}+\mathrm{O}_{2} \rightarrow \mathrm{CH}_{2} \mathrm{O}+\mathrm{OH}^{\circ} \\
& \mathrm{CH}^{\circ}+\mathrm{C}_{3} \mathrm{H}_{6} \rightarrow \mathrm{C}_{3} \mathrm{H}_{5}^{\circ}+\mathrm{H}_{2} \mathrm{O}
\end{aligned}
$$

These reactions require no discussion as thoy have been suggested by several authors $(25,30,31)$ and appear to be vell established reaction steps in the methene cxidation reaction.

It would be well to summarise the reactions suggested for the primaxy chein leacing to the prodretion of formaldehyie.

$$
\begin{array}{ll}
\mathrm{C}_{3} \mathrm{H}_{6}+\mathrm{Or}^{\circ} & \rightarrow \mathrm{C}_{3} \mathrm{H}_{5}^{\circ}+\mathrm{H}_{2} \mathrm{O} \\
\mathrm{C}_{3} \mathrm{H}_{5}+\mathrm{O}_{2} & \rightarrow \mathrm{O}_{3} \mathrm{HH}_{5} \mathrm{O}_{2} \\
\mathrm{C}_{3} \mathrm{H}_{5} \mathrm{O}_{2} & \rightarrow \mathrm{CO}+\mathrm{OH}_{2} \mathrm{O}+\mathrm{CH}_{3} \\
\mathrm{Cr}_{3}+\mathrm{O}_{2} & \rightarrow \mathrm{CH}_{2} \mathrm{O}+\mathrm{Cr}^{\circ}
\end{array}
$$

The thermoghemistry of these reations will now be considered. The heat of the first resotion is caloulable fron a lmowleage of the band dissociation energy of the II-OH bond in water which is $118 \mathrm{kads} .(76)$ and the bond dissoolation energy of the II-CyHs bond in ayolopropane. Trotman-Dickenson (77) taking the energy of activation of the metathetioal reaction

$$
\mathrm{CH}_{3}+\mathrm{CH}_{4} \rightarrow \mathrm{CH}_{4}+\mathrm{CH}_{3}
$$


as about $12 \cdot 8 \mathrm{kals} /$ mole and the bond dissociation energy $D$ $\left(\mathrm{Gr}_{3}-\mathrm{H}\right)=102$, showed that the relation $\Delta E=\alpha \Delta H$ held for the resotion of methyl radicals with a series of allenes where $\mathrm{E}=$ the activation energy of the methyl + alkane reactions and $\mathrm{H}=$ the heat of these reactions, i,e. the bond dissooiaticn energies of the cal bonds broken in the alkanes. ProtmanDiokenson and 3 teacie $(78)$ found that the energy of activation of the hyorrogen abstraction reaction of methyl with cyolopropane was $10 \cdot 2$ leals/mole.

$$
\begin{aligned}
& \text { Then } \Delta E=12 \cdot 8-10 \cdot 2=2.6 \\
& \text { if } \quad \alpha=0.5 \text {, then } \triangle H=5.2 \\
& \text { Itence } \mathrm{D}\left(\mathrm{C}_{3} \mathrm{H}_{5}-\mathrm{H}\right)=102-5 \cdot 2=97 \mathrm{kaals} \text {. }
\end{aligned}
$$

Trotman-Dicisenscn (77) auggested that due to the similarity between the bonds broken and formed, $\alpha$ should we closely equal to 0.5 . Even if $\alpha$ were rather less than 0.5 the bond as asociation energy derived would not differ very greatly frca 97 koals. Thus the flrst reation was written

$$
\mathrm{C}_{3} \mathrm{H}_{6}+\mathrm{OH}^{\circ} \rightarrow \mathrm{C}_{3} \mathrm{H}_{5}+\mathrm{H}_{2} \mathrm{O}+21 \mathrm{kcals} \cdot(118-27) \text {. }
$$

The change of heat ocntent involved in the seocnd and third reactions could not be caloulated since no infornation wos avaliable on the heat of formation of the oyolopropylpercoxyl. radical. It wes possible to calculate the exatherricity of the overall reaction

$$
\mathrm{C}_{3} \mathrm{H}_{5}+\mathrm{O}_{2} \rightarrow \mathrm{CO}+\mathrm{CH}_{2} \mathrm{O}+\mathrm{CH}_{3}
$$

since the heats of formation of methy 179$)$, formaldehyde (80) and arbon monoride (81) were known, and the heat of romation 
of the ayolopropyl radical wes calculable from a knomledge of the bond dissociation energy of the $\mathrm{C} 3 \mathrm{Hg}-\mathrm{H}$ bond in ayclopropane, the heat of fornation of a hyorogen atom (79) and the heat of formation of oyolopropane (82). The latter value was ostained from the heet of conbustion of oyolopropene and wes preferred to other values reported in the literature (83). The values of these heats of formation and the anloulation of the exothermiaity of the oxidation of the cyalopropyl radical are given below.

$\begin{array}{ll}\text { Compound } & \Delta H_{f}^{\circ} \text { keals. } \\ \text { Methyl } & +31 \\ \text { Formaldehyde } & -28 \cdot 7 \\ \text { Carbon monoxide } & -26.8 \\ \text { Hyatrogen atom } & +52 \\ \text { Cyclopropane } & -12.7\end{array}$

How $D\left(\mathrm{C}_{3} \mathrm{H}_{5}+\mathrm{H}\right)=\Delta H_{f}^{\circ}\left(\mathrm{C}_{3} \mathrm{H}_{5}\right)+\Delta H_{f}^{\circ}(\mathrm{H})-\Delta H_{f}^{\circ}\left(\mathrm{C}_{3} \mathrm{H}_{6}\right)$ $\therefore \Delta H_{f}^{\circ}\left(\mathrm{C}_{3} \mathrm{H}_{5}\right)=97-52-13=32 \mathrm{kaels}$.

And for

$$
\mathrm{O}_{3} \mathrm{H}_{5}^{\circ}+\mathrm{O}_{2} \rightarrow \mathrm{CO}+\mathrm{CH}_{2} \mathrm{O}+\mathrm{CH}_{3}
$$

$$
\Delta H=-27-29+31-32=-57 \text { kos.ls. }
$$

The exothemicity of the last reaction step (the oxidation of methyl) follows by subtraction of the heat of formation of methyl from the sum of those of forraldehyde and hydroxyl (79). Thus $\Delta \mathrm{H}=-29+10-31=-50 \mathrm{koals}$. The reaction steps matiten for the formation of formeldehyde from oyelopropane by a straight chain were, therefore, thermochemically acceptable and, at the save time, geometrically simple. 
The next problem was the meohenism of oxidntion of formaliehyde so that it functicned as a degenerete bronching intermediate in the resotion. The reaction of the aldehyde vith molecular axygen was constdered.

$$
\mathrm{Fr}_{2} \mathrm{O}+\mathrm{O}_{2} \longrightarrow \mathrm{CHO}^{\circ}+\mathrm{HO}_{2}^{\circ}
$$

This is a branching reaction and would appear to to suffictently endothernie to merit serious ansideration. The bond aissociaticn energy of the C-1l bond in formaldebyde has been the subjeat of scme aiscussion but mary authors believe it to be about $75-80$ kcals (e.8. Gorin (84), MaDowell and Mhomas (85), Roverts and Sicirner (86) Hoare and $/ \mathrm{lsh}(87)$ ) and about $78 \mathrm{kcals}$ seemed a reascnable value for $D(H C O-H)$. Such more asfirmalt to assign a value to is the energy liberated in the formation of the $\mathrm{H}-\mathrm{O}_{2}$ bond. Walsh (22) aiscussed previous evidence and estimates and conoluded that the velue of this energy lay in the range 60-70 kaels. In a later cormunication (87), however, Walsh took the energy evolution to be $55 \pm 10 \mathrm{keals.}$. If this value $1 \mathrm{~s}$ acoepted, the endotherniatiy of the reaction between formaldehyle and oxygen is $78-55 \pm 10=23 \pm 10$ konls. so thet its energy of activation would be probably rather nore then $25 \mathrm{keals} / \mathrm{mole}$. Inergetioal2y, therefore, the resotion is suitable. It is also necessary to atterpt to fustify the inolusion of formyl and hydroperoxyl. radials in the recotion soheme. The formation of the forryl racicals seems the $\mathrm{cnly}$ feasible result of any probably gasphase reaction of formaldehyde and they will be destroyed either by direot reaction with orygen to yield carbon moncoxide and hydropercoxyl radicals or by deccmposition to aarbon monoxide and 
hydrogen atons พt310is $w 1.21$. forra $110_{2}$ radicals loy reaction whth corygen. The overall effect will be the seme and it an be shown that the cholce of reaction offered vill not affoct the general kinetios. Isttle oar be said about the thermochenistry of the reaction

$$
\mathrm{HaO}^{\circ}+\mathrm{O}_{2} \rightarrow \mathrm{HO}_{2}+\mathrm{CO}
$$

since there is so wuoh doubt about the dissociation energy of the $\mathrm{G}-1 \mathrm{l}$ bond in the formy radias. Gorin (84) has given 26 koals as on upper limit so that it is very probable that the reaction is quite exothermic. A possible explanation of the formation of smill cuantities of hydrogen towards the end of the reaotion is that, at that time, the chence of a successful $\mathrm{H}^{\circ}+\mathrm{O}_{2}$ col13alen will be sarizer and hydrogen nay be formed by reaction with cyclopropene nolecules of hycirogen atcons forned by decorposition of formyl radiesls. In addition, due to depletion of the oxygen present, the probability of uninolecular decomposition of formy 1 will be greater wider these olroutstances. A similar explanetion of the proaluation of mall anounts of methene is possible aue to hyarogen abstraction reactions of methyl raciscals.

Another possible reaction of the formyl. radionl would be to add oxygen.

$$
\mathrm{HCO}^{\circ}+\mathrm{O}_{2} \longrightarrow \mathrm{HCO}_{3}
$$

The fonylpercxyl radioal thus formed might affuse to the walls to decompose to carbon alcoxide and a hydroxyl radical. This would explain the appearance of arbon dioxide in the end-produots of the coidation. It is, indeed, possible that 
the Sormation of hydropercoxyl radicals from forral radicals occurs by a sinilar prosess. The destruction of the latter would then be regresented:-

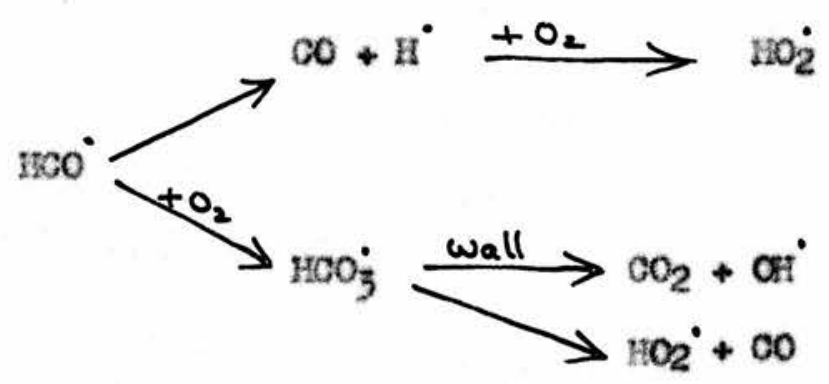

Disregarding the uninoleculax decomosition which will not affeot the kinetios of the naximum rate, the removal of fornyl radieals will then depend upon the pressures of formyl and crygen.

As to the 24kelihool of the portioipation of hydroperoxyl radion in the reaction, it is importent to oonstider the similarity between the aethane and oyolopropane oxidations. In both, forraldehyce is the essential intermediate and there is very strong evidenoe that, in the former reaction, the radioal responsible for the inttiation of the secondary chatn is the hydroperoxyl $(87,89)$. Walsh et al. axrived at this conclustion as a result of their study of the lead oxide inhibition of the combustion. The coating of a reaction veasel with lead oxide has been found to inhibit the slow octibustion of cyolopropsne (90). The HO2 radicals produced by the branching resetion will initiate the secondary chains by produolng oyelopropyl radicals from the hydrocarion by the reacticn:

$$
\mathrm{C}_{3} \mathrm{H}_{6}+\mathrm{HO}_{2} \longrightarrow \mathrm{C}_{3} \mathrm{H}_{5}+\mathrm{H}_{2} \mathrm{O}_{2}-1 \mathrm{kaal}
$$

The endothermiat.ty of this resotion was oaloulated from Walsh's estimate of the bond dissociation energy $\dot{D}\left(\mathrm{HO}_{2}-\mathrm{H}\right)=96^{\prime}(22)$. 
Ittle oan be said about the fate of the hydrogen percorlde thus formed although it probaliy decomposes heterogenecusly to water and oxygen (88).

The non-brenohing reactions of formaldehyde probably involve its reation with hyaroperoxyl and hydroxyl radicals (thus explaining the faolitty of the non-brarahing renotions compered with the branohing reaction). Thus

$$
\begin{aligned}
& \mathrm{H}_{2} \mathrm{O}+\mathrm{HO}_{2} \longrightarrow \mathrm{HOO}^{\circ}+\mathrm{H}_{2} \mathrm{O}_{2}+17 \mathrm{kch} 2 \mathrm{~s} \text {. Pollared by } \\
& \mathrm{HO}+\mathrm{O}_{2} \longrightarrow \mathrm{CO}+\mathrm{HO}_{2}^{\circ}
\end{aligned}
$$

The nett effect is $\mathrm{CH}_{2} \mathrm{O}+\mathrm{O}_{2} \rightarrow \mathrm{CO}+\mathrm{H}_{2} \mathrm{O}_{2}$.

Thus there is no inorease in the number of rallads consecuent upon that non-branohing reaotion. The same is true for the reaction of hydroxyl with formalehyde, although the nature of the radical changes.

$$
\begin{aligned}
& \mathrm{OH}_{2} \mathrm{O}+\mathrm{OH} \longrightarrow \mathrm{CrO}+\mathrm{H}_{2} \mathrm{O}+39 \text { keals. } \\
& \mathrm{CHO}^{\circ}+\mathrm{O}_{2} \longrightarrow \mathrm{CO}+\mathrm{HO}_{2}^{\circ}
\end{aligned}
$$

These reactions are not ocmplex ohnges and are suitably exom thermic and since the overall effect in each ase is the oxidation of formelcaehycie by carygen to inert products (oatalysed by a railoal), together they constitute a now-branohing mechanism of intermediatemenoval as required by the Semenov saheme of degenerate chatn branohing.

The reaction steps, so far discussed, form the basis of a reation soheme for the slov conbustion of ovelopropene. They are all chentoally probable and involve simple nolecules and radicals whose participation in sinjilar reacticns has often 
been suggested. Furthermore, the soheme explains the function of formaldehyde as degenerate chain branohing intermediste. It ressains to discuss possible ohain initiation and chatn termination reactions. Very little oan be sald about the Pormer since it is almost certainiy a heterogeneous reacticn but it might well involve the reaction of oyolopropene with axygen on the walls (possibly to form cyolopropyl and hydroperoxyl radicals). No initiation reation has been included in the complete soheme. It is very doubtrul if chain termination reactions could be justified experimentally but they are necessary if the scheme of reacticns is to yield a rate expression. The experimentally-deternined rate expression indicated that the ternination of the chalns involves destruction of chain carriers by reaction wh th either ayolopropane or cxygen and that one or both of these reactions ocours on the surface. Since the secondary chain intitiation depends upon the presence of hydroperoxyl radicals and in view of Falsh's conelusions about the importance of ternination by $\mathrm{HO}_{2}$ destruction in the methane oxidation, the following termination reactions are sug ested:-

$$
\begin{array}{lll}
\mathrm{C}_{3} \mathrm{H}_{6}+\mathrm{HO}_{2} & \longrightarrow & \text { Inactive products. } \\
\mathrm{O}_{2}+\mathrm{HO}_{2} & \longrightarrow & \text { Inactive products. }
\end{array}
$$

The difficulty is, of course, to narne these inactive products. The first, particularly if it occurred at the valls of the vessel, might lead to very greet struoturel changes, Reactions similar to this one and equally vague have been postulated in reaction schenes referring to hydrocarbon combustions in the 
"Iowmeraperature" region (e.g. 61). The second termination step above may possibly be explained in the following way. A hydropercaxyl radioal alffusing to the wall may alight olose to an adsorbed cxygen moleoule. The resulting complex an be represented thas:-

$$
\mathrm{O}_{2}-\mathrm{H}--\mathrm{O}_{2}
$$

1.e. there is reschance between the two ancrital forms

$$
\mathrm{O}_{2}+\mathrm{H} \quad \mathrm{O}_{2} \text { and } \mathrm{O}_{2} \mathrm{H}-\mathrm{O}_{2}
$$

On the approach of a second hydroperoxyl radical the following reaction ensues:-

$$
\mathrm{O}_{2}-\mathrm{Hi}--\mathrm{O}_{2}+\mathrm{HO}_{2}^{\circ} \longrightarrow 2 \mathrm{O}_{2}+\mathrm{H}_{2} \mathrm{O}_{2}
$$

The rate-deteraining step of this termination reaction will be the first whose effiaiency will depend upon the cxygen gas pressure if the extent of axygen adsorption is small.

vith the exoeption of the questionable primary initiation reaction the reactions are collected into a single scheme below. 1. $\mathrm{C}_{3} \mathrm{H}_{6}+\mathrm{HO}_{2}^{\circ} \longrightarrow \mathrm{C}_{3} \mathrm{H}_{5}+\mathrm{H}_{2} \mathrm{O}_{2}-1 \mathrm{keal}$.

2. $\mathrm{C}_{3} \mathrm{H}_{6}+\mathrm{Or} \longrightarrow \mathrm{C}_{3} \mathrm{H}_{5}^{\circ}+\mathrm{H}_{2} \mathrm{O}+21$ koals.

3. $\mathrm{C}_{3} \mathrm{H}_{5}+\mathrm{O}_{2} \rightarrow \mathrm{O}_{3} \mathrm{H}_{5} \mathrm{O}_{2} \rightarrow \mathrm{CO}+\mathrm{Cr}_{2} \mathrm{O}+\mathrm{CH}_{3}+57 \mathrm{kcals}$.

4. $\mathrm{CH}_{3}+\mathrm{O}_{2} \longrightarrow \mathrm{CH}_{3} \mathrm{O}_{2} \rightarrow \mathrm{CH}_{2} \mathrm{O}+\mathrm{OH}^{\circ}+50 \mathrm{kaals}$.

5. $\mathrm{OH}_{2} \mathrm{O}+\mathrm{O}_{2} \longrightarrow \mathrm{CHO}^{\circ}+\mathrm{HO}_{2}-23 \mathrm{kala}$.

6. $\mathrm{MH}_{2} \mathrm{O}+\mathrm{HO}_{2}^{\circ} \longrightarrow \mathrm{GHO}^{\circ}+\mathrm{H}_{2} \mathrm{O}_{2}+17 \mathrm{kals}$.

7. $\mathrm{CH}_{2} \mathrm{O}+\mathrm{OH}^{\circ} \longrightarrow \mathrm{MHO}^{\circ}+\mathrm{H}_{2} \mathrm{O}+39 \mathrm{kals}$.

8. $\mathrm{CHO}^{\circ}+\mathrm{O}_{2} \longrightarrow \mathrm{CO}+\mathrm{HO}_{2}^{\circ}+30 \mathrm{kana}$.

9. $\mathrm{C}_{3} \mathrm{H}_{6}+\mathrm{HO}_{2}^{\circ} \rightarrow$ inactive produots 10. $\mathrm{O}_{2}+\mathrm{HO}_{2} \rightarrow$ inactive produets 
Before any theoretial. relationships an be derived from this schene it is necessary to meke two assumptions, The first is, that at the time of ettainment of the maximum rate, a stationary state can be supposed for all radios.ls and for formaldehyde (experiment showed that the rate of formation of the aldehycle was equel to 1 ts rate of renoval at the time of the maximum rate). The seacon is that the pressures of reactants remaining at that time are proportional to their initial pressures. This an be shown for the crygen pressures. Ans2ysis showed $\left(\Delta p_{0_{2}}\right)_{t} \alpha(\Delta p)_{t}$ $\therefore$ At time $\theta \quad\left(\Delta p_{0_{2}}\right)_{\theta} \propto \Delta p_{\max }$.

Hut by experiment $\Delta p_{\max } \propto p_{o_{2}}$ (initial)

Hence $\left(\Delta p_{\mathrm{O}_{2}}\right)_{\theta} \propto \mathrm{po}_{2} \quad$ (intitia) 1.e. $\left(\Delta \mathrm{PO}_{2}\right)_{\theta}=K \mathrm{PO}_{2} \quad$ (initial) sut $\left(\Delta p_{\mathrm{O}_{2}}\right)_{\theta}=p_{\mathrm{O}_{2}}($ Initial $)-p_{\mathrm{o}_{2}}($ at time $\theta)$. $\therefore p_{o_{2}}($ at time $\theta)=(1-k) p_{0_{2}}$ (initial).

It is not possible to dersonstrate the existence of a similar expression for the cyclopropane pressure at the time of the maximun rate but inspection of the results of anelyses carried out under guite different conditions shows that $\frac{p_{p p} \text { (at tine } \theta \text { ) }}{p_{c p}(\text { initial })}$ is constant within the limits of experimental error.

The partial justification of the two assumptions makes it possible to attempt some deduction of the kinetios of the reaction. Calling the formaldehyde pressure (p) and the cyclopropane pressure (c), we have (disregarding the less important formaldehyde removal by reaction 5)

$\frac{a(p)}{d t}=k_{4}\left(\mathrm{CH}_{3}\right)\left(\mathrm{O}_{2}\right)+k_{3}\left(\mathrm{C}_{3} \mathrm{H}_{5}\right)\left(\mathrm{O}_{2}\right)-k_{6}(p)\left(\mathrm{HO}_{2}\right)-k_{7}(\mathrm{~F})(\mathrm{OH})$ 
At the time of the attaimment of the maximum rate, $\frac{a(p)}{d t}=0$ and $k_{4}\left(\mathrm{CH}_{3}\right)\left(\mathrm{O}_{2}\right)=k_{3}\left(\mathrm{C}_{3} \mathrm{H}_{5}\right)\left(\mathrm{O}_{2}\right)$

Then $2 k_{3}\left(\mathrm{O}_{3} \mathrm{H}_{5}\right)\left(\mathrm{O}_{2}\right)-k_{6}(\mathrm{~F})\left(\mathrm{HO}_{2}\right)-\mathrm{k}_{7}(\mathrm{P})(\mathrm{OH})=0$

Applying the method of the staticnary state to the ayolopropy2 radicals, we obtain

$$
\left(\mathrm{C}_{3} \mathrm{H}_{5}\right)=\frac{\mathrm{k}_{1}\left(\mathrm{HO}_{2}\right)+\mathrm{k}_{2}(\mathrm{OH})}{\mathrm{k}_{3}\left(\mathrm{O}_{2}\right)} \text { (c) }
$$

Substitution of (2) in (1) yields the expression

$$
\left\{2 k_{1}\left(H_{2}\right)+2 k_{2}(O H)\right\}(C)=k_{6}(p)\left(H_{2}\right)+k 7(r)(O H)
$$

1.e. at the time of attaiment of naximum rate

$$
(F)=(F) \max \cdot=\frac{2 k_{1}\left(\mathrm{HO}_{2}\right)+k_{2}(\mathrm{OH})}{\mathrm{k}_{6}\left(\mathrm{HO}_{2}\right)+\mathrm{k}_{7}(\mathrm{OH})} \text { (c) max. }
$$

Now $\frac{a(\mathrm{OH})}{d t}=k_{4}\left(\mathrm{OH}_{3}\right)\left(\mathrm{O}_{2}\right)-k_{2}(\mathrm{C})(\mathrm{OH})-k_{7}(\mathrm{~F})(\mathrm{OH})$

$$
\begin{aligned}
& =k_{1}(c)\left(\mathrm{HO}_{2}\right)+k_{2}(c)(\mathrm{OH})-k_{2}(c)(\mathrm{OH})-k_{7}(\mathrm{~g})(\mathrm{OH}) \\
& =\mathrm{k}_{1}(\mathrm{C})\left(\mathrm{HO}_{2}\right)-k_{7}(\mathrm{~F})(\mathrm{OH})
\end{aligned}
$$

At time $\theta,(\mathrm{Or})=\mathrm{k}_{1}(\mathrm{C})\left(\mathrm{HO}_{2}\right)$

$$
k 7(\mathrm{P}) \text { mex. }
$$

Substitution of (4) in (3) gives

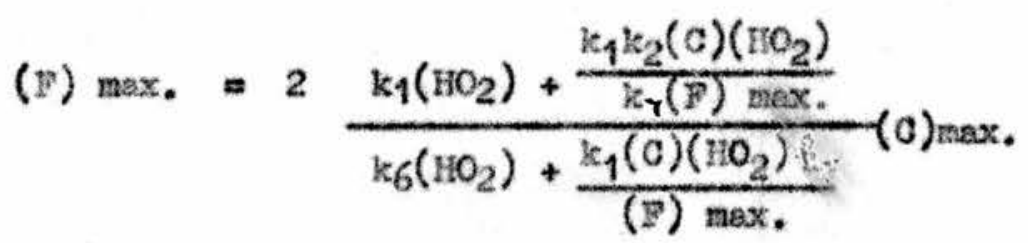

$$
\begin{aligned}
& =2 \frac{k_{1} k_{7}(p) \max +k_{1} k_{2}(c) \max }{k_{6} k_{7}(p) \max +k_{1} k_{7}(c) \max } \text { (c) } \max \text {. }
\end{aligned}
$$

$\therefore k_{6} k_{7}(p)_{\max }^{2}+k_{1} k 7(c) \max (F) \max =2 k_{1} k_{7}(c)_{\max }(F)_{\max }+2 k_{1} k_{2}(c)_{\max }^{2}$

1.e. $k_{6} k_{7}(\xi)_{\max }^{2}-k_{1} k-(c) \max (s) \max -2 k_{1} k_{2}(c)_{\max }^{2}=0$. 
This ecuation has two solutions for $(F) \max$, one of which is not adnisstble. The other is:-

$$
(F) \max =\frac{k_{1} k_{7}+\left(k_{1}^{2} k_{7}^{2}+8 k_{1} k_{2} k_{6} k_{7}\right)^{\frac{1}{2}}}{2 k_{6} k_{7}} \text { (c) tasex. }
$$

1.e. $(p)_{\max }=B(C)$ Initial, where $\mathrm{B}$ Inoludes a faotor to aceount for the proportionality between (c) initial ana (c) $\max$. Fhis result is in accord with the experimental finding that the naximum formaldehyde pressure attained during the reaction was proportional to the inttial ayelopropane pressure and, except at very low cocygen pressures, independent of the initial oxygen pressure. Due to the extremely complex nature of the proporticuality constant $B$, nothing can be said about the signifiaance of the observed temperature coeffioient with respect to the activation energies of the elementary reactions in the scheme.

The next decuetion is of the theoretial relationship between the rate of the reaction and the reactant pressures. Prom the suggested scheme, one may write:-

$$
\begin{aligned}
& \frac{-a(c)}{a t}=k_{1}(0)\left(\mathrm{HO}_{2}\right)+k_{2}(c)(\mathrm{OH}) \\
& \left(-\frac{a(c)}{d t}\right)_{\max }=k_{1}(c) \max \left(\mathrm{HO}_{2}\right)+\frac{k_{1} k_{2}(c)_{\max }^{2}\left(\mathrm{nO}_{2}\right)}{k_{7}(p) \max .} \\
& =k_{1}\left(1+\frac{k_{2}}{k j^{2}}\right)(c) \max \left(\mathrm{HO}_{2}\right)
\end{aligned}
$$

Now $a\left(\mathrm{HO}_{2}\right)=k_{5}(\mathrm{~F})\left(\mathrm{O}_{2}\right)+k_{8}(\mathrm{CHO})\left(\mathrm{O}_{2}\right)-k_{1}(\mathrm{c})\left(\mathrm{HO}_{2}\right)-k_{6}(\mathrm{~F})\left(\mathrm{HO}_{2}\right)-$ at

$$
\mathrm{k}_{9}(\mathrm{O})\left(\mathrm{HO}_{2}\right)-\mathrm{k}_{10}\left(\mathrm{O}_{2}\right)\left(\mathrm{HO}_{2}\right)
$$

And $\mathrm{kg}_{8}\left(\mathrm{OuO}_{\mathrm{O}}\left(\mathrm{O}_{2}\right)=\mathrm{k}_{5}(\mathrm{~F})\left(\mathrm{O}_{2}\right)+\mathrm{k}_{6}(\mathrm{~F})\left(\mathrm{HO}_{2}\right)+\mathrm{k}_{7}(\mathrm{~F})(\mathrm{OH})\right.$ at the maximum rate, 
And $k_{7}(r)(\mathrm{On})=k_{1}(\mathrm{C})\left(\mathrm{HO}_{2}\right)$ at the maximan rate,

and $\quad(p)=B(C) \max$, at the maximum rate.

$$
\left(\mathrm{HO}_{2}\right)=\frac{2 \mathrm{~kg}_{j} \mathrm{~B}(\mathrm{C})_{\max }\left(\mathrm{O}_{2}\right)_{\max }}{\mathrm{kg}_{9}(\mathrm{C})_{\max }+\mathrm{k}_{10}\left(\mathrm{O}_{2}\right)_{\max }}
$$

Substituting for $\left(\mathrm{HO}_{2}\right)$ in equation 5 and making use of the relations between the initial reactant pressures and those at the time of the maxinura rate, we obtain the equation:-

$$
\left(-\frac{a(c)}{a t}\right)_{\max }=\frac{K_{1}(c)^{2}\left(o_{2}\right)}{K_{2}(c)+K_{3}\left(O_{2}\right)} \begin{gathered}
\text { referring to initial } \\
\text { pressures. }
\end{gathered}
$$

Eut it was proved by analysis that the rate of removal of cyclopropane at any time was proportional to the rate of pressure increase at that tire. $\therefore\left(-\frac{a(c)}{a t}\right)_{\operatorname{mex}} \propto \rho_{\max }$

$$
\therefore \rho_{\max } \alpha \frac{\pi_{1}(c)^{2}\left(o_{2}\right)}{\pi_{2}(c)+\pi_{3}\left(o_{2}\right)}
$$

Conparison of this with the experimentally-ietermined rate expression is very favcurable. In a general way the kinetio behaviour is explained, although nothing can be saia regarding the overall activation energy of the recotion. The alove proportionelity does not include a terw depondent upon the surface but since both the termination reactions are probably surfiace dependent suoh a tern is unnecessary. The importance of the surface in the slow corsibustion of ayclopropane suggests that valuable oo elustons might be dravn from the results of experiments in vessels with different surfaces i.e. coated with different materials, If suoh experiments were performed, it might prove possible to state the initiation 
and termination, reactions with more certainty.

Another aspect of the work, worthy of further investigation,

is the effect of adding water vapour to the reaction mixture. The results obtained, so far, show a distinct positive catalytic effeot. It may be that the water, in some way, facilitates the branching reaction but since the effect of adding nore water beame less and less, it is possible that it ia due to deactivation of the surface as a chain terrainator. The termination reactions suggested in the renction scheme recuire the presence of cxygen (and probably also oyolopropane) on the walls so that, if water were preferentially adsozbed, the effect woula be explained.

It is not possible to deduce from the scheme a theoretioal expression for the incustion period in terns of reactant concentrations. It vas hoped to use the relationship:-

$$
=k_{5}(v-1)(\mathrm{r})\left(\mathrm{O}_{2}\right)-k_{6}(\mathrm{P})\left(\mathrm{HO}_{2}\right)-k_{7}(\mathrm{p})(\mathrm{OH})
$$

to deduce the net branching factor in those terns but this is, unfortunately, impossible since the net branohing faotor refers to the early stages of the reaction where there is certainly no stationary concentration of the radioals. 


\section{SU U U B Y}

The reaction between cyclopropane and oxygen has been investigsted by the static method in the temperature range $380^{\circ}$ to $430^{\circ} \mathrm{C}$, and with partial pressures of the reactants between 40 and $400 \mathrm{mo}$. There is en initiel period of negligible pressure chenge, the rate then accelerating exponentially to s waxlmum. The kinetics of the reaction have been studied by meosurement of rate of pressure change and anelysis has shown that this is equivalent to the rates of removel of the reactants and of formation of the products which are meinly cerbon monoxide and water.

The three rate cheracteristics - the maximum rate ( $\rho_{\text {max }}$ ), the net branching factor $\left(A^{\prime}\right)$ and the incuction period $(\theta$ or $\tau)$ obtained from the pressure-time curves, have been found to be surface-sensitive. Hydrogen hes an inhibiting effect which is probebly due to the removal of some reaction procuct from the vessel walls. The addition of nitrogen has no elfect but the adation of water vapour leads to sorne increase in $\mathcal{I} \max$ and $A^{\prime}$ and to a reduction in $\theta$, ggain probably due to a surface effect.

With lower oxygen presoures the maximim rate is proportionel to both the oxygen and cyclopropene pressures, while with higher oxygen presaures it vories as the squere of the hydrocarbon pressure and $i_{B}$ in ependent of the oxygen pressure. Which rate expression obtains, is shown to depend 
upon the teraperature and relative reactant pressures. The variation of the net branching factor is sirailar to that of the maximum rate but the reciprocel induction period always varies as the product of the cyclopropane and oxygen pressures. The overall activation energies for maximum rate and net branching factor are about $35 \mathrm{kcal}$, and for reciprocel induction period about $53 \mathrm{kcal}$. When cyclopropane is in excess the total pressure change is approximately half the initial oxygen pressure, and the pressure change preceding the attainwent of the maximata rate is proportionel to the oxygen pressure, indepencient of the pressure of cyclopropane, varies somewhat from veasel to vessel and exhibits a amall tempereture effect.

The products of the oxldation regnonsible for the increase of preasure are extremely simple, the only unstable intermediate detectable being formel chehrie whose pressure reaches a maximu at about the time of the maxiraum rate, the variation of its concentration parallelling the variation of rate of pressure change. The moximum pressure of formaldehyde is proportionel to the intis cyclopropsne pressure and, except at very low oxygen pressures, is indepencient of the oxygen pressure. Its variation with reaction temperature correaponds to an energy of activation of $10.5 \mathrm{kcal}$. The adoition of amall quantities of formaldehyce to the system leads to a drastic curtailnent of the induction period and the pressure increase may comence only a few seconis after admission of the last reactant. The results are discussed from the general point of view thet the reaction involves a chain mechanism with degenerate 
branching, and it is shown that the initiation step is probably heterogeneous. The kinetic characteristics of the reaction are compared with those of the slow combustion of other hydrocarbons and a mechanism is advanced. This involves the propagation of the primary reaction chain by cyclopropyl and hydroxyl radicals and the slow-branching intermediate is identified as formaldehyde which can react with oxygen to form hyaroperoxyl radicals which, in turn, initiate the primary chain, The non-branching reactions of formaldehyde are believed to involve hydroxyl and hyäroperoxyl radicals. Possible termination reactions are suggested and all the reaction steps have been shown to be sterically and energetically feasible. Application of the method of the stationary state to the formaldehyde and radicals at the time of the maximum rate leads to the deduction of the experimentally-deterained relationships between the maximum formaldehyde pressure and the maximum rate and the initial reactant pressures. The proposed reaction scheme also explains the formation of the products, including the small amounts of carbon dioxide, methane and hydrogen also found. 


\section{ACKNOFL}

The author wishes to recori his gratitude to Dr. Charles

F. ll. mipper for his unfailing ecivice ond encouregement, for his stimileting conversation and, bove all, for his enthusiasm for the rubject.

The best of thanks are also due to Professor James Kendall

for the proviaion of laboratory facilities and to the Anglom Iranian oil Company for a grant. 
$\mathrm{RE} \mathrm{ERKNCE}$

1. Armstrong. 1874 "Lanual of Organic Chemistry", 1st ecition, pp. 216,241 and 275 .

2. Bone and wheeler. 1902 J. Chem. Soc. p. 573

3. Bone anc theeler. 1903 J. Chem. Soc. p. 1074

4. Bone and stockings. 1904, I. Cher. Soo. p. 693

5. Bone and theeler. 1904. I. Chem. Soc. p. 1637

6. Newitt and Harfner. 1932 Proc. Roy. Soc. A, 134, 591

7. Bone, 1932 Proc. Roy. Soc. A, 137, 243

8. Cellendar. 1927 kngineering 123, 147, 182, 210

9. Bennett and Mardiles. 1927 J. Chela. Soc. p. 3155

10. Semenov, 1935 "Cherdical Kinetics and Chain Reactions". Oxford: Oxford University Press.

11. Backstrom. 1927 J. Amer, Chem, Soc. 49, 1460.

12. Egerton, 1928 Nature, tond., $122,20$.

13. Norriah. 1935 Proc. Roy. Soc. A, 150, 36

14. Hinshelwood et al. 1929 kroc. Floy. Soc. A, 125, 277

1930 Proc. Roy. Soc. A, 127, 218

1930 Proc. Roy. Soc. A, 129, 284

15. Jarkas, Haber and Harteck. 1930 Naturwisa. 18, 266.

16. Norrish and Foord. 1936 Proc. Roy. Soc. A, 157, 503.

17. Ubbelohde. 1935 Proe. Roy. Soc. A, 152, 354.

18. Bollend. 1949 Guert. Rev. Chem. Soc. $3,1$.

19. Hinshelwood et el. 1947 Disc. Fersday Boc. 2, 117, 128. (for example).

20. Minkoff.1947 Disc. Keraday Soc. 2, 151.

21. Eltenton. 1947 J. Chem. Phys. 15, 478 
22. We1sh. 1948 t. Chem. Soc. p. 331.

23. Norrish, 1951 Disc. Faraday Soc. 10, 269.

24. Axford and Norrish. 1948 Proc. Roy. Soc. A, $192,518$.

25. Norrish. 1949 Rev. Inst. Franç. Pétrole, 4, 288.

26. Pesse, 1938 J. Amer. Chem, 3oc. 60, 224,4.

27. Kulcahy. 1949 Irons. Paraday Soc. 45, 537.

28. Cullis and Hinshelwood. 1947 Diac. Faradey Soc. $3,117$.

29. Hinahelwood. 1951 Disc. Faraciy Soc. 10, 266.

30. Chamberlain and Falsh. 1949 Rev. Inst. Yranç. Pétrole, $4,301$.

31. Bates and Spence. 1931 J. Amer. Chem. Soc. 53, 1689.

32. Jones and Bates, 1934. J. Amer. Chem. Soc. 56, 2285.

33. For references, see Hawkins. 1950 quart.Rev.Chem.Soc. 45 251.

34. Lewin, 1933 Euil. Soc. Chem. Belg. 42, 141.

35. Velsh, 1947 Nature, Lond., 159, 165.

36. Lewar. 1946 J. Chem, Soc. pp. 406 and 777.

37. Hobinson, 1947 Nature, Lond., 159, 400.

38. Welah. 194,7 Nature, Kond, 159, 712.

39. Bastiensen and Kassel. 19l.5 Saertrykk av. Tids. KJem Bergvesen Met., 6, 71. C.A. 40, 6059.

4.0. Ioinnett. 1947 Nature, Lond., 160, 162.

41. Steacie and Le Roy. $1943 \mathrm{~J}$. Chem. Phys. 11, 164.

42. Wolsh. 1949 Trans. Faraday Soc. 45, 179.

43. Sugden, 1947 Nature, Lond., 160, 367.

4h. Day anc Pease. 1941 J. Aner. Chem, Soc. 63, 912.

45. Yorke. 1945 J. Sci. Instr. 22, 196.

46. Spence and wild. 1935 J. Chem. Soc. p. 338.

47. Feigl. 194.7 "Spot Tests". 3râ edition, p. 395. New York: Elsevier. 
48. Feigl. 1947 "Spot Tests", 3rd edition, p. 349. New York: Elsevier.

49. Young, Vogt and Weuwiend. 1936 Analyt. Cheri. 8, 198.

50. Feigl. 194,7 "gpot Fests", 3rd edition, p. 340. New York: \#lsevier.

51. Veigl. 1947 "Snot Tests", 3ra edition, po. $339-349$. New York: Msevier.

52. Smith, Bryent and Mitchell. 1939 t. Amer. Chesa. Soc. 61, 2407.

53. Bricker an Johnson. 1945 Ansiyt. Chera. 17, 400.

54. For exarmple, see Small anà Ubbelohde. 1952 J. Chern. 3oc. p.4619.

55. Hinshelwood, 1940 "Kineties of chendoal Change", 1st edition, p. 84. Oxford: Oxford University Press.

56. Ubbelohäe and Snall. 1951 Disc. Faraday Soc. 10, 323.

57. Frettre. 1936 compt. Rend. 203, 619.

58. Vanpee. 1947 Ann. mines Belg., 47, 111.

59. Chambers anả Kistiakowsky. $1934 J$. Amer. Cher. Soc. 56, 399.

60. Bardwel1. 1951 Proc. Roy. Soc, A, 207, 470.

62. Walsh. 1949 Rev. Inst. Franc, Pétrole, 4, 315.

63. Mulcehy. 1949 Trans. Farsdey Soc. 45, 575.

64. Herding and Norrish. 1952 Proe. Roy. Soc. A, 212, 291.

65. Pesse. $1938 \mathrm{~J}$. Amer. Chem. soc. 60, 224.4.

66. Cullis, Hinsheiwood and Kulcahy. 194,9 Proc. Roy. Boc. A, 196, 160.

67. Cullis and Sthith. 1950 Trana. Foradey Boc. 46, 42.

68. Cullis and Willsher. 1951 Proc. Roy. Soc. A, 208, 218.

69. Eastwood and Hinshelwood. 1952 t. Chem. Soc., p. 733.

70. Bardwel1 and Hinshelwood.1950 Proc. Roy. Soc, A, 201, 26.

71. Cullis. 1949 Trans. Faraday Soc. 45, 709. 
72. Mulcahy. 1947 DAsc. Faradey Soc. 2, 128.

73. Herding. 1951 Dise. Faraday Soc. 10, 317.

74. Walsh. 1951 Disc. Faraday soc, 10, 321.

75. Ubbelohde. 1949 Rev. Inst. Franç, Pétrole, 4, 315.

76. Dwyer end Oldenberg. 1944 J. Chen. Phys. 12, 351.

77. Trotmon-DLekeneon. 1951 Disc. Puraday Soc, 10, 111.

78. Frotmen-DLikenson and stescie. $1951 \mathrm{~J}$. Phys. Chem. 55, 908.

79. Szwarc. 1950 Ches. Rev. 47, 75.

80. Bichowsiky and Rossini. 1936 "Thermochemistry of Chemicel Substances", p. 45. Iiew York: Reinhold.

81. Bichowsky and Rossini. 1936 "Thermochemistry of Chemical Substances", \$. 43. New York: Reinhold.

82. Knowlton and Rossini. 1949 J. Research. Nat. Bur. Standaràs 43, 113. See C.A. 年, 1322.

83. For example, see Lucher, Vialden, Jea and Park. 1950 \%. Amer. Chem. Soc. 72, 331.

84. Gorin. 1939 J. Chem. Khys. 1, 256.

85. MaDowe11 ond Thomas. 1950.J. Cher Soc., p. 1462.

86. Roberts and Skinner. 1949 Irens. Forkiny Soc. 45, 339.

87. Hoare and Walsh. 1952 Proc. Foy. Soc. A, 215, 454.

88. Mackenzie and Ritchie. 1946 roc. Roy. Soc. A, 185, 207.

89. Chamberlain, Foare ond Walsh. 1953 Disc. Faraduy Soc. 14, 89

90. Brostch, private comrunication. 